\title{
Examining the Potential for Voluntary Fuel Economy Standards in the United States and Canada
}

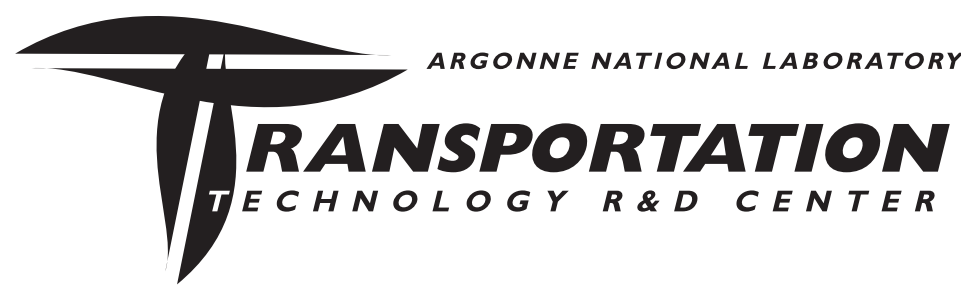

Center for Transportation Research Argonne National Laboratory

Operated by The University of Chicago, under Contract W-31-109-Eng-38, for the

United States Department of Energy 
Argonne National Laboratory, with facilities in the states of Illinois and Idaho, is owned by the United States Government and operated by The University of Chicago under the provisions of a contract with the U.S. Department of Energy.

\title{
DISCLAIMER
}

This report was prepared as an account of work sponsored by an agency of the United States Government. Neither the United States Government nor any agency thereof, nor The University of Chicago, nor any of their employees or officers, makes any warranty, express or implied, or assumes any legal liability or responsibility for the accuracy, completeness, or usefulness of any information, apparatus, product, or process disclosed, or represents that its use would not infringe privately owned rights. Reference herein to any specific commercial product, process, or service by trade name, trademark, manufacturer, or otherwise does not necessarily constitute or imply its endorsement, recommendation, or favoring by the United States Government or any agency thereof. The views and opinions of document authors expressed herein do not necessarily state or reflect those of the United States Government or any agency thereof, Argonne National Laboratory, or The University of Chicago.

Available electronically at http://www.doe.gov/bridge

Available for a processing fee to U.S. Department of Energy and its contractors, in paper, from:

\author{
U.S. Department of Energy \\ Office of Scientific and Technical Information \\ P.O. Box 62 \\ Oak Ridge, TN 37831-0062 \\ phone: (865) 576-8401 \\ fax: (865) 576-5728 \\ email: reports@adonis.osti.gov
}




\section{Examining the Potential for Voluntary Fuel Economy Standards in the United States and Canada}

by Steven Plotkin, David Greene, ${ }^{*}$ and K.G. Duleep*

Center for Transportation Research, Energy Systems Division,

Argonne National Laboratory, 9700 South Cass Avenue, Argonne, Illinois 60439

October 2002

Work sponsored by Office of Energy Efficiency and Renewable Energy, U.S. Department of Energy, and by Natural Resources Canada

* Greene is affiliated with Oak Ridge National Laboratory, Oak Ridge, Tenn.; Duleep, with Energy and Environmental Analysis, Inc., Arlington, Va. 


\section{NOTICE}

This technical report is a product of Argonne's Energy Systems Division. For information on the division's scientific and engineering activities, contact:

Director, Energy Systems Division

Argonne National Laboratory

Argonne, Illinois 60439-4815

Telephone (630) 252-3724

Publishing support services were provided by Argonne's Information and Publishing Division (for more information, see IPD's home page: http://www.ipd.anl.gov).

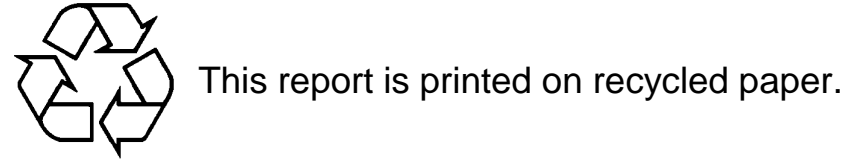




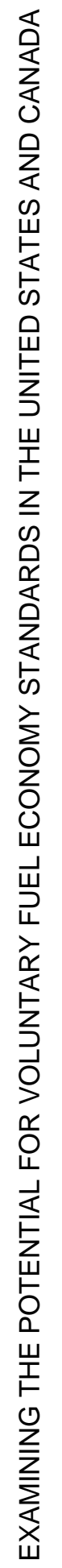

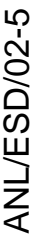





\section{Contents}

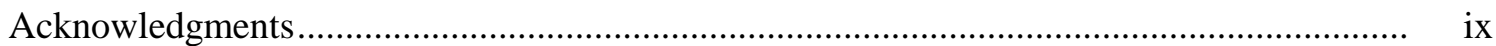

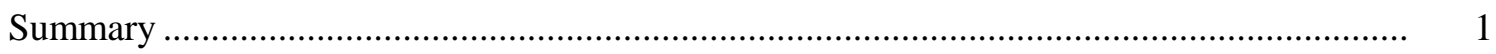

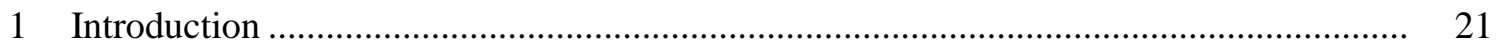

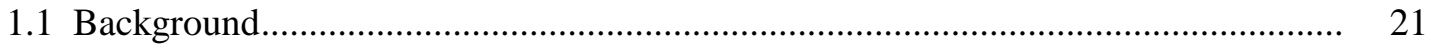

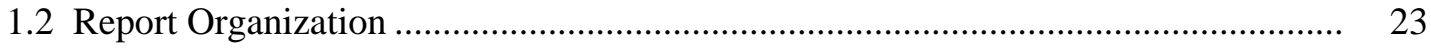

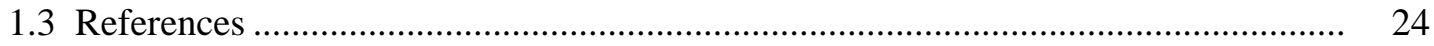

2 European and Japanese Initiatives to Boost Automobile Fuel Economy .......................... 25

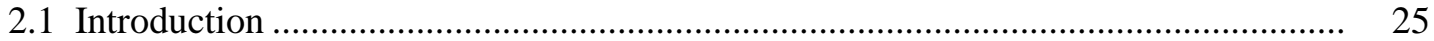

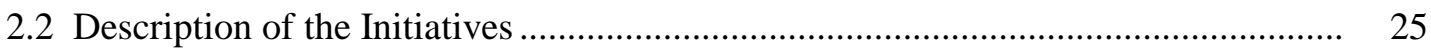

2.2.1 Japanese Weight Class Standards .......................................................... 25

2.2.2 ACEA Voluntary Commitment to the European Commission on Vehicle

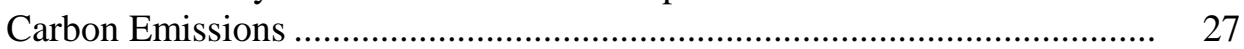

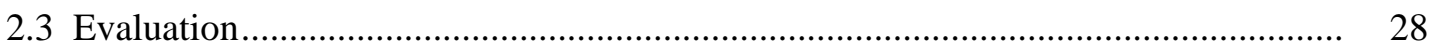

2.3.1 Japanese Weight Class Standards ........................................................ 28

2.3.2 European Voluntary Commitment ……..................................................... 31

2.3.3 Available Technologies — Europe ….................................................... 34

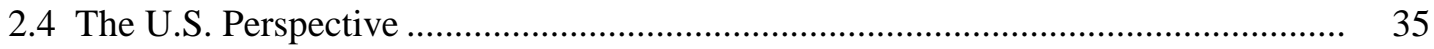

2.4.1 Fuel Economy Measurement/Driving Cycles ......................................... 36

2.4.2 Emissions Regulations ......................................................................... 38

2.4.3 Cost-Effectiveness of New Efficiency Technology — Comparison across

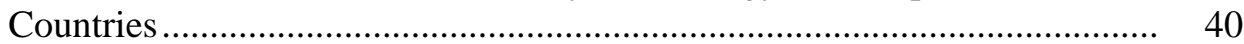

2.5 Recent Progress in the Japanese and European Markets........................................... 44

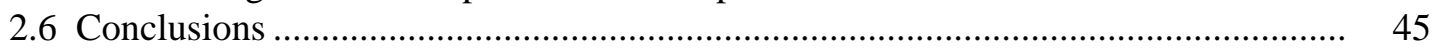

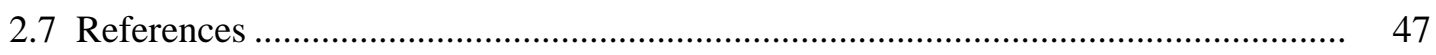

3 Approach to Evaluating Voluntary Fuel Economy Standards ...................................... 49

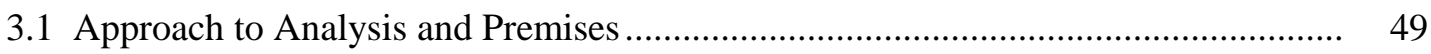

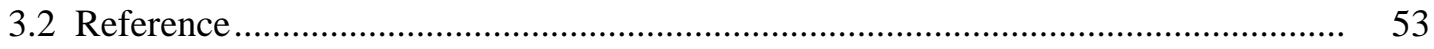

4 Potential for Technology to Improve Vehicle Fuel Economy …….................................... 55

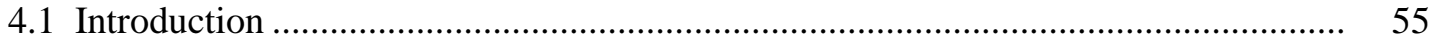

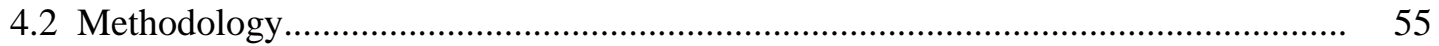

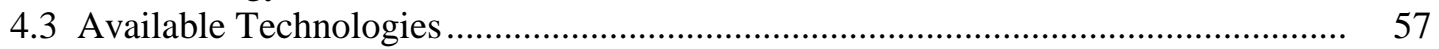

4.4 Load Reduction Technologies.................................................................. 58

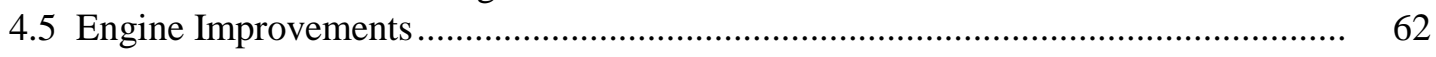


4.5.1 Variable-Valve and Other Technologies.................................................. 62

4.5.2 Lean Burn Engines — Diesel and Gasoline ................................................ 64

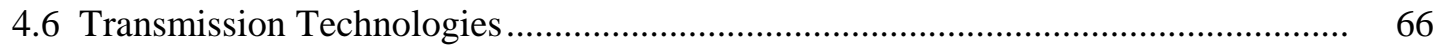

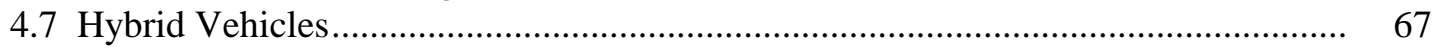

4.8 Fuel Economy Impact of Technology "Bundles"............................................ 70

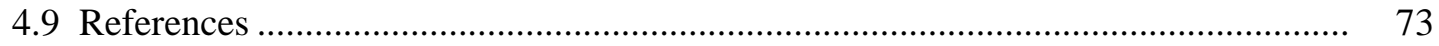

5 Developing and Evaluating Alternative Voluntary Fuel Economy Standards .................. 75

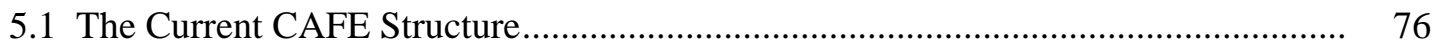

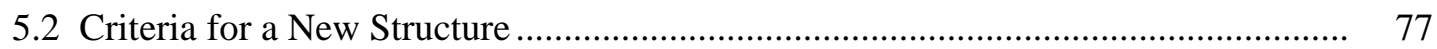

5.3 Developing an Alternative Fuel Economy Target Structure .................................. 78

5.3.1 Uniform Percentage Increase ............................................................. $\quad 78$

5.3.2 Standards Based on Vehicle Attributes .................................................... 81

5.3.3 Weight-Based Standard ................................................................ 82

5.3.4 Other Metrics for an Attribute-Based Standard ......................................... $\quad 92$

5.4 Evaluating Alternative Structures for a New Fuel Economy Standard ..................... 94

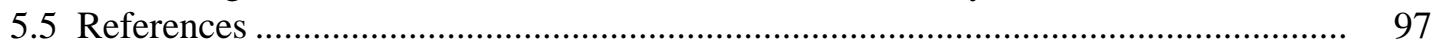

6 Analysis of the Costs and Benefits of Implementing Alternative

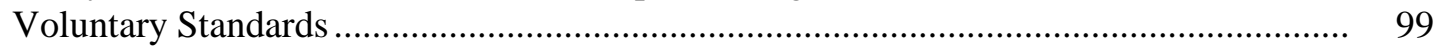

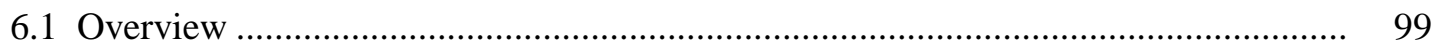

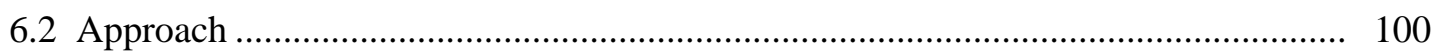

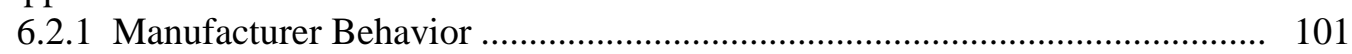

6.2.2 Consumer Behavior ............................................................................... 109

6.2.3 The Fuel Economy Market Model ......................................................... 113

6.2.4 Measuring Efficiency and Equity ........................................................ 113

6.3 Structure of Analysis ..................................................................................... 114

6.3.1 Levels, Forms, and Metrics: mpg, UPI, and Weight-Based Standards ......... 115

6.3.2 Modifications for the Weight-Based Analysis ......................................... 116

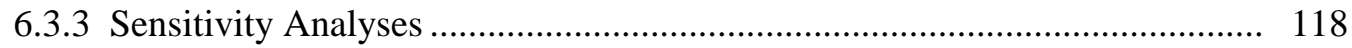

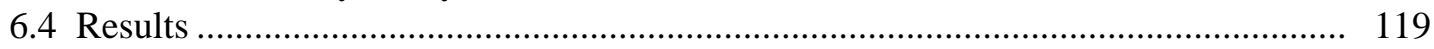

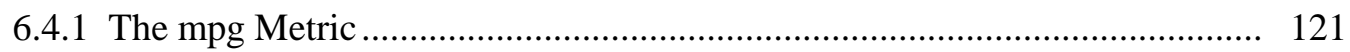

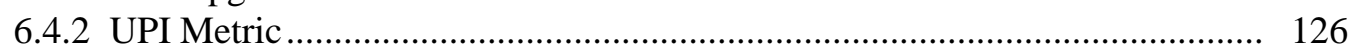

6.4.3 Weight-Based Metric ................................................................. 130

6.4.4 Sensitivity Analyses ...................................................................... 133

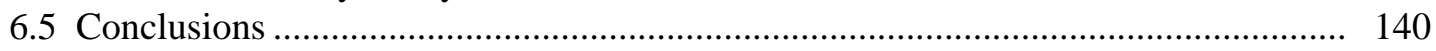

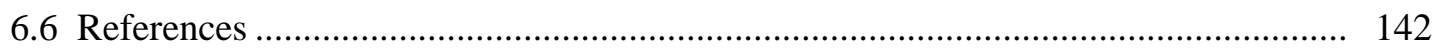

Appendix A Technology Baselines of Automobile and Light-Truck Manufacturers ............ 145

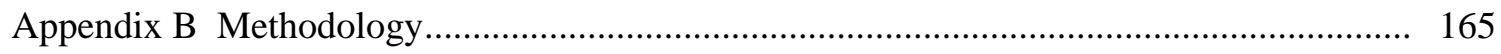




\section{Figures}

S-1 New Japanese Fuel Economy Standards.............................................................. 3

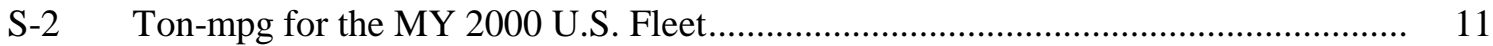

S-3 Corporate mpg Targets for Alternative Auto Standards, for Major Automakers,

S-4 Net Value of a 33\% Fuel Economy Increase vs. Form of Standard for Three Metrics, $\$ 10^{6}$

S-5 Marginal Cost per Gallon Saved, 33\% Manufacturer Standard ............................... 17

2-1 New Japanese Fuel Economy Regulations .......................................................... 26

2-2 Weight Distribution of the Japanese Light-Duty Vehicle Fleet, 1995 vs. 2000 ......... 32

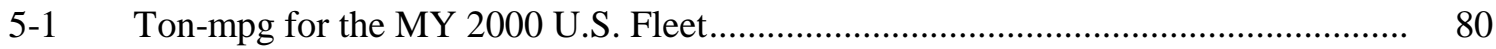

5-2 Fuel Consumption, gal/100 mi, vs. Curb Weight, All Cars, 1999 ............................ 83

5-3 Fuel Consumption, gal/100 mi, vs. Curb Weight, with Trendline, All Cars, 1999 .... 83

5-4 Automobile Fuel Consumption, gal/100 mi, vs. Curb Weight - Sales >10,000, with Regression Line and 20\% mpg Improvement Line ........................................ 84

5-5a Automobile Fuel Consumption, gal/100 mi, vs. Curb Weight - Sales $>1,000 \ldots \ldots \ldots . \quad 86$

5-5b Automobile Fuel Consumption, gal/100 mi, vs. Curb Weight — Sales >5,000...... 86

5-5c Automobile Fuel Consumption, gal/100 mi, vs. Curb Weight - Sales $>10,000 \ldots \ldots . .87$

5-6 Automobile Fuel Consumption, gal/100 mi, vs. Curb Weight, with Truck Trendline Superimposed, Sales $>1,000$................................................................... 88

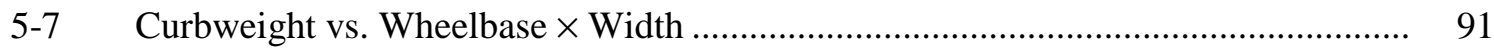

5-8 EPA Fuel Economy vs. Total Interior Volume for 1999 Cars $>5,000$ sales............... 93

5-9 Fuel Economy vs. Wheelbase $\times$ Width, 1999 Cars $>$ 5,000 Sales............................ 93

5-10 Corporate mpg Targets for Alternative Auto Standards, for Major Automakers, Based on 1999 Car Fleet

5-11 Corporate Automotive mpg Requirements for Alternative Standards, Niche Automakers, Based on 1999 Car Fleet 
6-1 Passenger Car Fuel Economy Technology Price Curve, EEA Industry Average Data, 2012-2015

6-2 Light Truck Fuel Economy Technology Price Curve, EEA Industry Average Data, 2012-2015

6-3 Comparison of Fuel Economy Technology Price Curves for Passenger Cars.

6-4 Comparison of Fuel Economy Technology Price Curves for Light Trucks

6-5 Cubic Fit to Retail Price of Light-Duty Vehicle Weight Changes

6-6 Industry Average Passenger Car Fuel Economy Price Curve without Weight Reduction

6-7 Industry Average Light Truck Fuel Economy Price Curve without Weight Reduction

6-8 Price and Value of Increased Fuel Economy to Passenger Car Buyer, Using NRC Average Price Curves.

6-9 New Light-Duty Vehicle Fuel Economy for Five Forms of Voluntary Standards by Using the mpg Metric

6-10 Change in Net Value of a Passenger Car by Manufacturer for Five Forms of mpg Standards

6-11 Change in Net Value of a Light Truck by Manufacturer for Five Forms of mpg Standards

6-12 Change in Net Value of a Passenger Car for UPI Standards .................................. 129

6-13 Change in Net Value of a Light Truck for UPI Standards ..................................... 129

6-14 Comparison of Changes in Net Value per Passenger Car between Weight-Based and mpg Metric Standards

6-15 Comparison of Changes in Net Value per Light Truck between Weight-Based and mpg Metric Standards

6-16 Effect of Form of Standard on Equity, Passenger Cars, Three-Year Simple Payback for Fuel Savings, 33\% Requirement.

6-17 Effect of Form of Standard on Equity, Light Trucks, Three-Year Simple

Payback for Fuel Savings, 33\% Requirement.

6-18 Effect of Form of Standard on Equity, Passenger Cars, Three-Year Simple Payback, 20\% Requirement. 
6-19 Effect of Form of Standard on Equity, Light Trucks, Three-Year Simple

Payback, 20\% Requirement

6-20 Effect of Gasoline Price on the Net Value Maximizing Level of Light-Duty

Vehicle Fuel Economy.....

\section{Tables}

S-1 Technologies for Improving LDV Fuel Economy ................................................ 6

2-1 Comparison of U.S., European Union, and Japanese Emission Testing Cycles ........ 37

2-2 Comparison of U.S., European Union, and Japanese Motor Vehicle Emissions

Standards

2-3 Evaluation of the Cost-Effectiveness of Direct-Injected Stratified Charge

Gasoline Engines in Several Countries.

4-1 List of Available Technology 58

4-2 Attributes of Load Reduction Technologies

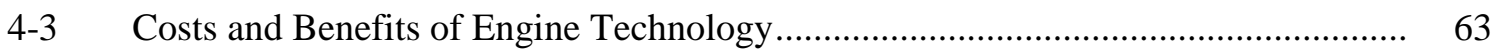

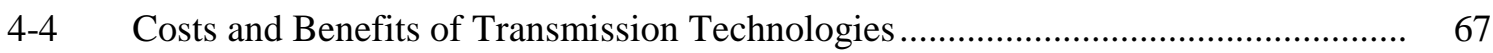

4-5 Hypothetical 2015 Midsize Car — Constant Attribute Case.................................... 72

4-6 Hypothetical 2015 Compact Four-Wheel-Drive SUV — Constant

Attribute Case

5-1 Manufacturer-Specific Percentage Improvement Requirements for Three Alternative Weight-Based Standards: 20\% Fleet Fuel Economy Improvement

6-1 Model Year 2000 Fuel Economy and Related Data by Manufacturer, Vehicle Type, and Origin

6-2 Fuel Economy Price Curve Data for Passenger Cars.............................................. 104

6-3 Fuel Economy Price Curve Data for Light Trucks .............................................. 105

6-4 Manufacturer-Specific Fuel Economy Technology Price Curves ............................ 108

6-5 Alternative Fuel Economy Technology Price Curves............................................. 111

6-6 Summary of Vehicle Price Increases and Fuel Savings for mpg Metric ................... 123

6-7 Marginal Cost per Gallon of Fuel Saved, 33\% Requirement ................................ 126 
6-8 Summary of Costs and Fuel Savings for UPI Metric.......................................... 128

6-9 Comparison of Costs and Savings of Weight-Based and mpg Standards.................. 131

6-10 Summary of Costs and Fuel Savings for mpg Metric, Three-Year

Simple Payback.

6-11 Comparison of Seven Alternative Fuel Economy Cost Functions .......................... 138

6-12 Comparison of Weight-Based and mpg Metrics at \$1.35 and \$1.75 per Gallon,

A-1 DaimlerChrysler Car Body, 2000 Baseline ......................................................... 146

A-2 DaimlerChrysler 2000 Engine Technology ........................................................ 148

A-3 Ford 2000 Car Body, 2000 Baseline..................................................................... 149

A-4 Ford 2000 Engine Technology Baseline ............................................................ 152

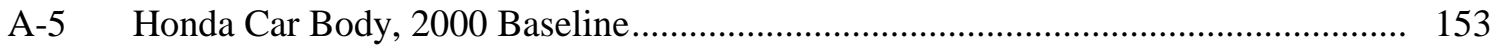

A-6 Honda 2000 Engine Technology Baseline................................................................ 154

A-7 DaimlerChrysler Light Truck Body, 2000 Baseline ........................................... 155

A-8 DaimlerChrysler 2000 Engine Technology Baseline ......................................... 158

A-9 Ford Light Truck Body, 2000 Baseline ….......................................................... 159

A-10 Ford 2000 Engine Technology Baseline............................................................. 161

A-11 Honda Light Truck Body, 2000 Baseline .......................................................... 162

A-12 Honda Light Truck 2000 Engine Technology Baseline ......................................... 163

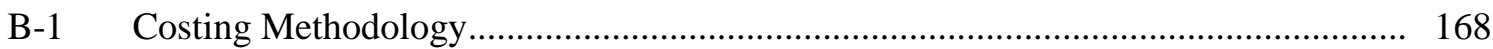

B-2(a) Energy Consumption as a Percent of Total Energy Requirements for a Midsize Car

B-2(b) Energy Consumption for a Midsize Car 


\section{Acknowledgments}

The authors would like to acknowledge the important contribution to this study of Ms. Janet Hopson of the University of Tennessee, who collaborated with David Greene in developing and running the optimization model used to evaluate alternative fuel economy standards.

The authors would also like to thank the following reviewers of the draft report:

John German, Honda North America

Barry Felrice, DaimlerChrysler Corporation

Karl Hellman, U.S. Environmental Protection Agency

James Sweeney, Stanford University

Charles Lave, University of California at Irvine

Kenichiro Takama, Toyota Motor Corporation

Noble Bowie, National Highway Traffic Safety Administration, U.S. Department of

Transportation

Walt Kreucher, Ford Motor Corporation

Lew Fulton, International Energy Agency

David Friedman, Union of Concerned Scientists

Ovi Colavincenzo, Canadian Ministry of Transportation

Although the reviewers provided us with invaluable insights, the authors bear sole responsibility for the contents of this report.

Finally, the authors would like to express our gratitude for the strong support and guidance provided by our co-project officers, Dr. Philip Patterson and Mr. Barry McNutt of the U.S. Department of Energy and Mr. Peter Reilly-Roe of Natural Resources Canada. 
$\Delta$ 


\section{Summary}

This report is designed to assist the U.S. Department of Energy, the U.S. government in general, and Natural Resources Canada with understanding the potential for voluntary fuel economy standards designed to increase the fuel economy of the North American fleet of lightduty vehicles (LDVs - passenger cars and light trucks) within a 10-15-year timeframe. The approach of this study has been:

- First, to examine and evaluate recent fuel economy initiatives taken in Japan and Europe;

- Second, to review the technologies available to improve fuel economy in the U.S. (and Canadian) fleets, focusing on their costs and fuel economy improvement potential;

- Third, to identify and broadly evaluate some alternatives to the current U.S. and Canadian Corporate Average Fuel Economy system ${ }^{1}$ of specifying uniform fuel economy targets (27.5 mpg for cars, 20.7 mpg for light trucks) for individual companies; and

- Fourth, to try to determine an approximate level of fuel economy increase and form of company agreements that would be conducive to a voluntary agreement, based on the assumption that an acceptable voluntary standard would impose an equitable burden on each manufacturer and would be approximately cost-effective from consumers' private perspectives.

We present key study conclusions in a question-and-answer fashion:

\section{How have Europe and Japan moved to increase the fuel economy of their fleets of light- duty vehicles? What are their prospects for success?}

The European Car Manufacturers Association (ACEA) has entered into a Voluntary Commitment ${ }^{2}$ with the European Union to reduce average "per new passenger vehicle" $\mathrm{CO}_{2}$ emissions by $25 \%$ by the year 2008, from a 1995 baseline level. Assuming no change in fuels,

1 The U.S. and Canadian systems are not identical. Most importantly, the Canadian standards are voluntary, in contrast to the U.S. regulatory system, which imposes fines for noncompliance. Although the numerical targets are the same, Canadian car fleets are not divided into separate domestic and import fleets, as is done in the U.S. system.

2 Note that many industry observers believe that the ACEA offered a voluntary agreement to the European Union (EU) because it believed it would otherwise be faced with a more stringent mandatory standard. 
this implies a $25 \%$ reduction in the per-vehicle rate of fuel consumption ${ }^{3}$ or a $33 \%$ improvement in fuel economy for the fleet, ${ }^{4}$ to about $41 \mathrm{mpg}$ for gasoline vehicles on the European driving cycle. The Commitment is fleetwide - it does not define fuel economy targets for each manufacturer - and it is contingent on government action to align fiscal policy, provide cleaner fuels, and help promote efficiency.

Taking a somewhat different tack, the Japanese government has imposed a set of weightclass fuel economy standards on its light-duty vehicle fleet. Assuming no changes in the weight distribution of the fleet, the standards require about a 23\% improvement in fuel economy for the new gasoline-fueled LDV fleet by 2010 from a 1995 baseline level, yielding a fleet average fuel economy of about $35.5 \mathrm{mpg}$. These standards assign mandatory fuel economy targets according to a vehicle's weight, with companies having to meet sales-weighted fuel economy averages in each weight class, with limited trading allowed across classes. Figure S-1 illustrates the standard for passenger vehicles. In the figure, vehicles in the 1,750-kg inertial weight class (vehicles whose curb weight is between 1,515 and $1,765 \mathrm{~kg}$ ) had an average fuel economy in 1995 shown by the bottom line; such vehicles are assigned a target fuel consumption for 2010 shown by the top line - which is $24 \%$ higher.

Since the baseline year of 1995, the fuel economies of both the European and the Japanese new vehicle fleets have improved - the Europeans by about $11 \%$ (for 2001) and the Japanese by about 5\% (for 2000). These are positive trends for the manufacturers to build on during the remaining 7-10 years ${ }^{5}$ to their respective deadlines. The technical prospects for meeting the standards seem good. In particular, for Japan, virtually all vehicles currently equipped with direct-injection gasoline engines already meet the 2010 standard. Other technologies that work particularly well in the low-speed stop-and-go traffic cycle in Japan, such as hybrid drivetrains and variable valve control, will also play key roles. In Europe, direct-injected engines, particularly DI diesels, are expected to play a major role in meeting the Commitment target (diesels went from $22.2 \%$ of the new vehicle market in 1995, the baseline year, to $32.6 \%$ in 2000), with weight reduction and improved aerodynamics also crucial. Improved transmissions will play an important role in both markets.

There are potential problems with attaining the targets in each market. In Japan, limitations on trading across weight classes and high targets in some weight classes may pose difficulties for European and U.S. automakers that export to the Japanese market. Also, the weight distribution of Japanese passenger vehicles is changing, with sales in the very lightest weight class $(750 \mathrm{~kg})$

3 Because different fuels have different carbon contents, changing the relative share of gasoline, diesel, and other fuels will also affect $\mathrm{CO}_{2}$ emissions. A shift to more diesel fuel, for example, would require a somewhat higher percentage reduction in fuel consumption to compensate for diesel's higher "per-gallon" carbon content.

${ }^{4}$ Fuel economy (e.g., mpg) is the inverse of the rate of fuel consumption (gpm). Thus, multiplying fuel consumption by 0.75 (equivalent to a $25 \%$ reduction) implies multiplying fuel economy by $1 / 0.75$, or 1.33 , a $33 \%$ increase.

5 From 2001 and 2000, respectively. 


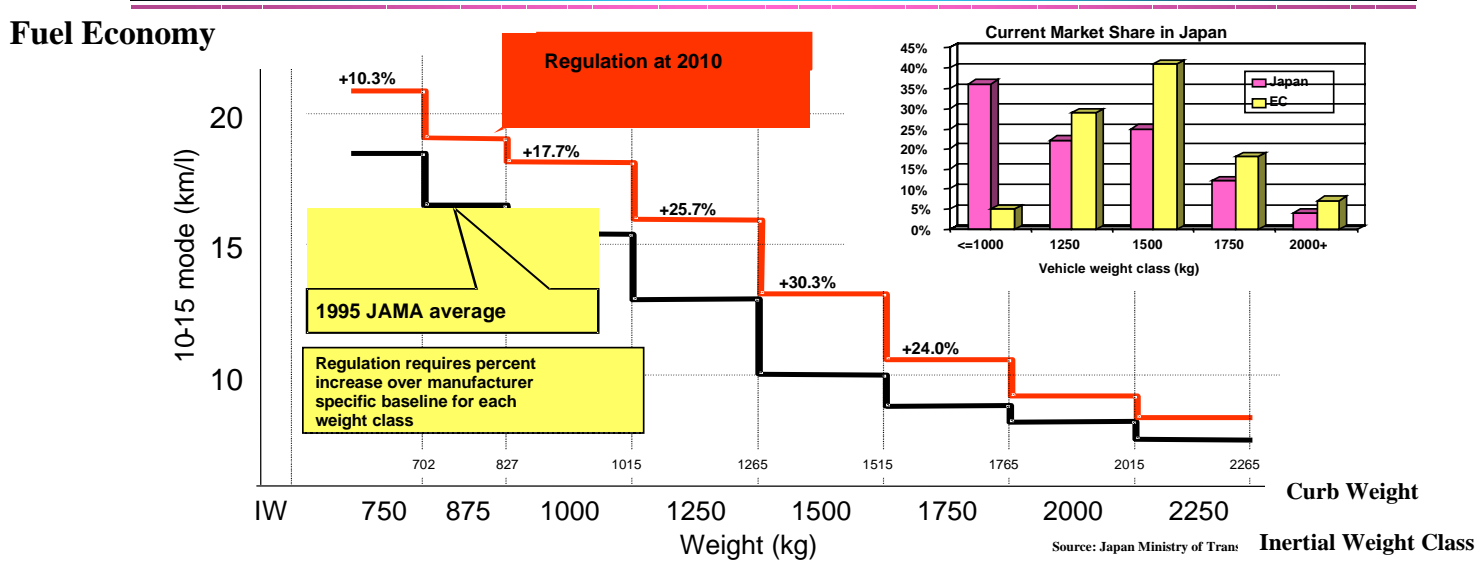

Figure S-1. New Japanese Fuel Economy Standards

plummeting and sales in the heaviest classes increasing. The net impact of these changes will likely decrease the future fuel economy levels attained by the fleet - for example, using the year 2000 weight distribution lowers the projected fuel economy target in 2010 to about $34 \mathrm{mpg}$ (from $35.5 \mathrm{mpg}$ ).

In Europe, the lack of specific company-by-company targets will make it difficult to assign blame to individual companies if the Commitment's target is not met. ${ }^{6}$ Also, the text of the Commitment contains some "escape clauses" that require reevaluating the targets if automakers are being hurt by them - which may be difficult to establish. Another cause for reevaluation is any action by the EU that interferes with technology commercialization - in language subject to interpretation. Finally, in both markets, relatively lenient (compared to U.S.) emission standards for $\mathrm{NO}_{\mathrm{x}}$ and particulates help direct-injected engines to have low costs and high-efficiency performance. Any future move to make these standards stricter could make the fuel economy targets somewhat more difficult to reach.

A potential problem in both areas is the potential for future changes in fleet composition and characteristics. As noted above, changes in the weight distribution of the Japanese fleet have reduced the percentage increase in fleet fuel economy likely to be obtained by the new standards from about $23 \%$ to about $18 \%$, based on 2000 data. Future changes in the weight distribution may create additional changes in the likely results of the standards. Similar changes in Europe may make successful attainment of the Voluntary Commitment's targets more difficult. And gradual increases in engine power and market share of light trucks in both markets will make attainment of their respective targets more difficult — there is a direct trade-off between engine power and fuel economy in vehicle design, and light trucks tend to be less efficient than automobiles of similar weight, because of inferior aerodynamics and other characteristics of light trucks. Note, however, that changes in power and other fleet characteristics have tended to be

6 Actually, the ACEA does not reveal the fuel economies of individual company fleets - it publishes only the collective fuel economy of the ACEA membership. Presumably, however, the EU could require that these data be made available. 
slower in Europe and Japan than in the United States (with the exception of the rapid change in weight distribution in the Japanese market), and high gasoline prices and other factors may work to suppress the rate of change in these markets.

\section{What key differences exist between the U.S. and European/Japanese markets that would affect the ability of the U.S. (and Canada) to take similar measures?}

There are important differences between the U.S. automotive market and those of Europe and Japan that will affect the potential for the United States to achieve similar fuel economy goals. The most obvious difference is the low gasoline prices in the United States, which ranged recently between about $\$ 1.15$ and $\$ 1.75$ per gallon, versus Japanese and European prices, which range from over $\$ 3.00$ per gallon to more than $\$ 4.00$ per gallon. This price differential clearly favors the Japanese and European markets in stimulating higher levels of fuel economy. Other important differences include:

- Driving cycles and conditions - Japanese driving conditions, and the official Japanese 10.15 driving cycle used to measure fuel economy for regulatory purposes, represent congested city driving. The U.S. regulatory cycle uses much faster speeds, and the European cycle is somewhat in-between. The effect of these differences is to reward certain key technologies that focus on improving "low load" efficiency (e.g., variable valve timing, hybrid drivetrains, idle-off) with significantly higher fuel economy "boosts" on the Japanese cycle than on the U.S. cycle. In contrast, improvements in aerodynamics are well rewarded on the U.S. cycle, but almost irrelevant on the Japanese cycle.

- Emissions regulations - These are strictest in the United States and most lenient in Japan. Unless excellent progress is made in lean-burn $\mathrm{NO}_{\mathrm{x}}$ control technology, strict U.S. $\mathrm{NO}_{\mathrm{x}}$ standards might serve to ban or significantly limit diesel use (by restricting it to high bins ${ }^{7}$ ) in the LDV fleet and reduce the fuel economy performance of DI gasoline engines. In contrast, European and Japanese standards allow for such "lean technologies" and, further, do not hold diesel-fueled vehicles to emissions levels as stringent as those for gasoline-fueled vehicles.

- Vehicle taxes - High vehicle taxes in Europe will, in some cases, serve to make new fuel economy technologies more expensive, since they apply to the price of the total vehicle. On the other hand, several EU countries (and Japan) impose taxes on vehicle sales and/or ownership that vary with fuel efficiency or with factors that are likely to affect fuel efficiency, especially engine size; these taxes provide a positive incentive for high-efficiency vehicles. In contrast, U.S. taxes are low and are unrelated to efficiency (except for tax credits applicable to hybrid-electric vehicles).

7 The forthcoming Tier 2 standards set emission targets for company fleets but allow limited numbers of vehicles in each fleet to meet more lenient targets (although these vehicles must be balanced by vehicles with emissions below the fleet targets). This creates a series of ranges of emission targets, called "bins," with the higher (more lenient) bins being allowed a limited percentage of each company's fleet. 
- Vehicle miles driven - LDVs are driven substantially farther in the United States $(\sim 14,000 \mathrm{mi} / \mathrm{yr}$ for the first five years) than in Europe $(8,000-9,000 \mathrm{mi} / \mathrm{yr})$ and $\mathrm{much}$ farther than in Japan $(\sim 6,000 \mathrm{mi} / \mathrm{yr})$. More driving means higher annual fuel savings from new technologies, improving the cost-effectiveness of new technology in the United States versus the other markets.

- Average vehicle size and efficiency - The lower baseline fuel economy in U.S. LDVs means that new technologies with the same percentage efficiency boost will save more fuel in U.S. vehicles than in more efficient Japanese and European vehicles.

- Fuel taxes - Aside from the substantially higher fuel taxes in Europe compared to the United States, most European countries levy significantly higher taxes on gasoline than on diesel fuel, stimulating sales and use of diesel-fueled vehicles.

- Company cars - Subsidized company cars are 30-50\% of new car purchases in Germany, the Netherlands, Norway, Sweden, and the United Kingdom. For many of these cars, the incentive for high fuel economy is lower than that for private cars. Our understanding is that some of these countries (e.g., the United Kingdom) recently have changed their tax codes to avoid this disincentive for efficiency.

The end result of these market differences is that higher fuel economy will be more attractive in the Japanese and European markets than in the United States, but perhaps not by as much as may seem apparent when examining only the differences in fuel prices. The greater amount of driving in the United States plays an especially strong role in narrowing the costeffectiveness gap between the United States and Europe and Japan. As discussed below, even at relatively low gasoline prices ( $\$ 1.35 / \mathrm{gal})$, significant levels of fuel economy improvement are cost-effective in the United States market, if consumers value fuel savings over the full lifetime of their vehicles.

Similar conclusions can be drawn about the applicability of the Japanese and European initiatives to Canada; the primary difference is that Canadian gasoline prices have tended to be a bit higher than those in the United States and Canadian vehicle taxes are a bit higher, the net result of which is that the commercialization potential for fuel economy technologies in both countries is similar.

\section{What are the key near- and mid-term technologies that can play a significant role in LDV fuel economy over the next decade? What fuel economies can be achieved - at what increase in vehicle price - for different packages of these technologies? What would be the lifetime gasoline savings resulting from these packages?}

A variety of technologies, most already introduced to the North American fleet, are available to improve the fuel economy of the fleet over the next decade (Table S-1). 
Table S-1. Technologies for Improving LDV Fuel Economy

\begin{tabular}{|c|c|c|}
\hline Technology & $\begin{array}{c}\text { Fuel Economy } \\
\text { Benefit (\%)a }\end{array}$ & Effect on Price (\$) \\
\hline \multicolumn{3}{|l|}{ Aero Improvements } \\
\hline $\mathrm{Cd}^{\mathrm{b}}(0.31$ to 0.28$)$ & 2.2 & 35 \\
\hline $\mathrm{Cd}(0.28$ to 0.25$)$ & 2.2 & 60 \\
\hline \multicolumn{3}{|l|}{ Improved Tires } \\
\hline$C_{R}^{c}(0.095$ to 0.085$)$ & 2.0 & 20 \\
\hline$C_{R}(0.085$ to 0.075$)$ & 2.0 & 30 \\
\hline \multicolumn{3}{|l|}{ Improved Accessories } \\
\hline Alternator & 0.5 & 15 \\
\hline Electric power steering (12 V) & 2.0 & 40 \\
\hline Gear drive oil pump & 0.5 & 3 \\
\hline \multicolumn{3}{|l|}{ Weight Reduction } \\
\hline $\begin{array}{l}\text { Computerized redesign and } \\
\text { increased use of high-strength steel }\end{array}$ & 3.3 & $0.30 / \mathrm{lb}$ saved \\
\hline Composites for closures & 1.7 & $0.50 / \mathrm{lb}$ saved \\
\hline \multicolumn{3}{|l|}{ Engine Improvements } \\
\hline Engine friction reduction & $2-4$ & $20-50$ \\
\hline \multirow[t]{2}{*}{ Variable valve timing and lift (VVTL) } & $6.5-8$ & 170 (4 cylinder) \\
\hline & & 230-290 (6 cylinder) \\
\hline Four-valve engine (+ higher CR) & 5 & 125 (4 cylinder) \\
\hline Cylinder deactivation + VVTL & $11-12$ & 350 (8-cyl DOHC) \\
\hline \multirow[t]{2}{*}{ Turbo DI diesel } & $35-38$ & $1,600$ (4 cylinder $)$ \\
\hline & & 2,200 (6 cylinder) \\
\hline \multicolumn{3}{|l|}{ Advanced Transmissions } \\
\hline Five-speed automatic & $2-4$ & 120 \\
\hline Continuously variable transmission & $5-8$ & 100 (long term) \\
\hline \multicolumn{3}{|l|}{ Hybrid Electric Drivetrains } \\
\hline 42-V mild hybrid & $8-9$ & 1,050 (long term) \\
\hline Prius-type full hybrid & $35-45^{d}$ & $3,600-4,800$ \\
\hline
\end{tabular}

a The fuel economy benefits shown here apply to the EPA test cycle; benefits on other test cycles will be different. The benefits may not be additive in every case. For example, the diesel benefit does not add fully to the benefit from hybridization, because both technologies are aimed at reducing engine inefficiencies at low vehicle loads. Benefit values are referenced to a current vehicle (e.g., the five-speed automatic transmission benefit is referenced to a four-speed automatic, the more common technology today). The benefits are measured on a "constant performance" basis - that is, the vehicle with the added technology and the baseline vehicle with which it is compared have the same performance.

b $\mathrm{Cd}=$ drag coefficient.

c $\mathrm{C}_{\mathrm{R}}=$ resistance coefficient.

d $45 \%$ benefit includes engine optimization. 
The key technologies include:

- Aerodynamic improvements from current levels to a Cd (drag coefficient) of about 0.27 or possibly 0.25 for passenger cars can yield fuel economy improvements of 4-6\% or greater on the EPA test cycle ${ }^{8}$ at a relatively low price. Other small but inexpensive improvements are possible from various measures to reduce engine friction and improve tires.

- Weight reduction measures offer significant improvements: a 2-3\% fuel economy gain is possible at a very low price $(\$ 0.30 / 1 b$ saved, which translates to about $\$ 27-40$ for a 3,000-lb vehicle, saving 90-135 lb), with several additional percent available in steps at increasing price. Available measures include computerized redesign and increased use of high-strength steel or alternative lightweight materials (aluminum, plastics, composites).

- Improved transmissions can add significantly to fuel efficiency. In the current fleet, fourspeed automatic transmissions are the dominant transmission. Moving from a four-speed to a five-speed transmission will yield about a $2.5 \%$ improvement in fuel economy; moving instead to a continuously variable transmission (CVT) might yield about a $6 \%$ improvement.

- Overhead-cam four-valve engines offer about a 5\% fuel economy boost over vehicles not using this technology. Only about one-half of the domestic car fleet and a substantially smaller fraction of the total light truck fleet have adopted this technology, so there is a substantial potential for fleetwide improvement. ${ }^{9}$

- Variable valve controls offer significant fuel economy increases - up to 8\% or so over a baseline four-valve engine when both valve timing and lift are controlled — to virtually all cars and many light trucks. The addition of cylinder cutoff to valve controls in larger engines will boost fuel economy still further.

- $42-\mathrm{V}$ electrical systems (conventional systems use $12 \mathrm{~V}$ ), combined with integrated starter/alternators and electric power steering, can yield a $9 \%$ fuel economy gain and are applicable to virtually the entire car and light truck fleet. Although these systems are expensive, 42-V architectures will likely be added to the fleet for reasons other than fuel economy, primarily because of growing electrical requirements in modern vehicles. Consequently, the incremental cost of the fuel economy increase, over and above the cost of the basic 42-V architecture, might be quite affordable.

- Advanced engines - gasoline and diesel direct-injection engines — can yield significant fuel economy gains, although they are expensive (especially the diesels) and must achieve significant advances in emissions controls to satisfy new emissions requirements.

\footnotetext{
8 All of the fuel economy increases discussed in this section apply to gains on the EPA test cycle.

9 However, a portion of light trucks requiring high-torque engines may not adopt this technology.
} 
- Hybrid drivetrains, with varying degrees of electrification, offer very substantial fuel economy gains - about 35\% for a so-called "full hybrid" such as the Toyota Prius but at high price increases that currently cannot be fully offset by fuel savings. For light trucks with towing requirements, hybridization will offer lower gains because the degree of engine downsizing - an important source of efficiency gains - will be limited. Substantial future technology price declines, or financial incentives offered to purchasers, are necessary to move these technologies out from niche markets to the mass market.

How might these technologies be combined into viable packages to create future massmarket vehicles with substantially improved fuel economy? A few examples for a midsize car, with a baseline fuel economy of $26.5 \mathrm{mpg}$ (EPA test rating), are:

- 2015 MODT (moderate technology) technology package yields an incremental improvement over the baseline vehicle with moderate improvements in aerodynamics $(0.28 \mathrm{Cd})$ and tires, valve timing and lift controls, and a five-speed automatic transmission - which, combined, are expected to yield about a $17 \%$ fuel economy improvement from the baseline $26.5 \mathrm{mpg}$ to about $\mathbf{3 1} \mathbf{~ m p g}$. Its estimated price increase is $\mathbf{\$ 5 8 5}$, measured against a 950-gallon lifetime fuel savings. The discounted value of that lifetime fuel savings, at $\$ 1.35$ per gallon, is about $\$ 685 .{ }^{10}$

- 2015 HT (high technology) package combines substantial weight reduction (16\%) from the use of an aluminum-intensive structure, an engine downsize from 6 cylinders to 4 (possibly with some increase in vibration and noise), further improvements in aerodynamics and tires, and a CVT to yield a bit more than $30 \%$ fuel economy increase over the baseline to $\mathbf{3 5 . 1} \mathbf{~ m p g}$. The estimated price increase from the baseline is $\mathbf{\$ 1 , 2 5 0}$, measured against a lifetime fuel savings of $\mathbf{1 , 6 3 0}$ gallons, which is worth a discounted $\$ 1,174$.

- $\quad 2015 \mathrm{HT}+42 \mathrm{~V}$ package adds an integrated starter-generator and electric power steering to the $2015 \mathrm{HT}$ to obtain an additional $8 \%$ fuel economy increase, to $\mathbf{3 8} \mathbf{~ m p g}$ (a total increase of $43 \%$ over the baseline $26.5 \mathrm{mpg}$ ). The estimated price increase (from the baseline) is $\mathbf{\$ 2 , 5 0 4}$ against a lifetime fuel savings of about $\mathbf{2 , 0 0 0}$ gallons (worth a discounted $\$ 1,800$ ) and improved noise and vibration levels.

- 2015 HT + 300V hybrid adds a full hybrid drivetrain to the previous example, adding a $26 \%$ fuel economy gain, to nearly $\mathbf{4 8} \mathbf{~ m p g}$, at a total price increase over the baseline of $\mathbf{\$ 4 , 8 7 0}$ and saving a total of $\mathbf{2 , 9 4 0}$ gallons of fuel (worth about $\$ 2,100$ discounted). Even without discounting, the lifetime fuel savings will not pay for the price increase unless fuel prices rise, or unless significant cost reductions in hybrid components are realized.

Similar packages of technologies were examined for a compact four-wheel-drive SUV, with somewhat similar results. A 2015 MODT package is expected to achieve a 20\% fuel economy

10 Assumptions: $12 \%$ discount rate, vehicle vmt/yr as described in Section 6. 
gain (20.3 mpg to $24.5 \mathrm{mpg})$, saving about 1,500 gallons ( $\$ 1,100$ discounted) of gasoline at a vehicle price increase of under $\$ 700$. The 2015 HT package is expected to achieve a $40 \%$ gain, to $28.4 \mathrm{mpg}$, saving nearly 2,500 gallons $(\sim 1,800)$ at a price of slightly more than $\$ 2,000-$ but with some loss of towing capacity because of its downsized engine. And the 2015 HT $+42 \mathrm{~V}$ package is expected to achieve nearly a $70 \%$ fuel economy gain, to $34 \mathrm{mpg}$, with a $\$ 3,600$ price and a gasoline savings of 3,500 gallons, which is worth about $\$ 2,500-$ and with some loss of both towing and off-road capability. The hybrid version $(2015 \mathbf{H T}+\mathbf{3 0 0 V})$ is expected to achieve an even higher increase, over $90 \%$ (to $39 \mathrm{mpg}$ ), with both high cost $(\$ 5,800)$ and high savings (over 4,100 gallons, or about $\$ 3,000$ ), but it loses its towing and off-road capability. The diesel engine is potentially a better prospect for the SUV, as its strong mid-range torque is well suited to towing and off-road performance. This engine, in combination with the rest of the MODT package, is likely to be comparable in price and in fuel economy to the $2015 \mathrm{HT}+42 \mathrm{~V}$ package but offer better performance than the baseline vehicle under some driving conditions.

It appears likely that at least some of these car and truck technology packages would be attractive to vehicle purchasers concerned with fuel economy and perhaps worried about future gasoline price increases (note that the value of fuel savings discussed above apply to gasoline at $\$ 1.35 /$ gal and will vary proportionately to gasoline price). It is important to remember, however, that the engine, transmission, and other improvements could be used to produce better performance rather than higher mpg if the market "preferred" performance over fuel economy. This preference has been dominant during the past decade and a half.

Also, these packages will seem far less attractive if consumers fail to value fuel savings over the vehicle's lifetime, but instead focus on savings only during its first few years. Some industry analysts, for example, have cited the first three years of driving as a more realistic measure of the fuel savings considered by the average vehicle purchaser. The difference in the value of fuel savings between lifetime accounting, as defined here, and a simple undiscounted first three years accounting is about a factor of 2. For example, the 950 gallon and $\$ 685$ value of the 2015 MODT package would be reduced to 257 gallons and $\$ 347$ by three-year accounting; the 1,630 gallon/ $\$ 1,174$ fuel savings value of the 2015 HT package would be reduced to 440 gallons and $\$ 594$. In other words, attractive or at least reasonable values are changed into plainly unattractive values by this short-term accounting. How consumers value fuel savings is thus a crucial factor in determining the attractiveness of a technology designed to improve fuel efficiency.

\section{What kinds of changes to the current CAFE structure might be considered, and what are their pros and cons?}

The current CAFE structure assigns the same set of fuel economy targets to each manufacturer, with separate targets for their domestic car fleets, import car fleets, and light truck fleets. ${ }^{11}$ This structure has been strongly criticized by the National Academy of Sciences and others for such perceived shortcomings as:

11 The targets are $27.5 \mathrm{mpg}$ for domestic and import car fleets and $20.7 \mathrm{mpg}$ for light truck fleets, with domestic and import truck fleets combined. The Canadian voluntary standards are structured essentially the same way, except that the domestic and import car fleets are combined. 
The "one size fits all" nature of the targets is economically inefficient and unfair, allowing manufacturers of smaller vehicles to satisfy the standards with little effort while demanding strong efforts from other manufacturers;

- The import vs. domestic split for cars fails to protect U.S. jobs and ignores the international nature of the auto industry; and

- The distinction between a car for personal use and a truck for work use/cargo transport has broken down, especially for minivans and sport utility vehicles (and more recently with so-called cross-over vehicles).

Despite its perceived shortcomings, however, the CAFE regulations have played a crucial role in the large increases in fuel economy that the U.S. light-duty vehicle fleet obtained in the late 1970s and early 1980s. They have also helped maintain these increased fuel economy levels through a prolonged period of low gasoline prices that have seen large increases in vehicle performance and weight — both antithetical to fuel efficiency.

One major attempt to change the form of CAFE was the early 1990s legislative proposal (S.279) of Senator Richard Bryan and others to institute Uniform Percentage Increase (UPI) standards, which demanded that each manufacturer improve its fleet's fuel economy by a uniform percentage over what it was in a base year. The appeal of this format depends primarily on the notion that current differences in manufacturers' fleet fuel economy levels mostly reflect differences in the sizes and types of vehicles they manufacture; i.e., that from the standpoint of technological efficiency, the company fleets are very similar. If this is so, and if one ignores the fact that many companies are changing their fleet size mixes over time, asking for a uniform percentage increase in fuel economy might come close to placing a uniform burden on each of the companies. Criticisms of the format are that (1) it ignores real technological differences among the companies (that is, that the technological efficiency of each company's fleet is not similar to the others), rewarding the efficiency "laggards" by giving them easier targets, and (2) it would restrict the ability of companies to move into new markets (by basing their mpg targets on their past mix of vehicles). Also, critics claim that the precedent of a UPI standard would discourage companies from exceeding their targets to avoid having new "baseline" fuel economy levels that are even more out of line with their competitors - and thus getting new targets that are also more out of line (i.e., more difficult) with their competitors - when the standards come up for renewal.

There is no easy way to measure the "technological efficiency" of a fleet, but an examination of variations in the "ton-mpg" achieved by individual manufacturers can show how much of the difference in fleet average fuel economy across manufacturers is due to differences in the size and type of vehicles they sell (as measured, imperfectly, by the average weight of their vehicles) and how much is due to other factors, such as technology. In fact, the results of an examination of the ton-mpg of the U.S. fleet in the year 2000 (see Figure S-2) are mixed. On the one hand, the differences in ton-mpg among the largest manufacturers are not great, implying that the differences in weight among their respective fleets probably is the most important factor explaining the differences in their fleet fuel economy levels. On the other hand, some companies (e.g., Toyota and Honda) do have a small but significant advantage over the others in ton-mpg, 


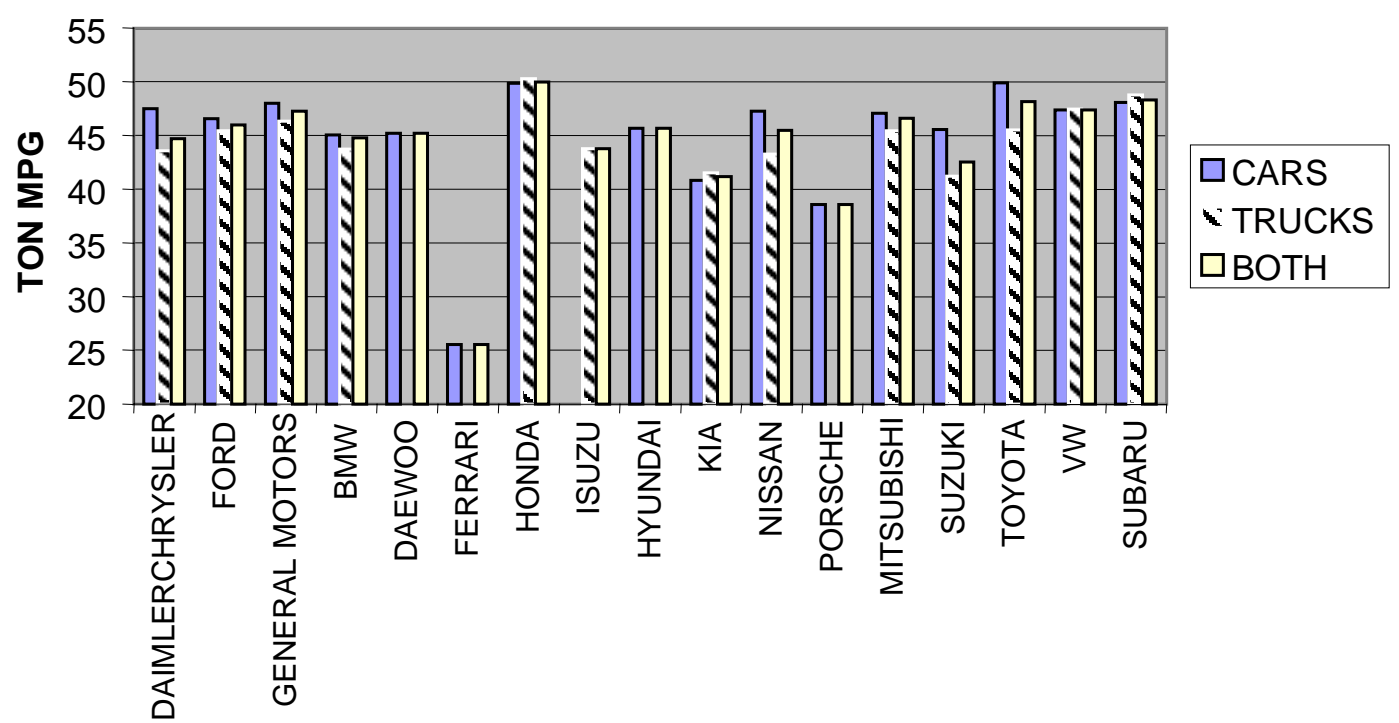

Figure S-2. Ton-mpg for the MY 2000 U.S. Fleet

implying that differences in other factors, like technology, do play an important role in explaining the fuel economy differences. This view somewhat supports the argument that a UPI standard would be inequitable in the challenges it places on different companies - although this would be trading one inequity for another, since the current CAFE system is also inequitable in that it clearly favors companies that focus on smaller vehicles. Of course, there may be variations of the simple UPI standard that could mitigate some of the above criticisms, but this report did not examine such variations.

Another approach to setting company standards is to base them on vehicle attributes, such as weight or size. ${ }^{12}$ Such a standard might, for example, require small or light vehicles to attain a higher mpg target than large or heavy vehicles. Note that using a vehicle attribute as the basis for a standard has the potential to reduce or eliminate any incentive to reduce the magnitude of that attribute. For example, a size-based standard will reduce the incentive to produce smaller cars to increase fuel economy (since the smaller cars would have to attain a higher mpg target), whereas the current (uniform) fuel economy standards do reward a move to smaller cars. A weight-based standard, which the Japanese have recently instituted (see Figure S-1), may assign company targets more equitably (in terms of the technological burden demanded) than either the current system or UPI and might make it more feasible to combine the car and light truck fleets (because more than half of the difference in fuel economy between these two fleets is due to differences in vehicle weights). However, a weight-based standard would reduce or eliminate the value of weight reduction as a "target-meeting" technology, probably increasing the overall cost of any particular level of required total fleet fuel economy increase. It may also fail to hold back further weight increases in the fleet, the average weight of which has been increasing steadily since the 1987 model year. Such weight increases might be welcomed by those who believe higher weight

12 A requirement to evaluate a weight-based standard was included in the House version of the 2002 Energy Bill, H.R. 4. 
means greater safety - and criticized by those disagreeing with this asserted relationship and wanting to maximize the potential for higher fuel economy by rewarding weight reduction.

Aside from weight, several vehicle attributes may form the basis of an attractive structure for a fuel economy standard. One example is wheelbase $\times$ track width, an attribute that should be strongly related to vehicle safety (wheelbase is related to crush space and vehicle directional stability; track width is related to rollover potential). Other attributes of interest include total interior (passenger plus luggage) volume and carrying capacity (for light trucks). Unfortunately, available databases for the light truck fleet are not satisfactory for evaluating attribute-based standards, other than those based simply on weight; constructing an improved light-truck database would be necessary for development of a satisfactory standard.

Figure S-3 explores how different forms of a new standard for cars designed to achieve a $20 \%$ fleetwide fuel economy improvement will affect individual company targets. A CAFE-type standard simply assigns a uniform mpg target to each company. A UPI-type standard (the second bar) simply multiplies each company's baseline fuel economy (first bar) by 1.2. Thus, companies like Honda, Nissan, and Toyota, which have high baseline fuel economies, are assigned high target mpg values that are well above the level they would obtain from a CAFE-type standard; companies with low baseline mpg values, such as Mercedes, are assigned targets well below what they would obtain from a CAFE-type standard (of course, UPI standards could be structured so that companies with baseline fuel economies well above or well below the average could be assigned adjusted targets - more lenient for the fuel economy leaders, more stringent for the fuel economy laggards). The three remaining lines represent three types of weight-based standard:

- A standard that assigns mpg targets based only on vehicle weight;

- A standard that adjusts its weight-based target by a measure of "weight efficiency," using weight/wheelbase $\times$ width as a measure of efficiency, to avoid any positive bias toward increased weight; and

- A similar "adjusted" standard that seeks to reward high weight efficiency by assigning "weight-efficient" cars with a reduced mpg target.

The three weight-based standards affect the various automakers in different ways. For example, a pure weight-based standard rewards Toyota and Mercedes, and to a lesser extent Chrysler, with mpg targets significantly below what they would get from a UPI standard. Compared to their peers, these manufacturers have attained high levels of fuel economy relative to the weight of their cars. For the other major manufacturers, there is little difference - below $1 \mathrm{mpg}$ - between UPI and a pure weight-based standard. Adding adjustments for weight efficiency to the standards hurts Mercedes, because its cars are luxury models that are comparatively heavy for their size. In contrast, Chrysler, Ford, and especially Honda are helped by the adjustments - their cars are relatively light for their dimensions. 


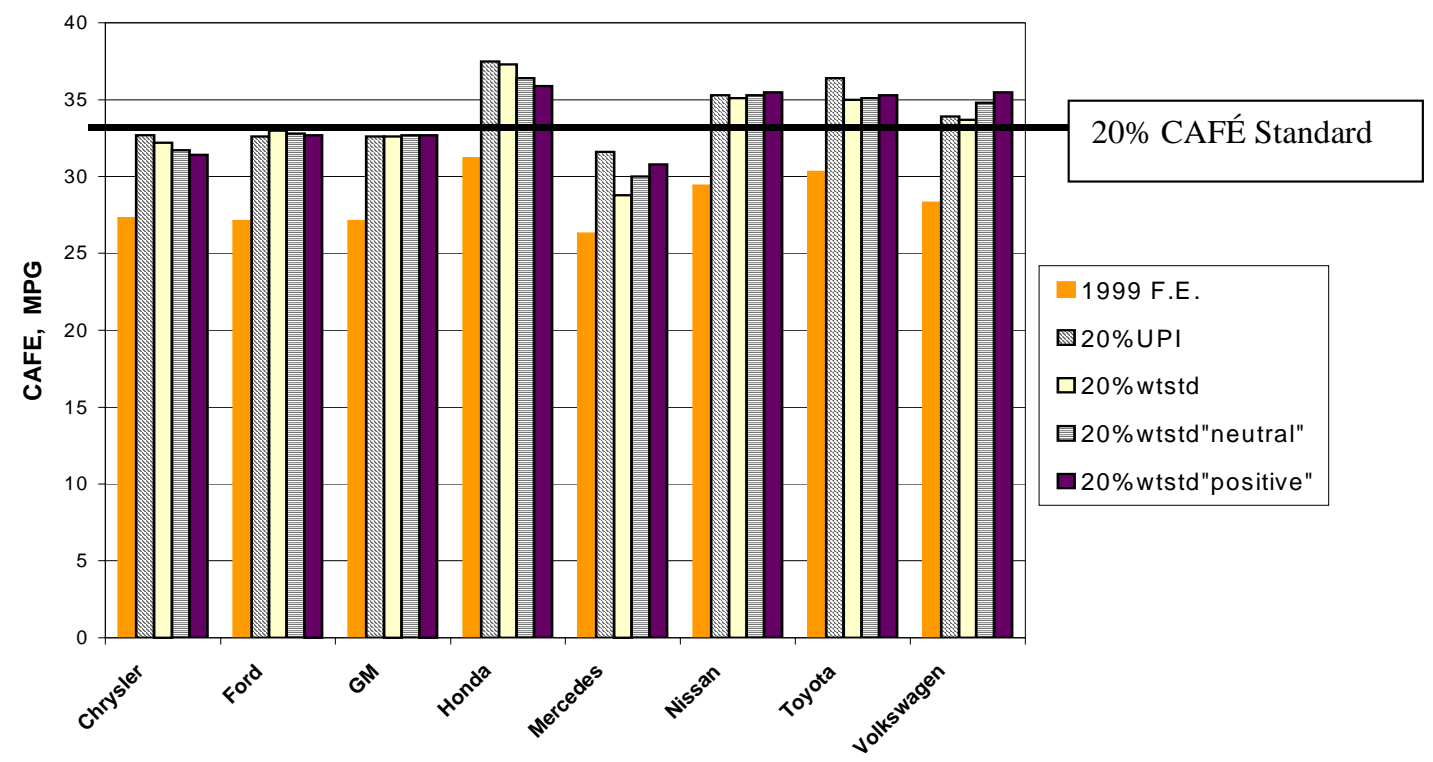

Figure S-3. Corporate mpg Targets for Alternative Auto Standards, for Major Automakers, Based on 1999 Car Fleet

The primary conclusion to be drawn from this comparison of different forms of standards is not that any one is better than the other - such a conclusion would require more analysis and would likely depend strongly on the particular objectives of policymakers. Instead, the comparison demonstrates that the form of a standard is extremely important in determining the relative impacts it will have on individual automakers, and policymakers and automakers might do well to examine different forms when examining the potential to undertake a voluntary agreement to improve fleet fuel economy.

\section{What levels of fuel economy increases for passenger cars and light trucks, and what forms of fuel economy standards, might be most conducive to formulating voluntary standards for the period 2012 to 2015 ?}

Key premises of the analysis of this question are that for voluntary fuel economy increases to be acceptable to manufacturers, (1) the size of the required increase must be close to the level that provides the greatest value to vehicle buyers and (2) the assignment of fuel economy targets to manufacturers must be generally perceived by manufacturers as fair. In this analysis, the value to car buyers of the changes in fuel economy is represented by the present value of fuel savings minus the increased price of higher-fuel-economy vehicles. The value to society of reduced oil dependence or decreased environmental impacts is not included in these calculations.

We do not claim that the "maximum net value" fuel economy levels we calculated in this study are the "best" values for a voluntary fuel economy standard. The calculated levels depend on a set of assumptions that others might take issue with - besides, different policymakers might choose other rationales than achieving maximum net value as the appropriate selection criterion for a new fuel economy target. However, we do believe that the maximum net value levels represent a reasonable set of targets with which to begin a negotiation about voluntary fuel 
economy levels, and our methodology provides a means by which other assumptions or goals can be factored into the negotiating process in a rational and measurable form.

In discussing different kinds of fuel economy standards, we identify them by two characteristics:

1. "Metrics," the way in which the fuel economy targets are calculated (e.g., a simple mpg value, or a value based on past performance, or a value based on some vehicle attribute), and

2. "Constraints," the way in which the targets are assigned to groups of vehicles — does the standard divide the fleet according to which company sells them, or further into company subfleets, or into broader categories (e.g., all light-duty vehicles — as in the European Voluntary Commitment)?

For each of the two levels of fuel economy increase tested (20\% and 33\%), three alternative fuel economy metrics were examined: (1) corporate average miles per gallon (mpg) applied to broad classes of vehicles, (2) a UPI in corporate mpg from a baseline year, and (3) a weightbased mpg formula. Within the first two metrics, five constraints, or rules, for assigning targets to manufacturers were examined, from a single industry-wide target for the entire fleet of cars and light trucks to a CAFE-like manufacturer-specific, passenger car versus light truck, domestic versus imported corporate average commitment. As noted above, the single industry-wide target is essentially the same form as the European Voluntary Commitment.

Key simplifications of the analysis are that (1) manufacturers are assumed not to alter their positions in the marketplace by introducing new product lines or dropping older ones; (2) vehicle attributes other than fuel economy and price are assumed to remain essentially unchanged (except for a 5\% increase in vehicle weight due to added safety devices); (3) we do not consider the possibility that new technologies, or design changes that reduce technology cost or improve fuel economy performance, might be introduced within the time period; and (4) in our analysis of impacts on individual manufacturers, we assume that each manufacturer's customers value fuel economy savings in the same way. Also, consumers are assumed to value fuel savings over the full 14-year operating life of a vehicle, with gasoline at $\$ 1.35$ per gallon. Alternative assumptions about technology costs, consumer valuation, and future gasoline prices were also considered in sensitivity analyses. For example, because some industry analysts claim that average vehicle purchasers consider only the first few years of fuel savings in their purchasing behavior, we examine, as a sensitivity case, the effect of accounting for only the first three years of savings.

Manufacturers certainly will change their product offerings between now and 2015 and vehicle attributes will change in response to changing consumer preferences. Also, because some manufacturers serve different market segments than others, it is likely that there are nonnegligible differences in how customers of different manufacturers value fuel economy. Therefore, we suggest that the estimated impacts on manufacturers not be interpreted as applying to specific manufacturers, but rather be treated as a general description of the kinds of impacts likely to occur to manufacturers with different product lines. 
Conditional on these premises, it appears that a fuel economy increase of about 22-23\% for cars and 24-26\% for light trucks would provide the maximum net value for consumers. The annual net private value of a $20 \%$ increase is estimated to be about $\$ 9.7$ billion per year, or about $\$ 500$ per vehicle, while that of a 33\% increase ranges from $\$ 3.9$ billion to $\$ 8.5$ billion per year, or about \$200-450 per vehicle. ${ }^{13}$ With alternative technological and cost assumptions, fuel economy increases yielding the highest net value range from a $60 \%$ increase (with optimistic assumptions and looking out to 2020 rather than 2012-2015) to well below $20 \%$ with pessimistic assumptions. If consumers value only the first three years of fuel savings, the fuel economy level providing the highest net value would be well below $20 \%$.

Not surprisingly, the assumed price of gasoline will also play a crucial role in determining what the "maximum net value" fuel economy point will be for the light-duty vehicle fleet. The above values of about a $24 \%$ increase for the light-duty fleet are associated with an assumed future gasoline price of $\$ 1.35$ per gallon, in 1999 dollars. If the assumed future price is $\$ 2.00$ per gallon, the maximum net value point increases to between 32 and $33 \mathrm{mpg}$ for the entire fleet, which is an increase of over $30 \%$. And at $\$ 4.00$ per gallon, the maximum net value point rises to about $38 \mathrm{mpg}$, which is an increase of over $50 \%$.

A key conclusion of this study is that, except for the weight-based standard discussed below, neither the metrics nor the constraints of the standards have a significant impact on the total (industry-wide) net benefits or costs of a given fuel economy increase, although differences in these benefits and costs would have been larger had the mpg increases considered been more stringent (Figure S-4 shows the variation of net value across the metrics and constraints examined here for the $33 \%$ increase in fuel economy). For the $20 \%$ increase requirement, differences in the net values of alternative constraints and metrics (mpg or UPI) have a range of under 5\% for all five alternative constraints; the range of net values increases to $12 \%$ for the more stringent 33\% requirement. Differences in the fuel economy levels achieved under different forms of voluntary standards are also quite small, typically a few tenths of an mpg.

For both the UPI and mpg metrics, the industry-wide standard appears to be the most efficient of the five alternative constraints. However, this is because the method used to compute costs and benefits assumes that each standard will be met in the most efficient manner, and for the industry-wide standard, this means equalizing the marginal cost of saving a gallon of fuel across manufacturers. Because it is not clear how responsibility for meeting such a standard (which is similar to the European agreement) might actually be allocated within the industry, it is best to treat the industry-wide standard as a "best-case" benchmark.

For the mpg metric, the least efficient constraint is that which combines cars and light trucks into a single category; that is, it specifies a single mpg target for each manufacturer, regardless of the mix of cars and light trucks it produces. For the 33\% increase, this standard

13 Public goods and external benefits have not been included in the net value estimates. 


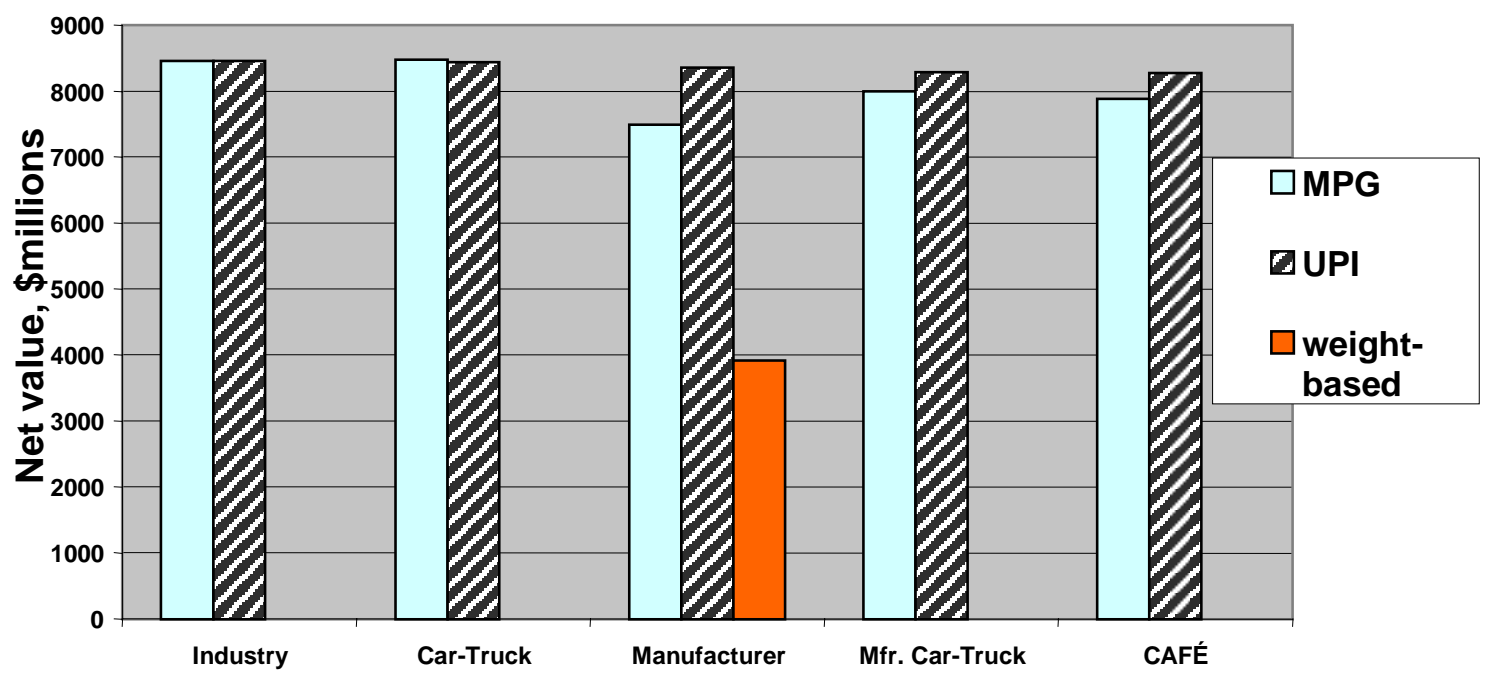

Figure S-4. Net Value of a 33\% Fuel Economy Increase vs. Form of Standard for Three Metrics, $\$ 10^{6}$

increases the annual price of new vehicles to consumers by $\$ 17.9$ billion and produces an annual $\$ 25.4$ billion in lifetime fuel savings, for a net annual value of $\$ 7.5$ billion. This amount compares with a net value of $\$ 7.9$ billion annually for CAFE-like standards (that is, separate targets for cars and light trucks, and for domestic and import fleets, for each manufacturer) and $\$ 8.5$ billion for the "best-case" industry-wide standard.

Differences in costs and benefits to consumers across the alternative constraints are still smaller for the UPI metric. For the 33\% percent increase, both the manufacturer-specific UPI standard and the CAFE-like standard result in an estimated net annual benefit of $\$ 8.4$ billion as opposed to $\$ 8.5$ billion for the industry-wide standard.

Except for the industry-wide requirement (for which there is no clear method of allocating company targets), no single metric or constraint was clearly the most equitable. In general, the UPI metric creates a greater burden for those manufacturers that currently have the highest fleet average fuel economy levels, while the mpg metric disadvantages those that currently have the lowest mpg levels. For example, Figure S-5 shows the marginal cost, in dollars per marginal gallon of gasoline saved, of the manufacturer-specific 33\% mpg and UPI standards for several individual manufacturers. As shown by the figure, Honda, Hyundai, Kia, Mitsubishi, and Toyota - all with high current fuel economy levels — spend less than $\$ 1.50$ per marginal gallon of gasoline saved under the manufacturer-specific 33\% mpg standard, but they spend $\$ 2.00$ or more per gallon under the equivalent UPI standard. In contrast, companies with lower current levels of fuel economy (such as DaimlerChrysler, Ford, General Motors, and BMW) would spend considerably more under the mpg metric than under the UPI metric. Similar patterns can be seen in the impacts of the alternative standards on the net value of different manufacturer's vehicles. As noted above, we urge readers to interpret these results as illustrations of the types of differences that might emerge for different types of automakers, not as accurate representations of the likely impact on the named companies. 


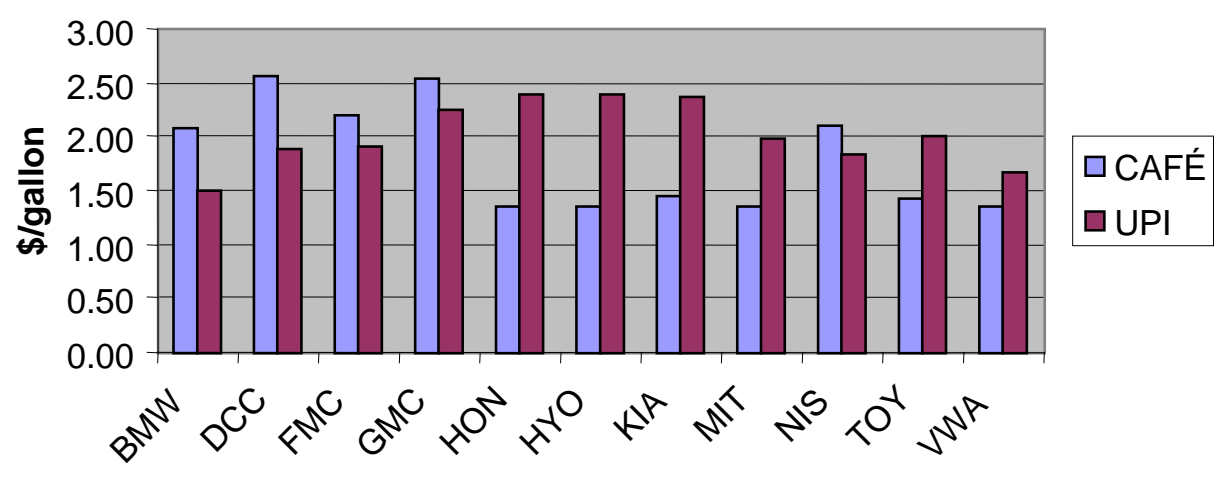

Figure S-5. Marginal Cost per Gallon Saved, 33\% Manufacturer Standard

This study also analyzed the costs, benefits, and impacts on vehicle weight of a weightbased formula for assigning fuel economy targets to manufacturers - the first of the three weight-based standards discussed in Question 4. The results should be considered very tentative because of substantial uncertainty about how accurately manufacturers' responses to a weight-based formula have been represented and because only one of many possible weightbased formulas has been analyzed. Given this caveat, the weight-based standard appears to be more expensive than the other metrics - a predictable result since the standard essentially removes weight reduction technology as a viable means of achieving the fuel economy targets. For a 33\% requirement, the weight-based standard was a bit more than $\$ 4$ billion (about 25\%) more costly per year than the "best-case" (industry-wide) mpg standard and about $\$ 2.4$ billion (about 13\%) more costly than least-efficient (mpg manufacturer-specific) standard. For the 20\% requirement, however, the cost of the weight-based standard was about the same as the other standards. As with the other types of standards, the weight-based standard also appears to disadvantage some manufacturers relative to others. This effect could be due to the specific formula tested, however.

A concern with weight-based standards is that they will allow and even encourage the average weight of the vehicle fleet to continue to grow, nullifying much of the effect of improved technology. Our analysis estimates only the direct effect of the standards on weight; it does not account for any weight gains associated with consumer demands (although we do include an assumed $5 \%$ weight gain to satisfy safety regulations). In our estimates, assumptions about how consumers value fuel economy play a key role in the estimated changes in weight associated with a weight-based standard. Assuming full lifetime accounting for fuel savings, the weight-based standard produced only small changes in vehicle weights. Average vehicle weight actually decreased by $1.5 \%$ for the $20 \%$ requirement and increased only $1.0 \%$ for the $33 \%$ requirement, compared with likely 5-10\% weight reductions with the mpg and UPI metrics (these changes are in addition to the assumed uniform 5\% weight increase because of safety requirements). With the assumption of three-year accounting, however, the 33\% requirement causes an average 5\% weight increase, and four manufacturer/vehicle-type/origin cases increased weight by $20 \%$ or more. We stress again that this analysis of weight-based standards should be considered just a first step toward understanding this approach to setting fuel economy standards. 
To sum up, our analysis shows the following:

1. Although there is no unambiguously "correct" or "best" level of fuel economy increase that might be the goal of voluntary fuel economy standards, it is possible to define a set of fuel economy targets that will provide the highest "net value" - present value of fuel savings minus the cost of the technology that brings the savings — using a selected set of accounting rules and estimated future price of gasoline. Aiming for attainment of targets by the 2012-2015 time period and assuming (1) a gasoline cost of $\$ 1.35$ per gallon, (2) no accounting for "externalities" (such as energy security or global warming impacts), (3) a 12\% rate of return on technology, (4) fuel savings over the full lifetime of the vehicle, and (5) an average vehicle weight gain of 5\%, the maximum net value for consumers will be reached at about a 22-23\% fuel economy increase for cars and a 24-26\% increase for light trucks.

2. Changing the accounting rules will change the results. If higher gasoline prices are expected, or if external costs of using gasoline are incorporated into the price, the maximum net value fuel economy increases will be higher. For example, at $\$ 2.00$ per gallon of gasoline, the maximum net value fuel economy increase will be a bit over 30\%, yielding a light-duty fleet of about 32-33 mpg. At $\$ 4.00$ per gallon, the maximum value point is about $38 \mathrm{mpg}$, which is an increase of over $50 \%$. On the other hand, some industry analysts claim that vehicle purchasers take into account only the first few years of fuel savings; if this were used as an accounting rule, the maximum net value fuel economy increase would be drastically lower.

3. Our limited examination of a few different configurations - combinations of metric and constraint - for new fuel economy standards reveals no one form that is clearly superior to all of the others. On the other hand, the examination shows that the various forms have some major differences in results especially with regard to variations in the impacts on different individual automakers - that make it quite clear that the selection of metric and constraint for any new standards will play a significant role in the perceived fairness of the standards and, to a lesser extent, will influence the overall economic efficiency of the standards. For example, the use of the mpg and UPI metrics ${ }^{14}$ seems to yield directly opposite results - companies that "benefit" from mpg standards "lose" with UPI standards (and vice versa). Some combination of the two types of standards might reflect a reasonable compromise, although issues about changing company fleet compositions would remain. ${ }^{15}$ Attribute-based

14 The mpg metric assigns the same mpg targets to the cars and light trucks in each company regardless of the physical characteristics of these vehicles; UPI assigns mpg targets to each company that reflect uniform percent increases from each company's fleet mpg levels in a baseline year.

15 UPI standards, because they are based on fleet attributes in a baseline year, cannot account for changes in fleet composition (e.g., a movement to upscale vehicles), and such changes could, in turn, cause large corresponding changes in a company's ability to meet a fuel economy target. 
standards, reflected in our analysis by an extremely limited examination of weight-based standards, remain an intriguing possibility that deserves careful analysis. Because our analysis was so limited, we urge further study of attributebased standards. 
$\Delta$ 


\section{Section 1 Introduction}

\subsection{Background}

In the three major markets for light-duty vehicles in the developed world - those of North America, Western Europe, and Japan - policies for improving the future fuel economy of these vehicles have evolved in sharply different directions. In the United States, federal government efforts at improving fuel economy have focused on shared research and development (e.g., the Partnership for a New Generation of Vehicles, recently superceded by the FreedomCar Initiative, a partnership aimed at developing practical hydrogen fuel cell vehicles) and proposed tax incentives for certain high-efficiency vehicles. ${ }^{16}$ The Corporate Average Fuel Economy (CAFE) standards originally promulgated in 1975 remain in force, ${ }^{17}$ although no future increases in the standards have been legislated (however, the State of California has established legislation calling for new-vehicle emission standards for $\mathrm{CO}_{2}$; these standards, if successfully enforced they are currently being challenged — are likely to achieve the same effect as fuel economy standards).

In Canada, automakers face the same fuel economy standards as in the United States, but the standards are voluntary — there are no fines. ${ }^{18}$ And the Canadian government has stated its intention to negotiate new, and higher, voluntary standards with its industry, although it recognizes that such standards would be far more practical if they were coordinated with simultaneous U.S. standards.

In Europe, the European Car Manufacturer's Association (ACEA) has proposed, and the European Union (EU) has accepted, a Voluntary Commitment pledging to reduce "per new passenger vehicle" $\mathrm{CO}_{2}$ emissions by $25 \%$ by the year 2008, from a 1995 baseline. This agreement implies a 25\% reduction in new-vehicle fuel consumption (assuming fuels do not change ${ }^{19}$ ), or a $33 \%$ improvement in fuel economy. ${ }^{20}$ And in Japan, the national government has

16 According to the Internal Revenue Service, hybrid-electric vehicles are eligible for "clean-fuel" tax deductions of up to $\$ 2,000$. The exact amount of these deductions for each vehicle was not yet determined at the time this report was written.

17 In 1974, before the passage of mandatory fuel economy standards, auto manufacturers accounting for 95\% of U.S. auto sales agreed to a voluntary program to achieve a $40 \%$ improvement in fuel economy by 1980 (EPA 1980).

18 An additional difference between the Canadian and U.S. systems is that the Canadian standards are applied to each company's combined import and domestic fleets, whereas the U.S. standards are applied separately to each company's import and domestic car fleets.

19 A shift toward more diesel, which is likely in Europe, will imply a requirement for a larger than $25 \%$ reduction in fuel consumption, because diesel fuel has a higher carbon content than gasoline.

20 Fuel economy (e.g., mpg) is the inverse of fuel consumption (gpm). Thus, a 25\% reduction in gpm is $0.75 \times \mathrm{gpm}$, and its inverse is $1 / 0.75 \times \mathrm{mpg}=1.33 \times \mathrm{mpg}$, which is a $33 \%$ increase in fuel economy. 
established a series of weight-class fuel economy standards that require approximately a $23 \%$ improvement in the fuel economy of gasoline-fueled light-duty vehicles by 2010, also from a 1995 baseline.

Further, both Europe and Japan promote high fuel economy by keeping transportation fuel prices quite high through taxation, and several European countries have levied vehicle sales and use taxes based on engine displacement or other factors associated with fuel efficiency. Japan also levies vehicle use taxes based on engine displacement.

If the Japanese and European fuel economy initiatives fully succeed, by 2010, Japan will have a gasoline light-duty passenger vehicle fleet average of $35.5 \mathrm{mpg}$ (measured on the Japanese 10.15 driving cycle), and the European light-duty passenger vehicle fleet will attain about $41 \mathrm{mpg}$ (measured on the European test cycle, in gasoline equivalent gallons) by 2008 . Note that fuel economy measured on either of these driving cycles is likely to be lower than if measured on the official U.S. test cycle - in other words, both the Japanese and European fleets would attain still higher fuel economy levels than shown above if they were measured on the same cycle on which the U.S. fleet is measured.

Recent forecasts by the Energy Information Administration (EIA) and others have projected that, in the absence of any changes in government policies, the fuel economy of the U.S. lightduty fleet will grow only modestly over the next 10 years. For example, EIA's Annual Energy Outlook 2002 projects, in its reference case, that new car fuel economy will increase from $28.6 \mathrm{mpg}$ in 2000 to $31.0 \mathrm{mpg}^{21}$ in 2015, which is about an $8 \%$ increase (EIA 2001). The fuel economy of the new light-duty truck fleet is projected to increase from $21.1 \mathrm{mpg}$ in 2000 to $23.3 \mathrm{mpg}$ in 2015 , or about $10 \%$. And the overall new light-duty fleet is projected to attain a fuel economy of $26.6 \mathrm{mpg}$ in 2015, which is a $9 \%$ gain from the 2000 level of $24.5 \mathrm{mpg}$. Such projections have not been reliable in the past and have overestimated future gains. However, the new forecast, if correct, implies that the current gap in fuel economy between the U.S. light-duty vehicle fleet and the Japanese and European fleets will grow over the next decade without further changes in national policy or unforeseen changes in energy prices or vehicle markets.

Last year, the U.S. Congress debated whether or not the current system of CAFE standards should be changed and/or raised. And, as noted above, the Canadian government has stated its intention to negotiate with the auto industry to enact a voluntary standard aimed at raising fleet fuel economy. The goal of this report is to inform the Congress and the Canadian government about the potential effects of new standards.

The approved Statement of Work for this study, which was jointly sponsored by DOE's Office of Transportation Technologies and Natural Resources Canada, called for an analysis that would:

- Examine the new Japanese and European fuel economy initiatives and evaluate differences in the Japanese, European, and U.S. auto markets likely to affect the ability

21 These values are the EPA test values, without any on-road adjustment factors, dual-fuel vehicle credits, or other adjustment to the data. 
of the U.S. and Canadian industry to achieve similar results. In other words, are there lessons to be learned about the level and form of these standards that are applicable to the United States and Canada?

- Examine alternative structures for voluntary fuel economy standards, given longstanding complaints about the current CAFE structure. Propose some candidate structures for further study.

- Evaluate the prospects for achieving $20 \%$ and $33 \%$ increases in fuel economy in the passenger car and light duty truck fleets, in terms of available technology, costeffectiveness, and effect on the competitiveness of individual automakers. Examine the effect of some of the proposed alternative structures on the ease of attainment of the fuel economy increases and on their potential acceptability to automakers.

In other words, we are trying in this study to better understand how voluntary fuel economy standards might work with respect to structure, level, and timing, and we have done so by looking at what others have done (in Europe and Japan), studying the technology potential and its cost, and qualitatively and quantitatively analyzing a variety of alternative standards.

\subsection{Report Organization}

The remainder of this report is structured as follows:

- Section 2 describes the Japanese and European initiatives and then evaluates them in terms of available technology, regulatory issues, and other factors. The chapter concludes with an examination of differences in the Japanese, European, and U.S. markets that can affect the commercial feasibility of efficiency technologies and a calculation of the cost-effectiveness of one technology example - direct-injection (DI) gasoline engines - in the three markets.

- Section 3 provides a broad overview of the methodology we use to evaluate voluntary fuel economy standards, including the development of technology cost curves, derivation of alternative standard structures, and evaluation of the technology costs and discounted fuel savings for several alternative standards aimed at increasing fleet fuel economy by $20 \%$ and $33 \%$.

- Section 4 presents the key fuel economy technologies we considered, their estimated costs (presented as Retail Price Equivalents [RPEs], where RPE is the average increase in retail price due to addition of that technology to a vehicle), and their effects on vehicle fuel economy (presented as percentage increases from a baseline vehicle). The chapter concludes with the development of a variety of year-2015 vehicles - midsized cars and SUVs - with alternative packages of technologies and their resulting total RPEs and fuel economies.

- Section 5 discusses concerns with the current CAFE regulatory structure, presents several alternatives to that structure, and analyzes their impact on the level of fuel economy increase required of individual automakers for $20 \%$ and $33 \%$ fleet-wide 
increases in fuel economy. The alternative structures evaluated are (1) Uniform Percentage Increase (UPI); (2) a "pure" weight-based standard that defines company fuel economy targets only on the basis of the sales-weighted average curb weight of their vehicles; and (3-4) two versions of a weight-based standard that adjust each company's target on the basis of a measure of the "weight efficiency" of its vehicles (that is, how heavy they are in relation to their size).

- Section 6 evaluates alternative fuel economy structures according to the potential changes they would cause to the net value of the total fleet and to individual company fleets, where net value is the change in RPE associated with the technologies used to attain the fuel economy targets, minus the discounted value of the fuel savings associated with the higher fuel economy. The discussion begins with a description of the technical approach, which involves developing fuel economy cost curves (curves of incremental changes in RPE vs. incremental changes in fuel economy associated with specific technologies, where the technologies are added in order of their cost-effectiveness) and developing a nonlinear programming model that finds solutions to defined fuel economy structures (and percentage increase targets) that maximize the resulting net value to consumers. The model is applied to two levels of fleet-wide fuel economy improvement targets (20\% and 33\%); three alternative fuel economy structures (based on uniform mpg targets, UPI targets, and "pure" weight-based targets as discussed above); and five types of constraints; that is, definitions of which vehicles are included in the sets of vehicles that must meet the targets - ranging from a standard that sets one target for the entire fleet of all cars and light trucks, to a standard that sets individual targets for every vehicle set of automaker/car or light truck, domestic or imported (that is, there is an individual target for the set of Ford domestically produced passenger cars, another for Ford imported cars, etc.).

\subsection{References}

EIA: Energy Information Administration

EIA, 2001, Annual Energy Outlook 2002, DOE/EIA-0383(2002), Dec.

EPA: U.S. Environmental Protection Agency

EPA, 1980, Office of Mobile Source Air Pollution Control, Passenger Car Fuel Economy: EPA and Road - A Report to the Congress, Jan. 


\section{Section 2 \\ European and Japanese Initiatives to Boost Automobile Fuel Economy22}

\subsection{Introduction}

As noted in Section 1, both Europe and Japan have taken strong measures to improve the fuel economy of their light-duty passenger vehicle fleets - a Voluntary Commitment to effectively improve fuel economy by $33 \%$ (over a 1995 baseline) by 2008 in Europe and regulations aimed at achieving approximately a 23\% improvement by 2010 in Japan.

Both the European and Japanese initiatives may have something to teach us about the potential for voluntary fuel economy standards in the United States. Because the European initiative is voluntary, ${ }^{23}$ its structure will be of particular interest to U.S. policymakers. The Japanese initiative is a compulsory standard, but its weight-based structure may be of strong interest to U.S. policymakers who are not satisfied with the current U.S. structure, which does not consider differences in vehicle attributes among the various manufacturers in establishing fuel economy targets. And because basically the same group of manufacturers participates in all three markets, the fuel economy targets and timing of both initiatives are of interest - although careful attention must be paid to differences among the three markets in terms of emission standards, fuel economy measurement requirements, gasoline prices, and other factors that will affect the ease with which new fuel economy targets may be met.

\subsection{Description of the Initiatives}

\subsubsection{Japanese Weight Class Standards}

The Japanese government has established a set of fuel economy standards for gasoline- and diesel-powered light-duty passenger and commercial vehicles, with fuel economy targets based on vehicle weight classes. The targets for gasoline-powered vehicles are to be met in 2010 (2005 for diesels). Figure 2-1 illustrates the percentage improvements and fuel economy levels (on the Japanese 10.15 driving cycle) required for each weight class of gasoline-powered passenger vehicles, as well as the current market shares for each class. ${ }^{24}$ In the original version of the

22 Substantial portions of this section appeared as a paper in Energy Policy 29 (2000).

23 As noted earlier, the Voluntary Commitment was offered by the ACEA in the face of a threat of stronger mandatory standards.

24 In Figure 2-1, the weights in larger type, in the row marked IW, are the inertial weight classes that represent a range of test weights, which are curb weights (with a full gas tank) plus $110 \mathrm{~kg}$ (representing the average weight of two passengers). The values in smaller type above the inertial weight class values are curb weights. 


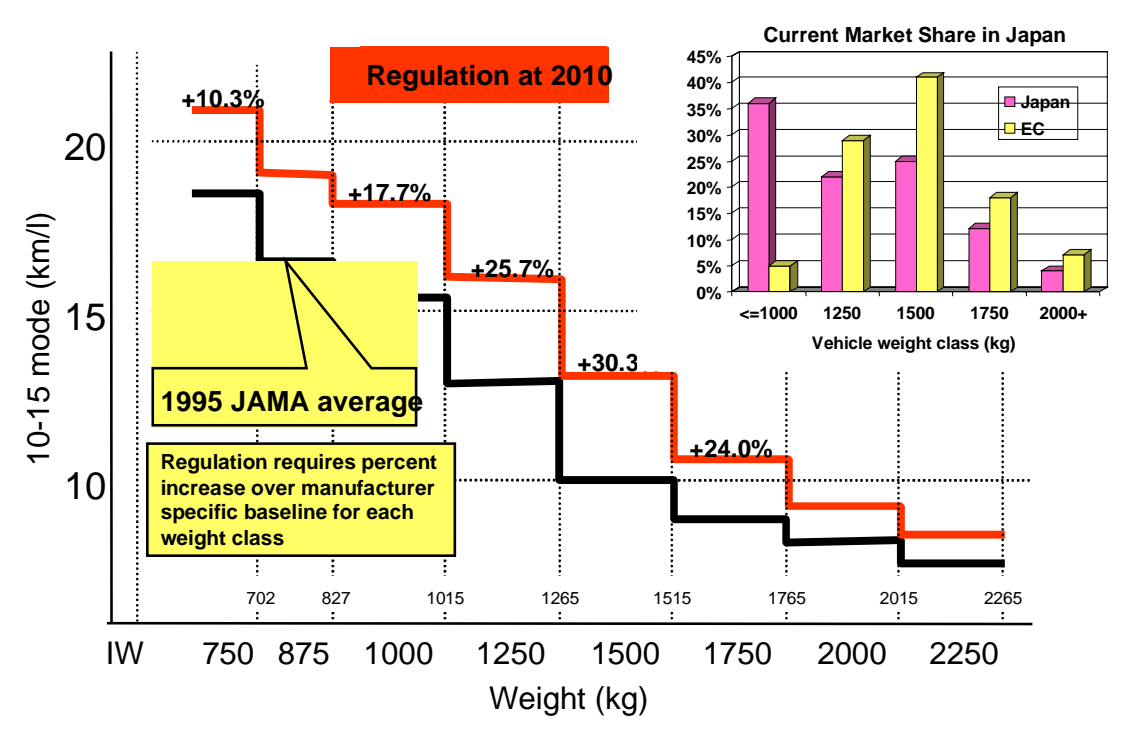

Figure 2-1. New Japanese Fuel Economy Regulations

standards, the targets were to be met by each automaker for each weight class, ${ }^{25}$ and any surpluses in one class were not to be used to offset shortfalls in another. Because of protests by U.S. and European automakers, the standards now allow such offsets, but on a two-for-one basis: credits earned by a better-than-target fuel economy performance in one weight class are discounted by $50 \%$ when applied to a worse-than-target performance in another weight class.

If there were no change in vehicle mix, these targets would imply a $22.8 \%$ improvement in gasoline passenger vehicle fuel economy ( $15.1 \mathrm{~km} / \mathrm{L}$ in $2010 \mathrm{vs.} 1995$ level of $12.3 \mathrm{~km} / \mathrm{L})$; the diesel requirements imply a $14.0 \%$ improvement in fuel economy $(11.6 \mathrm{~km} / \mathrm{L}$ vs. $10 \mathrm{~km} / \mathrm{L})$ compared to the 1995 fleet (MOT 2001). In other words, compliance with these standards will produce by 2010 and 2005, respectively, a Japanese gasoline-fueled light-duty passenger vehicle fleet achieving $35.5 \mathrm{mpg}$ and a diesel fleet achieving $27.3 \mathrm{mpg},{ }^{26}$ as measured by using the Japanese 10.15 driving cycle. Because the Japanese 10.15 driving cycle represents more congested, stop-and-go driving conditions than the combined U.S. city/highway cycle, the U.S. equivalent mpg for this fleet would likely be higher (Kenney 1999).

The fuel economy targets were selected by the "top runner" method: identifying representative "best-in-class" fuel economies in each weight class in the current fleet and demanding that the average new vehicle meet that level in the target year. The regulators sought to identify relevant targets and avoided identifying vehicles with manual transmissions as the top runner for vehicles with automatics or selecting vehicles with few sales or very expensive technology (e.g., hybrid drivetrains) as the top runner.

25 Each weight class target relates to a manufacturer's sales-weighted harmonic average fuel economy of its vehicles in that weight class.

26 In the Japanese fleet, diesel vehicles are larger, on average, than gasoline vehicles. 


\subsubsection{ACEA Voluntary Commitment to the European Commission on Vehicle Carbon Emissions}

The ACEA offered, and the European Commission accepted, a Voluntary Commitment to reduce the $\mathrm{CO}_{2}$ emissions from new light-duty passenger vehicles, with fleetwide targets of 140 $\mathrm{g} \mathrm{CO}_{2} / \mathrm{km}$ ( $41 \mathrm{mpg}$ for gasoline vehicles) by 2008, as measured under the new European test cycle (Directive 93/116/EC). This value represents about a 25\% reduction from the 1995 average of $187 \mathrm{~g} / \mathrm{km}$ ( $\sim 30 \mathrm{mpg})$. The European cycle is likely to produce lower fuel economy ratings than the U.S. combined urban/highway cycle (Kenney 1999), so the "U.S. equivalent" mpg ratings ${ }^{27}$ of the year 2008 European fleet will likely be higher than $41 \mathrm{mpg}$ if the targets are met.

Although the Commitment is officially called voluntary, all of our industry reviewers argued that the Commitment was offered by ACEA to forestall a more stringent $\left(120 \mathrm{~g} \mathrm{CO}_{2} / \mathrm{km}\right)$ regulation being considered by the European Commission. In other words, the widespread view is that the Commitment was essentially coerced.

The $140 \mathrm{~g} \mathrm{CO}_{2} / \mathrm{km}$ goal is a collective target, not a target for each individual company. The companies have not defined individual objectives, but before signing the Commitment, they discussed among themselves the likely trade-offs that would have to be made to achieve the goal. ${ }^{28}$ However, there is no agreement among observers as to whether the manufacturers agreed on a method of allocating targets.

The Commitment applies to light passenger vehicles classified as M1 in European Council Directive 93/116/EC, which includes vehicles with no more than eight seats in addition to the driver. The Commitment also includes a promise to introduce some models emitting $120 \mathrm{~g} / \mathrm{km}$ ( 48 mpg) or less by 2000 and a nonbinding 2003 target range of 165-170 g/km $(\sim 34-35 \mathrm{mpg})$. In addition, the commitment will be reviewed in 2003, with the aim of moving toward a fleet goal of $120 \mathrm{~g} / \mathrm{km}$ by 2012. Finally, the ACEA agrees to monitor compliance with the Commitment jointly with the European Commission.

The industry insisted that the Commitment was contingent on a number of conditions:

- Clean fuels availability. Because the industry believes that DI engines will play a key role in achieving the targets, the Commitment requires "full market availability" by 2005 of gasoline with $30 \mathrm{ppm}$ sulfur content, appropriate distillation temperatures, and less than $30 \%$ aromatics; the requirements for diesel fuel are $30 \mathrm{ppm}$ sulfur and acetane number $\geq 58$. The European Commission is now considering further sulfur reductions to 10 ppm, with requirements for wide availability by 2005 and $100 \%$ compliance by 2009 .

27 Without discounting. The mpg values that appear on new car stickers reflect a $10 \%$ discount off the city test results and a $22 \%$ discount off the highway test results, or $15 \%$ off the combined 55 city/45 highway rating.

28 Personal communication, Stephen Perkins, OECD, October 27, 1999. 
- Protection against unfair competition. Non-ACEA members must commit to similar goals, and the European Community will agree to try to persuade other car manufacturing countries to embrace equivalent efforts.

- Regulatory cease fire. No new regulatory measures to limit fuel consumption or $\mathrm{CO}_{2}$ emissions will be imposed.

- Unhampered diffusion of technologies. The companies assume that the Commission will take no action that would hamper the diffusion of efficiency technologies, particularly DI gasoline and diesel engines.

The Commitment also incorporates a statement that might be seen as an escape hatch: $O n$ the basis of the outcome of the monitoring, or if the impacts of this Commitment on the European automotive industry, particularly its employment situation and its global competitive environment, are detrimental, ACEA and the Commission will review the situation and make any necessary adjustments in good faith.

Both the Japanese Automobile Manufacturers Association (JAMA) and the Korean Automobile Manufacturers Association (KAMA) have agreed to a revised version of the ACEA targets - achievement of the 2008 target levels in 2009.

\subsection{Evaluation}

\subsubsection{Japanese Weight Class Standards}

The Japanese weight class standards appear, in general, to be a moderately ambitious undertaking (with some potential problem areas) for Japanese manufacturers and a more problematic undertaking for U.S. and European imports. Key features of the new standards that will affect the challenge they represent to automakers are described in the following paragraphs:

Relatively moderate emission standards. As discussed later, current Japanese emission standards are unlikely to provide a stumbling block to efficiency technologies, such as DI leanburn gasoline or diesel engines. Automakers should be free to pursue the full range of engine technologies without worrying about emissions noncompliance or unforeseen added costs from controls - unless emission standards become more stringent.

Fuel economy measurement based on a relatively slow, gentle driving cycle. The $\mathrm{km} / \mathrm{L}$ targets will be measured on the Japanese 10.15 driving cycle. This is a gentle urban cycle, with moderate maximum acceleration $(0.082 \mathrm{~g})$, maximum speed of $43.5 \mathrm{mph}$, and average speed of only $14.1 \mathrm{mph}$. About one-third of the cycle time is at idle. The nature of this cycle implies that technologies that enhance low-speed efficiency and reduce idle fuel rate will be especially effective in meeting the targets. Technologies such as idle off, variable valve timing, hybridelectric drivetrain, lean-burn engines, and gasoline direct-injection (GDI) engines should be particularly favorable. Tire efficiency will remain important, whereas aerodynamic efficiency will be unimportant to compliance. 
Targets are based on vehicle weight, which is correlated with fuel economy. U.S. CAFE standards apply the same target to every company's fleet regardless of the fleet's physical characteristics. In contrast, the Japanese regulations are more of a performance standard, so that manufacturers that focus on larger, heavier vehicles have a lower (fuel economy) target than manufacturers of smaller vehicles. This tends to equalize the technological challenge to each company, which is desirable. This equalization should be of particular value to European and U.S. automakers, some of which have concentrated on heavier vehicles in their Japanese sales efforts. On the other hand, the required percentage increases vary across weight classes, with the most stringent targets aimed at the higher-weight classes in which the European and U.S. manufacturers specialize (the largest increase, $30.3 \%$, is in the 2,800-3,300-lb Class). The weight class format provides little or no incentive to manufacturers to promote smaller vehicles or to reduce weight (since a substantial reduction would place the vehicle in a more demanding weight class). This attribute may be viewed either as positive (to those who believe that safety would suffer from a fleetwide weight reduction) or negative (because it limits the degree of fuel economy improvement that can be attained and possibly increases the cost of a particular level of increase by removing weight reduction as an option).

Limited trading across weight classes. Unlike the U.S. CAFE standards, which require only that each company's fleet of vehicles meet the standard as an averaged whole, ${ }^{29}$ the Japanese standards do not allow full fleet averaging, which limits credits across weight classes to half of the actual credits earned. Consequently, the opportunity for companies to produce a wide range of vehicles and balance less-efficient high-powered or utility vehicles with ultra-highefficiency models is limited (unless the vehicles are in the same weight class). This lack of flexibility may cause special problems for companies in niche markets emphasizing inherently less-efficient types of vehicles. Both U.S. and European companies that sell in Japan are concerned about the form of the standards, because many of their models are either high-powered luxury cars (especially the Europeans, e.g., BMW) or light trucks (e.g., DaimlerChrysler's Jeep Wrangler). For example, we calculate (based on computer-modeling ${ }^{30}$ ) that the Jeep Grand Cherokee ${ }^{31}$ will require a $38 \%$ fuel economy increase to achieve its weight class target of $8.9 \mathrm{~km} / \mathrm{L}$, versus a $16 \%$ improvement for the average vehicle in its $2,000-\mathrm{kg}$ weight class.

The best-in-class, "top-runner" method of selecting weight-class targets. A strong benefit of the top-runner approach is that it provides a clear example in each vehicle class that the fuel economy target is attainable on a vehicle already in production. An obvious concern with the approach is that the selected vehicles may not match their peers in traits that affect fuel economy (e.g., power, luxury features, two-wheel vs. four-wheel drive, etc.) or in cost. ${ }^{32}$ In fact,

29 However, in the United States, each fleet must be separated into domestically produced vehicles and imported vehicles, and autos and light trucks are considered separate fleets with different targets.

30 Using ADVISOR, a second-by-second vehicle model developed by the National Renewable Energy Laboratory.

31 With a 4.2-L engine.

32 U.S. manufacturers point out that the top 10 best fuel economy models in the U.S. market account for less than $1 \%$ of new vehicle sales because they lack amenities desired by most consumers. 
because the weight classes are so wide, a "top runner" chosen from the lower (lighter) end of a weight class may not be representative of vehicles at the upper (heavier) end of the class. As discussed earlier, Japanese regulators made an attempt to eliminate vehicle candidates that were not representative of the class - only vehicles with automatic transmissions were considered for personal vehicle "top runners," for example, and costly hybrid-electric vehicles were not considered. On the other hand, the concern is still relevant for vehicles that are not "average" a high-power four-wheel-drive vehicle might have to meet a target based on a lower-power twowheel-drive vehicle. This creates special concerns for the niche vehicles introduced by U.S. and European companies; these companies may not have multiple models with high fuel efficiency to offset the lower-fuel-economy niche vehicles.

Enforcement is problematic. The regulations call for civil penalties if the targets are not met, but these penalties are very small. Realistically, any enforcement will come from pressure from the government and the auto companies' desire to avoid public embarrassment. There are varying opinions about whether these will be sufficient to assure compliance.

\subsubsection{Available Technologies - Japan}

Japanese automakers have already introduced most of the key technologies that will likely be used to meet the new weight class standards. These include:

- DI gasoline engines. Mitsubishi, Toyota, and others have introduced this technology. Nissan sells over $6 \%$ of its vehicles in Japan with DI gasoline engines. ${ }^{33}$ Mitsubishi intends for $100 \%$ of its engines to be DI well before the target year.

- Lean-burn engines. Some Japanese companies will use conventionally injected engines with lean-burn capability.

- Variable valve controls. Honda first introduced a two-stage version of this technology in the early 1990s. By the target year, it seems likely that most vehicles will have at least two-stage controls, with many moving to infinitely adjustable controls.

- Electric hybrid. Toyota, Honda, Nissan, and others have commercialized hybrid technology, although the systems are somewhat different. Hybrid systems are particularly effective in slow, stop-and-go traffic, and a hybrid's "boost" in fuel efficiency over a conventional drivetrain will almost certainly be considerably greater on the Japanese 10.15 cycle than on either the U.S. or EU cycles. Cost remains a major problem with this technology, and the hybrids sold in the United States - Toyota's Prius and Honda's Insight and Civic — are thought to be sold at a net loss to their manufacturers. ${ }^{34}$ However, automakers are working hard on cost reduction — for

33 Fujii, N., Nissan North America, Inc., personal communication.

34 Toyota now claims that it is breaking even with the Prius. 
example, according to Toyota, the U.S. version of the Prius uses a second-generation battery that is about half the cost of the original Japanese version. ${ }^{35}$

- Continuously variable transmissions (CVTs). The efficiency of conventional automatic transmissions tends to be low in slow, stop-and-go traffic (as on the 10.15 cycle), and a CVT is a desirable substitute in such driving. CVTs have been widely introduced into the Japanese fleet; Nissan reports a $23.3 \%$ penetration of its current new car fleet. ${ }^{36}$

- Engine off. This technology is not used in the Japanese fleet except in hybrids, which are a tiny fraction of the fleet. However, about one-third of the 10.15 cycle's total time is at idle, and high idle times are certainly typical of much Japanese urban driving, so this technology could be very effective.

- Electric power steering. This technology is most likely to be used on hybrids and other vehicles with higher-voltage electrical systems.

\subsubsection{Effect of Changes in the Weight Distribution of the Fleet}

The approximately $23 \%$ increase in fuel economy for gasoline-powered passenger vehicles, to about $35.5 \mathrm{mpg}$ from a 1995 base of about $28.9 \mathrm{mpg}$, assumes no change in the weight distribution of the Japanese new vehicle fleet. In fact, recent data indicate that there have been substantial changes in the weight distribution (Minato 2002), in ways likely to reduce fuel economy. Figure $2-2$ shows that year-2000 sales in the lightest $(750 \mathrm{~kg})$ weight class have plummeted from 1995 levels, while sales in the heavier classes (e.g., 1,750 and 2,000 kg) have increased substantially. Using year-2000 sales data ${ }^{37}$ applied to the weight class standards yields a 2010 target level of about $14.5 \mathrm{~km} / \mathrm{L}$, or $34.1 \mathrm{mpg}$ - an $18 \%$ improvement from 1995 levels rather than the $22.8 \%$ level projected by the Japanese government. Continued shifts toward heavier vehicles could lower future fuel economy levels still further.

\subsubsection{European Voluntary Commitment}

The ACEA Voluntary Commitment, the $25 \% \mathrm{CO}_{2}$ reduction target of which implies a $33 \%$ improvement in (volumetric) fuel economy if there is no change in fuel mix, appears to be an ambitious undertaking that will require significant technological improvements, as well as restraint in existing trends of higher power levels and increased weight. A number of features of the Commitment bear careful examination.

35 Nakamura, N., Toyota Motor Co., personal communication.

36 Fujii, N., Nissan North America Inc., personal communication.

37 The values are not precise because we do not have exact figures for all weight classes, and the available data do not separate out gasoline-fueled from diesel-fueled vehicles. Nevertheless, we believe the fuel economy estimates to be accurate. 


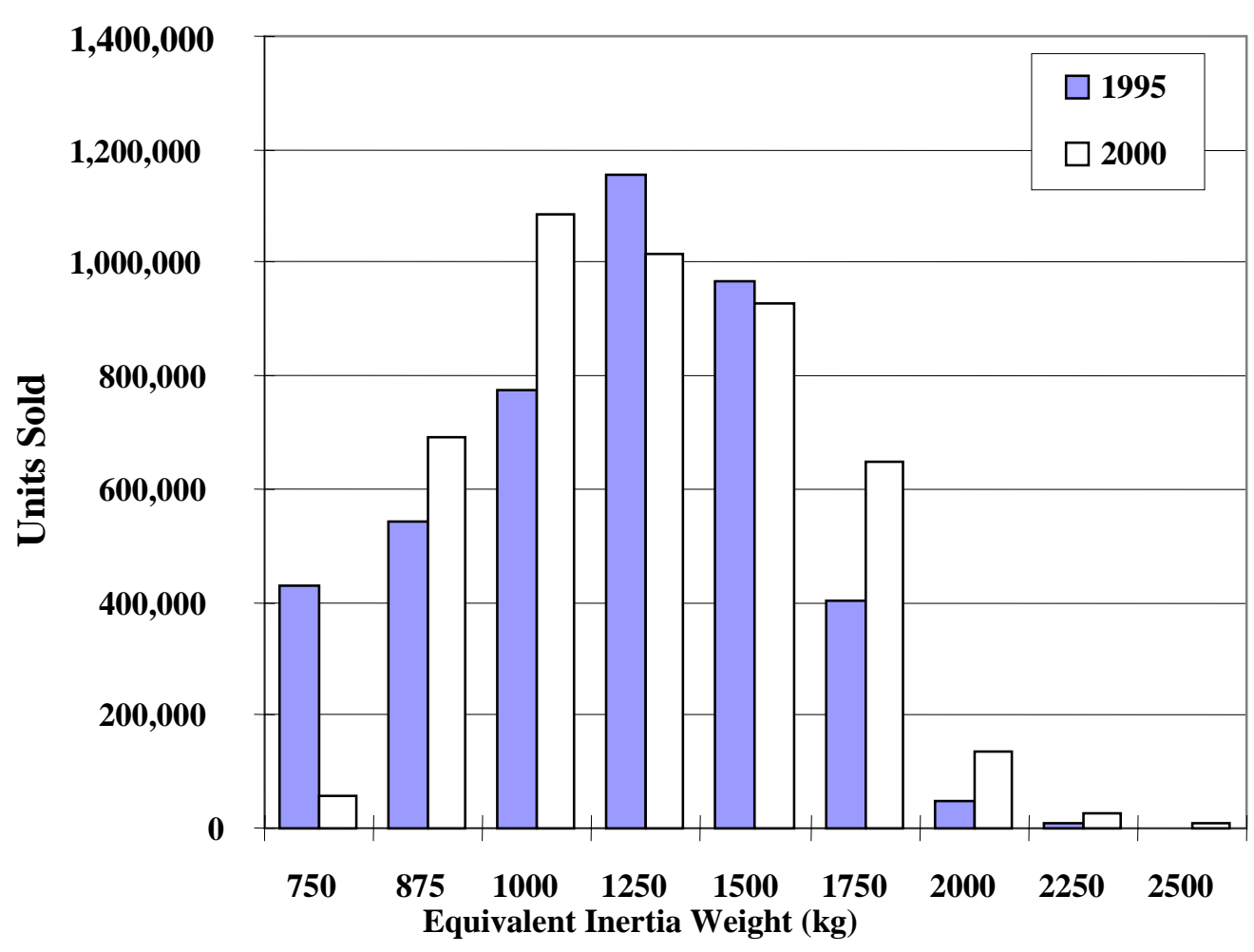

Figure 2-2. Weight Distribution of the Japanese Light-Duty Vehicle Fleet, 1995 vs. 2000. Source: Kiyoyuki Minato, Japan Automobile Research Institute

- The Commitment does not specify individual corporate targets, nor does it define mechanisms to guarantee attainment of the fleet target. The flexibility afforded by the lack of specified individual targets theoretically could lead to an efficient market solution, if companies could agree among themselves to attain levels of fuel economy improvement that represented approximately equal marginal net value (value of fuel savings minus technology cost). However, it is not clear that there is any agreement among the companies defining their individual targets, and there is no guarantee that all companies will make a fair effort toward meeting the fleet target. In fact, there will be an incentive to avoid such an effort if the necessary measures are not welcomed by the market. Based on its "business-as-usual" forecast, the European Commission apparently believes that the market would not demand improvements in fuel economy over the next decade without changes in policy. If the European Commission is correct, this implies that automakers complying with the Commitment will be producing vehicles with tradeoffs in efficiency, cost, and performance (or other attributes) to which potential purchasers are either indifferent or hostile. If consumers are hostile toward the changes and no further action is taken to stimulate demand for efficient vehicles, individual companies conceivably could gain market advantage by underachieving their fair share of the Commitment - producing vehicles that are more attractive to consumers because 
they are less efficient but cheaper or more powerful. Success of the Commitment may then depend on the nature of the monitoring system established by the European Commission and the type of pressure it can bring to bear on individual companies. The current European Commission/ACEA monitoring system reports annual $\mathrm{CO}_{2}$ emissions and fuel consumption values only for the total ACEA fleet and for each European Commission country's fleet. It does not report values for individual manufacturers (ACEA 2001). Unless this information is made available, it is problematic whether there will be any effective way to hold individual manufacturers accountable for failure to meet the target. However, perhaps it is reasonable to presume that any substantial lack of success in keeping on track to meet the fleet target will be met with irresistible pressure to disclose individual company data.

- Diesel technology's role in the current fleet depends in part on an artificial fuel price differential. Diesel sales in Europe are high — about a 28\% market share in 2000 (OTT 2000), and somewhat higher now - and the ACEA expects to expand this share significantly. Diesel's popularity in Europe is undoubtedly due in large part to its high fuel efficiency in an environment of high fuel prices. However, the high diesel share is also due to sharp differences in the level of diesel and gasoline taxes in several European countries, yielding diesel prices averaging 23\% lower (OTT 2000). With lower fuel prices, higher efficiency, and the tendency of longer-distance drivers to preferentially select diesels, the average diesel car is driven 40-70\% more than the average gasoline car in Europe (Schipper 2000). The portion of this higher mileage due to the first cause - driving stimulated by diesel's lower fuel price — should be factored into calculations of diesel's "greenhouse" advantage over gasoline; to the extent that diesel fuel's lower price causes more driving, part of a diesel vehicle's greenhouse advantage will be lost. Increased driving tied to lower diesel fuel prices, ${ }^{38}$ coupled with reduced fuel tax revenues from higher diesel shares, could pressure European governments to raise diesel taxes to be roughly equivalent to gasoline taxes. ${ }^{39}$ Such price increases would likely slow moves toward increased diesel market share. The ACEA could easily interpret this move as hampering the diffusion of technologies, triggering a review of the Commitment's target levels of $\mathrm{CO}_{2}$ emissions and possibly endangering the Commitment.

- Emissions standards represent only a moderate challenge to new technologies, but this could change. As discussed later, new European Stage 4 emissions standards, with a target date of 2005, are likely to create no constraints on engine technology, aside from some moderate development requirements for control systems in lean-burn (e.g., DI gasoline and diesel) engines for $\mathrm{NO}_{\mathrm{x}}$ emissions and in diesel engines for particulate emissions. However, there remains potential for more stringent Stage 5 standards. The

38 There is considerable evidence that reducing the variable costs/mile of driving leads to increased driving. In the United States., the price elasticity of vehicle miles traveled (vmt) is thought to be about 10 or $20 \%$ - that is, if fuel economy were doubled, fuel savings would be $40-45 \%$ (that is, $50 \%$ savings for each mile driven, minus the increased fuel use from the 5 to $10 \%$ "rebound" in driving).

39 The United Kingdom has equal volumetric taxes on diesel fuel and 95 RON gasoline. 
engine technology shift that ACEA contemplates, to 90\% percent DI engines (ACEA 1999), carries with it the potential to increase significantly emissions of ultra-fine particulates - especially when measured by the number of particles. Some scientists have become quite concerned about particles in the tiny size range emitted by DI injection diesel and gasoline engines (McCubbin 1996; Pope 1995), and continued research into their health effects presumably bears the potential to arouse public concerns and force a move to more stringent emissions standards. Also, if the expected engine technology shift greatly increases the percentage of diesels in the fleet, this could create concerns about $\mathrm{NO}_{\mathrm{x}}$ emissions, because the Stage 4 standards allow diesels to emit three times the $\mathrm{NO}_{\mathrm{x}}$ levels demanded of gasoline vehicles. New emission standards that significantly raise the cost of diesel drivetrains, or increase the difficulty of meeting $\mathrm{NO}_{\mathrm{x}}$ emissions requirements, could be interpreted by ACEA as compromising its responsibility to meet the $\mathrm{CO}_{2}$ emissions targets.

- The $\mathrm{CO}_{2}$ emissions/fuel economy targets must be met, regardless of future changes in the fleet. Europeans, like Americans, have been demanding more comfort, performance, safety, and size in their vehicles. European trends in horsepower and weight have been similar (though considerably milder) than those in the United States, and sales of light trucks have begun to grow. Between 1980 and 1990, for example, average engine power in European cars rose from $51 \mathrm{~kW}$ ( $\sim 68 \mathrm{hp})$ to $60 \mathrm{~kW}$ ( $\sim 80 \mathrm{hp}$ ), and average curb weight rose from $944 \mathrm{~kg}$ to $996 \mathrm{~kg}$ (European Conference 1995). The percentage of minivans and sport utility vehicles doubled between 1994 and 1998, to $5.2 \%$ (Kageson 2000). ${ }^{40}$ Any future surge in these trends could hamper the industry's ability to achieve the agreed-upon targets. We postulate, however, that the combination of high fuel prices, limited parking, and narrow streets in many European cities will tend to dampen such trends.

- The Commitment makes the $\mathrm{CO}_{2}$ emissions targets conditional on the avoidance of negative impacts on the financial performance, competitiveness, and employment in the industry. As discussed by Kageson (2000), the potential exists to blame any subsequent financial problems of any of the participating companies on the $\mathrm{CO}_{2}$ emissions requirements. In practical terms, it may be difficult to unambiguously define the cause of any problems as separate from or directly associated with the Commitment. Any individual company experiencing a loss in market share may be tempted to blame the Commitment for its difficulties and to absolve itself of its $\mathrm{CO}_{2}$ emissions reduction responsibilities - especially if it has reason to believe that the market will not punish it.

\subsubsection{Available Technologies - Europe}

European automakers have a range of technologies available to them that is quite similar to that of the Japanese automakers, although they have more experience with diesel technologies than the Japanese and less experience with DI gasoline engines and hybrid drivetrains.

40 In the U.S. market, light trucks - minivans, sports utility vehicles, and pickup trucks — comprise nearly half of all new light-duty vehicle sales. 
The European driving cycle is much faster than the Japanese cycle, so that improvements in aerodynamic efficiency will be important in meeting the EU requirements. Although a $\mathrm{Cd}$ of 0.25 is about the lower limit discussed by both European and Japanese automakers just a few years ago, ${ }^{41}$ the sub-0.20 Cds achieved by the American PNGV vehicles ${ }^{42}$ imply that better aero efficiencies may be possible. The higher speed of the European cycle will also lower somewhat (compared with the Japanese cycle) the improvements obtained by variable valve controls and electric hybrids, but the cycle has relatively low average loads, so the benefits of these technologies should still be substantial. Several European automakers have adopted valve control in several models, and the effect this technology has on the shape of the torque curve (it tends to flatten it, allowing higher torque at low rpm) is an attractive benefit that should promote its use.

Although not stressed in ACEA's public pronouncements about the Commitment, weight reduction could be an important efficiency technology in this timeframe. For vehicles with conventional drivetrains, a 10\% reduction in curb weight can translate into about a 6 or $7 \%$ increase in fuel economy at constant performance (OTA 1995). ${ }^{43}$ As noted above, European passenger vehicles are trending to greater weight and toward a greater share of light trucks, so weight-reduction measures will be needed to merely hold the line on weight - and perhaps they can accomplish considerably more. For example, adoption of "ultra-lightweight-steel" technology developed by the American Iron and Steel Institute, coupled with somewhat greater use of plastics and aluminum, should be able to achieve about $10 \%$ weight reduction from conventional unibody steel construction at relatively low cost (OTA 1995).

\subsection{The U.S. Perspective}

For a policymaker examining the Japanese and European fuel economy initiatives, an obvious question might be, "are the European or Japanese initiatives something we can or should be doing here?" It is certainly relevant that Ford, General Motors, and DaimlerChrysler compete vigorously in the European market and are participants in the Voluntary Commitment. Answering this question properly demands a complex and difficult analysis, a small part of which we attempt in the following sections. In the remaining portion of this section, however, we seek to better interpret what lessons we may draw from the knowledge that Europe and Japan have decided that it is reasonable to ask their fleets to improve their fuel economy by 33 and $23 \%$, respectively, within about 10 years. To interpret this properly, we need to understand those differences and similarities between the European and Japanese light-duty-vehicle "system" and the U.S. system that will affect the fuel economy improvement potential of their respective fleets. For example, emissions regulations can affect the cost and performance of engine technologies that might be used to improve fuel economy; the price of gasoline, miles driven per vehicle, and other socio-economic factors will influence the marketability of new fuel economy technologies.

41 Based on a series of interviews with Japanese and German automakers conducted by two of the authors in 1994.

42 Based on promotional brochures and presentations given by Ford, General Motors, and DaimlerChrysler.

43 The improvement in fuel economy would be somewhat less in a hybrid drivetrain. 
We attempt to develop some understanding of the differences and similarities of these factors in their respective markets in the following subsections.

\subsubsection{Fuel Economy Measurement/Driving Cycles}

Differences in fuel economy measurement systems and actual driving patterns among the United States, Europe, and Japan will affect the extent to which a fuel economy target in one market may be more or less difficult to attain than in the others. For one thing, the precise way that fuel economy is measured for regulatory purposes, including the driving cycle used, can strongly influence the measured impact on fuel economy of new technologies. However, to the extent that real-world driving yields sharply different results from test data, actual driving patterns need to be examined to understand how the driving public may value each new technology. Note that the gap between the fuel economy measured for regulatory purposes and the fuel economy actually attained by drivers under varying driving conditions may vary greatly for different technologies, so that a technology that appears most valuable for regulatory purposes (that is, to help a manufacturer satisfy a fuel economy regulation) may not appear to be the most valuable to the consumer.

The United States measures fuel economy for CAFE compliance purposes by using the harmonic average of the fuel economy test values on two driving cycles: the federal testing procedure (FTP) 44 (yielding city mpg) and the Federal Highway cycle (HWY) (yielding highway $\mathrm{mpg}$ ), with 55\% of the driving assigned to the FTP. EPA analyses (Hellman and Murrell 1984) concluded that the city values should be adjusted downward by $10 \%$ and highway values down by $22 \%$ ( $15 \%$ overall) to correspond more closely to on-road fuel economy obtained by the average driver. These adjustment factors are also used when presenting fuel economy estimates to the public (e.g., on stickers attached to new cars and in the EPA/DOE/DOT Fuel Economy Guide).

Table 2-1 presents some important parameters of the U.S. driving cycles and compares them with the driving cycles used to measure European and Japanese fuel economy. Power estimates are for a simulated Ford Contour.

A few values stand out. First, maximum acceleration and maximum power are relatively modest in all cycles. For example, maximum power for FUDS (and FTP) is $31.7 \mathrm{~kW}$, which is less than half the maximum power available from the vehicle's engine; the Japan 10.15 cycle is even gentler. Unless these cycles realistically represent actual driving conditions, their use might tend to exaggerate somewhat the benefits of technologies designed to improve efficiency at low loads. Similarly, average power levels are low (a small fraction of maximum power available) on all cycles. Note, however, that to a certain extent this simply reflects the reality that engines in highway vehicles with conventional drivetrains need to be sized for extreme requirements many

44 The FTP drives the vehicle through the federal urban driving schedule (FUDS) with a cold start, turns the engine off for $10 \mathrm{~min}$, and drives through the first $505 \mathrm{~s}$ of FUDS after a hot start. 
Table 2-1. Comparison of U.S., European Union, and Japanese Emission Testing Cycles ${ }^{a}$

\begin{tabular}{|c|c|c|c|c|c|}
\hline & Cycle & U.S. FUDS & U.S. HWY & EU NEDC & Japan 10.15 \\
\hline & Type of driving & Urban & Highway & Mixed & Urban \\
\hline & Start condition & Cold & Hot & Cold & Hot \\
\hline & Time (s) & 1,372 & 765 & 1,180 & 680 \\
\hline & Distance (mi) & 7.45 & 10.2 & 6.84 & 2.59 \\
\hline & Maximum acceleration (g) & 0.164 & 0.146 & 0.109 & 0.082 \\
\hline & Maximum speed (mph) & 56.7 & 59.9 & 74.6 & 43.5 \\
\hline & Average speed (mph) & 19.5 & 48.2 & 20.9 & 14.1 \\
\hline & Maximum power $(\mathrm{kW})^{\mathrm{c}}$ & 31.7 & 25.9 & 33.3 & 18.9 \\
\hline & Average power $(\mathrm{kW})^{\mathrm{c}}$ & 5.1 & 9.0 & 4.8 & 3.8 \\
\hline 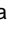 & \multicolumn{5}{|c|}{ Reprinted with permission from SAE 1999-01-3457 (C) 1999 SAE International. } \\
\hline o & \multicolumn{5}{|c|}{$\begin{array}{l}\text { The actual test procedure ("FTP"), which also is the test for emissions certification, } \\
\text { repeats the first } 505 \text { s of the FUDS cycle, hot started, after a 10-min hot soak. Starting } \\
\text { with MY 2001, the emissions test - but not the fuel economy test - incorporates a } \\
\text { supplemental cycle that simulates aggressive urban driving, coupled with an added air } \\
\text { conditioning load. }\end{array}$} \\
\hline & \multicolumn{5}{|c|}{$\begin{array}{l}\text { Simulated Ford Contour (3,000 lb, } 0.33 \mathrm{Cd} \text {, manual transmission, } 0.0073 \text { rolling } \\
\text { resistance coefficient). }\end{array}$} \\
\hline
\end{tabular}

times in excess of average requirements. Although the cycles appear to be more gentle than actual onroad driving (EPA 1993), average power levels would remain fairly low compared with maximum power - even if the cycles were adjusted to account for actual (more aggressive) driving. These low power values emphasize the value of technologies designed to improve engine efficiency at low load.

Second, average speeds are moderate - about $20 \mathrm{mph}$ on FUDS (and the FTP) and less than $50 \mathrm{mph}$ on HWY. Average speed is important because aerodynamic drag is a strong function of speed; energy used/mile varies with the second power of speed. In other words, the fuel used per mile to overcome aero drag is about four times as high at $60 \mathrm{mph}$ as it is at $30 \mathrm{mph}$. Improved aerodynamics will have little impact on the city cycle, but it will have an important effect on fuel economy on the highway cycle.

Both the EU and Japanese cycles have average speeds much lower than HWY, implying that improvements in aerodynamic design will have little impact on test measured fuel economy in either market. This effect probably will not translate into a lower effort to improve vehicle aerodynamics in European markets (and may not in the Japanese market either). European designs tend toward very high top speeds, perhaps as a bow to the German autobahn, and good aerodynamic design clearly is crucial to operating at such speeds. Japanese automakers argue that the image of high tech in the Japanese market is so important that sub-par aerodynamics may be unacceptable to many vehicle purchasers, even if a low-drag design has little practical value in the vast majority of driving situations. 


\subsubsection{Emissions Regulations}

Variations among nations in their emissions regulations have the potential to lead to significant differences in the fuel economy of their light-duty fleets and their potential for improvement - thereby influencing the degree to which the European and Japanese fuel economy targets may be harder or easier to attain. The major mechanisms behind such differences are the impact of regulations on fuels and control system requirements, on engine operations, and on propulsion system technology and design. Some examples:

- Required control systems (e.g., catalytic converters) can add weight and restrict exhaust flow, with negative impacts on fuel economy and performance.

- Stringent emission requirements can force automakers to improve fuel delivery and combustion control systems, which offer the potential to improve combustion efficiency.

- Emissions requirements can influence selection of combustion technologies. Stringent $\mathrm{NO}_{\mathrm{x}}$ requirements may hinder selection of diesels and gasoline direct-injection stratifiedcharge (DISC) engines, since $\mathrm{NO}_{\mathrm{x}}$ reduction catalysts do not work with lean-burn engines. Diesels may also be hindered by stringent PM standards.

- Similarly, emissions requirements can influence the operation of combustion technologies, with impacts on fuel economy. For example, stringent $\mathrm{NO}_{\mathrm{x}}$ requirements may narrow the range of operating conditions for lean operation of DISC engines, reducing the fuel economy improvement potential of these engines. ${ }^{45}$

- Fuels requirements for emissions control, especially requirements for fuel additives such as oxygenates, can have a measurable impact on volumetric fuel economy and possibly on energy-based fuel economy as well. ${ }^{46}$

Although standards may change, current forward-looking emission standards in the United States are substantially more demanding than those in Europe and Japan. Table 2-2 compares the latest forward-looking standards in the three markets. The Japanese 10.15 mode standards for gasoline vehicles appear similar to the EU standards numerically but actually are significantly more lenient because the driving cycle is hot-started; the cold-started 11-mode standards are numerically much weaker. Both are significantly higher (weaker) than the U.S. values - about double for $\mathrm{NO}_{\mathrm{x}}$ and an order of magnitude higher for hydrocarbons. Further, neither the European nor the Japanese test procedures include a high-speed, high-load segment similar to the new supplemental FTP that U.S. vehicles must cope with. Finally, both the EU and Japan set their diesel standards well above their gasoline standards for both $\mathrm{NO}_{\mathrm{x}}$ and $\mathrm{PM}$. In contrast, the United States has set its Tier 2 diesel standards at the same level as its gasoline standards,

$45 \mathrm{NO}_{\mathrm{x}}$ emissions can increase dramatically at high power, so lean-burn operations are limited to a (lower) power range, the ceiling of which will depend on the stringency of the $\mathrm{NO}_{\mathrm{x}}$ emissions standards.

46 Because the U.S. tests on indolene, U.S. oxygenate requirements would affect in-use fuel economy only. 
Table 2-2. Comparison of U.S., European Union, and Japanese Motor Vehicle Emissions Standards

\begin{tabular}{|c|c|c|c|c|c|c|c|c|c|c|}
\hline \multirow[b]{2}{*}{ Origin } & \multirow[b]{2}{*}{$\begin{array}{c}\text { Vehicle Size } \\
\text { and Type }\end{array}$} & \multirow[b]{2}{*}{ Fuel } & \multirow[b]{2}{*}{$\begin{array}{l}\text { Fuel } \\
\text { Quality }\end{array}$} & \multirow[b]{2}{*}{ Date } & \multirow[b]{2}{*}{$\begin{array}{l}\text { Longevity } \\
\text { (mi) }\end{array}$} & \multirow[b]{2}{*}{ Test } & \multicolumn{4}{|c|}{ Emissions $(\mathrm{g} / \mathrm{mi})^{\mathrm{a}}$} \\
\hline & & & & & & & $\mathrm{NO}_{\mathbf{x}}$ & $\mathrm{CO}$ & $\mathrm{HC}$ & $\mathbf{P M}$ \\
\hline U.S. Tier 2 & $\begin{array}{l}\text { to } 8500 / 10,000 \\
\text { lb GVW }\end{array}$ & All & Low sulfur ${ }^{b}$ & $\begin{array}{l}2007 / 2009 \\
\text { phased in }\end{array}$ & $\begin{array}{l}120,000 \text { option } \\
\text { to } 150 \mathrm{~K}\end{array}$ & FTP $^{C}$ & 0.07 & 4.2 & 0.018 & 0.01 \\
\hline \multirow[t]{3}{*}{ EU Phase 4} & $\begin{array}{l}\text { cars }+ \\
\text { LDTs }<2,880 \mathrm{lb}\end{array}$ & Gasoline & $50 \mathrm{ppm}^{\mathrm{d}}$ & 2005 & 62,000 & 93/116/EC & 0.13 & 1.61 & 0.16 & none \\
\hline & & Diesel & 50 ppm & 2005 & 62,000 & 93/116/EC & 0.4 & 0.8 & $\begin{array}{c}0.48 \mathrm{HC}_{+} \\
\mathrm{NO}_{\mathrm{x}}\end{array}$ & 0.04 \\
\hline & larger LDTs & Both & & 2006 & 62,000 & 93/116/EC & & more & lenient & \\
\hline \multirow[t]{6}{*}{ Japan } & $\begin{array}{l}\text { through } \\
\text { "ordinary } \\
\text { sized" }\end{array}$ & Gasoline & 10 ppm & 2000 & 50,000 & $\begin{array}{l}10-15 \\
\text { mode }^{e}\end{array}$ & 0.13 & 1.08 & 0.13 & none \\
\hline & $\begin{array}{l}\text { through } \\
\text { "ordinary } \\
\text { sized" }\end{array}$ & Gasoline & $10 \mathrm{ppm}$ & 2000 & 50,000 & 11 mode & 0.55 & 7.49 & 0.87 & none \\
\hline & $\begin{array}{l}\text { small cars } \\
(<3,000 \mathrm{lb})\end{array}$ & Diesel & 500 ppm & 2002 & 50,000 & $\begin{array}{l}10-15 \\
\text { mode }\end{array}$ & 0.45 & 1.01 & 0.19 & 0.084 \\
\hline & $\begin{array}{l}\text { medium cars } \\
(>3,000 \mathrm{lb})\end{array}$ & Diesel & 500 ppm & 2002 & 50,000 & $\begin{array}{l}10-15 \\
\text { mode }^{e}\end{array}$ & 0.48 & 1.01 & 0.19 & 0.09 \\
\hline & $\begin{array}{l}\text { LDT }(<3,400 \\
\text { lb) }\end{array}$ & Diesel & 500 ppm & 2002 & 50,000 & $\begin{array}{l}10-15 \\
\text { mode }^{e}\end{array}$ & 0.45 & 1.01 & 0.19 & 0.084 \\
\hline & $\begin{array}{l}\text { LDT }(3,400- \\
5,000 \mathrm{lb})\end{array}$ & Diesel & 500 ppm & 2002 & 50,000 & $\begin{array}{l}10-15 \\
\text { mode }\end{array}$ & 0.79 & 1.01 & 0.19 & 0.1 \\
\hline
\end{tabular}

a U.S. values are averages; companies can use "bins" for vehicles with higher emissions.

b Sulfur limits still under rulemaking.

c With supplemental (more aggressive) cycle.

d ACEA Voluntary Commitment demands gasoline and diesel fuels with $\leq 30 \mathrm{ppm}$ S.

e This cycle is hot-started.

although the regulations allow automakers to place some vehicles in "bins" with higher emissions levels (but these must be compensated for by vehicles with emissions levels significantly below the average requirements).

The differences among the three sets of standards do appear likely to impact the potential of the three markets to improve fleet fuel economy. In particular, the stringent U.S. requirements create the possibility that diesels may not be allowable in the light-duty fleet after 2007 or may not be allowable in large numbers. Further, even if the diesel standards are achievable, the control system requirements might increase costs and/or decrease fuel efficiency sufficiently to reduce this technology's potential market share. Note, however, that the U.S. Environmental Protection Agency has targeted a 15-ppm sulfur diesel fuel requirement as part of its Tier 2 requirements; the availability of ultra-low-sulfur fuel does improve prospects for the use of lean$\mathrm{NO}_{\mathrm{x}}$ storage catalysts and PM traps for diesels, increasing the chances of complying with the standards.

There are some indications that diesel emissions standards in Japan and Europe will change. Diesel particulate emissions have become an important public issue in Japan. Some analysts believe that Japanese diesel particulate standards will be substantially tightened by 2005 or so, 
requiring particulate filters or traps. Expectations are that diesel fuel sulfur limits will also be reduced, to $50 \mathrm{ppm}$ or less. ${ }^{47}$ Similarly, some EU member states are pushing for a tighter diesel PM standard, to force the use of particulate filters, and the EU is considering a 10-ppm sulfur cap for 2009, with a requirement for widespread availability by 2005 .

The differences in the emissions standards may also impact the potential for DISC engines to improve fleet fuel economy. The ability of these engines to meet U.S. Tier 2 standards is not proven, but some analysts believe that success is likely with the use of low-sulfur gasoline. However, engine operations, and fuel economy potential, may still be strongly affected by the standards. As noted above, stringent $\mathrm{NO}_{\mathrm{x}}$ requirements could force powertrain designers to lower the power "ceiling" on lean-burn operations, reducing fuel economy benefits. As discussed below, given the differences in emissions standards in the three markets coupled with the differences in their driving cycles, DISC engines may yield sharply different fuel economy gains over conventional engines in the different markets, with the gains likely being highest in Japan and lowest in the United States.

It is worth noting here that automotive industry warnings of dire consequences - high costs, compliance failures, degradation of reliability - from new emissions standards are nothing new, and up to this point, the industry has proved itself to be remarkably adept at complying with new standards at acceptable cost. The views of engine manufacturers and others about the likelihood of continued successful emissions control advances are quite mixed, but there are a number who claim confidence that both diesels and direct-injection lean-burn gasoline engines will be able to comply with the new U.S. standards.

\subsubsection{Cost-Effectiveness of New Efficiency Technology - Comparison across Countries}

It is often said that automotive technology is "fungible;" that is, that any technology available to one company or to one country will soon be available to all. The spread of technology through the industry in the past appears to confirm this principal, with a caveat. "Availability" of technology to all does not imply "equal market attractiveness" to all. And if a technology to improve fuel economy is more attractive in one market than another - if, for example, a new engine technology makes more economic sense to Japanese consumers than to U.S. consumers, or vice versa - this should be taken into account in trying to decide whether a policy mechanism adopted in Japan or Europe makes sense in the United States.

We would like to compare the relative attractiveness to vehicle purchasers of new fuel efficiency technologies in Japan, Europe, and the United States. This comparison is quite difficult to do because there are so many differences among the three markets. Crucial factors to consider include:

1. Gasoline prices. Fuel prices in the United States are less than half those of the EU and Japan, because these countries have chosen to impose high taxes

47 Michael Walsh, personal communication. 
on transportation fuels. Higher fuel prices tend to encourage manufacture and purchase of higher-fuel-economy vehicles.

2. Vehicle taxes. Taxes based solely on sales price raise the price of everything on the vehicle, including efficiency technologies. EU countries have valueadded taxes added directly into the selling price (e.g., 20.6\% in France). A few countries have extremely high additional taxes on sales - for example, $45.2 \%$ in the Netherlands, to an astonishing $180 \%$ in Denmark. These taxes reduce the cost-effectiveness of new efficiency technologies. However, Japan and many European countries levy some vehicle sales and ownership taxes based on engine size or other factors linked to fuel efficiency, encouraging higher fuel economy. The Japanese ownership tax charges an owner of a 1.5-L vehicle about $\$ 300$ per year and an owner of a $3.0-\mathrm{L}$ vehicle about $\$ 450$ per year, encouraging development of engines with higher levels of power/displacement. European ownership taxes are based on a variety of efficiency-related variables - engine size (Belgium, Greece, Ireland, Luxembourg, and Portugal), weight (Denmark, Germany, Netherlands, Sweden), fuel consumption (Denmark), and $\mathrm{CO}_{2}$ emissions (United Kingdom) (ACEA 2002a). In contrast, European sales taxes related to vehicle characteristics are generally based on engine displacement.

3. Driving conditions and emissions standards. As discussed above.

4. Annual miles driven per vehicle. Among developed nations, U.S. vehicles are driven most intensively, about 14,000 mi annually for automobiles during their first five years, and somewhat more for light trucks (DOE 1999). In contrast, Japanese passenger cars are driven about 6,000 mi annually on average. Even if vehicle lifetimes depended only on miles driven, the time value of money means that higher annual mileage makes fuel economy technologies more attractive.

5. Value of fuel economy in the used car market. If fuel economy is not a major factor in the used car market, new car purchasers will not value expected fuel savings beyond the time they expect to keep the vehicle.

6. Average vehicle size and efficiency. All else equal, fuel efficiency technologies save more fuel in less-efficient vehicles.

7. Prevalence of company cars, accompanying subsidies. In some European countries, companies and institutions buy a large percentage of the new cars for their employees and keep them for only two or three years. Further, in some cases, fuel costs for drivers of company cars are subsidized, drastically reducing the incentive for fuel savings. Company cars are 30-50\% of new car purchases in Germany, the Netherlands, Norway, Sweden, and the United Kingdom (OTT 2000). Our understanding is that recent changes in 
European tax laws have moved economic incentives for company cars more in line with fuel efficiency goals.

As an example case, we examine DISC engine technology in U.S., Canadian, Japanese, and European markets. DISC engines inject gasoline at high pressure directly into the cylinders and run largely unthrottled; that is, they allow high (lean) air/fuel ratios at low loads rather than throttling back air supply. Fuel economy gains come from reduced (1) pumping losses, (2) heat loss in the exhaust and through the cylinder walls due to lower combustion temperature, and (3) fuel use during idling.

An important performance issue with DISC engines is the stringency of $\mathrm{NO}_{\mathrm{x}}$ standards and success of $\mathrm{NO}_{\mathrm{x}}$ control development. DISC engines can have $\mathrm{NO}_{\mathrm{x}}$ emissions problems because the reduction catalysts used in ordinary (stoichiometric) engines do not work in the excessoxygen environment that exists in a DISC engine's exhaust. DISC engines introduced in Japan use special catalysts that store $\mathrm{NO}_{\mathrm{x}}$ during lean operation and then release it whenever increased engine loads move engine operation back into a stoichiometric mode, when a conventional catalyst can control it. Japan's $\mathrm{NO}_{\mathrm{x}}$ standards are substantially more lenient than U.S. Tier 2 requirements and somewhat more lenient than the European Stage IV requirements. Additional measures will have to be taken to meet the Tier 2 requirements. These measures include the development of advanced control systems and the provision of very-low-sulfur gasoline. They might include, as well, the need to reduce the operating regions where the engine runs lean. Advanced control systems will likely add to cost, assuming successful development. Reducing lean operation would reduce the fuel economy benefit of the technology. For the European requirements, some improvement in control systems will be needed, but it is less likely that lean operation of the engine will have to be seriously curtailed.

Another performance issue is the nature of the driving cycles in the various markets and their direct impact on measured fuel economy. The Japanese 10.15 cycle is the slowest cycle with the lowest loads among the markets, and Japanese driving patterns also are slow. This characteristic will yield very high benefits to DISC engines because they offer maximum benefit at low loads. The EU cycle has the highest maximum speed of the cycles, but its average speed is only slightly faster than the FTP, and the U.S. city/highway mixed cycle is faster. Also, the EU cycle has relatively low average loads, lower than the FTP. DISC engines should yield the highest fuel economy gain on the Japanese cycle and the lowest on the EPA mixed cycle. Emissions requirements could drive down U.S. performance even more.

A rough estimate of DISC engine fuel economy performance in 2005 and beyond, based on available test data and some assumptions about future improvements, is a $20 \%$ boost in Japan, $15 \%$ in Europe, and $12 \%$ in the U.S. market. ${ }^{48}$ We assume the engine's price boost, before taxes, to be $\$ 400$ in Japan and Europe and $\$ 450$ in the United States for six-cylinder engines, with the $\$ 50$ increment for additional emissions controls.

48 These values were suggested by K.G. Duleep, Energy and Environmental Analysis, Inc., and confirmed as reasonable by several industry experts. 
Table 2-3 shows the results of a net present value examination of DISC technology for the United States, Canada, Japan, France, and the Netherlands on the basis of June 2000 gasoline prices. ${ }^{49}$ The table compares the net present value of the first five years of fuel savings to the initial total price (including taxes) of the fuel efficiency technology and shows the gasoline price that would cause fuel savings to equal the added investment cost. We also examine the effects of vehicle purchasers accounting for 10 years of fuel savings rather than just five years of savings. Note that the analysis for the Netherlands applies to privately purchased cars only.

Some key observations from the table are:

1. Although DISC engines are not cost-effective for U.S. passenger cars, their break-even gasoline price is not especially high despite their modest performance (we assume it to be a $12 \%$ fuel economy increase ${ }^{50}$ ), because of a combination of high vmt/yr and modest baseline fuel economy (the lower the baseline, the more fuel saved for a constant percent reduction).

2. DISC engines are cost-effective for new light trucks in the United States, at June 2000 gasoline prices, because trucks are driven farther and have lower baseline fuel economy (yielding more gas savings per mile), on average, than cars.

Table 2-3. Evaluation of the Cost-Effectiveness of Direct-Injected Stratified Charge Gasoline Engines in Several Countries ${ }^{a}$

\begin{tabular}{|c|c|c|c|c|c|c|c|c|c|c|}
\hline Country & $\begin{array}{l}\text { Improve- } \\
\text { ment (\%) }\end{array}$ & $\begin{array}{c}\text { Price of } \\
\text { Technology } \\
\text { (\$) }\end{array}$ & $\begin{array}{l}\text { Base } \\
\text { mpg }\end{array}$ & $\begin{array}{c}\text { Gas } \\
\text { Price } \\
\text { (\$/gal) }\end{array}$ & $\begin{array}{c}\text { Tax } \\
\text { Rate } \\
(\%)\end{array}$ & $\begin{array}{c}\text { vmt/yr; } \\
5-y r \\
\text { average }\end{array}$ & $\begin{array}{c}\text { Gas } \\
\text { Saved } \\
\text { NPV, \$ }\end{array}$ & $\begin{array}{c}\text { Technology } \\
\text { Investment } \\
\text { (\$) }\end{array}$ & $\begin{array}{c}\text { Break- } \\
\text { Even } \\
\text { Gas } \\
\text { Price }\end{array}$ & Comments \\
\hline $\begin{array}{l}\text { United } \\
\text { States }\end{array}$ & 12 & 450 & 28 & 1.68 & 5 & 1,300 & 377 & 472 & 2.1 & \\
\hline $\begin{array}{l}\text { United } \\
\text { States }\end{array}$ & 12 & 550 & 20 & 1.68 & 5 & 15,700 & 636 & 578 & 1.53 & $\begin{array}{l}\text { Light truck, bigger } \\
\text { engine/vmt }\end{array}$ \\
\hline $\begin{array}{l}\text { United } \\
\text { States }\end{array}$ & 12 & 450 & 28 & 1.68 & 5 & 11,100 & 544 & 472 & 1.46 & $\begin{array}{l}\text { Account for } 10 \mathrm{yr} \\
\text { of gas savings }\end{array}$ \\
\hline France & 15 & 400 & 34.6 & 3.85 & 20.6 & 8,000 & 524 & 482 & 3.54 & $\begin{array}{l}\text { Gasoline vehicle } \\
\text { vmt }\end{array}$ \\
\hline France & 15 & 400 & 34.6 & 3.85 & 20.6 & $\begin{array}{l}6,600 \\
(10 \mathrm{yr})\end{array}$ & 787 & 482 & 2.36 & $\begin{array}{l}\text { Account for } 10 \mathrm{yr} \\
\text { of gas savings }\end{array}$ \\
\hline Netherlands & 15 & 400 & 30 & 4.22 & 62.7 & 8,800 & 727 & 651 & 3.78 & \\
\hline Japan & 20 & 400 & 30 & 3.63 & 10 & 6,000 & 546 & 440 & 2.92 & \\
\hline Canada & 12 & 450 & 29 & 1.85 & 10 & 13,100 & 403 & 495 & 2.27 & \\
\hline Canada & 12 & 550 & 20.6 & 1.85 & 10 & 13,300 & 578 & 605 & 1.94 & $\begin{array}{l}\text { Light truck, bigger } \\
\text { engine }\end{array}$ \\
\hline
\end{tabular}

a Assumptions: 10\% discount rate, Tier 2/EU Phase IV/year 2000 Japanese emission standards.

49 Aside from uncertainties about the cost and performance of the fuel economy technologies, there are only fair data about key parameters, such as annual miles driven per vehicle.

50 This value is quite sensitive to assumptions about the effectiveness and nature of the emission control system, which will affect the engine's ability to operate lean. 
3. In every case we examined, DISC engines are cost-effective in Japan and the two European countries. The high fuel prices and expected good performance of the technology (with less-severe emission standards and driving conditions that emphasize the DISC engines' strengths) overcome the lower levels of vmt/yr, higher vehicle taxes, and higher baseline fuel economies in these countries.

4. The Canadian results are quite similar to the U.S. results, although DISC engines barely miss out in light trucks - they are not cost-effective by a small margin (because of lower truck vmt/vehicle in Canada, and slightly higher taxes, than in the United States). ${ }^{51}$

Some may argue with our decision to limit the discounted years of fuel saving to five. We would argue that this is fair for the United States, at least from an average consumer's perspective, and likely to be applicable to Japan as well because strict licensing regulations tend to keep the fleet fairly "young." We note, however, that using full lifetime accounting is more appropriate for policy analyses focusing on energy security and global warming issues, where future reductions in oil use and carbon emissions are of crucial interest. Higher interest in fuel economy in Europe might justify using a longer time span for fuel savings, but this approach would only make this technology more cost-effective, over a rather high baseline level. For example, extending the number of years of gas savings that French consumers account for from five years to 10 reduces the gasoline break-even price from $\$ 3.54$ per gallon to $\$ 2.36$ per gallon, which is well below current French prices.

U.S. consumers might also value "distant" gas savings more highly if (1) the market came to value fuel economy performance highly in valuing used cars and (2) consumer anxiety about high gas prices grew. Applying 10-year accounting to the U.S. case reduces the gasoline breakeven price from $\$ 2.10 /$ gallon, which is considerably higher than the (June 2000) market price, to $\$ 1.46 /$ gallon, which is significantly below this price.

\subsection{Recent Progress in the Japanese and European Markets}

Both the Japanese and European new vehicle fleets have made significant progress toward their established efficiency goals since the baseline year of 1995. The ACEA reports an overall reduction in $\mathrm{CO}_{2}$ emissions/vehicle/kilometer from 1995-2001 of 11.4\% percent (ACEA 2002b), JAMA reports a $4.6 \%$ reduction for 1995-1999, and KAMA reports a $1.5 \%$ reduction over the same period. ${ }^{52}$ The Japanese Ministry of Transport reports an increase in fuel economy for the Japanese light-duty fleet of $4.9 \%$ for $1995-2000 .{ }^{53}$

51 Note that although the Canadian vehicle tax rate is about $15 \%$, we adjusted this down to $10 \%$ to account for lower manufacturer margins in the Canadian market; for roughly equivalent cars, Canadians pay about $13 \%$ less than U.S. consumers for autos and 10\% less for light trucks - source: Just-auto.com editorial team, "Canadian MSRPs," Oct. 12, 2000, website http://just-auto.com.

52 ACEA/JAMA/KAMA Joint EU Reports.

53 Japan Ministry of Transport (MOT) fuel economy report, in Japanese. 


\subsection{Conclusions}

Both Europe and Japan have initiated policy measures that, if successful, will give a significant boost to the fuel economy of their light-duty fleet. The technical potential to achieve the fuel economy goals of the initiatives is clearly available, with the Japanese goals being more modest on a fleet-wide basis and, based on the limited analysis we have completed, probably more easily achieved. An exception to this may be companies with limited numbers of models, especially if they are primarily in the more difficult weight classes, because of the Japanese system's limitation on averaging across weight classes. Potential roadblocks in both markets are possible future increases in the stringency of emissions standards (especially for particulates and $\mathrm{NO}_{\mathrm{x}}$ ) and adverse trends toward less-efficient vehicle types (e.g., SUVs) and attributes that conflict with fuel economy (e.g., high power). There are some enforcement issues for both initiatives, as well.

Are there lessons to be drawn from the two initiatives about the ability of the United States (and Canada) to implement a voluntary fuel economy standard?

The initiatives provide two models for allocating fuel economy targets among individual manufacturers that are quite different from the current CAFE standard. The Japanese weightbased standard seems more equitable than the flat CAFE standard; it answers industry criticisms that the flat standard places far more pressure on full-line manufacturers than it does on companies specializing in smaller cars. It also removes pressure for weight reduction, which may be viewed as positive or negative, depending on concerns about cost efficiency (as shown in Section 6, it tends to raise the cost of achieving a given standard, since it eliminates weight reduction as a compliance technology) and safety (some analysts argue that weight reduction adversely affects fleet safety, so a weight-based standard would appear especially positive to them). The use of weight classes rather than a continuous function of weight vs. fuel economy to define vehicle fuel economy targets creates some perverse incentives for weight increases in a percentage of the fleet, so policymakers may want to examine continuous functions as an attractive option. And the inability to fully average across weight classes, coupled with the higher percentage increase requirements in some of the higher weight classes, may cause problems for some companies, especially the European and U.S. importers.

The European industry-wide target may be difficult to translate into the U.S. political arena. Because it does not specify individual targets for each manufacturer, it may be difficult to know who to hold responsible if the targets are not met - although presumably the public and/or the media are likely to choose some "responsible" parties if this happens (and assuming that the fuel economy achievements of the individual companies are reported, which is not the case at present). In any case, European acceptance of this type of agreement clearly implies a reasonable level of trust between the government and the industry. Whether the U.S. Congress would agree to such a vague bargain seems problematic. As for Canada, our sense is that a voluntary standard using the European model may be more feasible there than in the United States.

What about the level and timing of the fuel economy targets: how well might they apply to the U.S. market? 
We have the grounds to draw only tentative conclusions about the relative difficulty automakers would face in improving U.S. fleet fuel economy by the same degree as proposed in Europe or Japan.

First, trends toward fleet characteristics that are antithetical to higher fuel economy are strong in the United States, although similar (but less severe) trends are apparent in Europe. We have no data, as yet, for Japan.

Second, emissions regulations and, to an extent, driving conditions put the U.S. market in a less-favorable position than Europe and Japan. The Japanese market is the most favorable of the three for obtaining strong increases from available drivetrain technology. In particular, DI engines will obtain especially strong gains on the slow Japanese cycle and have little problem complying with current emissions standards. Also, hybrid-electric drivetrains capture very sharp gains over conventional drivetrains in the slow, stop-and-go driving typical of Japanese conditions. Japanese companies have world-leading experience with both DI gasoline engines and hybrid-electric drivetrains. European conditions are perhaps in-between those of Japan and the United States, with great experience with and market acceptance for diesels a strong advantage.

For load reduction technology, advantages are mixed. Improved aerodynamics is not useful on the Japanese 10.15 cycle and will have little relevance for most Japanese urban road conditions. The largest gains from this technology should be on the U.S. highway cycle; average speeds on the EU cycle are similar to those on the FTP, which are well below speeds where aero drag becomes a large component of total load. However, there is sufficient high-speed driving on both U.S. and European highways to make improved aero design highly desirable. Another key area for load reduction - weight reduction - will be important on all cycles and for on-road conditions for all markets. However, the Japanese initiative gives no incentive for weight reduction, and it may not be a major component of fuel economy improvements in the Japanese market.

Third, both the Japanese and European markets appear more favorable than the U.S. market in terms of the cost-effectiveness of fuel efficiency technologies, but not as much as might be expected by the much lower fuel prices in the United States. The United States has certain advantages - primarily substantially higher rates of driving per vehicle and lower vehicle taxes - that reduce the marginal cost of the efficiency technologies.

The above discussion is very far from a definitive analysis, but it implies that were the United States to attempt the same kind of measures, the task would be somewhat harder here because of more consumer resistance and more difficult emissions standards. However, it is important to remember that the European targets, being voluntary, may be somewhat lower than what the manufacturers believe is achievable (industry analysts argue, though, that the targets really were not voluntary because the industry faced an impending — and stricter — regulatory target), and the lower Japanese targets are made somewhat more difficult by removing weight reduction as an option - although a North American weight-based standard would do the same. 
The Canadian government has stated its intentions of trying to negotiate a voluntary fuel economy standard with its automakers, and it seems likely that conditions for such a standard will be similar to those in the United States, with higher Canadian fuel prices somewhat offset by higher vehicle taxes and lower vmt/vehicle/year. There are, of course, other factors that could play a significant role in determining the viability of a future Canadian voluntary fuel economy standard, including generally lower income levels than in the United States, that might make it somewhat more difficult to sustain higher vehicle prices and possibly different levels of public consciousness about global warming and energy security concerns (Canadian tar sands production places Canada in a considerably different position vis-à-vis energy security). The small size of the Canadian vehicle market may make it quite difficult for Canada to obtain a voluntary agreement without a similar action in the United States. However, the European Voluntary Commitment will create numerous vehicle models with significant improvements in fuel economy produced by European affiliates of the same companies that market in Canada, which should make it somewhat easier for Canada to "go it alone."

\subsection{References}

ACEA: European Automobile Manufacturers Association.

ACEA, 1999, ACEA Commitment on $\mathrm{CO}_{2}$ Emissions Reductions from New Passenger Cars in the Framework of an Environmental Commitment between the European Commission and ACEA [www.acea.be/acea/Co2emissionscars.html].

ACEA, 2002a, "Motor Vehicle Taxation in Europe."

ACEA, 2002b, "European Automobile Manufacturers Association and the Commission Services," Monitoring ACEA's Commitment on $\mathrm{CO}_{2}$ Emissions Reductions from Passenger Cars.

EIA: Energy Information Administration

EIA, 1999, Annual Energy Outlook 2000, with Projections to 2020, U.S. Department of Energy DOE/EIA-0383(2000), Dec.

European Conference of Ministers of Transport, 1995, Trends in the Power Ratings of Cars and Heavy Goods Vehicles, CEMT/CS/ENV(94)3/REV1, Jan 10.

Hellman, K.H., and J.D. Murrell, 1984, "Development of Adjustment Factors for the EPA City and Highway mpg Values," Society of Automotive Engineers technical paper SAE 840496.

Kageson, P., 2000, The Drive for Less Fuel, European Federation for Transport and Environment, Brussels, Belgium, Jan.

McCubbin, D.R., and M.A. Delucchi, 1996, The Social Cost of the Health Effects of MotorVehicle Air Pollution, Institute of Transportation Studies, University of California at Davis, UCD-ITS-RR-96-3(11), Aug. 
Minato, K., 2002, “Trends in Fuel Economy Standards, Now and Future," JSAE 56(9) (in Japanese).

MOT, 2000. “Interim Report on Target Standards for Vehicle Fuel Consumption," from Japanese Ministry of Transport website (no longer available on the website).

OTT: DOE Office of Transportation Technologies

OTT, 2000, "Well-Oiled: Europe's voracious appetite for oilburning cars is still spiraling," Automotive Industry Data Newsletter, no. 0007, April 17, 2000. Reported in Fact of the Week \#136, July 17, 2000, OTT, DOE.

Pope, C.A., III, et al., 1995, "Particulate Air Pollution as a Predictor of Mortality in a Prospective Study of U.S. Adults," American Journal of Respiratory and Critical Care Medicine 151:669674.

Schipper, L., C. Marie-Lilliu, and L. Fulton, 2000, "Diesels in Europe: Analysis of Characteristics, Usage Patterns, Energy Savings and $\mathrm{CO}_{2}$ Emission Implications," presented at the Transportation Research Board 79 ${ }^{\text {th }}$ Annual Meeting, Washington, D.C., Jan. 9-13.

U.S. Congress, Office of Technology Assessment, 1995, Advanced Automotive Technology; Visions of a Super-Efficient Family Car, OTA-ETI-638, Washington, D.C., Sept.

U.S. DOE: U.S. Department of Energy

U.S. DOE, 1999, Office of Transportation Technologies, Fact of the Week \#87

[http://www.ott.doe.gov/facts/archives/fotw87.html], May 4.

U.S. EPA: U.S. Environmental Protection Agency

U.S. EPA, 1993, Federal Test Procedure Review Project: Preliminary Technical Report, Washington, D.C., May. 


\section{Section 3 Approach to Evaluating Voluntary Fuel Economy Standards}

In the remainder of this report, we will address the following question: How much of an increase in fuel economy would be reasonable for a voluntary standard over the next decade or so, and how might the standard be formulated to be both economically efficient and fair to vehicle manufacturers? The reason we have used the word "addressing" rather than "answering" is because the question is complex and has more than economic and technological dimensions deciding on a voluntary standard will involve judgments about risk and the value of societal objectives and will require trade-offs better made by an elected government than by scientists.

\subsection{Approach to Analysis and Premises}

We view our appropriate role as providing information useful in guiding discussions between the industry and the federal government and in helping them to reach decisions about the nature of any new standard. Our analysis proceeds as follows:

1. In Section 4, we address the technological and economic potential to increase light-duty vehicle fuel economy, focusing on individual vehicles. We identify a range of technologies capable of improving vehicle fuel economy; we restrict our focus to technologies that are either already in the fleet or will enter mass production by 2005. For each technology, we estimate its effect on a vehicle's retail price and the percentage increase in fuel economy it will accomplish. Finally, we calculate the price and fuel economy effect of a number of "bundles" of technologies applied in 2015 on two example vehicles - a midsized passenger car and a four-wheel-drive compact SUV.

2. In Section 5, we define and explore alternative forms of voluntary standards. In particular, we examine standards that are based on vehicle attributes by first examining the relationship between a series of attributes and vehicle fuel economy (using a data base of the 1999 U.S. fleet). Then, for a selected attribute (curb weight), we define an attribute-based standard (i.e., a weightbased fuel economy standard) and calculate, for each manufacturer, the fuel economy target that would result from applying that standard to the 1999 fleet. We then examine some variations of the weight-based standard in the same manner. In these analyses, we have assumed two levels of fleet-wide fuel economy improvement $-20 \%$ and $33 \%$.

3. In Section 6, we carry out a more advanced quantitative assessment of alternative forms of voluntary standards at the $20 \%$ and $33 \%$ levels of improvement in fleet-wide fuel economy. In this assessment, we calculate 
the fuel savings and change in retail price for the fleet as a whole and for individual manufacturers, for standards with fuel economy targets expressed as mpg requirements, percentage increases from a year 2000 baseline, or requirements based on vehicle weights. Each standard is applied either as one target for the fleet, separate targets for the passenger car fleet and the light truck fleet, or separate targets for each manufacturer (and for the latter, applied at the fleet level, at the car/light truck level, or further divided into domestic and imported vehicles).

We have adopted the following premises:

- The rate of capital turnover in motor vehicle manufacturing is at normal levels. We have chosen to examine voluntary standards that mature in the 2012-2015 timeframe, which seems long enough to allow manufacturers to recoup their costs on existing models and components and to avoid being forced to accelerate redesign or retooling. We also assume that manufacturers do not delay such redesign and retooling, given the long timeframe and the importance the buying public attaches to technology sophistication. A new technology's impact on vehicle price would be higher if a standard did not allow manufacturers to fit improvements into their normal redesign schedule, or if the alternative against which the new technology is measured is continuing production of an existing technology with the current tooling and plant, the investment costs of which have been fully amortized. In this timeframe, we believe that neither of the above is realistic.

- The basic composition of the fleet is held constant. We have not attempted to account for future changes in the distribution of vehicles across market segments or the introduction of new types of vehicles that may not fit in current segments. Such changes are ongoing in the fleet, but it would be difficult or impossible to track the changes in our analysis. Were we able to account for such changes, however, we believe that doing so might create substantial changes in the individual company results. Consequently, we use these results solely to examine the effects of different types of standards on a range of companies with different market characteristics. We do not consider the results accurate enough to use as a projection of what would likely happen to a particular company (for example, Toyota or General Motors), and we urge our readers not to interpret them in this way.

- Interior space and acceleration capabilities are held constant. Further, we have not attempted to evaluate the potential for future changes in interior space or acceleration capability. Instead, in our calculations, we treat the fleet as not changing in interior space or acceleration capability. In the analysis, this assumption means that where the introduction of new technologies might be used to change such attributes as acceleration capability, appropriate adjustments are made to keep attributes constant. For example, where introduction of a new engine technology would increase engine power density and thus improve acceleration performance if engine size were unchanged, we assume that the engine is downsized to maintain constant performance. This is a crucial assumption because these characteristics have been changing in the U.S. fleet over the past few 
decades and will certainly continue to change. Further, past changes have recently been in a direction that had an adverse impact on fuel economy, and some of the expected future changes are likely to continue in this direction if fuel prices remain low. However, forecasting these changes would introduce large uncertainties to our analysis, and further, the introduction of challenging new fuel economy goals might sharply reduce the rate of change of those attributes affecting fuel economy, at least to the extent industry decision-makers can control these changes.

- Changes in other vehicle attributes are assumed to be minimal and are not accounted for in the cost analysis. The approach we have adopted implicitly assumes that we can define the attractiveness of particular technologies solely in terms of their prices and their potential to improve fuel economy. Manufacturers choose technologies for incorporation into their vehicles by weighing additional factors, including effects on vehicle reliability and maintenance requirements, the extent to which the technologies portray a "high-tech" image, and changes to vehicle attributes that may be difficult to measure in economic terms but that affect vehicle marketability (e.g., impacts on shift feel, subtle changes in the engine torque curve). For the technologies we consider here, we believe that incorporation of these other factors into the analysis would not significantly affect the results. There are some technologies, however, that will affect consumer perceptions of the driving experience enough to potentially reduce marketability; we have avoided consideration of these technologies (an example is shift "optimization," where the transmission's shift points are altered significantly to maximize fuel economy).

For any but the most extreme targeted increases in fuel economy, manufacturers will have multiple avenues open to them to improve their fleet fuel economy and multiple technology pathways. They might choose to focus more on weight reduction and improvements in aerodynamics and less on drivetrain changes (or vice versa). They have available to them several different approaches to drivetrain improvement, including use of DI gasoline or diesel technologies or various levels of hybridization. And each manufacturer might choose different approaches based on its unique marketing strategy and technical capabilities.

For illustrative purposes, in Section 4, we have constructed some alternative cases showing the price and resulting fuel economy of applying some different technology combinations to individual vehicles. However, for our fleet-wide analysis in Section 6, we assume that every manufacturer will use the same basic strategy: that is, to attain an incremental increase in fuel economy, manufacturers will use the most cost-effective technology available until its maximum share of the fleet is attained and then use the next most cost-effective technology, and so on. This approach will identify what can be done, although it will not predict what will be done.

This approach is followed by constructing "price curves" for the industry as a whole (with separate curves for cars and light trucks) and for some individual companies. Price curves are ordered plots of technology price (on the x-axis) versus the percentage fuel economy increase (on the y-axis). Each point on the curve represents a technology, and the points are ordered so that, as one moves from left to right, the incremental price divided by the incremental percentage increase in fuel economy - the slope of the curve — is always either increasing or remaining the 
same. In other words, as the fleet or an individual company moves up the price curve from its current baseline vehicle technology toward advanced technologies and higher fuel economy, each segment of the curve represents a single technology that generally will be slightly less costeffective than the previous technology adopted (this condition may be violated if certain technologies must be adopted in a particular order).

The curves are constructed to account for synergies among technologies (that is, where the benefits of two technologies are not independent of each other) and the current degree of use of the technologies in the fleet. Synergy may occur because each technology addresses the same specific inefficiency or because two (or more) technologies interact with each other; both positive and negative synergies are possible. Where a technology has already achieved significant penetration in the fleet so that its additional fuel economy benefits to the fleet are limited, these limits are specifically incorporated. We note, however, that data about the penetration of fuel efficiency technologies are not uniformly available, and in some cases, we must estimate these penetration rates by using other variables as proxies for the presence of these technologies.

We recognize that different individuals and stakeholders — including "society" as a stakeholder - will use different measures of "cost-effectiveness." In our analysis, the key variable is the rate of return required by consumers for their fuel economy investments and the number of years for which fuel savings have been accounted. As discussed in Section 6, a relatively high rate of return will be required because passenger cars - and the technology embedded in them - are depreciating assets, with essentially zero value at the end of their lifetimes. On the other hand, different actors would require different rates of return and perhaps count different numbers of years of fuel savings. For example, a vehicle purchaser intending to keep a vehicle for five years and believing that its value in the used car market is unlikely to be affected by its fuel economy would likely count no more than five years of fuel savings; another purchaser intending to keep the car until it was no longer running, or one who believed that its higher fuel economy would be fully valued by the used car market, would likely count lifetime fuel savings. Because we are interested in setting a target fuel economy for a societal purpose to improve U.S. energy security and reduce greenhouse emissions - we choose as a baseline case a relatively low rate of return of $12 \%$ and account for lifetime fuel savings (since society does not care who owns the car, only that it uses oil). ${ }^{54}$

We also examine the effects of an alternative set of assumptions - the desire to pay off the technology costs in three years, without discounting — because analysts in the industry have claimed that consumers actually behave, in their purchasing decisions, as if they valued fuel economy this way. Although we expect to find that this assumption will tend to allow only a relatively small amount of fuel economy improvement as "cost-effective" - since manufacturers, presumably using this accounting method in their decisions, have made few

54 Note that society is likely to value fuel savings at a rate higher than indicated by the market price of the fuel because society would incorporate the cost of externalities - energy security costs, global warming costs, etc. - into the value of fuel. Ignoring these externality costs, which we have done, should lead to a level of fuel economy somewhat lower than ideal. 
improvements over the past decade - we do believe it will be useful to examine the effect of applying this type of accounting.

There remains some controversy about the performance and price of key fuel economy technologies, with more argument about price. All of the technologies of interest have penetrated the fleet, and there are considerable performance data available from technical journals, numerous conference presentations, and industry announcements, as well as from consideration of the published performance of the vehicles themselves. There is far less publicly available information about costs or prices, although publications such as Automotive Engineering International do offer some cost information based on data obtained from the industry.

The price and performance values used to construct the price curves used in Section 6 and to evaluate the "technology packages" shown in Section 4 are assembled from an extensive literature review and analysis combined with intensive interviewing of automotive manufacturers and suppliers. In addition, the values have been compared with those in a recent report to Natural Resources Canada based on a U.S. automobile industry-sponsored analysis (with access to industry data) of many of the technologies examined here (Sierra Research 1999). Some of the technologies have been introduced in Japan or Europe before their U.S. introduction, and so there are data available from these markets; care has been taken to account for differences between these markets and the United States in emission standards and in the driving cycles under which performance was measured, both of which can affect technology performance and price. Where the "performance" of technologies is reported in terms other than changes in fuel consumption or fuel economy (e.g., reduced weight or percentage improvement in aerodynamic drag coefficient), the impact on fuel economy is calculated by using an engineering model that follows the work by General Motors Research Laboratory scientists Sovran and Bohn (described in Appendix B).

\subsection{Reference}

Sierra Research, 1999, Alternative and Future Technologies for Reducing Greenhouse Gas Emissions from Road Vehicles, prepared for Transportation Table Subgroups on Road Vehicle Technology and Fuels, Canada, July. 
$\Delta$ 


\section{Section 4 \\ Potential for Technology to Improve Vehicle Fuel Economy}

\subsection{Introduction}

In this section, we introduce a range of technologies available now or within a few years to improve the fuel economy of U.S. light-duty vehicles and provide estimates of their fuel economy benefits and costs; the latter are expressed as increases in retail price. In addition, we present, as illustrations, two sample vehicles - a midsize passenger car and a compact fourwheel-drive SUV - to which we add a variety of technology packages and compute the resulting fuel economy and the retail price increase associated with the packages. This information combined with information about the fuel economy and technology characteristics of the year 2000 new car and light truck fleets - is at the core of our analysis to compute the costs of increasing the fuel economy of the new vehicle fleet by $20 \%$ and $33 \%$, respectively, by about 2015.

\subsection{Methodology}

Technologies to improve fuel economy have been extensively studied over the last two decades. The methodology to estimate future vehicle fuel economy potential, and the net retail price increase as a result of improving vehicle technology, has also been developed over this period. Our current methodology is based on a three-step process using:

- A baseline of actual vehicle technology market penetration and measured fuel economy in a specific year,

- A detailed assessment of the cost and benefit of individual technologies for improving fuel economy,

- A model to assess the combined effect of multiple technological improvements in future vehicles.

For this analysis, we have used a 2000 model year baseline of technology and fuel economy, which is described in Appendix A.

The heart of the methodology for estimating fuel economy improvement potential is the estimation of costs and benefits of individual technologies to improve fuel economy. Candidate technologies are first identified by extensive searches of technical publications, manufacturer announcements, and reports on government-funded research worldwide. Fuel efficiency benefit estimates are also based on the same sources, which often report fuel economy benefits data from prototype versions of the technology and discuss the source of such benefits (for example, reduction in pumping losses, friction reduction). Data are also available through extensive and continuous interviews of automotive suppliers, automakers, and industry consultants. 
We have restricted the technologies considered in this analysis to those that either have already attained mass production status somewhere in the world, or that are expected to attain such status by 2005 on the basis of announced auto-manufacturer plans. Mass production is defined here as volume in excess of 20,000 units per year. This definition would exclude such technologies as the use of carbon fiber structural components (currently in production for some exotic sports cars, like Ferrari) or the fuel cell, where most manufacturers have announced plans to have small numbers of vehicles introduced before 2005. It would include such technologies as aluminum-intensive body structures (already in mass production on the Audi A2) and hybrids of both the $42-\mathrm{V}$ and $150 / 300-\mathrm{V}$ types, which are expected to exceed production levels of 20,000 per year in the United States by 2005. Since the ultimate objective of this analysis is to examine fuel economy potential in the 2012 to 2015 time frame, these definitions of "available" technologies ensure that there is adequate lead time for the technologies considered to have significant market share by 2015 .

Cost data on individual technologies are not easily available, and the term cost itself is confusing. Our analysis focuses on estimating "Retail Price Equivalent," or RPE, which is an estimate of how much consumers would have to pay for a technology in a competitive market. (Economic theory shows that in competitive markets, retail prices must be a function of costs, on average, although in real markets there are cross subsidies between car models). We estimate technology RPEs from four sources: (1) actual price comparisons between similar cars with and without a technology where the technology is offered as an option, (2) manufacturer or supplier cost for add-on technology, (3) engineering studies of technology costs, and (4) confidential manufacturer submissions to regulatory bodies that are aggregated across all manufacturers to preserve confidentiality. Cost and pricing data from different parts of the supply chain (e.g., component supplier, manufacturer plant gate, etc.) are compared and combined by using a structured set of assumptions about profit margins at each step of the chain. High-volume production is assumed, and the estimating procedure uses what we consider to be normal amortization of fixed costs of development, engineering and tooling, and market launch.

A particularly crucial point here is that we are interested in the long-term potential of the industry to improve fuel economy, over a period of 10 years or longer. Therefore, in estimating incremental costs, we assume that, at the time of model redesign or introduction, each manufacturer's choice for individual vehicle components is between a new version of either a baseline technology or an advanced technology. In the short term, some manufacturers might simply choose to continue using a fully depreciated older plant and tooling and continue to produce an existing component, with fixed costs essentially zero, rather than designing a new component. In a competitive marketplace that places a high value on up-to-date design, this option is not realistic for very long. A comprehensive description of the costing methodology and input assumptions can be found in Appendix B.

A crucial underlying assumption of our estimates of technology benefits and costs is that vehicle attributes of size, acceleration performance, and features are kept constant (or as constant as possible given the technology characteristic). For example, if four-valve/cylinder technology is employed, the engine is downsized and the axle ratio is increased to keep performance "constant" in terms of passing and launch acceleration. Costs would vary, depending on the extent of downsizing assumed, since modest adjustments of bore/stroke can be accomplished at 
low cost, but larger displacement reductions may require a new engine design. Vehicle attribute changes can then be modeled independent of any compounding effects from technology changes.

The third element of the estimation procedure is modeling the effects of multiple technologies adopted simultaneously. While the benefits of some technology combinations are additive, the benefits of other combinations are not. In particular, many technologies affect engine pumping loss and friction loss, and combining two or more such technologies will yield much less benefit than the sum of benefits each would achieve when employed by itself. For example, variable-valve lift and timing and cylinder cutout provide much less benefit in combination than the sum of their individual benefits. We modeled the synergistic effects of technology combinations by using a lumped parameter model that is capable of accounting for primary synergies in pumping and friction loss. ${ }^{55}$ The model results have been bench marked against actual test results for high-fuel-economy prototypes displayed by the manufacturers. The model is described in Appendix B.

\subsection{Available Technologies}

Fuel economy can be improved by two primary methods: (1) by reducing the loads that need to be overcome to accelerate the vehicle and keep it moving and (2) by increasing the efficiency with which fuel energy is converted to power at the wheels. Reducing the load required to move the vehicle can be accomplished by (1) reducing vehicle weight, (2) reducing vehicle aerodynamic drag, (3) reducing tire rolling resistance. Increasing the efficiency with which fuel is converted to usable power means increasing the efficiency of the engine and drivetrain; this is accomplished by (1) increasing the cycle thermodynamic efficiency, (2) decreasing internal engine and transmission friction loss, (3) decreasing the pumping loss at part throttle, (4) decreasing the frictional loss in the axles and driveshafts, (5) improving the matching of the load requirement to engine operating conditions, and (6) reducing parasitic loss to such accessories as the power steering pump or the water pump. Many technologies for the engine and drivetrain can simultaneously affect several of the above areas. The internal combustion engine/electric drive hybrid adds a new feature to the system, in that electrical motor power can be used at operating conditions where the internal combustion engine is inefficient, and braking energy loss can be recaptured.

Table 4-1 provides a list of "available" technologies as defined above. Note that DI gasoline and diesel engines have some unique issues related to meeting future emission standards, so that their availability in the U.S. market depends on successful development of new emission controls.

55 Since the lumped parameter model carries an explicit representation of pumping losses and friction losses, it is inherently impossible to double count benefits to the extent that fuel economy gains beyond the theoretical limit of zero losses are ever forecast. Also, primary synergies that account for reduced benefits with each additional technology acting upon the same source of efficiency loss is also accounted for in this modeling approach. However, additional data from more detailed simulations or from actual measurement are required if two technologies affect the same loss but are effective at different engine operating conditions to determine the exact non-additivity between technologies. 
Table 4-1. List of Available Technology

\begin{tabular}{|c|c|}
\hline Category & Technology \\
\hline \multirow[t]{7}{*}{ Weight Reduction } & Improved packaging \\
\hline & HSLA $^{a}$ intensive design \\
\hline & SMC/RIMb body closures \\
\hline & Aluminum castings (engine/transmission) \\
\hline & Aluminum forgings \\
\hline & All-aluminum structure \\
\hline & Lightweight interiors (seats/door inserts/dashboard/headliner) \\
\hline Drag Reduction (Cd) & Up to $20 / 25 \%$ reduction from 2000 levels \\
\hline Rolling Resistance Reduction (Cd) & Up to $20 / 25 \%$ reduction from 2000 levels \\
\hline \multirow[t]{4}{*}{ Accessories } & Improved water/oil pump \\
\hline & Efficient alternator \\
\hline & Electric power steering \\
\hline & Electric water/oil pump \\
\hline \multirow[t]{6}{*}{ Spark Ignition Engines } & Variable-valve lift/timing \\
\hline & Cylinder deactivation \\
\hline & Variable compression ratio \\
\hline & Mechanical friction reduction \\
\hline & Roller cam followers \\
\hline & Lean burn \\
\hline \multirow[t]{3}{*}{ Direct-Injection (DI) Engines } & Gasoline (DI) stoichiometric \\
\hline & Gasoline (DI) lean burn \\
\hline & Diesel (DI) \\
\hline \multirow[t]{5}{*}{ Transmissions } & Torque converter loss reduction \\
\hline & Five-/six-speed automatic transmission \\
\hline & Continuously variable transmission \\
\hline & Electrically shifted manual transmission \\
\hline & Four-wheel drive improvements \\
\hline \multirow[t]{4}{*}{ Hybrids } & Mild 42-V Hybrid \\
\hline & On-demand $42-\mathrm{V}$ four-wheel-drive system \\
\hline & $150 / 300-V$ hybrids \\
\hline & Integrated starter-generator (ISG) \\
\hline \multirow[t]{3}{*}{ Electronic Control } & Early or partial lock-up of torque converter \\
\hline & Electronic throttle control \\
\hline & Electrically actuated valves \\
\hline
\end{tabular}

a High-strength low-alloy steel.

b Sheet-molded compound/reaction injection molding.

\subsection{Load Reduction Technologies}

Weight reduction is the major focus of load reduction efforts for most advanced prototype high-fuel-economy cars that have been displayed, but weight reduction encompasses a number of "'technologies," " including more efficient design or packaging of a vehicle, more extensive use of high-strength low-alloy (HSLA) steels, the use of such alternative materials as plastics or aluminum, and potentially, the use of such alternative construction techniques as the unibody or space frame. For convenience, we have grouped some technologies that appear to have very similar costs in terms of dollars per pound saved. 
For a given vehicle type, weight is also a function of the vehicle attributes of size, luxury features, body rigidity, and safety. Since the analysis is being done for vehicles at constant size, features, and performance, only the issue of body rigidity has to be considered. Body torsional rigidity helps driveability and handling and also provides a more "solid" feel to the vehicle; for these reasons, torsional rigidity has increased dramatically in the last decade and may continue to do so in the future, adding weight. Body rigidity also affects vehicle crash safety, although the relationship is not a simple one. ${ }^{56}$ Although our analysis generally seeks to maintain constant attributes relative to the baseline and thus does not specifically address further increases in rigidity relative to 2000 model year vehicles, we have allowed for weight increases associated with safety improvements (both required by regulation and desired by consumers) as estimated by the Alliance of Automotive Manufacturers in submissions to the National Academy of Sciences (NAS) study on fuel economy.

Packaging improvements reduce weight primarily through improved design. This technology involves only capital costs and, theoretically, has a negative variable cost (due to reduced material use). However, it is usually applied with improved materials in a "clean sheet of paper' design so that we do not treat it separately. In addition, there is no good benchmark to estimate how extensively this technology has been used in the baseline 2000 models. The analysis of the baseline vehicle characteristics for MY 2000 did not show significant differences in packaging efficiency for the three manufacturers studied in detail (with some notable exceptions, such as the Honda Civic and CR-V).

Extensive use of HSLA steels has been analyzed by the American Iron and Steel Institute (AISI) (1998) (using Porsche as a contractor), and the institute's study estimated a net $140 \mathrm{lb}$ structural weight reduction for a midsize car at a cost reduction of $\$ 50$. Including modest secondary effects, this would translate to a $5 \%$ weight reduction at a cost saving of about $\$ 0.50 / \mathrm{lb}$. However, it should be noted that packaging improvements were also factored into this study. Our interviews show that auto manufacturers believe that the AISI study contains good ideas, but it is too optimistic in its weight savings estimates. Examples of the trade-offs in the AISI design mentioned by manufacturers are reduced wheel-turning radius due to straight frame rails and excessive intrusion of thin wall channel sections into the passenger compartment. In addition, the companies believe that the cost methodology used by the AISI does not capture some important effects, such as the accelerated wear of the stamping dies when HSLA steel is used. Manufacturers believe that there are modest costs, not savings, associated with increased use of HSLA.

Wider use of plastic composites for the bumper assembly and closures (hood, fenders, deck lid) has the potential to save $25 \%$ of the weight of these components, or about $80 \mathrm{lb}$ in a midsize car. Plastic components can be lower in cost than steel at low volume production $(<4,000 /$ month $)$ because of low tooling costs, but they impose penalties of $\$ 0.30-0.40$ per pound saved at high volume (>15,000/month). Some of the costs are associated with the need for special steps in the

56 Increased rigidity of the passenger compartment should be uniformly good for safety. Because the rest of the car's structure is designed to crush at a controlled rate and to absorb crash energy, extremely high or low rigidity must be avoided. Also, high rigidity of this portion of the car's structure may be detrimental to the safety of other vehicles. 
painting process and the plastic's inability to withstand bake oven temperatures. A total weight savings of $5 \%$ for a midsize car is estimated for complete conversion of bumpers, hood, deck, and fenders.

Aluminum is the material of choice in many advanced prototypes, but the costs and benefits vary by application type. Aluminum can be used in castings that replace cast iron for the engine block, cylinder heads, transmission housing, and intake manifold. Aluminum sheet can be used for body closures (hood, fenders, etc.). Aluminum forgings can be used to replace steel in the suspension, steering, axles, driveshafts, and wheels. A complete aluminum body-in-white from laser-welded "tailored" blanks, or a space frame structure, can replace an all-steel body-in-white.

Available data show that for castings, the cost per pound saved is around $\$ 1.00 ; 57$ for example, an aluminum block for a four-cylinder engine saves about $50 \mathrm{lb}$ at a cost of $\$ 50$. Fixed costs for aluminum castings are generally comparable with, or lower than, fixed costs for iron castings. On the other hand, data from the manufacturers show body closure costs at around $\$ 2.00$ per pound saved, and even higher estimates of cost have been made for conversion of a body-in-white to aluminum.

Recent studies by IBIS Associates (EEA 1998) suggest that for all-aluminum bodies, the space frame structure may be the most cost-efficient method to construct the vehicle. Manufacturers are not uniform in this belief, as several manufacturers still believe that the monocoque design is better, while Audi is very public in its belief about the superiority of the space frame structure. The all-aluminum body is one area where our projected costs are significantly lower than those of some other cost projections (NAS 2001).

A detailed presentation by Audi (2001) provided insight into these cost differences. First, the weight reductions in the primary body structure allow for significant secondary weight reductions that result in cost savings that can reduce net costs. Audi used, for illustrative purposes, an analysis by Ford (2001) of its AIV (aluminum-intensive vehicle); the analysis showed the following for weight reduction:

\begin{tabular}{lr} 
Aluminum Structure & $125 \mathrm{~kg}$ \\
Aluminum Closures & $48 \mathrm{~kg}$ \\
\cline { 2 - 2 } Total Primary Weight Savings & $173 \mathrm{~kg}$
\end{tabular}

Ford estimated that secondary weight savings would be $138 \mathrm{~kg}$, of which the engine size reduction was the largest contributor $(54 \mathrm{~kg})$ and suspension weight was the second, at $29 \mathrm{~kg}$ (much of engine weight savings apparently is associated with adopting a four-cylinder engine relative to the V-6 used in the base car). Audi believes that the cost differentials between different analyses can be accounted for by treatment of secondary cost savings. These savings are incorporated in this analysis.

57 National Academy of Sciences, data submitted to the NAS by manufacturers/suppliers. 
Second, future cost savings from increased manufacturing experience may be extremely important. Audi believes it is on a steep learning curve with regard to aluminum fabrication. It points to such advanced techniques as structural beam hydroforming, development of multifunctional die castings, laser-welding, and riveting as new manufacturing processes that have led to significant cost declines for its new space frame A2 vehicle, which is a secondgeneration vehicle relative to the first-generation A8 aluminum-body vehicle. For example, Audi has estimated fabrication costs for aluminum-extruded parts to be reduced by more than $50 \%$ in going from its first-generation vehicle to the second generation, with potential third-generation costs to be as low as $25 \%$ of first-generation costs. ${ }^{58}$

Porsche has produced a follow-on study to the original Ultralight Steel Body Study. ${ }^{59}$ Using ultra-high-strength steel and some of the same manufacturing techniques used by Audi for its aluminum body vehicle, Porsche now believes that steel bodies can approach the weight reduction levels of aluminum bodies at much lower costs.

In both drag reduction and rolling resistance reduction, the estimates of benefits and cost are relatively uniform and not contested by manufacturers. Sierra Research has stated that $\mathrm{Cd}$ reductions for cars to levels below 0.28 could result in loss of consumer attributes (Austin 1999). However, most manufacturers agreed that a $\mathrm{Cd}$ level of 0.25 is readily feasible with modest limitations in design flexibility, and the recent market entry of several models, such as the Audi A2 and Lexus LS430, at Cd levels of 0.25/0.26 suggest that additional reductions, possibly to 0.22 , may be feasible by 2015. Minimum Cd values for vans, SUVs, and pickups were estimated at $0.30,0.34$, and 0.38 , respectively, for two-wheel-drive (2WD) vehicles, with a Cd increment of 0.02 for four-wheel-drive vehicles, with Sierra in agreement. Note that the 2001 Acura MDX (SUV) has already attained a $\mathrm{Cd}$ of 0.36 .

Tire manufacturers have publicly stated that tire rolling resistance can decline significantly over the next decade. For example, Michelin has developed tires with an advanced silica-based tire material that have $20 \%$ lower rolling resistance relative to similar current tires and claims that these tires have no loss in traction and braking performance. Similarly, Goodyear has developed a tire using a starch-based material that also has a $20 \%$ reduction in rolling resistance with no loss of other desired characteristics.

In the area of accessory technologies, several suppliers are displaying prototypes of more efficient alternators $(12-\mathrm{V})$ for very low incremental costs (under \$10) relative to current alternators. ${ }^{60}$ Current oil pumps that are crankshaft mounted are also very inefficient, and more efficient models utilizing a gear drive are a "no-cost" option, except for engine packaging and design (i.e., they involve fixed costs, not variable costs).

58 Audi, 2001, presentation to the National Academy of Sciences Committee, April.

59 Porsche, 2001, presentation to the NAS Committee on the results of the ULSAB Advanced Vehicle concepts Study, April.

60 National Academy of Sciences, information provided by electrical system suppliers to the NAS committee, April. 
In the United States, electric power steering (EPS) will be widely used as a replacement for hydraulic power steering in the near term. GM has announced (Automotive News 2001) that the new Saturn SUV will feature EPS in 2002, and EPS will enter high-volume production when incorporated into the new midsize GM cars for 2004. Supplier-based information suggests that costs over hydraulic systems are in the \$20-25 range, which translates into an RPE of \$40. Some suppliers suggest that it is a zero-cost option, but this may exclude the electrical system upgrades that are required for use of EPS with current 12-V systems. A summary of the cost and benefit values used in this analysis for load reduction technologies is provided in Table 4-2.

\subsection{Engine Improvements}

\subsubsection{Variable-Valve and Other Technologies}

Improvements to spark-ignition engines include variable-valve timing, variable-valve lift and timing, cylinder deactivation, variable compression ratio, and internal friction reduction. No significant disagreement exists in the fuel economy estimates of benefits of these technologies, but we received new information on costs in recent interviews with suppliers and auto manufacturers. Table 4-3 shows the estimated fuel economy benefits and RPEs of these technologies.

Table 4-2. Attributes of Load Reduction Technologies

\begin{tabular}{|c|c|c|}
\hline Technology & $\begin{array}{c}\text { F/E Benefit } \\
(\%)\end{array}$ & $\begin{array}{c}\text { Technology RPE } \\
(\$)\end{array}$ \\
\hline \multicolumn{3}{|l|}{ Weight Reduction ${ }^{a}$} \\
\hline Packaging and HSLA & 3.3 & $0.30 / \mathrm{lb}$ saved \\
\hline Composites for closures & 1.7 & $0.50 / \mathrm{lb}$ saved \\
\hline Aluminum for castings & 3.3 & $1.20 / \mathrm{lb}$ saved \\
\hline Aluminum for forgings & 1.7 & $1.50 / \mathrm{lb}$ saved \\
\hline Aluminum for closures & 1.7 & $2.40 / \mathrm{lb}$ saved \\
\hline Lightweight interior & 1.7 & 0.90/lb saved \\
\hline All-aluminum body & 3.3 & 2.40/lb saved \\
\hline \multicolumn{3}{|l|}{ Drag Reduction } \\
\hline $\mathrm{Cd}(0.31$ to 0.28$)$ & 2.2 & 35 \\
\hline $\mathrm{Cd}(0.28$ to 0.25$)$ & 2.2 & 60 \\
\hline \multicolumn{3}{|l|}{ Rolling Resistance Reduction } \\
\hline$C_{R}(0.095$ to 0.085$)$ & 2.0 & 20 \\
\hline$C_{R}(0.085$ to 0.075$)$ & 2.0 & 30 \\
\hline Improved alternator & 0.5 & 15 \\
\hline Electric power steering (12 V) & 2.0 & 40 \\
\hline Gear drive oil pump & 0.5 & 3 \\
\hline
\end{tabular}

a All benefits are incremental in order of appearance. 


\begin{tabular}{|c|c|c|c|}
\hline & Technology & $\begin{array}{c}\text { F/E Benefit } \\
(\%)\end{array}$ & $\begin{array}{c}\text { Technology RPE } \\
\text { (\$) }\end{array}$ \\
\hline \multirow{2}{*}{\multicolumn{2}{|c|}{ Four-valve (+ higher CR) }} & \multirow[t]{2}{*}{5} & 125 (4-Cyl.) \\
\hline & & & 180 (6-Cyl.) \\
\hline & $\mathrm{DOHC}$ over SOHC & $\begin{array}{l}\text { (makes VVT } \\
\text { possible) }\end{array}$ & None \\
\hline & \multirow[t]{2}{*}{$\mathrm{VVT} T^{\mathrm{a}}$} & \multirow[t]{2}{*}{$2-3$} & 30 (in-line engine) \\
\hline & & & 90 (V-engine) \\
\hline \multirow{2}{*}{\multicolumn{2}{|c|}{ VVL $^{b}$ (two position) }} & \multirow[t]{2}{*}{$4-5$} & 140 (4-Cyl.) \\
\hline & & & 200 (6-Cyl.) \\
\hline \multirow{2}{*}{\multicolumn{2}{|c|}{$V_{V T L}{ }^{c}$}} & \multirow[t]{2}{*}{$6.5-8$} & 170 (4-Cyl.) \\
\hline & & & 230-290 (6 Cyl.) \\
\hline & Cylinder deactivation & $7-8$ & 120 (On V-8) \\
\hline & VVTL and cylinder deactivation & $11-12$ & 350 (DOHC V-8) \\
\hline & \multirow[t]{2}{*}{$\mathrm{GDI}^{\mathrm{d}}\left(\right.$ Tier $\left.2^{\mathrm{e}}\right)$ and VVT } & \multirow[t]{2}{*}{$13-15$} & 480 (4-Cyl.) \\
\hline & & & 650 (6-Cyl.) \\
\hline \multirow{2}{*}{\multicolumn{2}{|c|}{ Turbo DI diesel (Tier 2) }} & \multirow[t]{2}{*}{$35-38$} & 1,600 (4-Cyl.) \\
\hline & & & 2,200 (6-Cyl.) \\
\hline & Engine friction reduction & $2-4$ & $20-50$ \\
\hline \multicolumn{4}{|c|}{ a Variable-valve timing. } \\
\hline \multicolumn{4}{|c|}{ b Variable-valve lift. } \\
\hline c & \multicolumn{3}{|l|}{ Variable-valve lift and timing. } \\
\hline$d$ & \multicolumn{3}{|l|}{ Gasoline direct injection. } \\
\hline e & \multicolumn{3}{|c|}{$\begin{array}{l}\text { Tier } 2 \text { refers to emission standards. All benefits relative to two-valve SOHC } \\
\text { engine, with mid-range torque constant between comparisons. }\end{array}$} \\
\hline
\end{tabular}

Variable-valve-timing systems appear to have benefited from significant cost declines. The cam phasing mechanism is apparently now available for a cost of around $\$ 40$, and variable-valve timing can be used to eliminate exhaust gas recirculation (EGR). Cost savings from the elimination of EGR can reduce the net cost of variable-valve timing to around \$15-20 for an in-line engine. Since two cam phasers will be required for a V-block engine, costs will be around $\$ 50-60$. Incorporating these variable-valve-timing systems do not require any significant investment in engine tooling or assembly, and an RPE of $\$ 30$ for inline engines and $\$ 90$ for V-block engine appears appropriate.

The second area for which new cost information was received is for cylinder deactivation systems. VVLT systems using a two-position cam follower have a mechanism that can be easily adapted to disable the valves for cylinder deactivation. Manufacturers believed that cylinder deactivation can be added on to VVLT at a very low additional cost of about \$25-\$30 for a V-8. In addition, Delphi has developed a cylinder cutout system for application to overhead valve (OHV) V-8 engines that is estimated to have an RPE of \$120 for application without a VVLT mechanism. While cylinder cutout systems introduced in the early 1980s had significant performance problems, the new generation of systems has been almost transparent to users; the S-class Mercedes model (the top of the Mercedes model line) now uses this technology on all 
$\mathrm{V}-8$ and V-12 engines, and GM has publicly stated that it will use cylinder cutout in most truck $\mathrm{V}-8$ engines in the near future.

Discussions with Japanese manufacturers have confirmed our earlier cost estimates for twoposition VVL ( $\$ 140$ for a 4-cylinder and $\$ 200$ for a V-6). The addition of cylinder deactivation will be only an additional $\$ 40$ and $\$ 60$, respectively, to the VVL system. Variable timing can be incorporated into a DOHC system only.

The ultimate goal of unthrottled, camless valve control is made possible by both mechanical systems and by the use of electro-magnetic solenoids to open and close the valves. Several auto manufacturers, notably BMW, have pursued the mechanical control technology, but the benefits relative to a two-position VVLT system may be small (3-4\%) relative to the cost, which may be in the order of $\$ 500$. It is also not clear if the electrical solenoids have the required durability, or if the electrical systems will be in produced in large enough quantities by 2005 to be considered as an available technology. Hence, it has not been included in the list.

Information received on friction reduction also confirmed that a maximum of 15-20\% reduction in friction mean effective pressure - which will translate into a 3-4\% improvement in fuel economy - was possible with low-cost technologies by 2015. Key friction-reduction technologies include dimpled pistons and piston rings (through shot peening), offset crankshafts for in-line engines, and plasma metal sprays on cylinder bores. The new Honda Civic engine (for 2001) already features many of these technologies.

\subsubsection{Lean Burn Engines - Diesel and Gasoline}

The diesel engine, while extremely popular in Europe, has made little penetration into the U.S. light-duty market, although it is becoming more popular in the larger classes of light trucks (over 8,500 lb GVW). In its current form, a diesel engine can provide a $40 \%$ fuel economy benefit over an "equal performance" gasoline engine, for a retail price premium for about $\$ 1,200$ for a four-cylinder engine to about $\$ 2,500$ for a V-8 in a large pickup truck. In the short term (to 2010), there is considerable concern about the diesel engine's ability to meet the Tier 2 emission standards. While engine-out $\mathrm{NO}_{\mathrm{x}}$ is low, aftertreatment systems with $85 \%+$ efficiency are still required to meet Tier 2 standards, and current catalyst systems used for spark-ignition engines cannot operate in the lean exhaust of the diesel engine.

Recent technological improvements to diesel engines and emission controls now suggest that diesel engines may be able to meet Tier 2 emission standards, especially if the rate of technology progress can be sustained. The relevant engine technology improvements include:

- Four-valve heads with central fuel injector,

- Common-rail electronically controlled fuel-injection systems,

- Variable geometry turbocharging, and

- Cooled exhaust gas recirculation. 
These technologies have already been incorporated into some of the new diesel engines emerging in Europe, but further improvements can be realized. In particular, suppliers of secondgeneration common-rail fuel-injection systems claim that there is potential for further and significant reductions in emissions, with such systems reaching commercial production in the next two to three years.

Aftertreatment technology focusing on $\mathrm{NO}_{\mathrm{x}}$ and $\mathrm{PM}$ emission continues to improve and has raised the expectations of diesel engine manufacturers about meeting Tier 2 standards. VW has stated that it is reasonably confident of meeting Tier 2 standards by 2007, assuming availability of low-sulfur diesel fuel. Catalyzed diesel particulate filters (already commercialized by Peugeot in Europe) have demonstrated the capability to reduce PM emissions to levels well below applicable Tier 2 standards. Selective Catalytic Reduction (SCR) technology has also shown the capability to attain the $\mathrm{NO}_{\mathrm{x}}$ reduction levels of over $90 \%$ (cycle average) that will be required to meet Tier $2 \mathrm{NO}_{\mathrm{x}}$ standards. This technology requires urea to be stored on board the vehicle and replenished periodically. Although there is no technical issue with this requirement, the need for a urea distribution infrastructure is a barrier to commercialization.

Another promising avenue is with $\mathrm{NO}_{\mathrm{x}}$ adsorber technology, where $\mathrm{NO}_{\mathrm{x}}$ is adsorbed during lean air-fuel-ratio operation, but it is desorbed and converted to nitrogen during rich operation. Since diesel engines never operate rich under normal conditions, special operating conditions and post-injection of fuel are required to achieve the necessary conditions for $\mathrm{NO}_{\mathrm{x}}$ desorption and reduction. Diesel engine manufacturers have estimated that the rich "excursions" needed for emission control will reduce fuel economy by about 4-5\%. In addition, the $\mathrm{NO}_{\mathrm{x}}$ adsorber is easily poisoned by sulfur so that very-low-sulfur diesel is essential for its use. While $\mathrm{NO}_{\mathrm{x}}$ adsorber technology needs further development to provide adequate $\mathrm{NO}_{\mathrm{x}}$ conversion efficiency for meeting Tier 2 standards, the EPA considers it to be the most promising path to meet emission goals.

Plasma-assisted lean $\mathrm{NO}_{\mathrm{x}}$ catalysts are a third aftertreatment possibility for diesel engines. Although interest in this technology declined last year, some critical new advances have made this technology a possible competitor in the future. New innovations include low-powerconsumption plasma generators and a system of sequenced plasma generators and catalysts. Efficiency levels of close to $80 \%$ on the FTP have been attained, but additional developments are required to reach the $85 \%+$ conversion efficiency needed to meet Tier $2 \mathrm{NO}_{\mathrm{x}}$ standards.

Finally, a new type of combustion system called "Homogenous Charge Compression Ignition" is being developed and shows the potential to reduce engine-out $\mathrm{PM}$ and $\mathrm{NO}_{\mathrm{x}}$ emissions by $70-80 \%$ with little loss in efficiency. Such systems could emerge in 10-15 years and provide high fuel economy with low emissions, if current limitations are overcome. Such a system could use lower-efficiency aftertreatment systems to reduce the costs of meeting Tier 2 standards.

The gasoline direct-injection (GDI) engine is also a lean-burn engine with similar concerns about meeting future $\mathrm{NO}_{\mathrm{x}}$ standards. However, meeting emission standards is somewhat easier than with a diesel engine, for several reasons. First, the GDI engine exhaust is hotter than that of the diesel, making the job of $\mathrm{NO}_{\mathrm{x}}$ reduction by catalysis easier. Second, the GDI operates at rich 
air-fuel ratios at high loads so that $\mathrm{NO}_{\mathrm{x}}$ adsorber technology can be more easily integrated with the GDI if low-sulfur gasoline is available. Third, the occasional high exhaust temperature surges at high-load operation result in some desulfation of the adsorber without any special desulfation cycle operation. As a result, some prototypes have already shown compliance with Tier 2 standards. Some manufacturers (notably Mitsubishi and VW) have announced plans to introduce GDI engines in the U.S. market by 2005.

On the negative side, the GDI engine provides only a $12-13 \%$ fuel economy benefit over current spark-ignition engines on the U.S. fuel economy test cycle. Future gasoline engines with VVLT and cylinder cutout significantly reduce the incremental fuel economy benefit of the GDI, since these technologies attack the same engine losses that GDI engines attack. Hence, the future advantage of the GDI may be only in the three to four percent range, making it cost-ineffective. Additional emission risks may make the GDI a less likely candidate for widespread market introduction.

Because neither diesel nor GDI engines have met Tier 2 standards and the design of an emission control system that will meet standards is by no means finalized, emission control costs for these engines are somewhat uncertain. The GDI engine has brighter prospects to meet these standards, and costs of $\mathrm{NO}_{\mathrm{x}}$ aftertreatment should increase its RPE modestly (\$100-150). The diesel will require both a diesel particulate filter and $\mathrm{NO}_{\mathrm{x}}$ aftertreatment; according to two European manufacturers providing data to the National Academy of Sciences committee, increases in RPE of \$400-600 are considered to be reasonable "targets" for aftertreatment costs later in this decade, although costs are much higher now. Costs and benefits listed in Table 4-3 include these estimated aftertreatment costs.

\subsection{Transmission Technologies}

Our interviews with manufacturers have resulted in updates on the cost and performance of continuously variable transmissions (CVTs), and we have obtained new information on two technologies: reduction of torque converter losses and the electrically shifted manual transmission.

Significant progress has occurred in belt-drive CVT technology, with several Japanese manufacturers unveiling more efficient models (with reduced internal losses). Audi has unveiled a CVT model capable of handling up to $300 \mathrm{~N}$-m of torque, which is adequate for a six-cylinder application. In addition, Nissan has also developed a toroidal CVT that can be used with a V-8 engine. Toyota and Audi provided data on a CVT-equipped vehicle that showed a $10 \%$ improvement in fuel economy relative to a four-speed automatic transmission coupled to an engine with VVT. Manufacturers also indicated that our estimated prices are too low for the belttype CVT in the current market, largely because a single supplier (Van Doorne) controls the belt market. However, they expect prices to fall substantially as new belt types and new suppliers enter the market and concur with our estimates as appropriate for 2012-2015.

Table 4-4 summarizes the cost and benefits of transmission improvements used in this study. Reduction in torque converter losses by reducing 'spin' losses and by partial or early lock-up is already occurring in many automatic transmission designs. Data presented by GM to the National 
Table 4-4. Costs and Benefits of Transmission Technologies

\begin{tabular}{|c|c|c|}
\hline Technology & $\begin{array}{c}\text { F/E Benefit } \\
(\%)\end{array}$ & $\begin{array}{c}\text { Technology RPE } \\
(\$)\end{array}$ \\
\hline Torque converter lock-up & $2.5-3.0$ & 55 \\
\hline Advanced low loss torque converter & 1.5 & 25 \\
\hline Five-speed automatic & $3.0-5.0$ & 120 \\
\hline CVT & $5.0-8.0$ & $\begin{array}{c}250 \text { (short-term) } \\
100 \text { (long-term) }\end{array}$ \\
\hline $\begin{array}{l}\text { Electrically shifted manual } \\
\text { transmission }\end{array}$ & $6.0-8.0$ & $\begin{array}{c}\text { None } \\
\text { (+ hedonic cost?) }\end{array}$ \\
\hline
\end{tabular}

Academy of Sciences fuel economy committee indicated that a $2 \%$ fuel efficiency gain is possible from these improvements, although the estimate is very baseline-dependent. Both Mercedes and Toyota may have already incorporated these technologies in several of their new transmissions in 2000.

The electrically shifted manual transmission (ESMAT) is a technology for which we received widely differing opinions on its consumer acceptability. Several manufacturers said that the "shift shock" 61 was much higher with ESMAT than for a conventional automatic transmission, while others believed it is acceptable. (Ferrari already offers this technology.) Several manufacturers stated to the NAS committee that they believed that a five-speed ESMAT would have lower cost than a four-speed automatic transmission and provide efficiency benefits similar to those of the CVT. At this point, no consensus has emerged, but the ESMAT is an intriguing example of zero or negative cost technology. One suggestion was that the $42-\mathrm{V}$ starter/alternator system (described in Section 4.7) could make this technology more viable by reducing shift shock.

\subsection{Hybrid Vehicles}

Hybrid electric vehicles, or HEVs, are vehicles with drivetrains that combine an electric drive (including electric motor and some form of electricity storage) with a refuelable powerplant (e.g., an internal combustion engine). This combination is capable of significantly improving vehicle efficiency by:

1. Regenerative braking. The motor can be used in generator mode to brake the vehicle, generating electricity to be stored in the battery, and thus recapturing some of the energy normally lost as heat in conventional brakes.

2. Engine downsizing. The power added by the electric drive may allow the engine to be downsized, maintaining most engine operation at a higher percentage of rated torque - that is generally more efficient.

61 Shift shock refers to the jerk felt by the vehicle occupants when the transmission upshifts or downshifts gears. 
3. "Idle-off." Use of the motor as a starting motor, with the battery available to run the accessories, allows the engine to be turned off during stops (and perhaps also during braking and coasting), saving energy that would otherwise be lost during these events.

4. Electric launch. In some configurations, the motor alone can be used to accelerate from a stop, avoiding a driving mode where the engine in a conventional drivetrain would be particularly inefficient.

Toyota's Prius and Honda's Insight cars are both HEVs, the first commercial examples.

Most available analyses of gasoline-electric hybrids have focused on designs similar to the Prius, where the engine is designed to be powerful enough to meet a maximum continuous power requirement, such as for grade climbing (a moderate requirement of $55 \mathrm{mph}$ up a $6 \%$ grade requires about $30 \mathrm{~kW}$ per ton of vehicle weight [U.S. Congress 1995]), and the motor supplies the additional power needed to satisfy peak power requirements, such as for highway acceleration (requiring 0-60-mph acceleration capability of about $12 \mathrm{~s}$ would require about $20 \mathrm{~kW}$ per ton of vehicle weight, in addition to the $30 \mathrm{~kW}$ per ton supplied by the engine). Current "average" cars need 30-35 kW continuous power and $40-50 \mathrm{~kW}$ of peak power per ton of vehicle weight. In general, these types of systems can provide about $35 \%$ fuel economy improvement from the drivetrain, with another $10 \%$ possible by optimizing the engine for hybrid application. Toyota confirmed to the National Academy of Sciences committee that EEA's analysis of hybrid costs was reasonable, and the typical RPE range in volume production for a Prius-type "full hybrid" is $\$ 3,600$ for a small car $(2,750 \mathrm{lb})$ to $\$ 4,800$ for a large car $(4,250 \mathrm{lb})$.

More recently, the industry appears to have shifted some of its attention to the 42-V "mild" hybrid. The 42-V systems generally replace the existing alternator and starter motor with an integrated high-power device. Incorporating an integrated starter/alternator (ISA) between the engine and transmission allows the following:

- Engine off at idle;

- Modest amounts of launch assistance and regenerative braking;

- Improved electrical power generation efficiency;

- Downsizing or elimination of the torque converter; and

- Easier implementation of electric power steering, brakes, and water pump.

Engine off at idle (and during long decelerations) is made possible by the large capacity of the starter alternator (allowing for extremely fast engine restart) and can be particularly useful in city traffic with lots of stop-and-go driving. However, with the air conditioner on, significant battery capacity is required to keep the air-conditioner operating for periods of, say, several minutes. The air conditioner can be shut down for periods of up to a minute (depending on 
ambient conditions) before the interior temperature starts to climb significantly, so that most typical stops at intersections can be accommodated without having to restart the engine.

Launch assistance and regenerative braking are possible because of the direct coupling of the ISA to the engine and transmission. Of course, the extent of these is limited by the capacity of the ISA, and the amount of energy delivered or saved is modest. The ISA is also much more efficient than the low-cost alternator used now (over $85 \%$ relative to the current $60 \%-65 \%$ ), so that modest benefits in fuel consumption result at the same electrical load.

Elimination of the torque converter (or downsizing) is possible because the ISA can provide some additional torque at low engine speed, and "shift shock" can be electrically dampened. While elimination of the torque converter maximizes fuel economy, it is not yet clear if the electrical system can function as smoothly as a hydraulic system.

Incorporating all of these features can provide an 8-9\% benefit in fuel economy, with a very modest weight penalty. Most of the benefit (4-5\%) comes from the engine-off feature. In addition, the $42-\mathrm{V}$ system may enable cheaper electric power steering and makes EPS applicable for large vehicles where the power demand would be too large for a $12-\mathrm{V}$ system. Typically, the ISA size is a function of vehicle weight, with $6 \mathrm{~kW}$ per ton of vehicle weight a typical target power level. Maximum power ratings cannot exceed 10-12 kW to keep cost low.

The 42-V system can also enable a number of features that add hedonic value, such as instant winter heat, quick clearance of windshield ice, and side window defrosting. Four-wheelsteering systems in large vehicles are also made possible for relatively low cost. In addition, the ISA may make it possible to substitute a four-cylinder engine for a V-6 with no loss in noise, vibration, and harshness (NVH) by employing electrical damping of torque pulsations. Also, $42-\mathrm{V}$ systems may enable the use of advanced safety systems that integrate brake-by-wire and steering control to prevent rollover. In fact, much of the current activity on $42-\mathrm{V}$ systems is not for its fuel economy benefit, but for the other potential attribute enhancements.

The cost of a 42-V system in the near term will be relatively high because of the need for a dual-voltage (12/42) system that will allow the vehicle to be jump-started with a conventional battery. By 2015, it is anticipated that adequate 42-V infrastructure (in terms of light bulbs, starting aids, etc.) will exist to allow transition to a single voltage system. The entire $42-\mathrm{V}$ system is expected to add about $\$ 1,000$ in cost to a typical 3,300-lb midsized car in the near term (2005), for a RPE of about $\$ 1,600$. By 2015, expected cost reductions in motor, battery, and control electronics, plus savings from elimination of the $12-\mathrm{V}$ system, are expected to reduce system cost to under $\$ 700$, for an RPE of about $\$ 1,050$. This information was confirmed by several suppliers and two auto manufacturers; only one auto manufacturer projected much higher costs, even in the long term.

The use of 42-V systems to develop an 'on-demand' four-wheel-drive system appears to be an even more cost-effective application. In this design, an electric motor drives the rear wheels, while the engine and integrated starter/alternator drive the front wheels. Of course, power to the rear wheels is limited to the maximum of motor power (about 10-12 kW), and so the system serves only as a limited-function four-wheel-drive system. The system allows elimination of the 
drive shafts, transfer case, and center differential in a conventional four-wheel-drive system. These cost savings can more than offset the cost of the extra electric motor and controller. GM has unveiled such a system (called the ParadiGM) for production in 2003 and claims a $20 \%$ fuel economy benefit over a conventional four-wheel-drive system. While detailed technical specifications are not yet available, a preliminary estimate of RPE is that it is 50\% higher than that of the two-wheel-drive system detailed above.

The value of the hedonic benefits of $42-\mathrm{V}$ systems may be as large or larger than the value of the fuel economy benefit and could be an important consideration in the overall system costbenefit. On the other hand, the need for battery replacement and the cost of the battery are major open issues. Some Ni-MH battery manufacturers have claimed that the battery could last the life of the car, but lead-acid batteries will need replacement at least every four to five years.

\subsection{Fuel Economy Impact of Technology "Bundles"}

Technology cannot be considered singly, but only in terms of "bundles" of technologies adopted in future vehicles. The fuel consumption equations in Appendix B provide clear insights into the nature of technology additivity and synergy. Reductions in body forces of weight, drag, and rolling resistance are generally additive in their effects for similar proportional reductions in all three variables. Changes in cycle brake-specific fuel consumption (bsfc), drivetrain efficiency, and net changes in body forces have multiplicative synergy. However, technologies that change pumping loss do not produce additive benefits, nor do technologies that change friction loss. Hence, benefits of VVT or VVTL are not fully additive with benefits from five-speed automatic transmissions, CVTs, or GDI. We estimate the non-additivity effects from published data on technology combinations or simulations of the synergistic effects on pumping loss or friction.

While these synergies can be captured on average, it should be noted that individual makes/models can have significantly different results, depending on the baseline vehicle powerto-weight ratio, engine efficiency, axle ratio, and transmission shift points. For a manufacturer with many models in several market segments, under- and over-predictions will tend to cancel out in terms of a CAFE-type fleet-wide calculation. There is less assurance for manufacturers with limited markets (e.g., those that focus on high-performance vehicles). However, any general modeling approach will have limitations in properly estimating benefits for a manufacturer with only one or two product lines.

In the vehicle fuel economy estimates presented here, we have adopted a conservative approach to estimating both cost and benefit. We have not included some potentially low-cost technologies, such as the electrically shifted manual transmission or ultra-high-strength steel bodies, because the data we have obtained on these technologies are incomplete. In addition, we have not considered the potential for further improvements in technology performance, although such improvements are quite possible. Finally, we have tended to use conservative estimates for the magnitude of positive synergies (that is, where paired technologies yield improvements that are higher than would be expected by examining the technologies singly).

We used the lumped parameter model to estimate the fuel economy of the two example

vehicles, a midsize car and a sports utility vehicle, with several different technology packages. In 
each case, we selected a 2000 baseline vehicle with known characteristics as the starting point and added different bundles of technologies representing different levels of cost-effectiveness, keeping vehicle size and performance constant.

Table 4-5 shows the evolution of a midsize car (usually the most popular example in fuel economy studies), starting from the characteristics of the MY2000 Ford Taurus with a 200-hp DOHC V-6. The first scenario, the moderate technology (2015 MODT) case, involves a modest weight reduction of about five percent from improved packaging and more extensive use of highstrength low-allow steel (HSLA) and a 10\% reduction in drag and rolling resistance relative to the 2000 vehicle. Note that the MODT vehicle's fuel economy should not be taken as an indicator of the fleet fuel economy since the mix of vehicles and engine options sold can vary independently. For example, if fuel prices are very low and incomes rise significantly by 2015 , then more customers will opt for higher performance and more luxury. To keep performance constant, ${ }^{62}$ we downsize the V-6 from $3.0 \mathrm{~L}$ to $2.7 \mathrm{~L}$ and incorporate variable-valve lift and timing. ${ }^{63}$ A fuel economy improvement of $16.6 \%$ is observed for this car, and it represents a case where only the most cost-effective technology is used. A 2015 "high-technology without hybrid" (2015 HT) case using higher levels of drag, weight, and rolling resistance reduction is also modeled. The reduced weight allows an engine size reduction of such magnitude that a fourcylinder can be used instead of a V-6 (although the four cylinder will not be as smooth as a V-6). A net fuel economy increase of $32.5 \%$ is forecast for this bundle.

The last two columns examine the influence of two popular hybrid technology designs, starting from the 2015 HT case. The 300-V system (2015 HT 300-V hybrid) is a hybrid with a Toyota Prius-type drivetrain with an all-aluminum body, and fuel economy is increased almost $80 \%$ relative to the 2000 base vehicle. The $42-\mathrm{V}$ mild hybrid version $(2015 \mathrm{HT}+42 \mathrm{~V})$ has fuel economy $43 \%$ better than the 2000 vehicle, but the cost increment is only about half that of the "full hybrid." These example vehicles are provided only to illustrate technology effects, not to suggest the order of technology appearance. In reality, the 42-V integrated starter-alternator mild hybrid system would likely be more cost-effective than the all-aluminum body and likely would be introduced first.

The last row shows the lifetime fuel savings, assuming a 150,000-mi vehicle life. Although future fuel savings will be discounted by a vehicle purchaser, the 2015 MODT ( 17\% fuel economy improvement) and 2015 HT ( $32 \%$ improvement) appear to be attractive at moderate gasoline prices - if vehicle purchasers pay attention to fuel savings over the full life of the car. The more fuel-efficient packages, especially the full hybrid, are not likely to be viewed as costeffective, although the 42-V system iRPE may be misleadingly high — it ignores the possibility that such systems may be adopted for reasons other than fuel economy.

62 Defined as holding constant the ratio of torque at 2,000 rpm to weight.

63 The peak horsepower-to-weight ratio actually increases because of the nature of VVLT-equipped engines. 
Table 4-5. Hypothetical 2015 Midsize Car — Constant Attribute Case

\begin{tabular}{|c|c|c|c|c|c|}
\hline Parameter & $\begin{array}{l}2000 \\
\text { Base }\end{array}$ & 2015 MODT & 2015 HT & $\begin{array}{c}2015 \text { HT 300- } \\
\text { V Hybrid }\end{array}$ & $2015 \mathrm{HT}+42 \mathrm{~V}$ \\
\hline Weight (lb) & 3,320 & 3,295 & 2,790 & 2,910 & 2,830 \\
\hline Body & Steel & HSLA-intensive & $\begin{array}{l}\text { Aluminum- } \\
\text { intensive }\end{array}$ & $\begin{array}{l}\text { Aluminum- } \\
\text { intensive }\end{array}$ & $\begin{array}{l}\text { Aluminum- } \\
\text { intensive }\end{array}$ \\
\hline $\mathrm{Cd}$ & 0.31 & 0.28 & 0.25 & 0.25 & 0.25 \\
\hline $\mathrm{C}_{\mathrm{R}}$ & 0.0095 & 0.0085 & 0.0075 & 0.0075 & 0.0075 \\
\hline Engine & 3.0 L V-6 & 2.7 L V-6 & $2.3 \mathrm{~L} \mathrm{I-4}$ & $1.6 \mathrm{~L} \mathrm{I-4}$ & 2.2 L I-4 \\
\hline Valves & 4 & $4 \mathrm{w} / \mathrm{VVLT}$ & $4 \mathrm{w} / \mathrm{VVLT}$ & $4 \mathrm{w} / \mathrm{VVLT}$ & $4 \mathrm{w} / \mathrm{VVLT}$ \\
\hline $\mathrm{HP}$ & 200 & 200 & 160 & 100 & 145 \\
\hline Transmission & 4 - Auto & 5-Auto & CVT & ECVT & CVT \\
\hline Motor & None & None & None & $30 \mathrm{~kW}$ & $7.5 \mathrm{~kW}$ \\
\hline Power Steering & Hydraulic & Hydraulic & Hydraulic & Electric & Electric \\
\hline $\mathrm{F} / \mathrm{E}(\mathrm{mpg})$ & 26.5 & 30.9 & 35.1 & 47.4 & 37.9 \\
\hline Hedonic Attributes & Base & No change & Some loss of NVH & $\begin{array}{l}\text { Improved NVH, } \\
\text { quick heat }\end{array}$ & $\begin{array}{l}\text { Improved NVH, } \\
\text { quick heat }\end{array}$ \\
\hline IRPE (\$) & Base & 585 & 1,244 & 4,870 & 2,504 \\
\hline $\begin{array}{l}\text { Lifetime fuel } \\
\text { savings (gal) }\end{array}$ & Base & 948 & 1,631 & 2,936 & 2,003 \\
\hline
\end{tabular}

Includes fuel economy penalty for safety equipment and Tier 2 emission (estimated at about $4 \%$ ). Improvements common to all 2015 cases are engine friction reduction by $15 \%$, low-friction lubricants, and accessory improvements ( $\mathrm{x} / \mathrm{EPS}$ ).

Vehicle lifetime $=150,000$ miles, assumed on-road degradation factor 0.85 .

Similar results are shown for the SUV model in Table 4-6. These vehicles are often used for towing, and engine downsizing results in some loss of towing capacity. The Prius-type hybrid has limited continuous power capability and is not suited for towing. Alternatively, a diesel engine could be used to provide very similar fuel economy (on a volumetric, not energy, basis) as the full hybrid and can actually improve towing capability because of the very high low-rpm torque capability. For the SUV, low-speed off-road performance can also suffer with hybrids, but it should be recognized that most SUVs sold today never leave the pavement. Still, the diesel engine may be a preferred solution for buyers who require the towing and serious off-road capabilities.

Comparing the incremental RPEs and lifetime fuel savings, the results appear similar to those for the midsize cars - the 2015 MODT (21\% fuel economy improvement) and 2015 HT (40\% improvement) appear attractive, assuming purchaser consideration of lifetime fuel savings. The 2015 full $(300 \mathrm{~V})$ hybrid probably would not be considered economically attractive. The 2015 HT on-demand four-wheel-drive hybrid vehicle (modeled after the GM ParadiGM system) is much closer to a break-even proposition in terms of fuel savings. This is because the base vehicle (nonhybrid) has much lower fuel economy than a two-wheel-drive vehicle, and the ratio of fuel economy benefit to cost (in percentage terms) is also better than for a two-wheel-drive hybrid. Even if costs exceed fuel savings, the value of other hedonic benefits (such as instant winter heat) may be enough to result in significant market penetration for this technology. 
Table 4-6. Hypothetical 2015 Compact Four-Wheel-Drive SUV — Constant Attribute Case

\begin{tabular}{|c|c|c|c|c|c|}
\hline Parameter & $\begin{array}{l}2000 \\
\text { Base }\end{array}$ & 2015 MODT & 2015 HT & $\begin{array}{c}2015 \text { HT 300-V } \\
\text { Hybrid }\end{array}$ & $\begin{array}{l}2015 \text { HT On- } \\
\text { Demand four- } \\
\text { wheel-drive }\end{array}$ \\
\hline Weight (lb) & 4,150 & 3,940 & 3,360 & 3,500 & 3,420 \\
\hline Body & $\begin{array}{l}\text { Steel } \\
\text { body-on- } \\
\text { frame }\end{array}$ & $\begin{array}{l}\text { HSLA-intensive } \\
\text { (unibody) }\end{array}$ & $\begin{array}{l}\text { Aluminum-intensive } \\
\text { (space frame) }\end{array}$ & $\begin{array}{l}\text { Aluminum-intensive } \\
\text { (space frame) }\end{array}$ & $\begin{array}{l}\text { Aluminum- } \\
\text { intensive (space } \\
\text { frame) }\end{array}$ \\
\hline $\mathrm{Cd}$ & 0.45 & 0.41 & 0.38 & 0.38 & 0.38 \\
\hline $\mathrm{C}_{\mathrm{R}}$ & 0.0105 & 0.0095 & 0.0085 & 0.0085 & 0.0085 \\
\hline Engine & 4.0 L V-6 & 3.5 L V-6 & 2.7 L V-6 & 2.2 L I-4 & 2.5 L V-6 \\
\hline Valves & 2 & 4 w/VVT & $4 \mathrm{w} / \mathrm{VVLT}$ & 4 w/VVT & $4 \mathrm{w} / \mathrm{VVLT}$ \\
\hline $\mathrm{HP}$ & 205 & 220 & 200 & 135 & 175 \\
\hline Transmission & 4-auto & 5-auto & 5-auto & ECVT & CVT \\
\hline Motor & None & None & None & 40 kW (300 V) & $2 \times 10 \mathrm{~kW}(42 \mathrm{~V})$ \\
\hline Power Steering & Hydraulic & Hydraulic & Hydraulic & Electric & Electric (42 V) \\
\hline F/E (mpg) & 20.3 & 24.5 & 28.4 & 38.9 & 34.0 \\
\hline Hedonic Attributes & Base & No change & $\begin{array}{l}\text { Some loss of towing } \\
\text { capacity }\end{array}$ & $\begin{array}{l}\text { Serious loss of towing } \\
\text { and off-road } \\
\text { capability }\end{array}$ & $\begin{array}{l}\text { Some loss of } \\
\text { towing and off- } \\
\text { road capability }\end{array}$ \\
\hline IRPE (\$) & Base & 665 & 2,063 & 5,830 & 3,595 \\
\hline $\begin{array}{l}\text { Lifetime fuel } \\
\text { savings (gal) }\end{array}$ & Base & 1,490 & 2,479 & 4,156 & 3,503 \\
\hline
\end{tabular}

Includes fuel economy penalty for safety equipment and Tier 2 emission (estimated at about $3 \%$ ). Improvements common to all 2015 cases are engine friction reduction by $15 \%$, low-friction lubricants, and accessory improvements (x/EPS).

Vehicle lifetime $=150,000$ miles, assumed on-road degradation factor 0.85 .

\subsection{References}

AISI: American Iron and Steel Institute

AISI, 1998, Ultra-light Steel Body Final Report, Second Edition, Washington, D.C., May.

Audi, 2001, presentation to the National Academy of Sciences Committee, April.

Austin, T., et al., 1999, Alternative and Future Technologies for Reducing Greenhouse Gas Emissions for Road Vehicles and Fuels, NR Canada, June.

Automotive News, 2001. May $28^{\text {th }}$ issue.

EEA: Energy and Environmental Analysis, Inc.

EEA, 1998, Assessment of the Cost of Body-in-White and Interior Components for an Electric Vehicle, report to CARB, March.

Ford Motor Company, 1997, Presentation at the DOE Contractor's Coordination Conference, Oct.

National Academy of Sciences, data submitted to the NAS by manufacturers/suppliers. 
National Academy of Sciences, information provided by electrical system suppliers to the committee, April.

Porsche, 2001, Presentation to the NAS Committee on the results of the ULSAB Advanced Vehicle Concepts Study, April.

U.S. Congress, 1995, Office of Technology Assessment, Advanced Automotive Technology: Visions of a Super-Efficient Family Car, OTA-ETI-638, Washington, D.C., U.S. Government Printing Office, Sept. 


\section{Section 5 Developing and Evaluating Alternative Voluntary Fuel Economy Standards}

If voluntary increases in light-duty fuel economy are negotiated by the auto industry and the U.S. government, maximum attention is likely to be paid to the fleet fuel economy target or percentage increase proposed. However, the form or structure of a voluntary standard - the way in which the fuel economy increase is allocated among individual companies - will be a crucial factor in the likelihood of success and economic impact of the standard and the extent to which the standard distorts the light-duty vehicle market.

A new fuel economy standard may bring about improved fuel economy in various ways, by:

1. Encouraging greater use of the fuel-efficient technology as described in Section 4;

2. Promoting design trade-offs that favor fuel economy over other attributes (e.g., horsepower); or

3. Inducing sales mix shifts from less- to more-efficient vehicle classes (e.g., from larger to smaller vehicles, or from light trucks to passenger cars).

Changing the form of a standard may lead to different emphases on each of these three ways to improve fuel economy. And because today's vehicle manufacturers sell different mixes of vehicles and may emphasize different vehicle attributes, a new form would have a different pattern of impacts on individual manufacturers. Finally, a new fuel economy standard will achieve higher economic efficiency to the extent that the marginal cost of saving the next gallon of gasoline is relatively equal across all vehicles - and different forms of standards may deviate from the ideal "equal marginal cost" in different degrees. In other words, changing the form of a standard can lead to different emphases on ways of improving fuel economy, different impacts on the various manufacturers, and different levels of economic efficiency - a good reason to examine alternative forms quite carefully.

This section examines how alternative structures can be developed and evaluates a few of these structures by examining the individual company fuel economy targets they create, given a fleet fuel economy improvement target of 20\%. Section 6 takes this evaluation a considerable step further for a few of these alternative structures by estimating their impact on vehicle prices and fuel costs, for fleet targets of $20 \%$ and $33 \%$ improvement. The evaluation is conducted on both a fleetwide basis and an individual company basis by using databases assembled by the National Highway Traffic Safety Administration and expanded by Energy and Environmental Analysis, Inc. The analysis in Section 5 was begun well before the analysis in Section 6 and uses 1999 fleet data; the analysis in Section 6 uses 2000 fleet data. 


\subsection{The Current CAFE Structure}

The current CAFE structure has been strongly criticized for a series of perceived shortcomings:

1. "One size fits all." The CAFE regulations apply the same fuel economy targets to all automakers, regardless of their fleet characteristics. Thus, automakers that focused primarily on small cars and light trucks (at the time the standards were put into place, this included the Japanese automakers) faced the same 27.5/20.7-mpg standard as automakers producing a full lineup of car and truck sizes (i.e., the U.S.-based automakers) or primarily larger, performance-oriented models (e.g., European automakers, such as Mercedes, Porsche, and BMW). The result was that the small-car manufacturers had to do little or nothing to meet the standards and, in fact, were free to "upscale" their product lines - thereby diminishing the net fuel savings from the standard. The full-line manufacturers met the standards only through significant efforts including, they claim, underpricing small cars in an effort to achieve mix shifts among their customers, and the performance-oriented automakers largely failed to meet the standards and paid fines.

2. Import vs. domestic split. The regulations split company automobile fleets into import and domestic fleets, each of which has to meet the 27.5 mpg standard. ${ }^{64}$ The original purpose of dividing the fleet was to preserve U.S. jobs by preventing U.S. manufacturers from simply importing large quantities of small cars to balance their domestically produced large cars, avoiding the need to manufacture small cars in the United States. This provision did force U.S. automakers to produce small cars, but later it had some perverse effects on U.S. jobs. Ford, for example, shifted its large Crown Victoria to its import fleet for a period by increasing its content of imported parts, thereby boosting the fuel economy of its domestic fleet (without actually changing its overall fleet fuel economy). The National Academy panel has recommended shelving the domestic/import distinction (NRC 2002); the United Autoworkers Union, on the other hand, still vigorously supports the distinction.

3. Cars vs. light trucks split. The regulations also separated cars from light trucks (vans, pickups, and sports-utility vehicles), requiring a $27.5 \mathrm{mpg}$ standard for cars while assigning the task of setting a light-truck standard to the National Highway Traffic Safety Administration (NHTSA). The current light-truck standard is $20.7 \mathrm{mpg}$. At the time the standard was first set, light trucks made up a relatively small percentage of the total light-duty fleet (less than 20\%) and were thought to be used primarily as work vehicles. In the intervening years, the advent of the minivan and sports-utility vehicle, coupled with changing consumer tastes, have yielded a radical shift in the light-truck market — light

64 To be a part of the domestic auto fleet, a vehicle must have $75 \%$ of its content domestic, with additional rules governing what constituted "content" and "domestic." The light-truck fleets are not split this way. 
trucks now make up nearly $50 \%$ of light-duty sales, and light trucks are used overwhelmingly as passenger vehicles. The shift in sales has dragged down overall U.S. light-duty fleet fuel economy, from a peak of $25.9 \mathrm{mpg}$ (unadjusted) in 1987 to a year 2001 level of $23.9 \mathrm{mpg}$.

\subsection{Criteria for a New Structure}

In a 1986 paper (McNutt and Patterson 1986), Barry McNutt and Philip Patterson of the U.S. Department of Energy defined a set of criteria for a new CAFE standard that may serve as a useful starting point for defining criteria for a Voluntary Standard:

1. The standards should be set on a basis that encourages/requires improvement in vehicle fuel efficiency through technology improvement and not by denying consumers desired vehicle attributes.

2. The standards should not hold manufacturers responsible for factors that are beyond their direct control (such as size mix shift).

3. The standards should not discriminate arbitrarily between cars and light trucks but should reflect their real similarities and differences.

4. There should be more equal improvements required from manufacturers of different types of product lines (e.g., full vs. limited product line).

5. The standards should recognize the international nature of auto manufacturing and not draw artificial distinctions among vehicles produced in different countries by the same manufacturer.

6. The form of the standards should be consistent with an energy policy that focuses on improved economic efficiency and not only reduced oil use.

7. The administrative difficulties should not be substantially greater than the current program.

This list of criteria will not be uncontroversial. In particular, some critics of market shifts toward larger light trucks (especially SUVs) and ever-more-powerful engines may be uncomfortable with both 1 and 2; they might very well want restrictions on vehicle size and engine horsepower. Also, although Japanese automakers (and others) testifying to the National Academy of Sciences panel on CAFE standards advocated dropping the domestic/import split (criterion 5), the United Auto Workers were strongly against such a change. On the other hand, criteria 4 and 6 both argue for greater attention to economic efficiency, a crucial factor in a potential agreement that, if designed poorly, could have strong economic repercussions on an industry that is critical to the U.S. economy.

An important point about economic efficiency is that maximum efficiency will be achieved when, at the end of the process of designing their new fleets, each automaker has the same 
marginal cost for the last gallon of gasoline saved by the redesign ${ }^{65}$. To understand why this is so, note that if the marginal costs were not identical, it would have been less expensive for the company with lower marginal costs to have done more and the company with higher marginal costs to have done less to save the same total amount of gasoline.

\subsection{Developing an Alternative Fuel Economy Target Structure}

A number of alternative structures for fuel economy regulations - which can be used for a voluntary standard, as well — have been proposed. These structures include a "UPI," which requires each company's fleet to attain a fixed percentage increase from its fleet fuel economy in a base year (proposed in 1989 by Senator Richard Bryan in S.279); weight-class standards that establish separate targets for all vehicles in each inertia weight class and set each company's fleet target according to a sales-weighted harmonic average of the targets for each of its vehicles (similar to regulations established by Japan in recent legislation); similar standards that establish vehicle targets based on a continuous curve of fuel economy vs. weight; "volume-average standards" that establish targets based on the interior volume of vehicles, as discussed by McNutt and Patterson (McNutt and Patterson 1986); and standards based on multiple vehicle characteristics, such as curb weight, torque, and interior volume (proposed in 1990 by MercedesBenz, BMW, and Porsche as an alternative to S.279).

\subsubsection{Uniform Percentage Increase}

As noted above, a UPI standard demands that each automaker achieve a fleet target that is a fixed percentage higher than its fleet fuel economy in a base year (e.g., 2000). In other words, if company A had a $25 \mathrm{mpg}$ average and company B a $33 \mathrm{mpg}$ average fuel economy in the base year, and a UPI standard demanded a $20 \%$ increase by 2010 , A would have to achieve $30 \mathrm{mpg}$ $(1.20 \times 25)$, and B would have to achieve $39.6 \mathrm{mpg}(1.20 \times 33)$ by 2010 . The original S.279 language modified this structure by setting a floor and ceiling fuel economy level for the target year - a company with a very low base-year mpg level would have to meet the floor-level target, even if this demanded a percentage increase higher than the UPI level, and a company with exceptionally high base-year mpg would have its target limited to the ceiling level, even though this demanded less than the UPI percentage increase.

Supporters of UPI proposals have argued that they are inherently fairer than the existing CAFE system because they take into account differences in the mix of vehicles sold by the different automakers. According to this view, the primary reason for differences in fleet fuel economy among competing automakers is differences in the type of vehicles they sell, not inherent differences in technical efficiency.

Critics of the UPI proposals, including the National Academy of Sciences (NRC 2002), argue that the UPI (1) rewards companies that have failed to use the best designs and technologies (and thus have low base-year fuel economy levels) with a low mpg target and a complete array of unused technologies to achieve that target and (2) penalizes companies at the leading edge of fuel economy design and technology with high targets coupled with less

65 Assuming that each automaker has made economically optimal choices within its own fleet. 
technological "headroom" to improve their fleets (since they have already used many of the available technologies). The same critics argue that UPI standards are anti-competitive; that by locking in each company's targets according to its fuel economy — and vehicle mix — in a particular base year, they will severely restrict the ability of companies to move into upscale markets in future years. And they further argue that the precedent set by a UPI standard would provide a strong negative incentive against companies choosing to beat rather than to just meet the standards, because future increases in the standard would then penalize them with a higher target based on their superior fuel economy performance.

Representatives of the U.S. companies find these arguments somewhat ironic, because they believe the current system has hamstrung their own companies while leaving their competitors free to move upscale into the more profitable large-car markets. They further complain that, while their companies have been forced by CAFE standards to improve their fleet fuel economies by large amounts, the fleet fuel economies of Japanese companies' have improved little and, in some cases, have dropped.

Whatever has occurred in the past, the relevant question for this analysis is whether the various arguments are correct for a future standard based on UPI. We must basically agree with the arguments that a UPI standard will tend to provide an incentive to avoid doing more than just meeting the standard and further will tend to punish companies that seek to move "upscale." For example, Japanese companies that have entered the light-truck market primarily with relatively small vehicles, with high CAFE values as a result, would have great difficulty entering the fullsize pickup and SUV markets because their high baseline mpg would give them a high target mpg.

The argument that UPI rewards "laggards" and punishes technology leaders is theoretically correct, but gauging its relevance in the real world is more complicated. The question boils down to this: What accounts for the differences in fuel economy among competing automakers? Is it largely the mix of different types of vehicles in their fleets? Their efficiency design and use of advanced technologies? Their focus on power and luxury features? The severest critics of UPI imply that differences in design and technology play a large role in the company-to-company fuel economy differences; UPI proponents claim that differences in market mix play the dominant role, with differences in technology and design playing an insignificant role.

Although this is an oversimplification, a UPI standard would be at its fairest if, in the base year, there was sufficient similarity among various company fleets that their level of usage of fuel economy technology and overall design was quite similar and they had achieved very similar levels of technical efficiency (i.e., fuel efficiency adjusted to account for differences in market segments). ${ }^{66}$ In fact, as noted above, those who argue that UPI is unfair make precisely the argument that automakers have not adopted similar levels of technology and efficiency design, and that this is a primary cause of the existing differences in fleet fuel economy. How can we show whether this argument is correct or not?

66 This term is necessarily imprecise, because many variables influence fuel efficiency — size and weight, vehicle purpose as it influences body shape, acceleration performance, and so forth. 
One simple (though limited) measure of technical efficiency is ton-mpg; that is, fuel economy normalized to vehicle curb weight. Ton-mpg measures how efficient a vehicle is at moving a pound of its own weight. It is an imperfect measure of technical efficiency because it says nothing about how much weight a vehicle can carry, how much it can tow, how well it can perform, or how "weight-efficient" its design is. However, ton-mpg is a much better measure of technical efficiency than mpg, which ignores all of these factors as well as vehicle weight.

Figure 5-1 shows the 2000 sales-weighted values of ton-mpg for each automaker in the U.S. fleet (data from U.S. EPA).

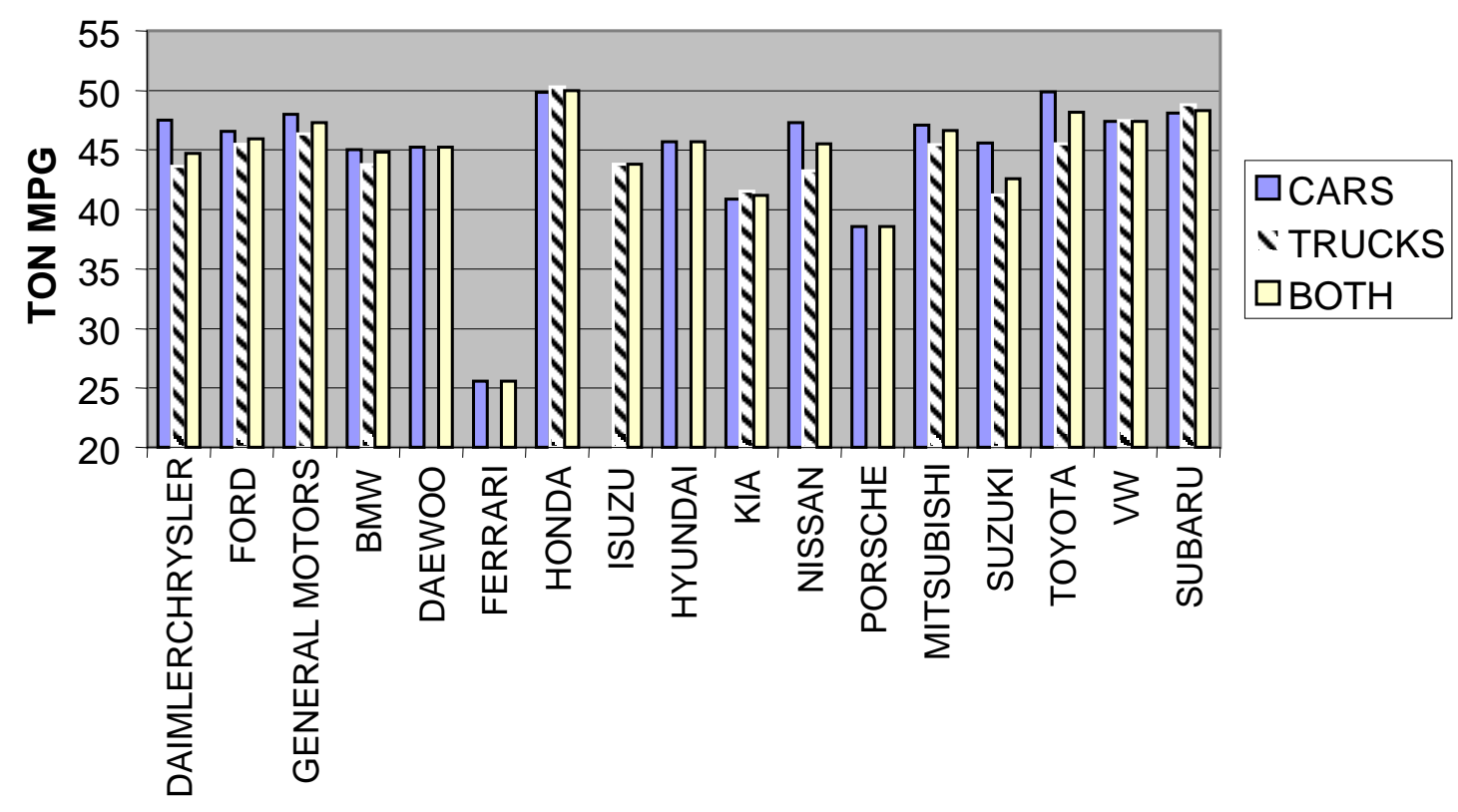

Figure 5-1. Ton-mpg for the MY 2000 U.S. Fleet

Figure 5-1 shows that there are moderate differences in fleet ton-mpg values among the major automakers (the truly large differences are reserved for Porsche and, especially, Ferrari, both specializing in high-powered luxury vehicles, and to a lesser extent for Kia and Suzuki, perhaps because of lagging technology). Not surprisingly, Honda and Toyota, both of whom have been vociferously opposed to UPI, ${ }^{67}$ have the highest fleet ton-mpg values among the larger automakers, although General Motors and Volkswagen are not far behind Toyota. A comparison of the ton-mpg values of the individual automakers lends some support to both positions on UPI. On the one hand, market positioning alone does not explain differences among the companies in fleet fuel economy levels, supporting the argument by Japanese automakers that there are real differences in technical efficiency among competing automakers. On the other hand, the differences in ton-mpg are smaller, on a percentage basis, than differences in fleet fuel economy, implying that differences in fleet mix are an important factor in the differences in fuel economy.

67 Honda and Toyota, 2001, presentation to the National Academy of Sciences. 


\subsubsection{Standards Based on Vehicle Attributes}

The other types of standards listed above set vehicle targets based on individual vehicle characteristics, such as weight, size, horsepower, or other characteristics associated with fuel economy. Under such standards, vehicles that are larger in size, that weigh more, or that carry more cargo or tow more weight would not be required to attain as high a level of fuel economy as smaller, lighter, or less-powerful vehicles. The general concept behind such standards is that consumers should be able to choose the type of vehicle they want, but that the vehicle should be as efficient as others in the fleet for the type of vehicle it is.

This general concept of an "attribute-based standard" tends to comply with several of the criteria discussed in Section 5.2, but it will not be easy to select a specific set of attributes on which to base a standard. For example, what if we chose to base a fuel economy standard on vehicle carrying capacity - if it can haul twice as much, should we not expect it to use twice as much fuel? One problem with this choice is that carrying capacity may not reflect very well how a vehicle is actually used - the occupancy rate of all light-duty vehicles is very close to 1.0, and it is not clear at all that larger vehicles carry more people most of the time. Another problem is that it may be difficult to define carrying capacity for the purpose of standard setting without rewarding vehicle attributes with less-positive connotations. For example, horsepower is one component of carrying capacity, since high power is needed for a vehicle carrying a heavy load to deliver acceptable performance. However, high power is also associated with vehicles with rapid acceleration and high top speeds, so one would want to be careful that a standard that rewards high carrying capacity does not also reward high-performance vehicles.

We explored a few different attribute-based standards, with the goal of finding an attribute (or set of attributes) that is related to fuel economy and that is clearly associated with such positive values as vehicle size, carrying capacity, and safety. We also focused on continuous functions, rather than sets of vehicle "class" targets, to avoid the "edge effects" identified in the analysis of the Japanese inertia weight class standards (see Section 2.3.1).

We used a database of the 1999 U.S. car and light truck fleet, assembled by Energy and Environmental Analysis, Inc., to examine a number of vehicle characteristics as potential metrics for an attribute-based standard. Unfortunately, light trucks come in multiple configurations that have different curb weights, wheelbase, overall length, and so forth, and the individual data points for truck lines do not identify clearly which configuration is attached to which wheelbase, for example. As a result, the truck examination is limited to evaluating fuel economy vs. curb weight or inertia weight; no credible evaluation of functions of wheelbase, vehicle length, or measures of interior volume or truck bed dimensions could be made with this data base (or any other that we had access to).

We want to stress that our goal is to examine some promising options for a restructuring of fuel economy standards - and not to define a specific proposal for a standard. We believe that such a proposal should follow from a dialog and cooperative analysis between government and industry. 


\subsubsection{Weight-Based Standard}

A promising type of a attribute-based standard is one based on either curb weight or vehicle test weight. In the discussion that follows, we show one example of how this type of standard could be derived. First, Figure 5-2 shows a plot of fuel consumption (from the EPA test of fuel economy), measured as gallons of gasoline needed to drive 100 miles, versus curb weight ${ }^{68}$ for the 1999 U.S. car fleet. Although there are several outlying points, the clustered points appear to define a strong linear relationship between weight and fuel consumption. The outlying points represent vehicles that have especially high or low fuel consumption rates for their weight and are mostly high-powered sports cars (high fuel consumption) or special "high-efficiency" models (low fuel consumption), both of which have relatively low sales volumes.

Next, we draw the trendline through these points (Figure 5-3); this represents a type of industry average "fuel consumption vs. curb weight" relationship, though note that the trend line is not sales-weighted. ${ }^{69}$ The mass market vehicles in the fleet tend to lie fairly close to this trend line. In constructing an actual standard, sales-weighting might be seen as desirable since the resulting line would best represent a true fleet average. On the other hand, a non-sales-weighted line may better represent fleet potential, especially if models with very low sales volumes or with characteristics that clearly make them unsuitable for future mass market sales are eliminated from the data set. We examine the effect of removing models with low sales volumes later.

Finally, we add another line that represents a $20 \%$ improvement in fuel economy, or about a $17 \%$ reduction in fuel consumption, simultaneously filtering the data base to eliminate vehicles with sales below 10,000/year (Figure 5-4). This line could serve as a weight-based fuel consumption standard designed to achieve a $20 \%$ improvement in fleet fuel economy. Alternatively, we could repeat the last two steps with a sales-weighted trend line and a " $20 \%$ improvement line" based on it.

A more generalized form of the standard can be expressed by the formula:

fuel consumption target, gallons per 100 miles $=$

$(0.0012 \times c u r b$ weight,$l b+0.0013) /[1+$ fleet fractional improvement target $]$

68 We deliberately chose this metric to match the metric used by the recent National Research Council report on fuel economy, to make our analysis more easily comparable with theirs.

69 For this effort we used Microsoft Excel ${ }^{\mathrm{TM}}$, which does not have a sales-weighting option, for data analysis. 


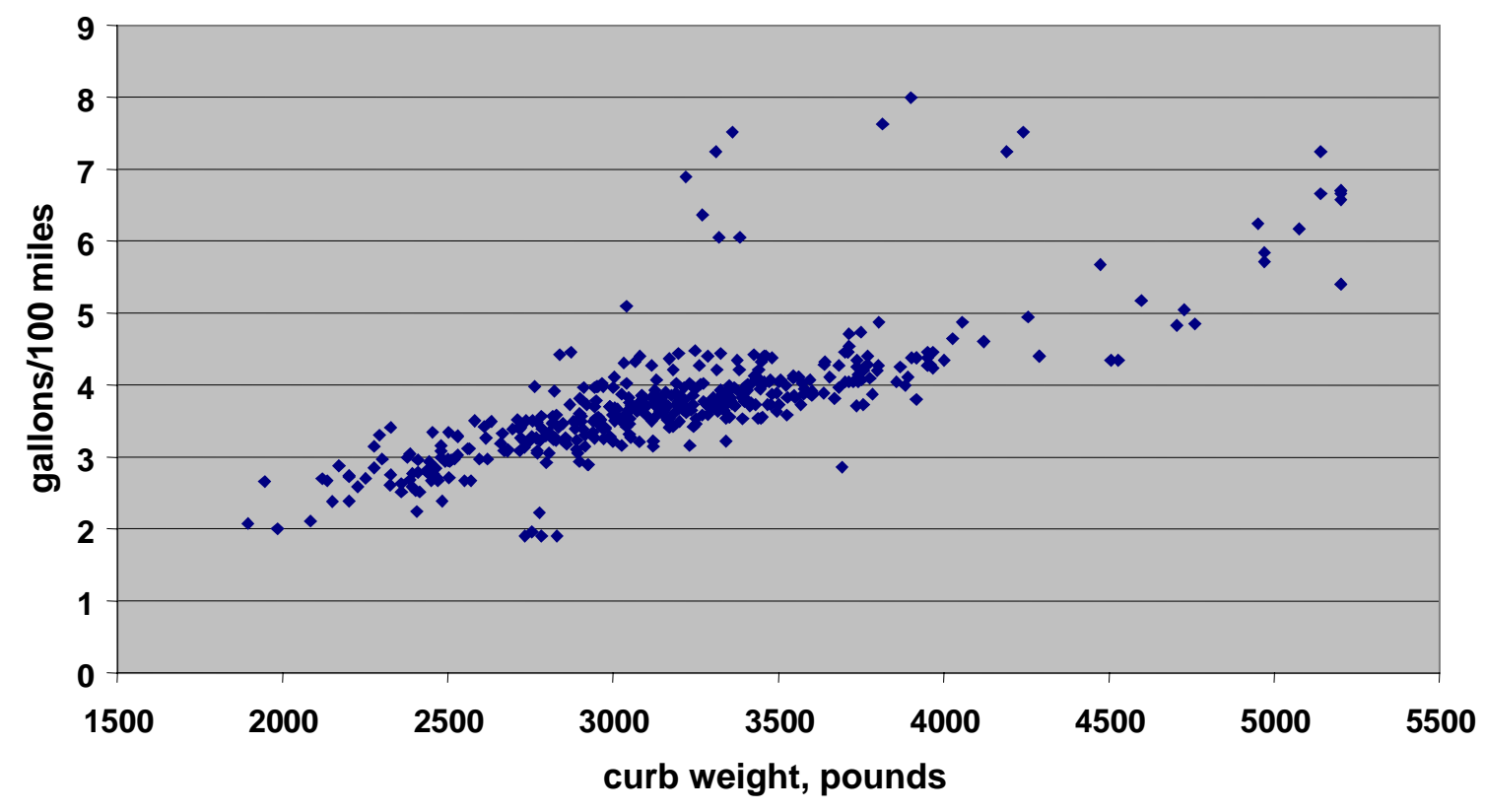

Figure 5-2. Fuel Consumption, gal/100 mi, vs. Curb Weight, All Cars, 1999

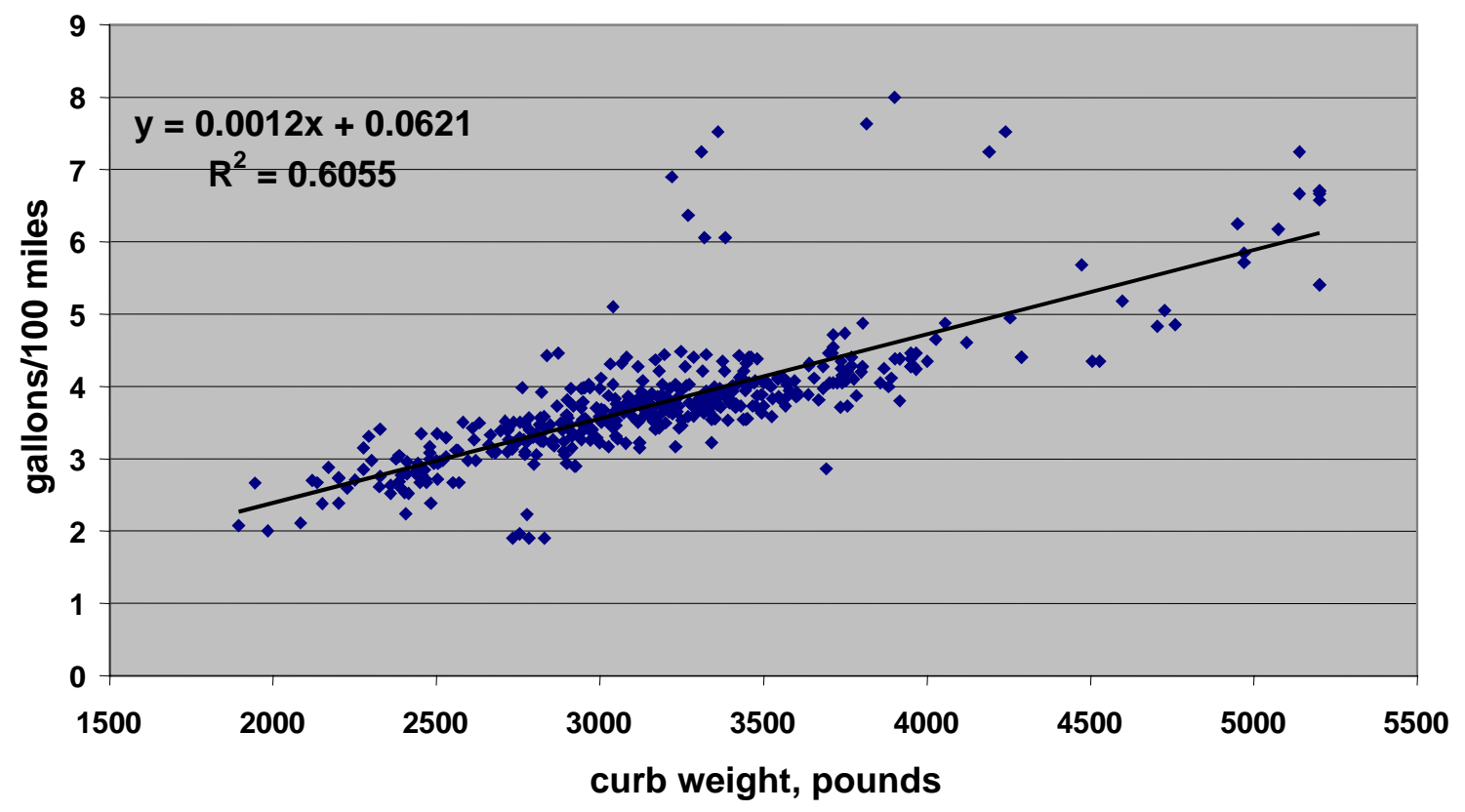

Figure 5-3. Fuel Consumption, gal/100 mi, vs. Curb Weight, with Trendline, All Cars, 1999 


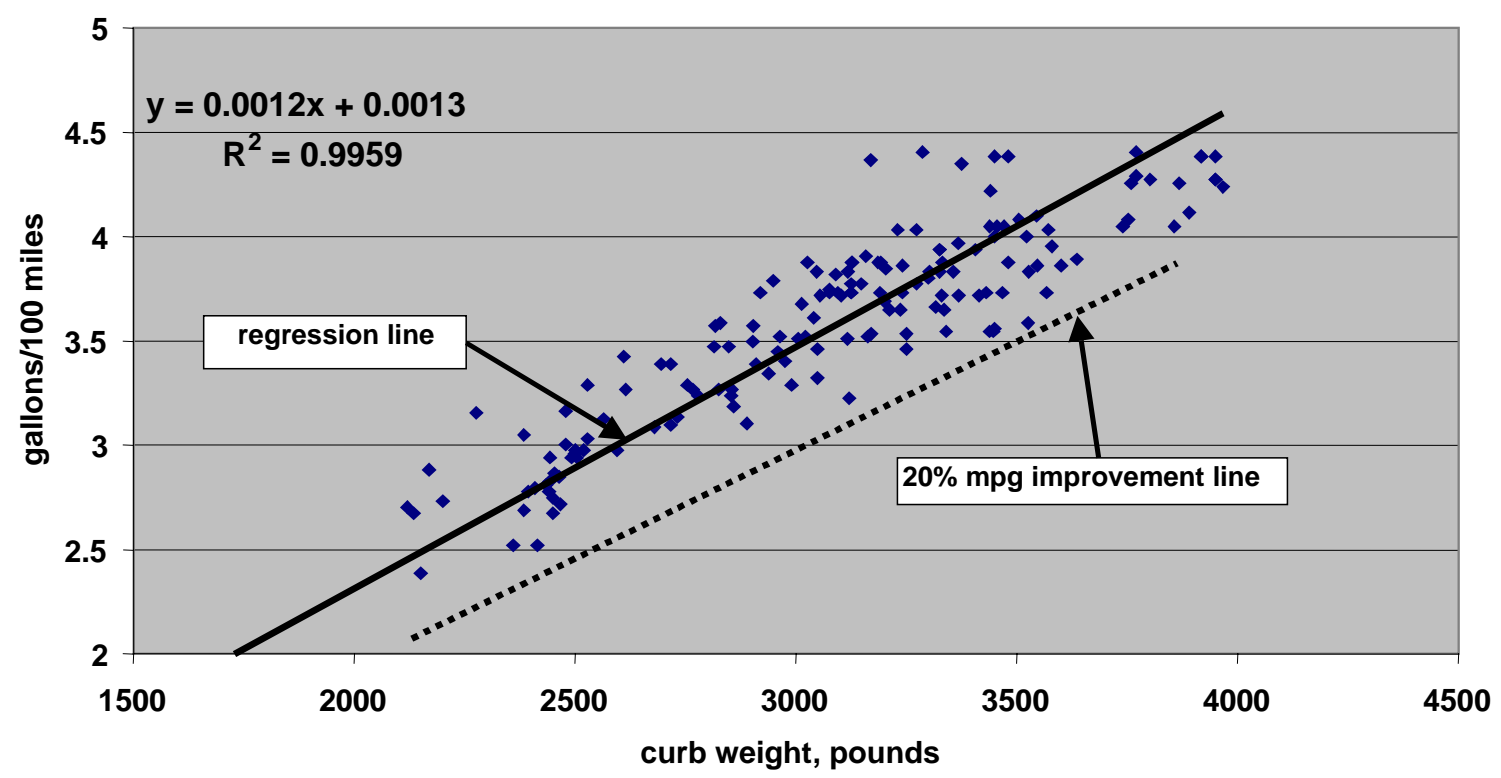

Figure 5-4. Automobile Fuel Consumption, gal/100 mi, vs. Curb Weight - Sales $>10,000$, with Regression Line and $20 \%$ mpg Improvement Line

Because the regression line was not sales-weighted, this form of the formula would not yield precisely the target fleet improvement desired, even if the weight distribution of the fleet remained unchanged. Formula (5.1a) applies a correction factor (1.039) to the target to correct for this:

fuel consumption target, gallons per 100 miles $=$

$(0.0012 \times$ curb weight,$l b+0.0013) /[(1+$ fleet fractional improvement target $) \times 1.039]$

This sample "standard" resembles the Japanese weight-class standards, except that the standard is a continuous function rather than a series of targets for individual weight classes. The standard also calls for precisely the same percentage increase in fuel economy for every weight, whereas the Japanese standards have differential percentage improvement requirements across the different classes. Note that the line can easily be redrawn to provide differential percentage improvement requirements for vehicles with different weights, either by rotating it (clockwise would yield a smaller improvement requirement for lighter cars and a larger requirement for heavier cars, providing some incentive for reducing weight) or by changing the shape and location of the line. Rotating the curve would also promote reducing vehicle size, however, because smaller vehicles (as well as lighter ones) would have more lenient improvement requirements than larger, heavier ones.

The concept we have in mind is that each automaker would obtain its own unique fleet fuel economy target by first obtaining targets for each model in its fleet from the curve (or from formula 5.1) and then calculating the sales-weighted harmonic average of these targets. Automakers would have complete flexibility in determining how to achieve their fleet targets, balancing vehicles that are less efficient than their individual targets with those that are more efficient - as is the case with the current CAFE standard. 


\subsubsection{Should We Use the Full, Model-By-Model Data Set, or a "Filtered" or Sales-Weighted Set?}

Even if this general form of standard is preferred, a number of issues should be examined before choosing a final format and standard. One issue is whether to use a sales-weighted data set for setting the standard or to instead use a model-by-model data set, as was done above. If a model-by-model data set is used, an important issue is whether models that are anomalous in some way should be eliminated from the data set. For example, it may be reasonable to use only models that have relatively high sales. Figures 5-5a, b, and c show the data clouds, trendlines, and trendline formulas for the data sets with vehicles of sales below 1,000/year, 5,000/year, and $10,000 /$ year eliminated. The progression of these figures is toward fewer outlying vehicles and a better correlation between fuel economy and curb weight — note the progression to higher $\mathrm{R}^{2}$ values. This may or may not be viewed as positive. On the one hand, the higher correlations will appear positive to those who approach the standard-setting process as one of identifying a set of average vehicles and trying to gradually improve them in a uniform manner. On the other hand, eliminating vehicles with lower sales (or negating their influence by sales-weighting) will appear negative to those who view the standard-setting process as identifying a set of ambitious fuel economy targets based on what is possible - some of the vehicles that are excluded might represent a leading edge of vehicles that could serve as a model for future fleet improvement. In an actual standard-setting exercise, a number of alternative forms of the data set should be examined.

The trendlines in Figures 5-5a-c, representing sales $>1000,5,000$, and 10,000/yr, are substantially more robust than the one in Figure 5-3, with $\mathrm{R}^{2}$ greater than 0.99 vs. one of 0.6055 . As noted above, this may or may not be viewed as positive by the standard-setter. For formula 5.1a, we adopted the equation associated with the regression line for the data set of vehicles with sales greater than 10,000/yr, although all three equations from Figures 5-5a-c are quite similar. Note that we do not mean to imply that this equation is superior to the others.

\subsubsection{Can We Incorporate Light Trucks Into the Standard?}

In the current CAFE system, light trucks and passenger cars have separate targets, and the large difference between the two targets - $27.5 \mathrm{mpg}$ for cars, $20.7 \mathrm{mpg}$ for trucks - reflects at least, in part, real differences in the fuel economy potential of the two fleets. Although the technology of the passenger car fleet appears to be somewhat more advanced than that of the light truck fleet, key causes of the fuel economy differential are the greater average weight of the light truck fleet, off-road capability of a significant portion of the truck fleet (with heavier, lessefficient four-wheel-drive systems; higher ground clearance, yielding poorer aero drag characteristics; and higher rolling resistance tires), other aerodynamic issues aside from higher ground clearance (especially for pickup trucks, with open beds), and high-torque engines needed for towing and load-carrying (the exception here is the greater use of efficient diesel engines in the light truck fleet). 


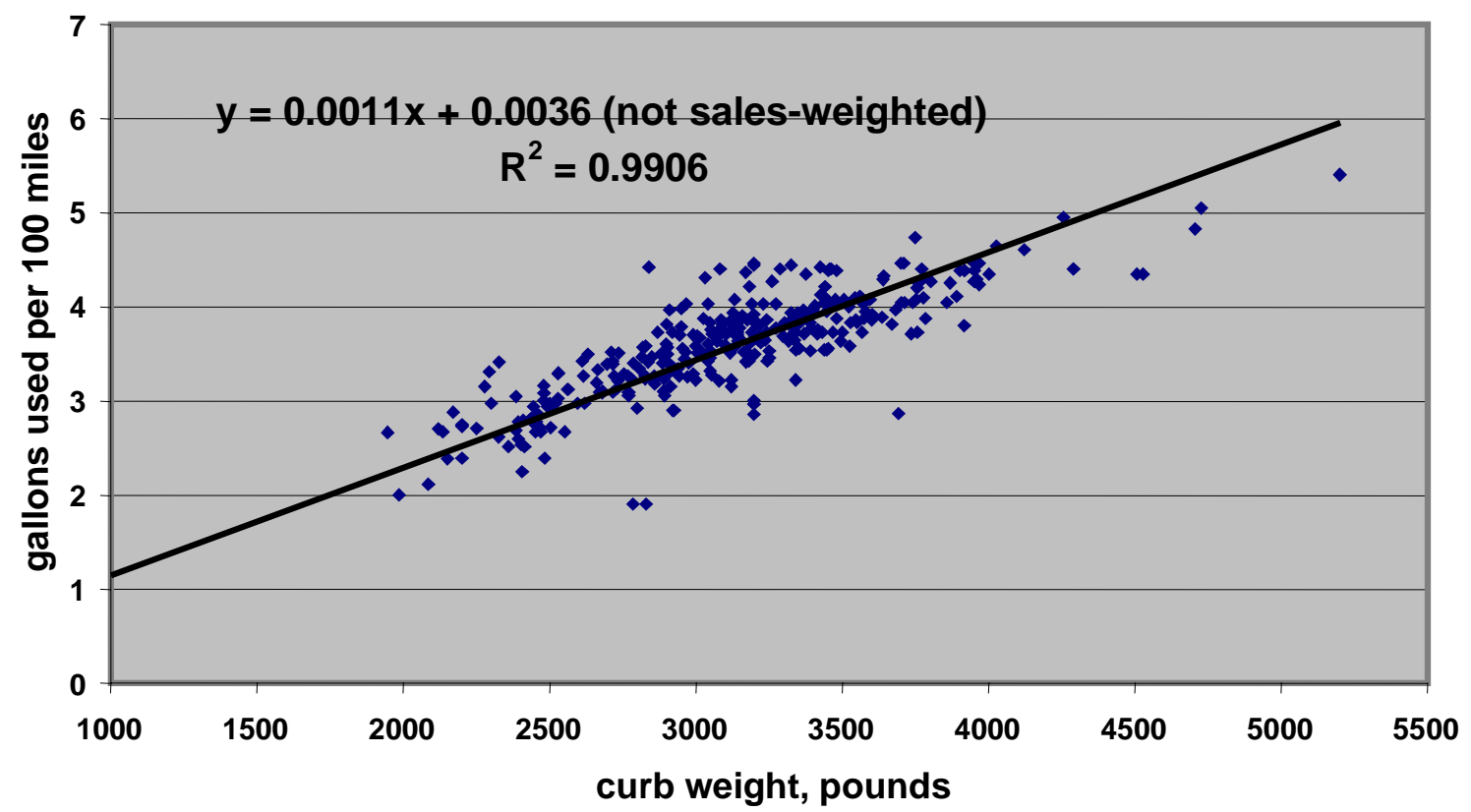

Figure 5-5a. Automobile Fuel Consumption, gal/100 mi, vs. Curb Weight - Sales $>1,000$

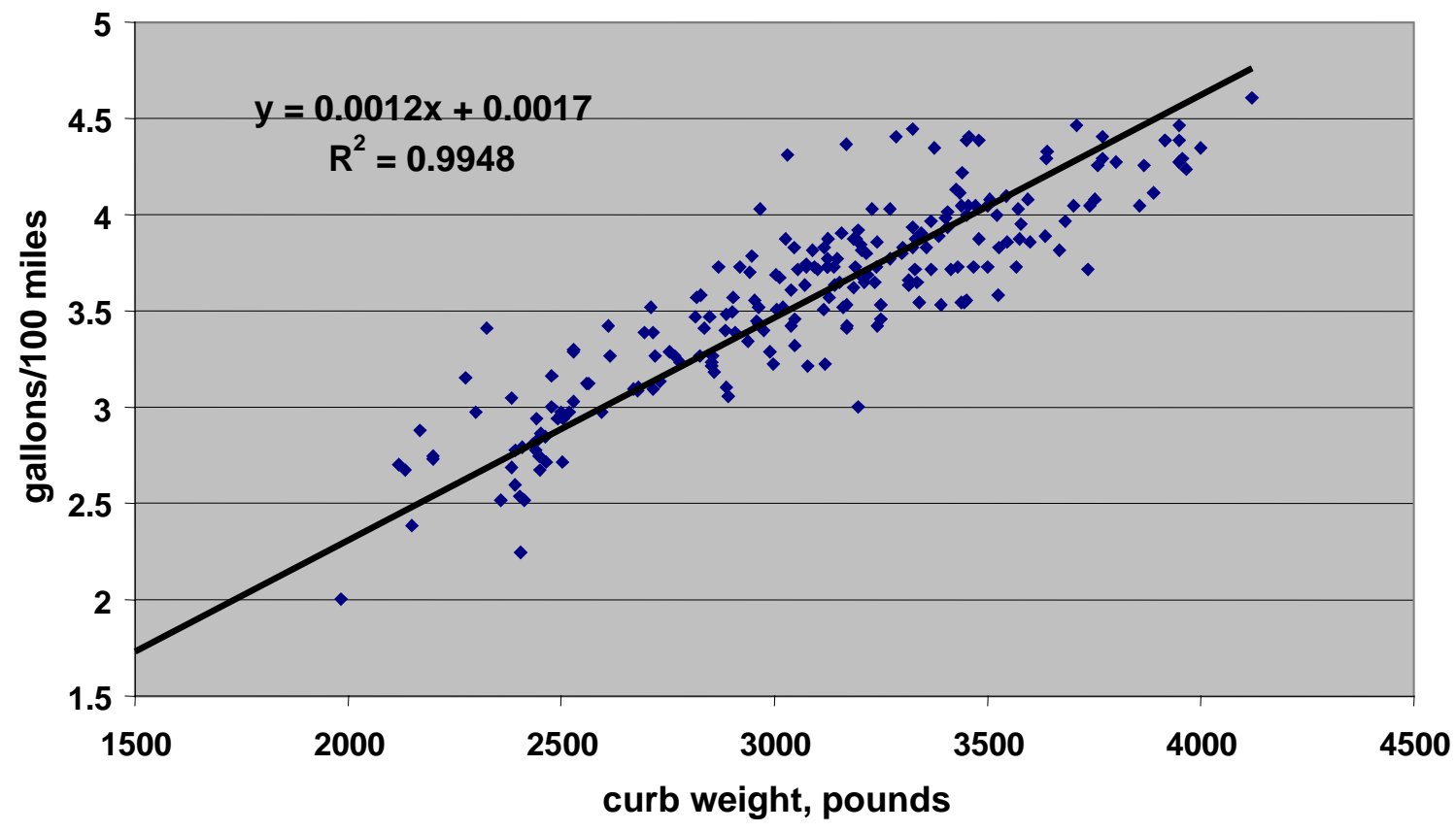

Figure 5-5b. Automobile Fuel Consumption, gal/100 mi, vs. Curb Weight - Sales $>5,000$ 


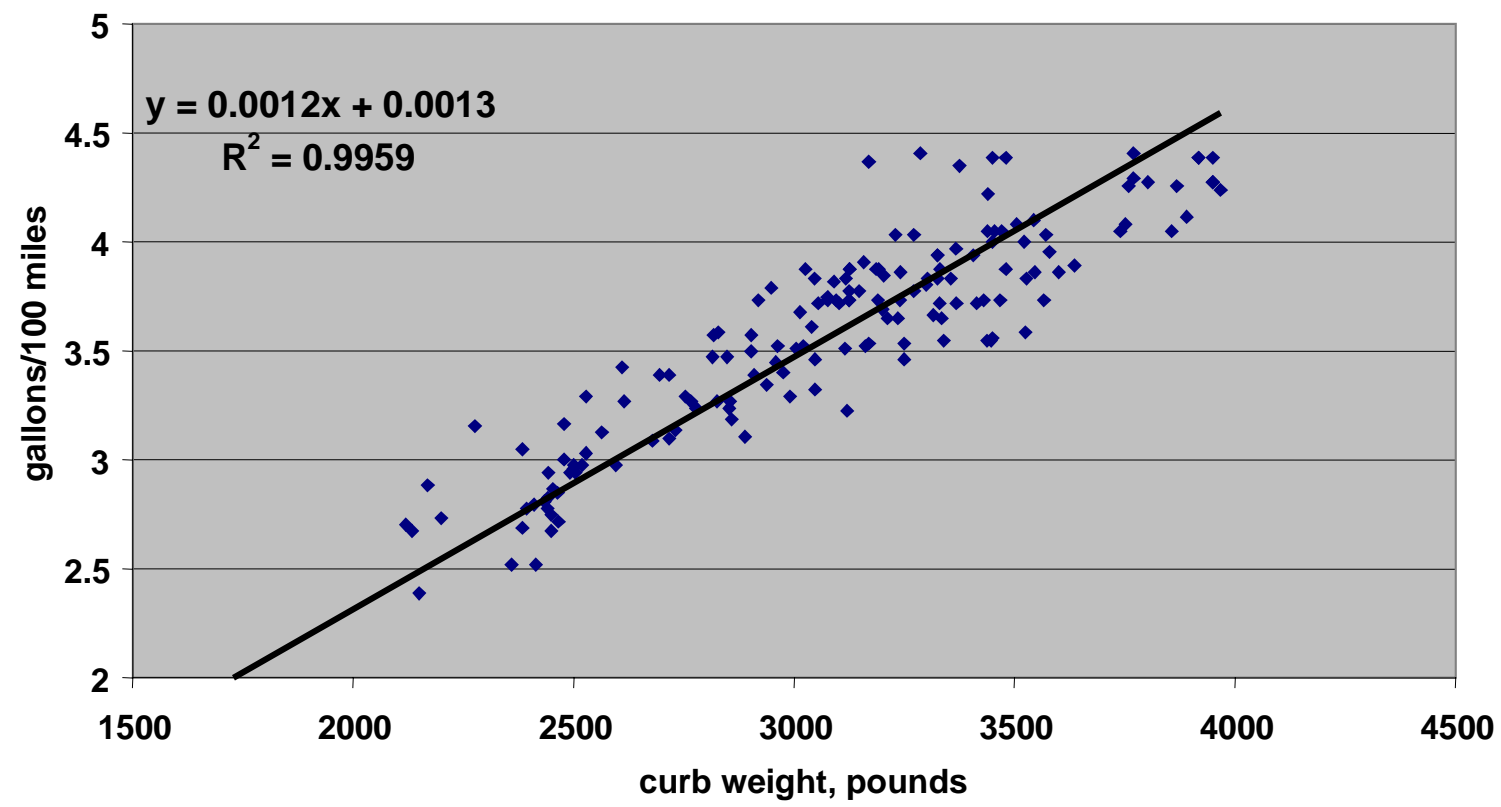

Figure 5-5c. Automobile Fuel Consumption, gal/100 mi, vs. Curb Weight - Sales $>10,000$ (with regression line)

Figure 5-6 repeats Figure 5-5a, showing the weight vs. fuel consumption data cloud and trendline for the 1999 car fleet (excluding cars with less than 1,000 sales annually), with the trendline for the light truck fleet superimposed. The truck trendline ranges from the fuel consumption equivalent of about $4 \mathrm{mpg}$ lower than the passenger car trendline at lower weights to close to zero difference at high weights. A similar analysis by the National Academy of Sciences using a year 2000 database yielded nearly parallel car and truck trendlines, about $2.5 \mathrm{mpg}$ apart (National Research Council 2002), versus a $7.5 \mathrm{mpg}$ difference for the fleets as a whole (EIA 2001).

The implication is that about two-thirds of the difference between the car fleet's fuel economy level and the light truck fleet's fuel economy level is due to the weight difference between cars and light trucks - for equal weight vehicles, trucks have about $2.5 \mathrm{mpg}$ lower fuel economy than cars.

The appropriate interpretation of these figures is somewhat complicated. On the one hand, the average $2.5 \mathrm{mpg}$ difference between cars and light trucks at similar weights means that a weight-based standard that combined cars and light trucks would leave light trucks at about onethird of the disadvantage vis-à-vis cars that they would face if combined with cars using a CAFElike uniform target for each company's fleet. On the other hand, it does not mean that a car and light truck of similar size - perhaps measured by passenger capacity or passenger plus cargo capacity — would necessarily be different by $2.5 \mathrm{mpg}$. Many trucks — particularly pickup trucks, but also many SUVs - have body structures based on body-on-frame designs, which are inherently heavier than the unibody structures of passenger cars. 


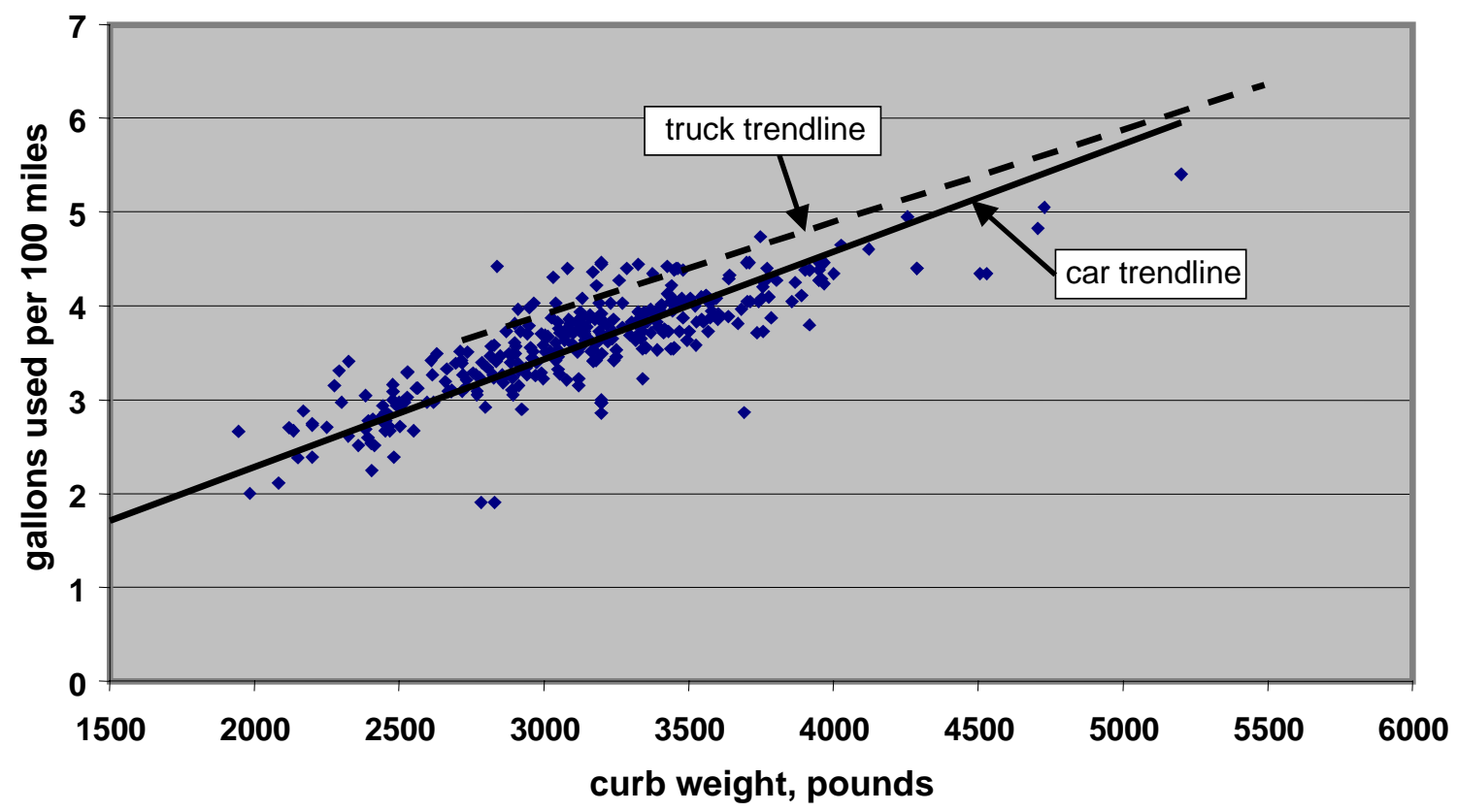

Figure 5-6. Automobile Fuel Consumption, gal/100 mi, vs. Curb Weight, with Truck Trendline Superimposed, Sales $>1,000$

\subsubsection{Concerns about a Weight-Based Standard}

A fear about a weight-based standard, or virtually any attribute-based standard, is that automakers that have been forced to produce small cars will cease to do so, "retreating" to the more profitable, larger market segments. Some domestic manufacturers have asserted that they have, at times, sold their smallest models at zero profit, or even at a loss, in order to raise their corporate fuel economy average high enough to avoid CAFE fines.

Some manufacturers may choose to move away from small car production if attribute-based standards are put into place. Although we do not have the capability to conduct a market analysis of the impact on small car production and sales, we note, first, that the sale of small, entry-level cars is considered by many automakers to represent an important part of their marketing strategy, which is to "capture" young drivers who will then move to larger models as they mature and their income increases. Second, companies that clearly do not need them to comply with CAFE regulations (e.g., Toyota and Honda) manufacture some of the most popular small cars. It seems likely that any retreat from small car production on the part of some automakers will be met primarily with an increase in small car sales by competing companies rather than a shift in buying patterns toward larger cars. However, it may be useful to pursue further study of this issue.

Some have described a standard based solely on vehicle weight as being essentially neutral to vehicle weight, neither promoting nor discouraging changes in weight. This supposed neutrality is considered positive by those especially concerned that further decreases in vehicle weight will compromise safety and negative by those who are concerned about recent trends of increasing vehicle weight or who believe that weight reduction must be an important component 
in improving the efficiency of the vehicle fleet. In reality, however, the standard described by formula 1a is not truly neutral to weight reduction - it will actually penalize weight reduction that is not accompanied by changes in vehicle exterior dimensions, especially cross-sectional area. Because the regression line of weight vs. fuel consumption defined by formula 5.1a was drawn from data on the current fleet, moving to higher weights (to the right in Figure 5-4) while remaining on the line means essentially moving to vehicles that are both heavier and larger. If a vehicle that falls right on the line is made heavier without getting larger, its representative point will move to the right but end up below the line, because its aerodynamic drag will be unchanged; in other words, its efficiency relative to the line will have improved. And a vehicle that, through redesign and materials substitution, becomes lighter without changing size or shape will move to the left in Figure 5-4 but actually fall above the line - its relative efficiency will have decreased.

A numerical computation will illustrate the point. A 4,000-lb vehicle just meeting the " $20 \%$ fuel economy improvement target" in Figure 5-4 would have a fuel consumption rate of 4.0 gallons $/ 100$ miles, or $25.0 \mathrm{mpg}$. If it is lightened to 3,600 pounds without changing performance or size, its fuel economy should improve to about $1.066 \times 26.1=26.7 \mathrm{mpg}$ $(3.75 \mathrm{~g} / 100 \mathrm{~m}) .{ }^{70}$ However, its new target fuel economy (the value of the target line at curb weight $=3,600 \mathrm{lb}$ ) is $27.8 \mathrm{mpg}$, so its fuel economy has actually declined by $1.1 \mathrm{mpg}$ relative to its target fuel economy. Similarly, if the original vehicle had increased its weight by $400 \mathrm{lb}$, its fuel economy would decline to about $23.6 \mathrm{mpg}$, but its target would decline to only $22.7 \mathrm{mpg}$, so its efficiency relative to the target has actually improved by $0.9 \mathrm{mpg}$. This provides a bonus - a less-stringent regulatory target — to vehicles that add weight without adding size. ${ }^{71}$

The small positive incentive for a weight increase embedded in a "pure" weight standard is particularly troubling because, as noted above, the average weight of light-duty vehicles has grown substantially during the past decade and a half despite the strong incentive for weight reduction provided by the current CAFE standards. For example, the average curb weight of passenger cars has increased from 3,030 lb in 1987 to 3,386 lb in 2000, which is a 12\% increase; during the same period, light trucks increased in weight from $3,712 \mathrm{lb}$ to $4,432 \mathrm{lb}$, or by $19 \% .{ }^{72}$ The result of this weight increase, coupled with parallel increases in vehicle performance and a strong shift in sales toward light trucks, is that overall light-duty-fleet fuel economy has actually declined during the 1987-2000 period from 25.9 mpg to $24.0 \mathrm{mpg}$ despite an increase in ton-mpg — the very metric that a weight-based standard is designed to increase - from 42.1 ton-mpg to 46.7 ton-mpg, or $11 \%$.

70 Assuming that a $10 \%$ weight reduction yields about a $6.6 \%$ improvement in fuel economy at constant performance.

71 Of course, the actual fuel economy change caused by the change in weight does provide a positive or negative monetary incentive to the vehicle owner, in the form of reduced or increased expenditures on fuel.

72 Office of Transportation and Air Quality, U.S. Environmental Protection Agency, 2000, Light-Duty Automotive Technology and Fuel Economy Trends 1975 through 2000, EPA420-R00-008, Dec. 
In other words, had there been in place in 1987 (in addition to the CAFE standard) a weightbased standard calling for an $11 \%$ increase in ton-mpg by 2000 , the standard would have been fully satisfied, even though actual light-duty fuel economy had decreased by $7 \%$. Further, had a weight-based standard been in place without having the CAFE standard in tandem, the resulting fleet fuel economy might well have been still lower.

Another related concern about a weight-based standard is that in addition to providing a positive incentive to future weight gains, a pure weight-based standard would punish automakers that have already made their vehicles relatively weight-efficient. If, for example, automaker A produces a vehicle that is $10 \%$ lighter but otherwise identical to automaker B's vehicle, vehicle A would have a future fuel economy target about $10 \%$ higher than B's but would have a current fuel economy only about 6-7\% higher. In other words, the more weight-efficient vehicle is penalized by having a more difficult fuel economy improvement requirement.

The implication is that, to be effective in increasing fleet fuel economy, a weight-based standard may have to be combined with a positive incentive for weight efficiency, or at least a neutral incentive. How might this be done?

\subsubsection{Inserting an Incentive for Increasing Weight Efficiency into a Weight- Based Standard}

One means of inserting an incentive for increasing weight efficiency — that is, reducing weight while leaving size unchanged - into a weight-based standard is to find a relationship between weight and other vehicle attributes that allows us to define a reasonable measure of the average weight efficiency of the fleet and penalize or reward vehicles that can be identified as weight-inefficient or efficient relative to the rest of the fleet. If a manufacturer increases vehicle weight efficiency by reducing weight while holding other attributes (like interior volume or carrying capacity) constant, it can be rewarded for that improvement. The attributes should measure vehicle size, carrying capacity, safety, or some combination of attributes.

We examined a number of attributes, including vehicle interior volume, interior volume + luggage volume, length $\times$ width (footprint), and wheelbase $\times$ width, for the 1999 car fleet. The latter two terms have been identified as strongly related to vehicle safety, since wheelbase and length are associated with the amount of crush space available to the vehicle in frontal crashes, wheelbase is related to vehicle directional stability and resistance to rollover, and width is related to resistance to rollover. None of the relationships between these attributes and vehicle weight was as robust as we would have liked to have found, but the most robust relationship appeared to be that between curb weight and wheelbase $\times$ width in the passenger car fleet (note that we did not examine the light truck fleet because of shortcomings in our data base). This relationship is illustrated in Figure 5-7.

This relationship between "average" curb weight, which we can call $\mathrm{W}^{*}$, and wheelbase $\times$ width can then be used to add a weight reduction or stabilization incentive to a weight-based standard in the following manner. First, note that were a vehicle designer to reduce weight by $10 \%$ while maintaining constant size, drivetrain efficiency, and performance, the vehicle's fuel economy should increase about $6.6 \%$ and its fuel consumption rate should decline by about 


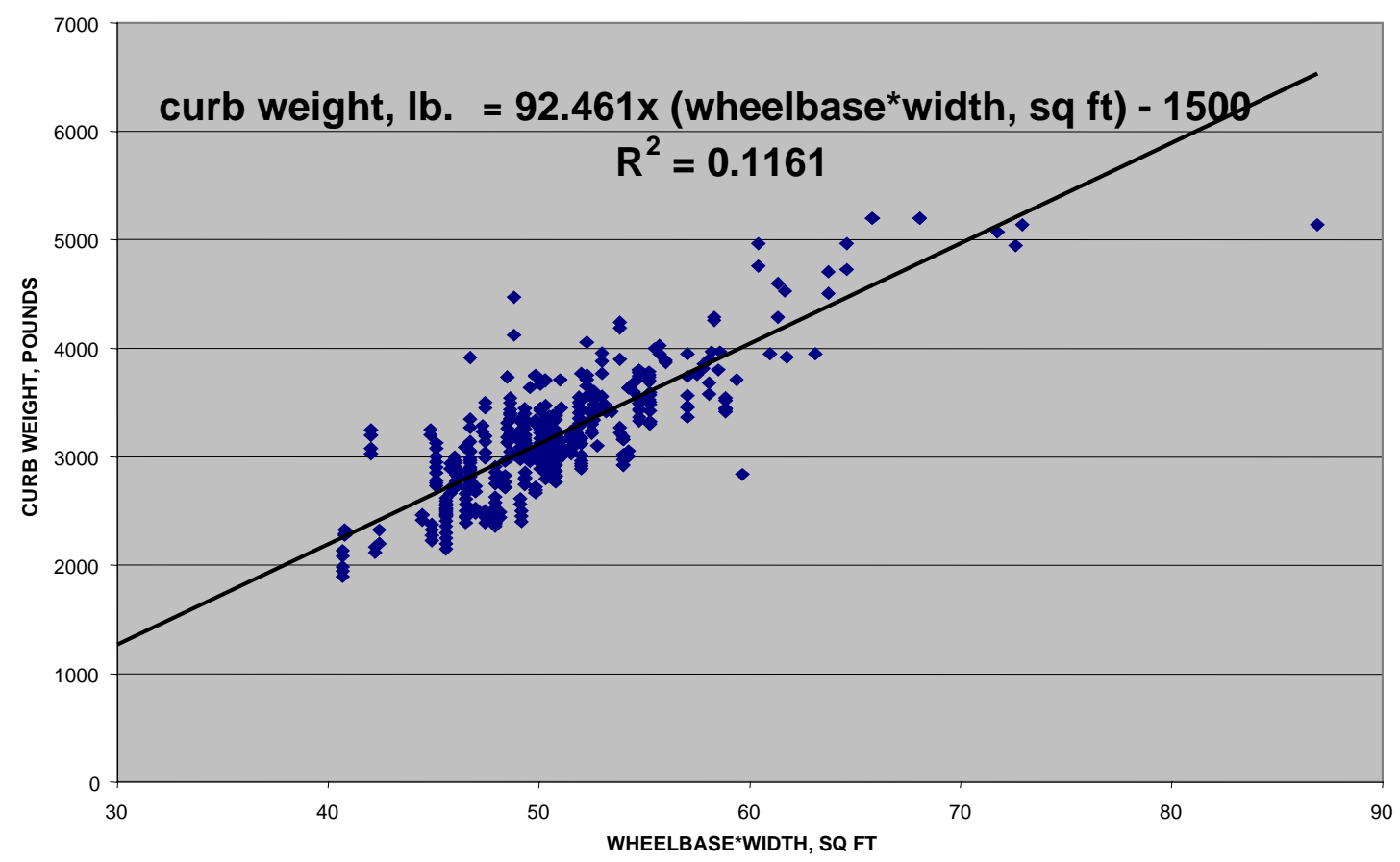

Figure 5-7. Curbweight vs. Wheelbase $\times$ Width

$6.2 \%$, on average. Second, the average slope of the target line in Figure 5-3 is about $+0.1 \mathrm{lb} /(\mathrm{gal} / \mathrm{mi})$ - that is, a weight reduction of $10 \%$ will yield approximately a $10 \%$ decline in the target level of fuel consumption. ${ }^{73}$ Consequently, awarding a fuel consumption "credit" of about $(10 \%-6.2 \%)=3.8 \%$ (in addition to the $6.2 \%$ reduction in actual fuel consumption) for a $10 \%$ weight reduction would approximately neutralize the negative incentive for weight reduction posed by a standard based solely on weight. And awarding a larger credit would provide a positive incentive for weight reduction.

We can now present two additional versions of a weight-based standard, on the basis of information in Figures 5-3 and 5-6. For a $20 \%$ improvement target, the first has the form:

$$
\begin{gathered}
\text { G/100M target }=(0.0012 \times \text { curb weight, } l b+0.0013) \times[1.38-0.38 \times \text { curb weight } / \\
\{92.5 \times(\text { wheelbase }, f t) \times(\text { width }, f t)-1,500\}] /[(1+0.20) \times 1.058]
\end{gathered}
$$

This version adjusts the standard so that it is roughly neutral to changes in weight without corresponding changes to size, measured as wheelbase $\times$ width. The correction factor 1.058 in the denominator adjusts the formula to account for the lack of sales weighting in both the "fuel consumption vs. curb weight" relationship and the "curb weight vs. wheelbase $\times$ width

73 Note that the slope of the target line will change as the percentage improvement target changes. The original regression line for the 1999 fleet has a slope of $+0.12 \mathrm{in} \mathrm{lb/gpm} \mathrm{space.} \mathrm{A} 20 \%$ improvement target line thus has a slope of $+0.12 / 1.2$, or 0.1 ; a $33 \%$ improvement target line would have a slope of 0.09 . 
relationship. ${ }^{74}$ Weight is measured against a baseline weight (at every wheelbasexwidth) defined by the line in Figure 5-7. In other words, if the standard is formulated correctly, increasing the weight efficiency of a vehicle would neither decrease nor increase the percentage improvement in fuel economy required by the standard. This contrasts with both a "pure" weight-based standard, in which increasing weight efficiency increases the required percentage improvement in fuel economy, and the current CAFE standards, in which increasing weight efficiency has the opposite effect of decreasing the required percentage improvement.

The third version further adjusts the standard to provide a bonus mpg credit that adds a positive incentive for weight reduction without size reduction. The magnitude of the credit is optional; in the case shown, the credit gives roughly a $2 \%$ fuel economy credit for every $10 \%$ weight reduction at constant wheelbase $\times$ width, which is again measured against the baseline weight defined by the line in Figure 5-7.

$$
\begin{array}{r}
\text { G/100M target }=(0.0012 \times \text { curb weight, } l b+0.0013) \times[1.58-0.58 \times \text { curb weight } / \\
\{92.5 \times(\text { wheelbase }, f t) \times(\text { width }, f t)-1,500\}] /[(1+0.20) \times 1.069]
\end{array}
$$

In formula 5.3, the factor of 1.069 is the correction factor to correct for the lack of salesweighting. This ability to modulate the degree of incentive given for weight efficiency may be seen as a very positive attribute of a standard of this sort.

Note that we are not recommending use of these equations for a standard, for several reasons. Most importantly, a voluntary standard obviously must be developed with the cooperation of the automobile industry; we consider these equations to be illustrations of an approach to setting standards, not as any final product. Second, the equations are definitely not applicable to the light truck fleet; we did not have the data to derive equations for this fleet, and we believe that appropriate adjustment factors for light trucks would be substantially different from those derived for passenger cars.

\subsubsection{Other Metrics for an Attribute-Based Standard}

As discussed earlier, a number of other metrics are available for constructing a new fuel economy standard. For example, vehicle interior volume was raised as a possible metric by the Office of Technology Assessment during the fuel economy debates of the early 1990s (OTA 1991), and Patterson and McNutt suggested it in 1986 (McNutt and Patterson 1986). As shown by Figure 5-8, interior volume seems to be virtually unrelated to fuel economy. This implies that other factors (e.g., performance, technology, and weight) are more important than size in determining fuel economy. The lack of a clear relationship between size and fuel economy may make it harder to define an acceptable size-based standard, but such a standard may still be worth examining. Another potential metric is the direct use of wheelbase $\times$ width, which was used above as the metric for a weight reduction incentive. Figure 5-9 shows a plot of fuel

74 Again, note that this would not be necessary with salesweighting, which we did not use because the analysis software did not have it as an option. 


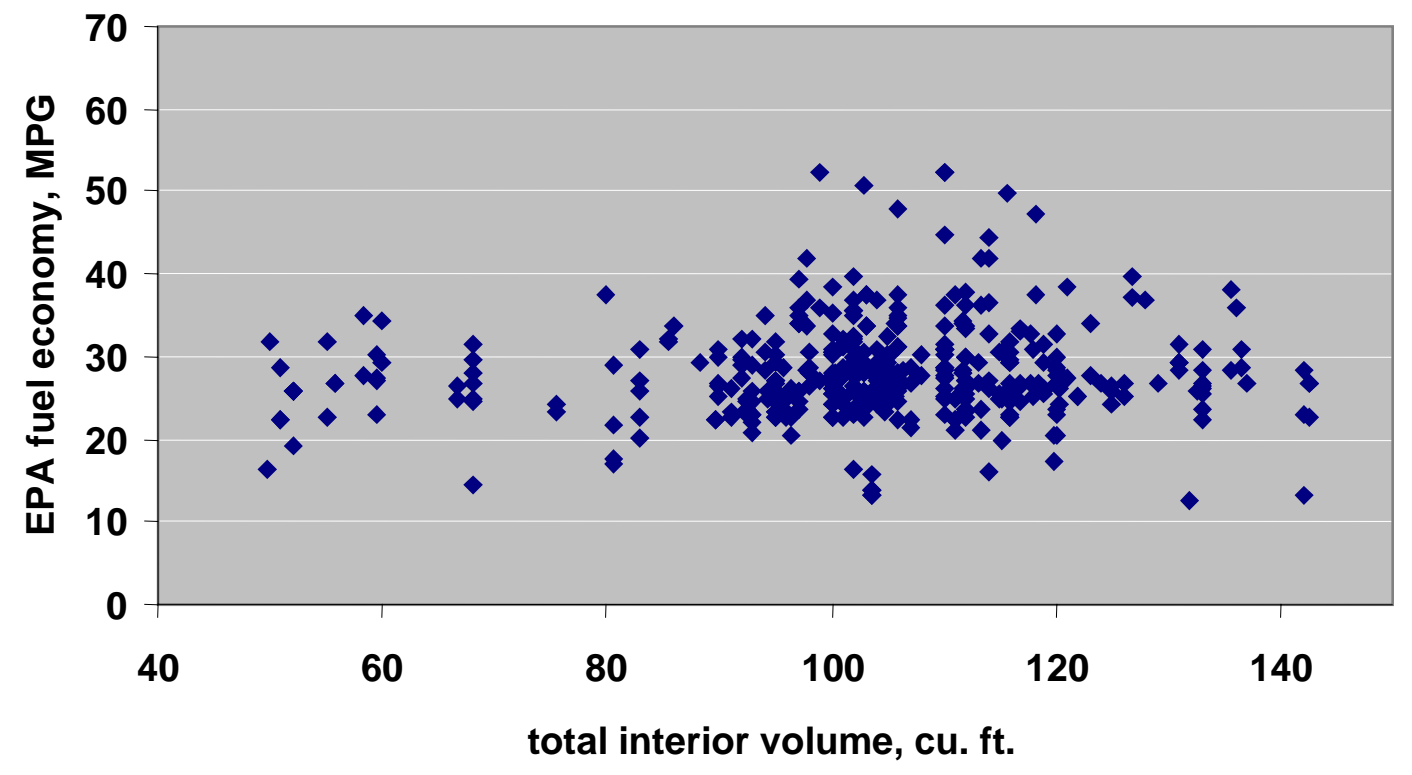

Figure 5-8. EPA Fuel Economy vs. Total Interior Volume (passenger volume + luggage volume) for 1999 Cars $>5,000$ sales

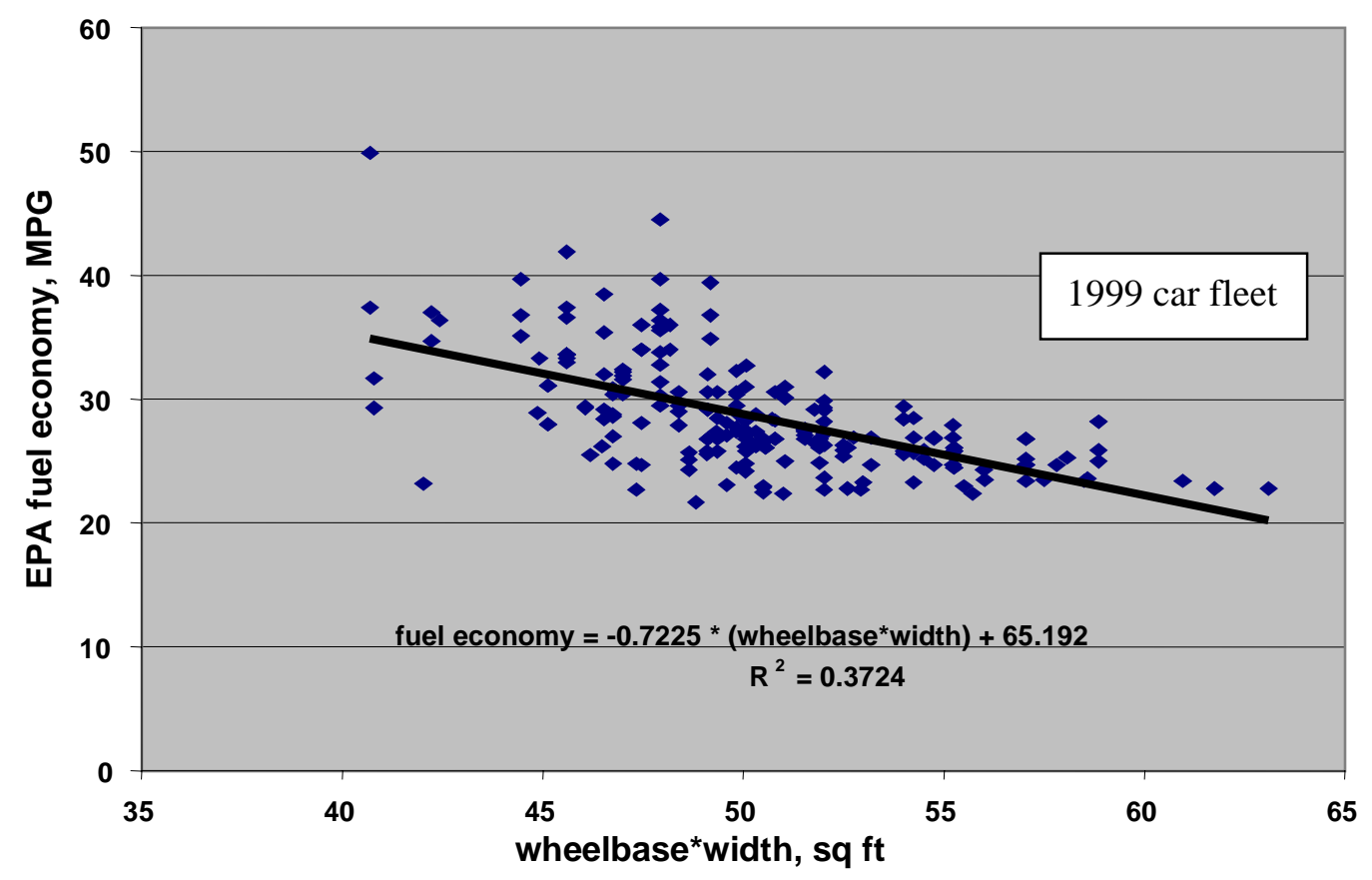

Figure 5-9. Fuel Economy vs. Wheelbase $\times$ Width, 1999 Cars $>5,000$ Sales 
economy vs. wheelbase $\times$ width; this metric is not as highly correlated to fuel economy as is curb weight, but nevertheless it should be considered a potential candidate for an attribute-based standard. It has the strong advantage of fully retaining increasing weight efficiency as a means of complying with a new fuel economy target.

\subsection{Evaluating Alternative Structures for a New Fuel Economy Standard}

In this section, we evaluate four forms of fuel economy standards that may be considered as alternatives to the current CAFE form of a uniform mpg target. UPI is evaluated because it was the form adopted by fuel economy legislation debated in the late 1980s and early 1990s and was strongly supported at that time by the Motor Vehicle Manufacturers Association. The other three forms are variations of a weight-based standard, and this type of standard has been adopted in the Japanese market.

The evaluation here is limited to an examination of the varying mpg targets that each form of standard applies to the different manufacturers, as compared with the flat mpg targets associated with the current CAFE standards. Each form of standard will create a different pattern of fuel economy improvements required from each manufacturer. Qualitatively, a UPI standard places the highest mpg requirement on the companies with the highest baseline fuel economies - among the major manufacturers, probably Honda and Toyota. A standard based only on weight should tend to equalize the degree of effort required from each manufacturer (especially as compared to a CAFE-like uniform mpg standard), although in this case Honda and Toyota would be expected to have somewhat smaller percentage requirements than other mainline automakers on the basis of their high year-2000 fleet values of ton-mpg (see Figure 5-1). And, for weight standards adjusted to neutralize negative incentives for weight increase or to create a positive incentive for weight reduction, the result will be less clear without quantitative analysis.

For attribute-based standards, the fuel economy improvements required from each manufacturer cannot be predicted precisely before the year of application, because the standards depend on the actual attributes of the fleet in that year (which will not be known for models not yet introduced) and sales values for each model. However, applying the standards to a recent model year can serve to illuminate how the standards may work in the future. The four standards discussed above - UPI, a "pure" weight-based standard, a weight-based standard adjusted to eliminate a bias towards weight gain, and a weight-based standard adjusted to provide a positive incentive for weight reduction - were applied to the 1999 passenger car fleet, assuming that a fleetwide $20 \%$ fuel economy increase was desired.

Table 5-1 shows the percentage increase values for fuel economy required from each manufacturer for the latter three of the four types of standards - the value for UPI will simply be a uniform 20\%. Figures 5-10 and 5-11 show the mpg targets for each of the four standards for a number of the largest manufacturers (with Chrysler and Mercedes shown separately, although their fleets would be combined for any future standard) and a number of small, niche automakers. 
Table 5-1. Manufacturer-Specific Percentage Improvement Requirements for Three Alternative Weight-Based Standards: 20\% Fleet Fuel Economy Improvement

\begin{tabular}{|c|c|c|c|}
\hline Make & $\begin{array}{c}20 \% \text { Weight } \\
\text { Standard }\end{array}$ & $\begin{array}{c}20 \% \text { Weight Standard - } \\
\text { "neutral" }\end{array}$ & $\begin{array}{l}20 \% \text { Weight Standard - } \\
\text { "positive" }\end{array}$ \\
\hline Bentley & 32 & 32 & 34 \\
\hline BMW & 22 & 25 & 28 \\
\hline Chrysler & 18 & 16 & 15 \\
\hline Ferrari & 119 & 126 & 131 \\
\hline Ford & 22 & 21 & 21 \\
\hline Subaru & 20 & 24 & 26 \\
\hline GM & 20 & 21 & 21 \\
\hline Honda & 20 & 17 & 15 \\
\hline Hyundai & 32 & 30 & 29 \\
\hline Kia & 33 & 29 & 27 \\
\hline Lamborghini & 108 & 111 & 112 \\
\hline Lotus & 74 & 77 & 78 \\
\hline Mercedes & 10 & 14 & 17 \\
\hline Mitsubishi & 26 & 27 & 28 \\
\hline Nissan & 19 & 20 & 21 \\
\hline Porsche & 48 & 57 & 63 \\
\hline Rolls Royce & 28 & 30 & 31 \\
\hline Suzuki & 28 & 25 & 23 \\
\hline Toyota & 16 & 16 & 17 \\
\hline Volkswagen & 19 & 23 & 25 \\
\hline Volvo & 15 & 20 & 23 \\
\hline
\end{tabular}

Among the major manufacturers, Mercedes and Toyota appear to benefit significantly from shifting from a UPI standard to a weight standard. These manufacturers have managed to attain high levels of weight-adjusted fuel economy in comparison with their peers. Ford is hurt by the shift, but only marginally. Honda, which has lobbied against UPI, apparently is not helped by the shift to a weight-based standard. A likely cause is that Honda's cars are relatively light for their size, so they face mpg targets that, in most other fleets, would be applied to smaller cars. Also, it is possible that there are significant differences between Honda's sales-weighted fleet characteristics in 2000 (the model year used to develop Figure 5-1) and 1999 (the model year used to develop Figure 5-10); there may also be errors in the database.

Toyota does not benefit from the "weight-efficiency" adjustments made in the latter two standards, and Mercedes is hurt somewhat by the adjustments. This latter impact is not unexpected, because Mercedes cars are luxury models that are comparatively heavy for their size. On the other hand, Chrysler, Ford, GM, and especially Honda are helped by the adjustments their cars are relatively light for their dimensions.

Some of the niche manufacturers will face a difficult challenge with any of the weight-based standards, because they produce very high-powered passenger cars (Ferrari, Lamborghini, 


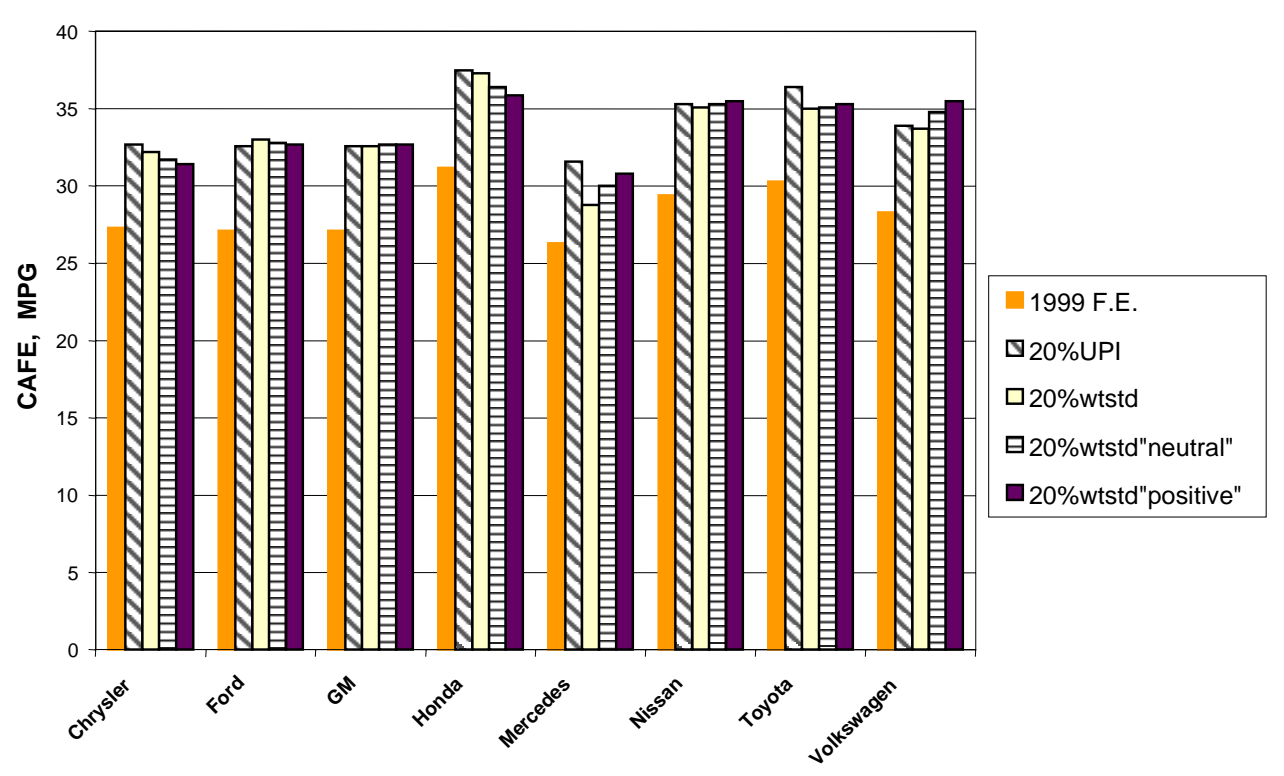

Figure 5-10. Corporate mpg Targets for Alternative Auto Standards, for Major Automakers, Based on 1999 Car Fleet

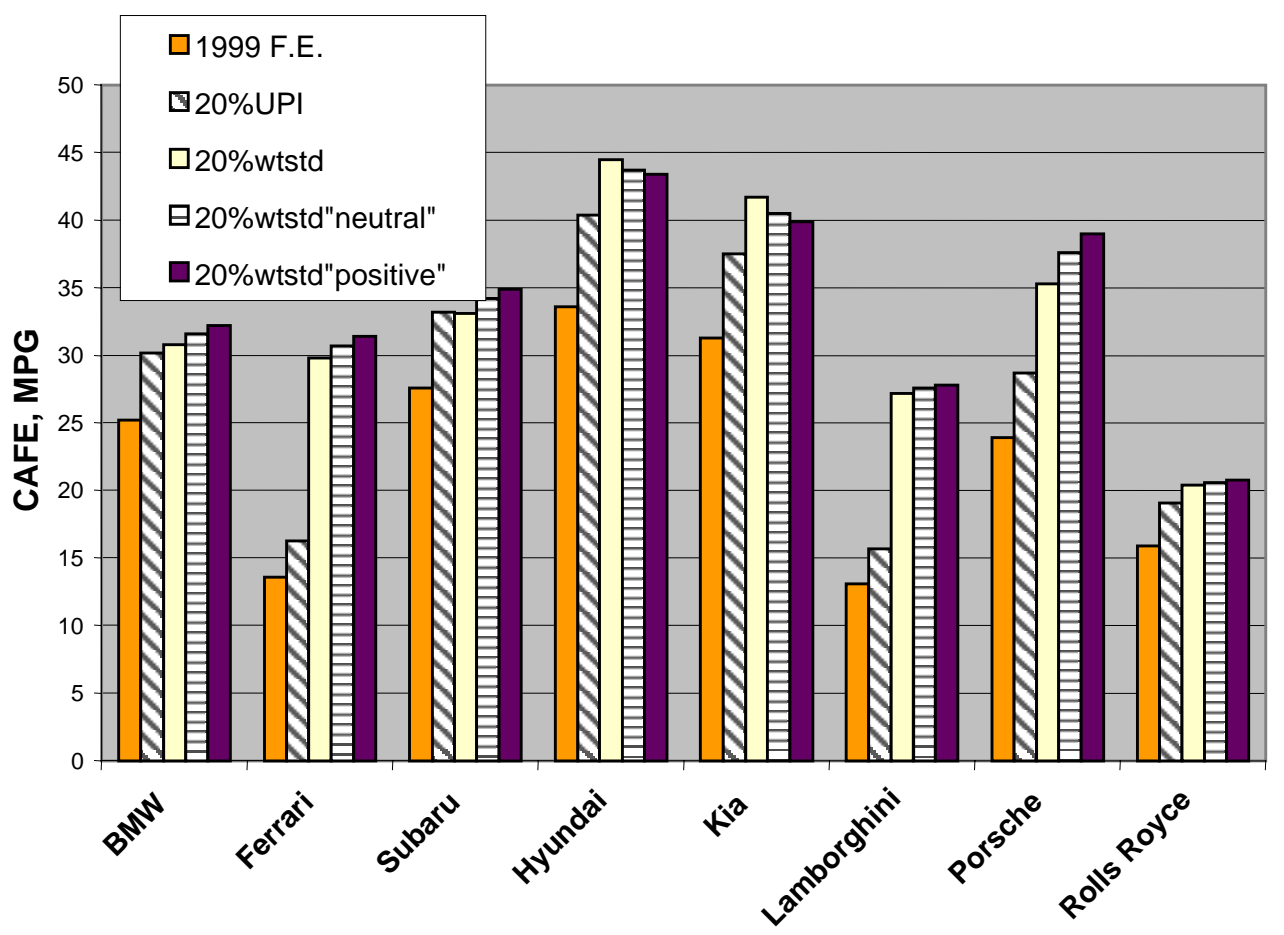

Figure 5-11. Corporate Automotive mpg Requirements for Alternative Standards, Niche Automakers, Based on 1999 Car Fleet 
Porsche) that attain low fuel economy levels for their size and weight. Porsche's mpg requirement will be raised by the weight efficiency incentives, because their cars are somewhat heavy for their dimensions. Surprisingly, Rolls Royce, which we would have assumed would be hurt by the weight efficiency incentives, was essentially unaffected by them; apparently, Rolls Royce cars are of average weight for their size.

The above discussion and analyses demonstrate that it is possible to design alternative forms of fuel economy standards that can begin to address some of the problems associated with the current CAFE system. A weight-based standard, for example, will make it more feasible to combine the car and light truck fleets, because more than one-half of the fuel economy difference between the average car and light truck is due to the higher weight of trucks - and this is accounted for in a weight-based standard. Attribute-based standards will, in general, tend to equalize across the different manufacturers the degree of difficulty or level of effort required to achieve required fuel economy targets, as compared with the current "one size fits all" standard. However, choosing an appropriate standard would be aided by additional analysis aimed at quantifying the degree to which various types of standards achieve economic efficiency or equity among manufacturers.

Section 6 takes the analysis one major step further - for UPI and the first type of weightbased standard, as well as for a standard assigning a uniform mpg target to all or part of the fleet (as in the current system), we calculate the impact of each type of standard on fuel savings and vehicle price for the fleet as a whole and for each manufacturer. This analysis will allow us to distinguish among these alternative forms as to their overall economic efficiency - the fleetwide change in the value (fuel savings - technology price) will be largest for the most efficient form - and as to their differential impact on the value of each manufacturer's cars and light trucks.

\subsection{References}

EIA: Energy Information Administration.

Energy Information Administration, 2001, Annual Energy Outlook 2002, DOE/EIA-0383(2002), U.S. Department of Energy, Dec.

McNutt, B., and P. Patterson, 1986, “CAFE Standards — Is a Change in Form Needed?," Society of Automotive Engineers paper 861424.

NRC: National Research Council.

NRC, 2002, Effectiveness and Impact of Corporate Average Fuel Economy (CAFE) Standards, Committee on the Effectiveness and Impact of Corporate Average Fuel Economy (CAFE) Standards, National Research Council, National Academy Press, Washington, D.C.

OTA: Office of Technology Assessment. 
$\Delta$

OTA, 1991, Improving Automobile Fuel Economy: New Standards, New Approaches, OTA-E504, U.S. Congress, Office of Technology Assessment, U.S. Government Printing Office, Washington, D.C., Oct.

UAW: United Auto Workers.

UAW, 2001, International Union, United Automobile, Aerospace and Agricultural Implement Workers of America, UAW, "Statement to the National Research Council Committee on the Effectiveness and Impact of Corporate Average Fuel Economy (CAFE) Standards," Slide Presentation, March 12. 


\section{Section 6 \\ Analysis of the Costs and Benefits of Implementing Alternative Voluntary Standards}

\subsection{Overview}

The success or failure of a voluntary standard will depend on both its economic practicability and fairness to manufacturers. Practicability depends on the balance between the cost of increasing fuel economy and the willingness of consumers to pay for fuel economy improvements. Fairness requires maintaining a level playing field — which means not altering the competitive positions of manufacturers. This section assesses the economic practicability and differential impacts on manufacturers of different levels and forms of voluntary fuel economy standards. This section does not address the mechanisms by which voluntary agreements could be implemented, monitored, or enforced. The goal is to discover what range of fuel economy improvement may be feasible and what forms of voluntary standards are most likely to be acceptable. The assumption is that voluntary standards will be phased-in gradually and will have their full effect in the 2012-2015 period.

This section develops a method for measuring costs and fuel savings benefits, as well as competitive impacts, and applies it to evaluating alternative levels and forms of voluntary fuel economy agreements. Manufacturers are assumed to maximize the net value to their customers of using advanced technologies to increase fuel economy, subject to a constraint, or requirement, that fuel economy targets are met or exceeded. Net value is measured by the difference between the present value to the customer of future fuel savings and the increase in vehicle price caused by the use of fuel economy technologies. This approach is not intended to imply that fuel economy is the only source of either cost or value, but rather that all other attributes are held constant in order to isolate the trade-off between fuel economy and vehicle price. Fuel economy technologies can also be used to permit increases in vehicle weight or performance while holding fuel economy constant. Holding other attributes constant is a key premise of this analysis. Calculating the present value of fuel savings requires making several assumptions about vehicle use, the price of fuel, rates of return, and so on. The results presented are critically dependent on the particular values chosen.

Two levels of fuel economy improvement (20\% and 33\%) and three metrics (corporate average mpg, UPI, and a weight-based formula) are assessed, along with various alternative structures for establishing targets (industry-wide, manufacturer-specific, etc.). Several additional analyses were carried out to test the sensitivity of results to key assumptions.

Given our reference assumptions about how customers will value fuel economy gains and our estimates of the cost of increasing it, a $20 \%$ increase in mpg is below the level that provides the greatest net value to car buyers over the full life of the vehicle. This result is dependent on, however, a number of critical assumptions, not the least of which is that vehicle performance and sales mix remain constant. For most manufacturers, the $33 \%$ increase requirement was above the 
evel that provides the greatest net value to car buyers, again given our reference technology cost functions.

The original intent of this study was to include the Canadian as well as the U.S. vehicle market in the analysis. However, we were not able to resolve inconsistencies between the data bases of the two countries in time to include the Canadian statistics.

This study overlapped in time with the National Research Council's assessment of the Effectiveness and Impacts of Corporate Average Fuel Economy Standards. This study's focus, however, is not on the CAFE system, but rather on better understanding manufacturer-based voluntary alternatives to CAFE. And while fuel economy technology cost curves developed by the National Research Council (NRC) panel are used in this study's sensitivity analyses, the conclusions of this study are based on an entirely independent assessment of fuel economy technology potential, as described in Section 4.

The framework for analyzing costs and benefits, and equity, is presented in the following section. Section 6.3 describes how the technology available to manufacturers for improving fuel economy is represented as fuel economy versus vehicle price curves. Section 6.4 presents the levels of fuel economy improvement considered, forms of alternative standards, fuel economy metrics, and sensitivity analyses. Results of the analysis are presented in Section 6.5, including cost-benefit comparisons, analysis of competitive effects, and sensitivity analysis

\subsection{Approach}

To estimate the impacts of alternative voluntary standards, both manufacturer and consumer behavior must be represented. Model year 2000 is the base year for this analysis. In future years, manufacturers are assumed to add fuel economy technology to their model year 2000 vehicles until they meet their voluntary fuel economy targets. They add technology so as to create the greatest value for their customers, subject to the constraint that their voluntary targets are met or exceeded. Manufacturers will exceed voluntary standards if consumers are willing to pay for higher levels of fuel economy. In such a case, we say that the fuel economy constraint is not "binding." Maximizing the net value of fuel economy changes subject to satisfying a voluntary fuel economy standard can be formulated as a mathematical optimization problem. The components of the optimization problem are (1) the objective function to be maximized; (2) the constraints representing the voluntary commitments; and (3) the decision variables that determine the fuel economy improvement for each manufacturer, vehicle type, and origin. The objective function is the difference of (1) the value of the fuel economy increases to customers minus (2) the increase in vehicle price caused by increasing mpg.

No changes to the model year 2000 product lines are allowed, other than improving fuel economy. In effect, this implies that manufacturers not only do not significantly alter the designs of model year 2000 vehicles, but that the sales mix of vehicles (large and small, cars and trucks, etc.) does not change. These are strong assumptions and are undoubtedly not an accurate prediction of how light-duty-vehicle markets will evolve over the next 10-15 years. The advantage of these assumptions is that they greatly simplify the analysis and, at the same time, tie it to something concrete: market conditions in the year 2000. However, in interpreting the results 
of this analysis, it is important to bear in mind that manufacturers will alter their positions in the market place, not only by creating new products and discontinuing older ones, but through mergers and acquisitions as well. Consumers' preferences will also change as incomes grow and demographics shift, among other factors. In particular, inferences about equity and manufacturerspecific impacts are strongly conditioned by model year 2000 market conditions. Because future market conditions will surely be different, it is best to interpret this analysis as either generally indicative of the kinds of impacts that might occur 10-15 years from now or strictly conditional on the assumption that conditions do not change.

Each manufacturer's product lines are aggregated into four groups: (1) domestic passenger cars, (2) imported passenger cars, (3) domestic light trucks, and (4) imported light trucks. Thus, the "vehicles" of this analysis are sales-weighted averages of makes, models, and configurations. Data for model year 2000 vehicles in the United States were derived from NHTSA's Manufacturer's Fuel Economy Reports, with corrections and additions made by the authors. The base-year data are summarized in Table 6-1.

Inspection of Table 6-1 clearly shows that not all manufacturers have product offerings in all vehicle-type/origin categories. Closer examination of the weight and horsepower data also reveals that manufacturers' product offerings differ substantially within categories.

\subsubsection{Manufacturer Behavior}

Manufacturers are assumed to adhere strictly to their voluntary fuel economy commitments. They are further assumed to rely entirely on technology for improving fuel economy and not to subsidize or "tax" particular makes and models to alter the distribution of vehicle sales. Greene (1991) has shown that manipulating vehicle prices to change the mix of vehicles sold is a relatively expensive means for a manufacturer to increase its corporate average mpg and would be used by a profit-maximizing manufacturer only to achieve temporary increases of a few tenths of an mpg.

Beginning with the most cost-effective technologies, manufacturers are assumed to add fuel economy technologies to vehicles so as to maximize the net value of the vehicles to their customers, subject to meeting their voluntary fuel economy commitments. In a competitive market, maximizing net consumer value subject to an mpg constraint can be shown to be equivalent to maximizing profits in the face of the same constraint (Greene and Hopson 2002).

Only the monetary costs and benefits of fuel economy are considered in this section. Fuel economy technologies are assumed to be hedonically neutral. Except for their impacts on fuel economy and vehicle price, these technologies do not enter into a consumer's purchase decision or affect a consumer's satisfaction with a vehicle. Changes in hedonic value due to changes in vehicle attributes are not only difficult to predict, but difficult to value as well. 
Table 6-1. Model Year 2000 Fuel Economy and Related Data by Manufacturer, Vehicle Type, and Origin

\begin{tabular}{|c|c|c|c|c|}
\hline Manufacturer $^{\mathrm{a}}$ & $\mathrm{mpg}$ & $\begin{array}{l}\text { Production } \\
\text { (thousands) }\end{array}$ & $\begin{array}{c}\text { Curb } \\
\text { Weight (lb) }\end{array}$ & Horsepower \\
\hline \multicolumn{5}{|l|}{ Passenger Cars } \\
\hline BMW-imported & 24.7 & 173.7 & 3,697 & 200 \\
\hline Daimler-Chrysler-domestic & 27.3 & 816.3 & 3,394 & 173 \\
\hline Daimler-Chrysler-imported & 25.2 & 146.0 & 3,960 & 243 \\
\hline Ford Motor Company—domestic & 27.8 & $1,606.5$ & 3,547 & 167 \\
\hline Ford Motor Company_imported & 27.3 & 301.8 & 3,406 & 177 \\
\hline Subaru-imported & 28.0 & 143.4 & 3,462 & 163 \\
\hline General Motors—domestic & 27.5 & $2,526.8$ & 3,500 & 181 \\
\hline General Motors_imported & 24.9 & 55.4 & 3,687 & 190 \\
\hline Honda-domestic & 34.8 & 455.5 & 2,816 & 128 \\
\hline Honda-imported & 28.8 & 499.0 & 3,387 & 169 \\
\hline Hyundai-imported & 30.0 & 249.1 & 2,962 & 133 \\
\hline Kia-imported & 29.8 & 101.0 & 2,875 & 125 \\
\hline Mitsubishi-imported & 29.2 & 181.5 & 3,133 & 150 \\
\hline Nissan-domestic & 27.8 & 124.4 & 3,240 & 155 \\
\hline Nissan-imported & 28.3 & 165.2 & 3,305 & 195 \\
\hline Porsche-imported & 24.1 & 20.3 & 3,189 & 250 \\
\hline Suzuki-imported & 34.8 & 22.3 & 2,533 & 113 \\
\hline Toyota-domestic & 33.2 & 287.9 & 3,088 & 154 \\
\hline Toyota-imported & 28.8 & 708.1 & 3,383 & 163 \\
\hline Volkswagen-imported & 28.5 & 397.3 & 3,353 & 146 \\
\hline Passenger Car Average mpg & 28.2 & & & \\
\hline \multicolumn{5}{|l|}{ Light Trucks } \\
\hline BMW-imported ${ }^{b}$ & 17.1 & 36.9 & 5,028 & 206 \\
\hline Daimler-Chrysler-domestic & 21.3 & $1,730.7$ & 4,291 & 193 \\
\hline Ford Motor Company_domestic & 20.9 & $1,866.0$ & 4,438 & 202 \\
\hline Ford Motor Company_imported & 23.1 & 50.6 & 4,000 & 170 \\
\hline General Motors-domestic & 20.9 & $2,160.4$ & 4,314 & 221 \\
\hline Honda-domestic & 24.0 & 102.2 & 3,000 & 205 \\
\hline Honda-imported & 27.2 & 82.9 & 3,456 & 146 \\
\hline Isuzu-domestic & 27.3 & 4.4 & 2,775 & 119 \\
\hline Isuzu-imported & 20.8 & 135.3 & 4,273 & 199 \\
\hline Kia-imported & 23.4 & 66.6 & 3,628 & 130 \\
\hline Mitsubishi-imported & 21.5 & 49.8 & 4,184 & 176 \\
\hline Nissan-imported & 21.1 & 313.2 & 3,870 & 165 \\
\hline Suzuki-imported & 23.0 & 36.4 & 3,489 & 155 \\
\hline Toyota-imported & 21.8 & 590.4 & 4,016 & 191 \\
\hline Volkswagen-imported & 28.5 & 397.3 & 3,353 & 146 \\
\hline Light-Truck Average mpg & 21.2 & & & \\
\hline Light-Duty-Vehicle Average mpg & 24.6 & & & \\
\hline
\end{tabular}

a The definition of domestic used here is that of the "CAFE" law: $75 \%$ domestic content, by value.

b Includes Land Rover, which BMW owned for part of 2000. 
Although care has been taken to select technologies that do not grossly violate this assumption, it is only approximately correct. In reality, the technologies described in Section 4 will have some positive and negative effects on customer satisfaction, adding an additional degree of uncertainty to the results of this analysis.

\subsubsection{Fuel Economy Price Curves}

Given the above framework, the key to modeling manufacturer behavior is describing the technology available for improving fuel economy. This task is accomplished by means of fuel economy price curves, which are based on the technology and price data of Section 4 . The potential to improve fuel economy at a cost can be described by mathematical functions relating fractional fuel economy increases to cumulative retail price increases. Different price curves are needed for passenger cars and light trucks in order to reflect the differing applicability of technologies to cars and trucks. In addition, manufacturer-specific price curves were estimated for major manufacturers to better reflect differences in their product lines and their current use of technologies to increase mpg. The prices and fuel economy impacts of technologies are assumed to not vary across manufacturers.

Price curves were fitted to industry-wide and manufacturer-specific data consistent with the technology data of Section 4. An explanation of the technologies on this list, their fuel economy impacts, and prices can be found in Section 4. Examples of these data for an average of all manufacturers are shown for passenger cars and light trucks in Tables 6-2 and 6-3. Data for all of the manufacturer-specific curves can be found in an appendix to Greene and Hopson (2002). For each technology listed, four key data items are required: (1) the initial market penetration in 2000 , (2) the market penetration estimated to be achievable by 2015, (3) the percent improvement in fuel economy provided, and (4) the retail price increase. The estimated percent improvements in fuel economy in Table 6-2 take into account interactions with technologies listed above them in the table. A weighted improvement in fuel economy is calculated by multiplying the change in market share by the percent improvement achievable for an individual vehicle. A weighted price is calculated in the same way. Weighting by change in market penetration allows otherwise incompatible technologies to be included in the analysis.

The fuel economy improvement potentials are defined relative to the next-best technology of that type. For example, the five-speed automatic transmission's 4\% gain in fuel economy is an incremental benefit over the four-speed automatic. Thus, the market shares of these two technologies need not sum to one. On the other hand, the sum of alternative transmission types (manual, automatic) must sum to one. Thus, in Table 6-2, CVT-4 and Auto-5 displace Auto-4, but not Man-6. The sum of CVT-4, Auto-5, and Man-6, plus a residual for less-advanced transmissions, must sum to one.

The "vehicle" to which the price curve applies is a composite of all vehicles of the same manufacturer, vehicle type, and origin. The technology price curve is an aggregate description of a manufacturer's ability to supply fuel economy, rather than a technical plan for improving the fuel economy of a particular vehicle. 


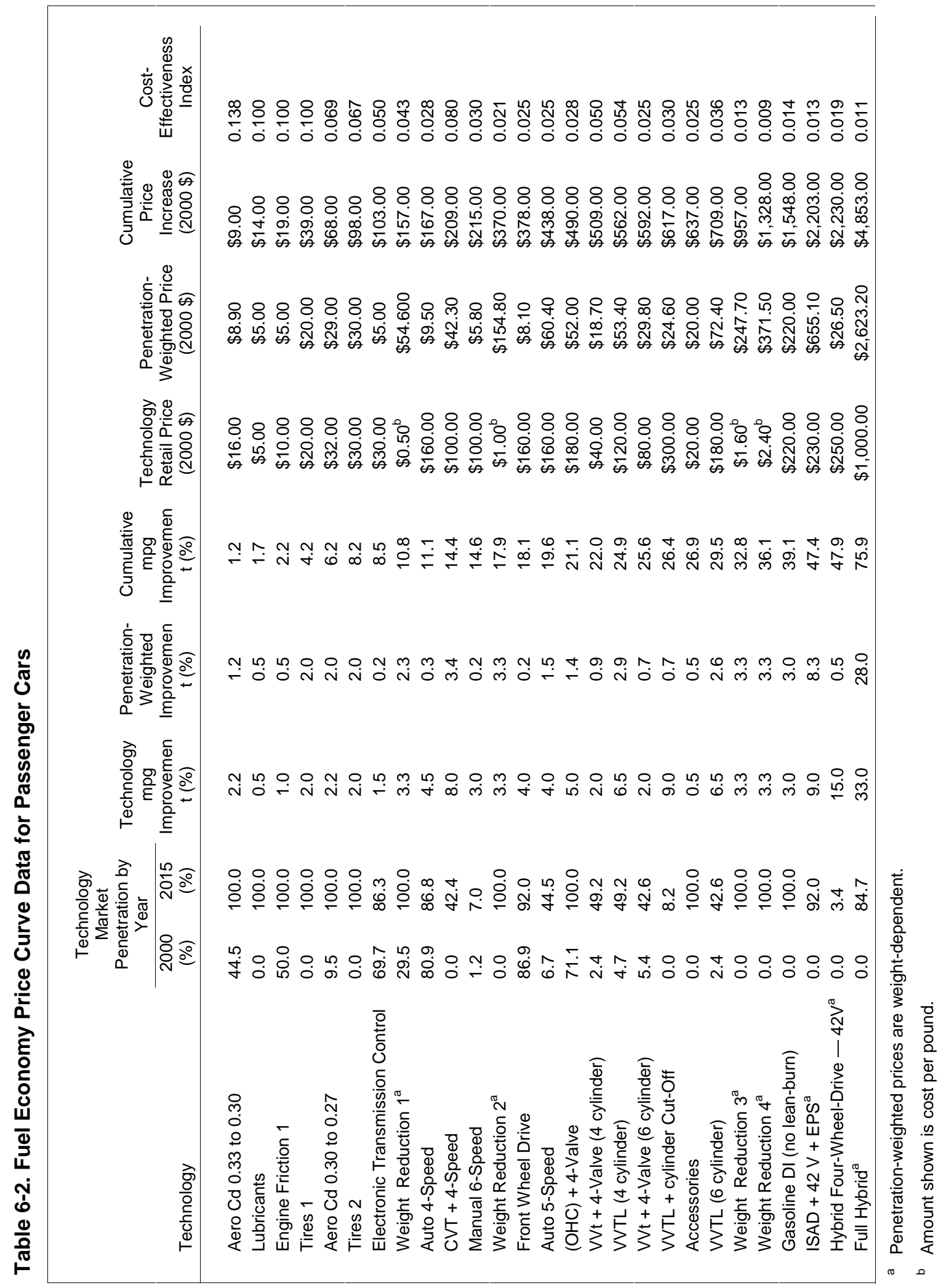




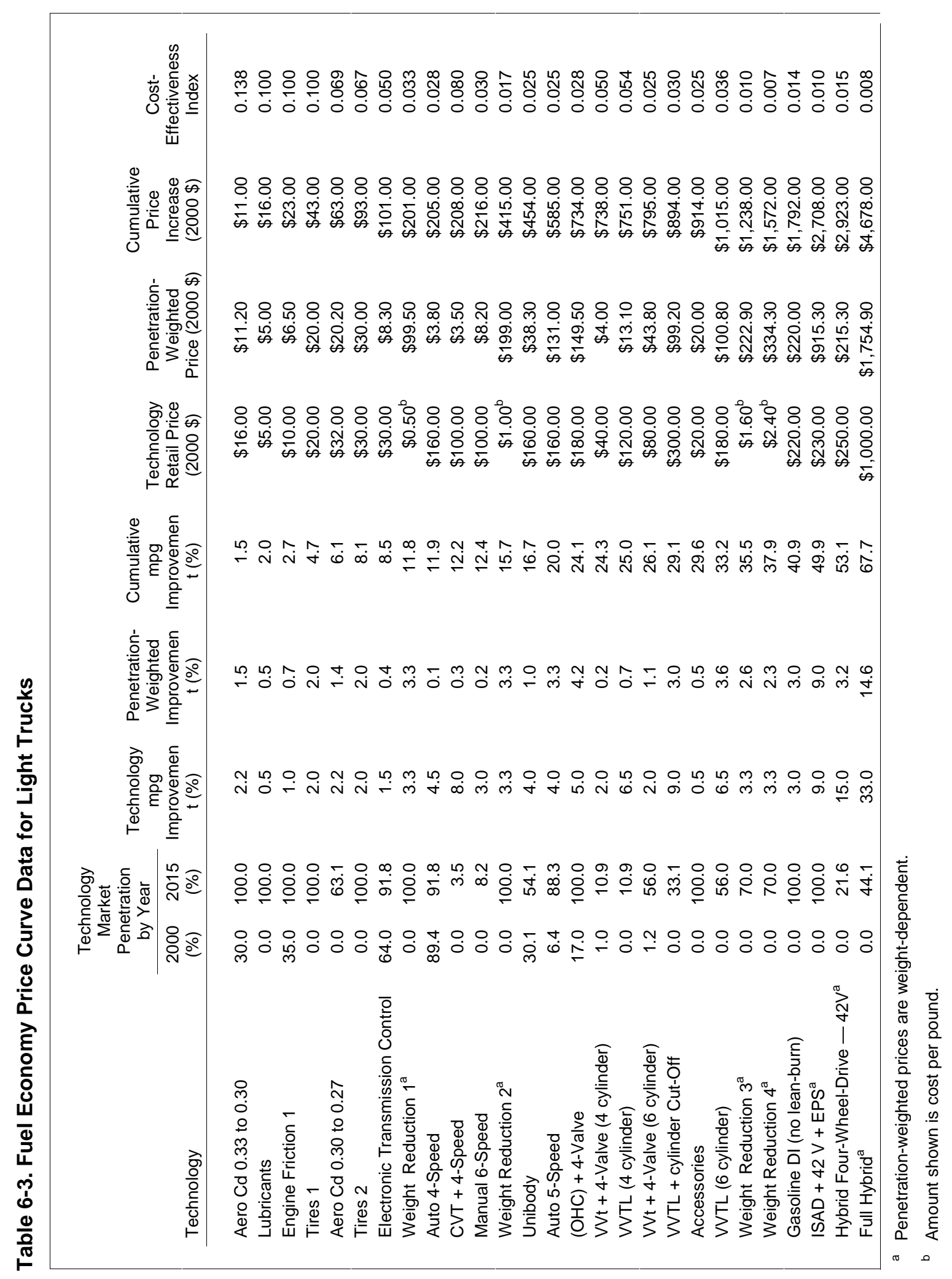


Before mathematical functions are fitted to the data, the technologies are ranked by a costeffectiveness index equal to the percent improvement in fuel economy divided by the price increase. This procedure ensures that technologies are implemented in order of increasing marginal cost, in accordance with economic theory. ${ }^{75}$

A recent review of the technology cost literature indicated that two-parameter quadratic curves fit data from all studies well (Greene and DeCicco 2000). Let $x$ be the fractional improvement in mpg ( 0.2 representing a $20 \%$ improvement). The two-parameter quadratic price function is shown in equation 1.

$$
P(x)=b x+c x^{2}
$$

$\mathrm{P}(\mathrm{x})$ is the retail price increase for a 100x percent increase in fuel economy, and $b$ and $c$ are parameters to be estimated.

The quadratic curve in fractional mpg improvement space can be readily transformed into mpg space by multiplying the $b$ coefficient by a base mpg value and the c coefficient by mpg ${ }^{2}$. This approach allows an industry-wide curve, for example, to be calibrated to each manufacturer's base year fuel economy. The method is also used here to calibrate price curves for manufacturers for which detailed technology data (as in Tables 6-2 and 6-3) were not available.

Quadratic functions without a constant (intercept) were fitted to the ranked technology price data by using the regression procedure of the Excel ${ }^{\mathrm{TM}}$ spreadsheet software. The parameter estimates are intended to be curve fits and not statistical estimations. The intercept terms are omitted because, by construction, the curves pass through the origin $(0 \%$ improvement has $\$ 0$ cost). Two-parameter quadratic functions fit the data well, with adjusted $\mathrm{R}^{2}$ values exceeding 0.93 in all instances. The fitted curves for industry-average passenger cars and light trucks are shown in Figures 6-1 and 6-2. The curves are intended to apply to composite cars and light trucks having the average characteristics of all model year 2000 vehicles of each type. Significant "gaps" in the technology price data can be seen - above about $30 \%$ for passenger cars and $40 \%$ for light trucks. These gaps reflect the implementation of hybrid technology, which can yield a large jump in fuel economy. Interpolation of the price between these gaps relies on the fact that an average car can be $10 \%$ hybrid, although an individual car cannot. Still, one could legitimately question whether the quadratic form was the best for interpolating between these points. Fortunately, what is important is that the fitted curves accurately reflect the rate of increase in retail price for a percent increase in fuel economy for the full range of fuel economy improvements being considered. For this study, that range is approximately 20-33\%. As a result, the interpolation is a minor detail.

75 Ranking by cost-effectiveness also can place technologies out of order in terms of the engineering requirements for implementation. One solution is to merge such technologies into one, so that they can only be implemented simultaneously. Experimentation with this method showed that it had negligible impact on the shape of the cost curve, and so it was not pursued. 


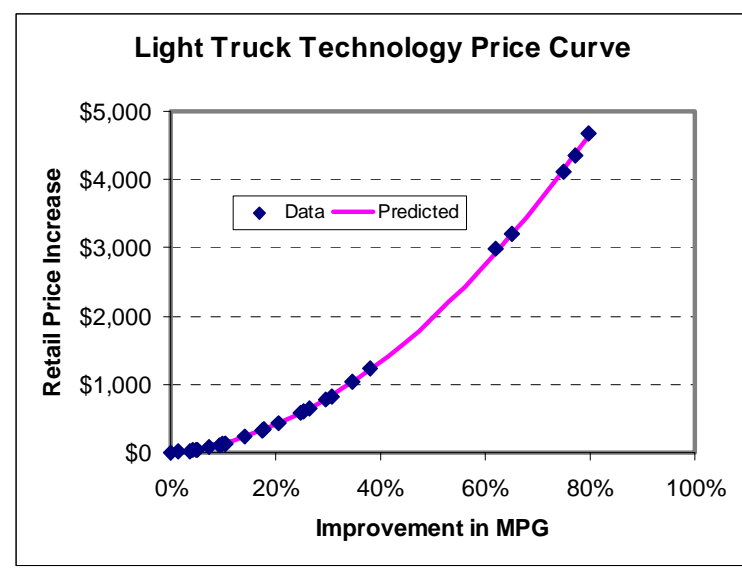

Figure 6-1. Passenger Car Fuel Economy Technology Price Curve, EEA Industry Average Data, 2012-2015

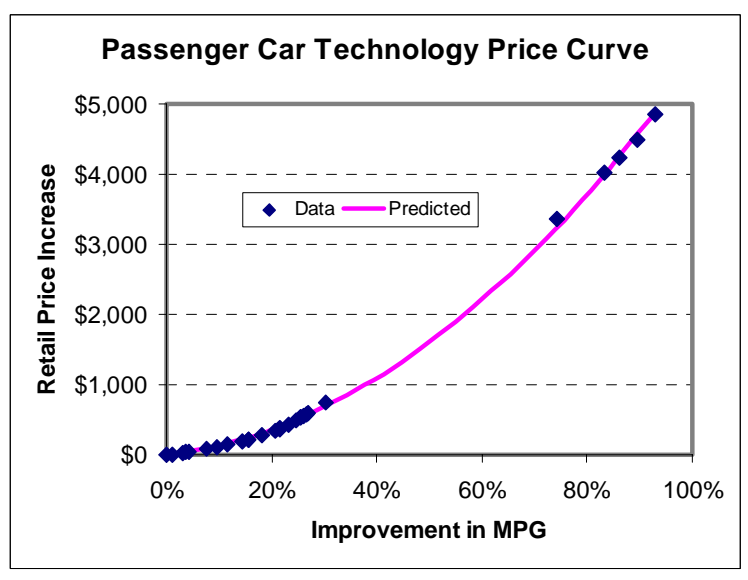

Figure 6-2. Light Truck Fuel Economy Technology Price Curve, EEA Industry Average Data, 2012-2015

The industry-wide quadratic fuel economy price equations for passenger cars and light trucks are shown in equations 6.2 and 6.3, where $x$ is again the fractional improvement in mpg.

$$
\begin{aligned}
& P(x)=833.85 x+4754.36 x^{2} \\
& P(x)=794.79 x+6323.70 x^{2}
\end{aligned}
$$

Parameters for the manufacturer-specific equations are shown in Table 6-4. These curves were developed from manufacturer-specific data compiled by EEA, Inc., on the model year market penetration of fuel economy technologies and the same estimates of technology price and performance shown in Tables 6-2 and 6-3. These data were not provided by the manufacturers themselves. Data were available for only certain of the largest manufacturers (Daimler-Chrysler, Ford, GM, Honda, Nissan, Toyota, and VWA). Other manufacturers were assigned the parameters of a "similar" manufacturer in the same country of origin. No data were available for Korean manufacturers, which were assigned the industry average cost curve parameters.

\subsubsection{Alternative Price Curves}

To test the sensitivity of results to the underlying fuel economy-price relationships, industry-wide but not manufacturer-specific price curves were fitted to data from several other studies. Quadratic price curves were fitted to data developed by Sierra Research (Austin et al. 1999) and the National Research Council (NRC 2001) by using the methods described above. The NRC and Sierra Research studies provide data in a format similar to that shown in Tables 6-2 and 6-3, from which quadratic price curves could be estimated.

Quadratic curves were also developed based on studies by the Massachusetts Institute of Technology (MIT) (Weiss et al. 2000) and the American Council for an Energy Efficient Economy (ACEEE) (DeCicco et al. 2001) but using a different approach. The MIT study takes a longer look ahead than this study, 2020 instead of 2015, and explicitly incorporates likely 
Table 6-4. Manufacturer-Specific Fuel Economy Technology Price Curves (price as a function of percent increase in fuel economy)

\begin{tabular}{|c|c|c|c|c|c|c|c|c|}
\hline \multirow[b]{3}{*}{ Manufacturer } & \multicolumn{4}{|c|}{ Passenger Car } & \multicolumn{4}{|c|}{ Light Truck } \\
\hline & \multicolumn{2}{|c|}{ Domestic } & \multicolumn{2}{|c|}{ Import } & \multicolumn{2}{|c|}{ Domestic } & \multicolumn{2}{|c|}{ Import } \\
\hline & b & c & b & c & b & c & b & c \\
\hline $\mathrm{BMW}^{\mathrm{a}}$ & 252.97 & $2,200.88$ & 737.82 & $3,342.14$ & $1,093.81$ & $5,510.97$ & $1,093.81$ & $5,510.97$ \\
\hline Daimler-Chrysler & 905.22 & $3,971.64$ & $1,089.66$ & $5,622.38$ & 994.61 & $4,995.50$ & $1,525.30$ & $6,095.59$ \\
\hline Ford Motor Company & 802.97 & $4,786.37$ & 965.49 & $4,696.37$ & $1,298.02$ & $4,303.49$ & $1,152.79$ & $4,599.86$ \\
\hline Subaru $^{b}$ & $1,144.19$ & $3,685.65$ & $1,144.19$ & $3,685.65$ & 645.03 & $5,230.27$ & 645.03 & $5,230.27$ \\
\hline General Motors & $1,034.03$ & $4,319.61$ & 893.39 & $3,521.41$ & 465.52 & $7,772.78$ & 454.15 & $3,849.56$ \\
\hline Honda & 882.62 & $4,880.92$ & 882.62 & $4,880.92$ & 964.41 & $3,997.46$ & 964.41 & $3,997.46$ \\
\hline Hyundai $^{c}$ & 833.85 & $4,754.36$ & 833.85 & $4,754.36$ & 794.79 & $6,323.70$ & 794.79 & $6,323.70$ \\
\hline Isuzu ${ }^{b}$ & $1,144.19$ & $3,685.65$ & $1,144.19$ & $3,685.65$ & 645.03 & $5,230.27$ & 645.03 & $5,230.27$ \\
\hline $\mathrm{Kia}^{\mathrm{c}}$ & 833.85 & $4,754.36$ & 833.85 & $4,754.36$ & 794.79 & $6,323.70$ & 794.79 & $6,323.70$ \\
\hline Mitsubishi ${ }^{\mathrm{b}}$ & $1,144.19$ & $3,685.65$ & $1,144.19$ & $3,685.65$ & 645.03 & $5,230.27$ & 645.03 & $5,230.27$ \\
\hline Nissan $^{b}$ & $1,144.19$ & $3,685.65$ & $1,144.19$ & $3,685.65$ & 645.03 & $5,230.27$ & 645.03 & $5,230.27$ \\
\hline Porsche ${ }^{a}$ & 252.97 & $2,200.88$ & 737.82 & $3,342.14$ & $1,093.81$ & $5,510.97$ & $1,093.81$ & $5,510.97$ \\
\hline Suzuki $^{b}$ & $1,144.19$ & $3,685.65$ & $1,144.19$ & $3,685.65$ & 645.03 & $5,230.27$ & 645.03 & $5,230.27$ \\
\hline Toyota & 966.75 & $3,963.53$ & 966.75 & $3,963.53$ & 661.63 & $5,376.44$ & 661.63 & $5,376.44$ \\
\hline Volkswagen $^{\mathrm{a}}$ & 252.97 & $2,200.88$ & 737.82 & $3,342.14$ & $1,093.81$ & $5,510.97$ & $1,093.81$ & $5,510.97$ \\
\hline
\end{tabular}

technological progress in its estimates. The ACEEE study is generally more optimistic than the NRC and Sierra studies about the price and performance of future fuel economy technology, as well as the willingness of customers to accept small changes in vehicle characteristics. The ACEEE study provides both "moderate" and "advanced" vehicle designs. Only the more optimistic advanced designs have been used here. The MIT and ACEEE studies produced fuel economy estimates for distinct vehicle designs comprising particular combinations of technologies. Using computer simulation models, they then estimated the fuel economy of these designs over the federal test cycles. Thus, it is not possible to estimate fuel economy price curves with the same meaning for these studies. Instead, quadratic curves were fitted through the origin (\$0,0 mpg) and two particular technology combinations. These price curves can be interpreted as describing a technology envelope for fuel economy improvement that is generally consistent with the conclusions of the two studies. However, the studies do not provide information demonstrating what the path between technologies might be. It is simply assumed here that a quadratic path exists. Thus, results obtained by using these curves should be interpreted as suggesting what things might be like given either a greater degree of technological progress (MIT) or greater optimism about the performance and price of fuel economy technologies (ACEEE).

Fuel economy price curves derived from all four studies are shown in Figures 6-3 and 6-4. Base-year mpg values of 28.4 for passenger cars and 20.1 for light trucks are assumed for the price curves in Figures 6-3 and 6-4, which are plotted in terms of a change in mpg. 
Only the NRC study provides upper and lower uncertainty bounds on its price curves. In general, the passenger car and light truck price curves used in this study fall within those bounds over the range of fuel economy improvements of interest. This study's passenger car fuel economy price curve is toward the lower end of the NRC range, while the light truck price curve used here is toward the upper-bound NRC curve.

In addition, the analysis of weight-based standards requires technology price curves that do not include weight-reduction technologies. A pair of industry-average passenger car and light truck curves was constructed from this study's industry average curves by deleting the four weight-reduction technologies. The remaining technologies were then ranked by their costeffectiveness indices and the quadratic curves fitted in the usual way. Parameters for all of the alternative curves are shown in Table 6-5.

\subsubsection{Impact of Future Regulations}

While no attempt is made to predict how changes in future market conditions may affect the demand for fuel economy versus other vehicle attributes, a small adjustment is made for the likely impact of future safety and emissions standards. Such regulations are assumed to add approximately $5 \%$ to the weight of passenger cars and light trucks, incurring about a $3 \%$ fuel economy penalty. Thus, each manufacturer will have to add fuel economy technology to make up for the 3\% penalty just to maintain 2000 base fuel economy levels, in addition to increasing fuel economy to achieve the standard.

In the mathematical programming analysis, the effect of the $5 \%$ weight increase is represented by requiring a $[(1.20 \times 1.03)-1] \times 100=23.6 \%$ fuel economy increase in the $20 \%$ requirement case. The $33 \%$ standard thus becomes a $[(1.33 \times 1.03)-1] \times 100=37 \%$ increase. Future fuel economy numbers are then adjusted downward by dividing by 1.03 , to account for the effect of the 5\% weight increase. However, keep in mind that a realized $20 \%$ increase requires a $23.6 \%$ increase, and a 33\% increase calls for a 37\% increase over the unadjusted baseyear level. Reported vehicle price increases and fuel savings reflect the costs and benefits of overcoming the $5 \%$ weight increase.

\subsubsection{Consumer Behavior}

The consumer is the other principal actor in the market for fuel economy. Consumers are assumed to treat fuel economy improvement as an investment that will yield a known rate of return but the capital value of which will depreciate over time. Consumers are assumed to be concerned with the net value of fuel savings over the life of the vehicle, which is estimated to be 14 years (Davis 2000; Table 6-9): the present value of lifetime fuel savings minus the increase in purchase price. In reality, not all consumers value fuel economy the same way, and few calculate the discounted present value of future fuel savings. These assumptions are used here for analytical clarity and rigor. Sensitivity analysis is used to explore an alternative assumption. 


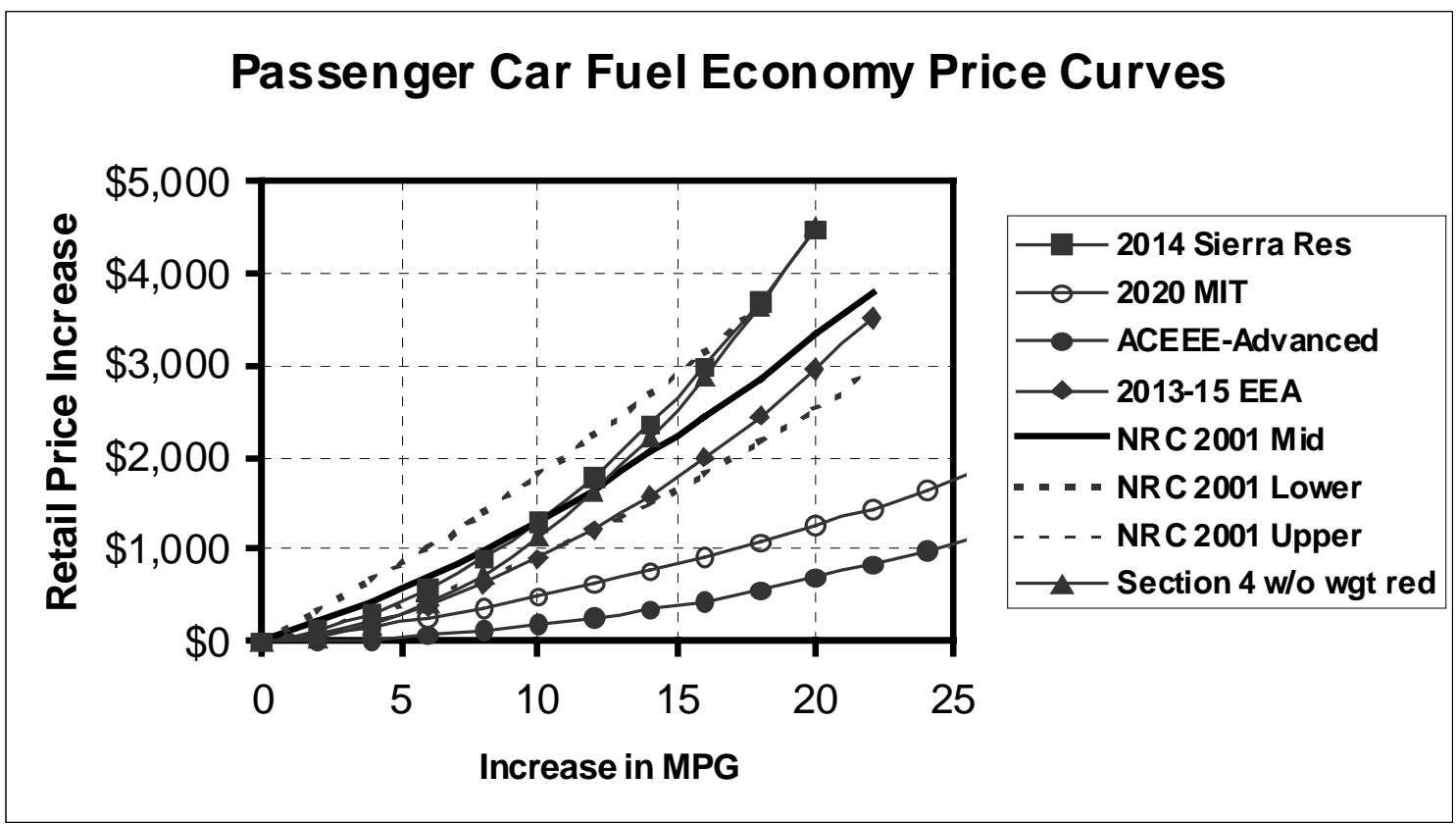

Figure 6-3. Comparison of Fuel Economy Technology Price Curves for Passenger Cars

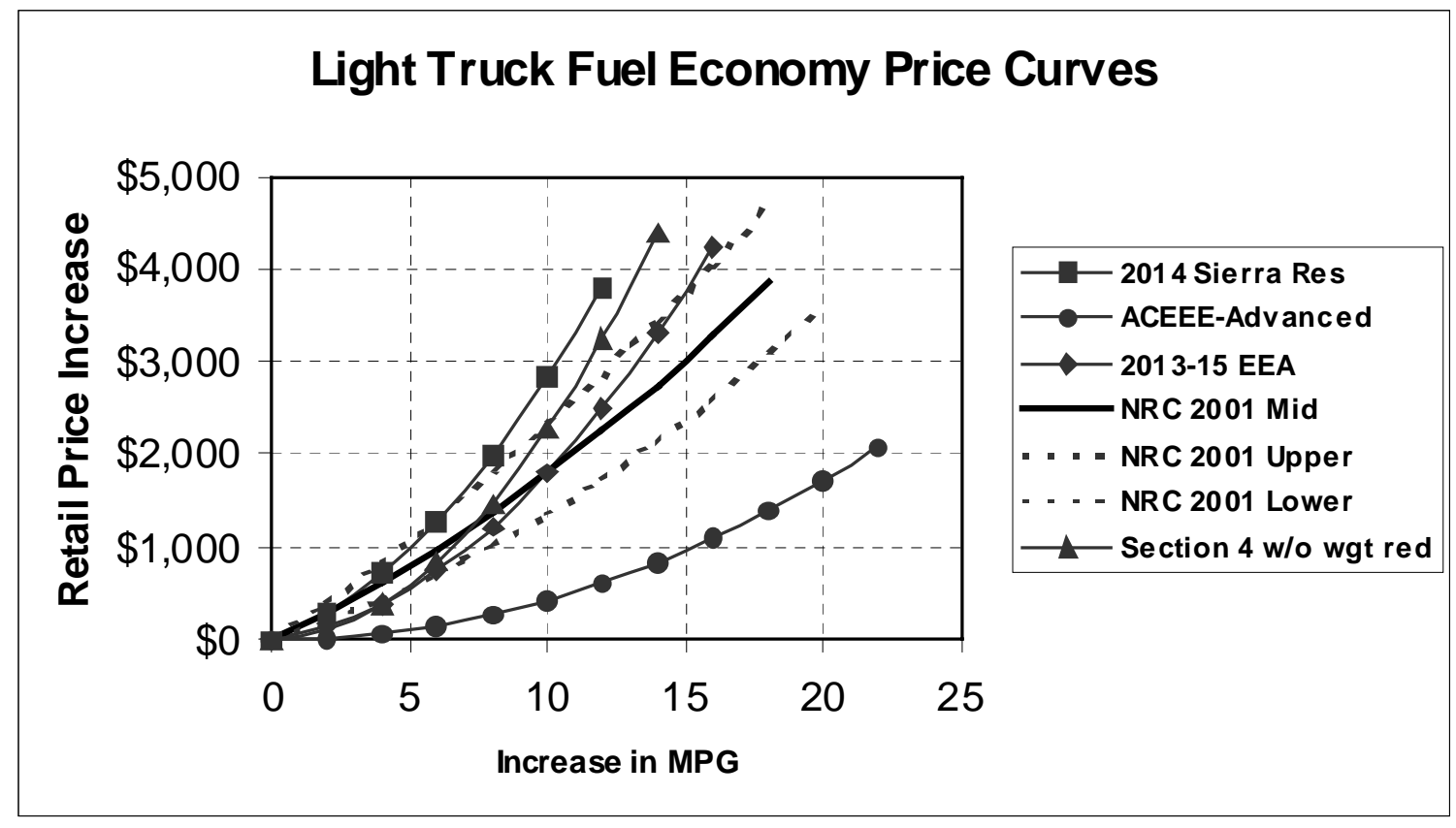

Figure 6-4. Comparison of Fuel Economy Technology Price Curves for Light Trucks 
Table 6-5. Alternative Fuel Economy Technology Price Curves ${ }^{a}$ (Retail price as a function of percent increase in fuel economy)

\begin{tabular}{|c|c|c|c|c|}
\hline \multirow[b]{2}{*}{ Source } & \multicolumn{2}{|c|}{ Passenger Car } & \multicolumn{2}{|c|}{ Light Truck } \\
\hline & b & c & b & c \\
\hline $\begin{array}{l}\text { Section } 4-\text { without Weight } \\
\text { Reduction }\end{array}$ & 16.41 & $9,025.10$ & 219.33 & $8,772.83$ \\
\hline Sierra Research & $1,097.36$ & $7,480.18$ & $2,101.95$ & $6,183.04$ \\
\hline NRC High-Cost/Low-MPG & $4,211.21$ & $1,429.82$ & $3,916.68$ & $1,019.78$ \\
\hline NRC Average & $2,460.87$ & $2,359.27$ & $2,528.87$ & $1,587.88$ \\
\hline NRC Low-Cost/High-MPG & $1,336.76$ & $2,404.51$ & $1,559.07$ & $1,688.99$ \\
\hline ACEEE Derived & 0 & $1,392.34$ & 0 & $1,734.18$ \\
\hline MIT 2020 Derived & 952.85 & $1,196.11$ & $1,013.31$ & $1,352.74$ \\
\hline
\end{tabular}

Note that in this analysis, fuel economy is valued from a private and not a societal perspective. Since voluntary fuel economy standards are being assessed, it is important to estimate how the different standards appear from the manufacturers' perspective, and making this estimate requires valuing fuel savings as their customers would.

\subsubsection{Key Assumptions}

Treating fuel economy technology as a depreciating asset implies that the consumer will demand a higher rate of return for an investment in fuel economy than for an investment in a non-depreciating asset, such as a certificate of deposit or savings bond. This required higher rate of return should not be confused with the consumer's discount rate. Assuming that the value of a vehicle is approximately zero at the end of its life, the rate of return consumers will demand for fuel economy improvements will be primarily determined by the expected life of the vehicle. This scenario can be illustrated by an example.

Suppose that a prospective car buyer has a time discount rate of 5\% per year and can invest at a real, after-tax rate of return of $6.5 \%$ per year in a virtually risk-free, non-depreciating asset. The economically rational car buyer will demand a rate of return on an investment in fuel economy that equates the return on fuel economy over the life of the vehicle to the return on the alternative investment. Although expected lifetimes for passenger cars and light trucks appear to vary by model year, a reasonable median life expectancy is approximately 14 years (Davis 2001; Tables 6-9 and 6-10). Let $X$ be the cost of the fuel economy investment and $\alpha$ be the required rate of return. The car buyer's problem is represented by equation 6.4, which has the discounted present value of the fixed investment on the left-hand side and the present value of the fuel economy investment on the right-hand side.

$$
X e^{(0.065) 14} e^{(-0.05) 14}=\int_{0}^{14} \alpha X e^{-0.05 t} d t=\frac{\alpha X}{-0.05}\left(e^{(-0.05) 14}-1\right)
$$


Solving for $\alpha$ shows that even with these modest rates of return and discount rates, the consumer will demand a rate of return of $12 \%$ for an investment in fuel economy, chiefly because of the need to recoup the original investment.

$$
\alpha=\frac{0.05 e^{0.21}}{\left(1-e^{-0.7}\right)} \cong 0.12
$$

Although higher rates of return on fuel economy investments could be argued for, $12 \% /$ year is used as a base case assumption in this analysis.

The most recent national survey data indicate that new private automobiles travel 15,600 miles in their first year of operation. However, vehicle use declines with vehicle age, which implies declining annual fuel savings. Survey data for the United States indicates an average annual rate of decline of approximately $4 \%$ per year for household vehicles (Davis 2001; Tables 6-6 and 6-7). The annual mileage and rate of decline estimates for household vehicles are used here for all automobiles and light trucks.

Clearly, consumers do not know what future fuel prices will be. It is assumed that consumers will have static expectations; that is, they will assume that the future price of fuel will be the same as the current price of fuel. A price of $\$ 1.35$ per gallon is used for the base case and $\$ 1.75$ for an alternative case for sensitivity analysis.

Finally, there is definitive evidence that consumers typically achieve lower fuel economy in actual on-road driving than the EPA dynamometer test mpg numbers (e.g., Hellman and Murrell 1984). Although there is evidence that the shortfall for trucks may be larger than that for passenger cars (Mintz et al. 1993), the average shortfall of 15\% implied by EPA official correction factors is used here for both vehicle types. Survey evidence suggests that the shortfall has remained roughly constant over time (Harrison 1996).

The representative consumer of this analysis carefully calculates the value of fuel savings over the full-expected life of the vehicle and expects future fuel prices to be about the same as those today. An alternative hypothesis, that consumers do not consider full lifetime fuel savings, is tested in the sensitivity analysis. The alternative assumes that consumers consider only the first three years of fuel savings but do not discount the savings. In general, this implies that consumers will place less than half as much value on fuel savings. In theory, failing to account for real future fuel savings would represent a market failure, in the sense that real-world consumers would not be acting like the fully informed, rational consumers of economic theory and, thus, the market for fuel economy would not be economically efficient.

In reality, there is not only one type of consumer with one discount rate, one annual vehicle miles of travel, and so on. Consumers use their vehicles differently, demand different rates of return, and have different preferences for fuel economy versus other vehicle attributes. To some extent, the differences among manufacturers' current levels of fleet fuel economy can be explained by the different market segments they serve. No attempt is made here to account for such differences in consumer preferences across manufacturers. For this reason, it is most appropriate to interpret the estimated impacts of alternative standards on manufacturers as being 
generally indicative of the kinds of impacts the standards may have, rather than as a prediction of the impacts on a particular manufacturer.

\subsubsection{The Fuel Economy Market Model}

Maximizing net value to consumers of increasing fuel economy to meet voluntary standards can be formulated as a mathematical programming problem. The objective function is the weighted sum across product lines of the discounted present value of fuel savings to the consumer minus the increases in purchase prices caused by the addition of fuel economy technology. Weights are the base-year 2000 production numbers for each product line.

Constraints represent the voluntary fuel economy standards, and their form depends on precisely which standard is being evaluated. Formulated in terms of miles per gallon, the problem is nonlinear in both the objective function and constraints. The objective function and constraint for an industry-wide fuel economy standard are shown in Equation 6.6.

$$
\begin{aligned}
& \operatorname{Max} \sum_{m} \sum_{v} \sum_{o}\left[\left\{s_{m v o} k_{v}\left(\frac{1}{f_{m v o}}-\frac{1}{f_{m v o}\left(1+x_{m v o}\right)}\right)\right\}-\left\{b x_{m v o}+c x_{m v o}^{2}\right\}\right] \\
& \text { s.t. } \\
& F(1.03) \leq \frac{1}{\sum_{m} \sum_{v} \sum_{o} \frac{s_{m v o}}{f_{m v o}}}
\end{aligned}
$$

The variables $s$ and $f$ represent base-year market shares and fuel economy levels, while $k$ is a constant term reflecting the consumer's valuation of fuel economy. The decision variables, represented by $x$, are the fractional improvements in mpg. $F$ is the fuel economy target that must be met or exceeded. The subscripts $m, v$, and $o$ index manufacturer, vehicle type, and country of origin.

The nonlinear programming problem was implemented using GAMS ${ }^{\text {TM }}$ (Brooke et al. 1998) software. The "nlp" solver of GAMS was used in all cases. A copy of the code can be found in the appendix of Greene and Hopson (2002).

\subsubsection{Measuring Efficiency and Equity}

The objective of this portion of the study is to measure the performance of alternative forms and levels of voluntary fuel economy standards along two dimensions: (1) economic efficiency and (2) differential impacts on manufacturers. Neither manufacturers nor the government would be likely to agree to standards that were grossly inefficient and wasteful of society's resources. Manufacturers would also be unlikely to voluntarily agree to fuel economy standards that would noticeably degrade the value of their products to their customers. Achieving a voluntary agreement will also require reaching consensus among manufacturers. It would be difficult to reach consensus on a standard that seriously disadvantaged some manufacturers relative to others. Thus, the competitive impacts of alternative forms of standards is also a key factor. 
The principal measure of efficiency is the net benefit or cost of a standard, which is equal to the total increase in vehicle prices due to increasing fuel economy minus the total amount their customers are willing to pay for the higher mpg. Unless a voluntary standard is set at a very high level, it is likely to have net total benefits rather than costs because maximizing net value to the consumer requires adding fuel economy up to the point at which the marginal cost of the next fuel economy improvement just equals the marginal value of the fuel it saves. Further improvements would cost more than the value of their fuel savings. All previous improvements cost less. Therefore, at the maximum value point, the total cumulative value of savings exceeds the total cost. If voluntary standards require fuel economy improvements beyond the point of maximum value, the net total benefits will be decreased and, at some point, will become net costs as the level of the standard is increased.

Impacts on manufacturers are measured by changes in the net value to customers of each manufacturer's product lines and by the marginal cost of gasoline saved by increasing vehicle fuel economy. If a particular form of standard imposes a more severe constraint on one manufacturer than another, the constrained manufacturer will have to decrease the net value of its products more (or increase the net value less) in order to meet the standard. To the extent that a voluntary standard appears to require some manufacturers to significantly reduce the value of their products relative to others, it will be difficult to persuade disadvantaged manufacturers to concur with that standard. If a standard requires more effort from some manufacturers than from others, then the marginal cost per gallon saved by the first group of manufacturers will be higher. A higher marginal cost indicates that more expensive technologies had to be used to meet the fuel economy requirement.

Because, in this analysis, manufacturers' product lines are aggregated into broad categories (such as domestic passenger cars and imported light trucks), the change in net value per vehicle should be considered only a general indicator of competitive impacts. Another important consideration is that the competitive positions of specific manufacturers will change over the next decade or so. Thus, the calculated impacts may not actually apply to any specific manufacturer in 2015. The premise is that manufacturers are more likely to agree to a standard that appears to be fair given their current competitive position than they are to one that does not.

Finally, the impacts on individual manufacturers estimated in this analysis must be interpreted cautiously. No attempt is made, for example, to account for the fact that manufacturers sell vehicles to different market segments. Differences in the tastes and preferences of consumers across market segments, especially with respect to fuel economy, would lead manufacturers to use different levels of fuel economy technology. The analysis makes no attempt to account for such differences.

\subsection{Structure of Analysis}

The alternative voluntary standards considered consist of (1) two levels of overall fuel economy improvement (20\% and 33\%), (2) three alternative fuel economy metrics, (mpg, UPI, and weight-adjusted), (3) five constraint structures, and (4) several sensitivity analyses to test key assumptions. Estimated manufacturer-specific cost curves are used as the preferred description of 
technology costs. However, several alternative industry-wide cost functions were tested in the sensitivity analysis.

\subsubsection{Levels, Forms, and Metrics: $\mathrm{mpg}$, UPI, and Weight-Based Standards}

Two fuel economy levels were evaluated for the 2015 period: $20 \%$ and $33 \%$ improvements. Given a base year fuel economy standard of $28.2 \mathrm{mpg}$ for passenger cars, a $20 \%$ improvement implies a 2015 target of $33.8 \mathrm{mpg}$. Similarly, a $33 \%$ improvement implies a target of $37.5 \mathrm{mpg}$. The corresponding targets for light trucks are $25.4 \mathrm{mpg}$ and $28.2 \mathrm{mpg}$ (compared to a base level of 21.2), and the combined light-duty fleet numbers are $29.5 \mathrm{mpg}$ and $32.7 \mathrm{mpg}$, versus a current level of $24.6 \mathrm{mpg}$.

The form of a fuel economy standard is defined by (1) the metric it uses to specify a target fuel economy level and (2) the structure of the constraints it places on manufacturers. Three principal metrics are examined:

1. A sales-weighted harmonic mean mpg standard,

2. A UPI over a reference level, and

3. A weight-based fuel consumption formula.

Five constraint structures are tested:

1. Industry-wide constraint — sets a single mpg target to be met by the industry as a whole but allows manufacturers' fleet average mpg levels to differ.

2. Industry-wide vehicle type constraints - sets one industry-wide target for passenger cars and another for light trucks.

3. Manufacturer-specific constraints - sets an mpg target for each manufacturer.

4. Manufacturer-vehicle type constraints - sets separate targets for each manufacturer's passenger car and light truck fleets.

5. Manufacturer-vehicle type-origin constraints — sets individual mpg targets for each manufacturer's domestic and imported passenger car and light truck fleets.

The first type of constraint, industry-wide, places no specific requirement on an individual manufacturer. Each manufacturer is assumed to maximize net value to customers, subject to the industry as a whole meeting or exceeding the $20 \%$ or $33 \%$ objective. This constraint is directly analogous to the European voluntary agreement. How the industry would monitor and enforce such an agreement is not clear. Indeed, just how the European agreement will be enforced is not known. 
The fifth constraint structure is identical to the original CAFE law. However, the NHTSA abolished the distinction between domestic and imported light trucks after model year 1995. Constraint 5 requires that both cars and trucks meet separate import and domestic standards. The equations used to implement each set of constraints can be found in Greene and Hopson (2002).

A standard that adjusts to the types of vehicles sold by different manufacturers can be formulated on the basis of the average weight of the vehicles sold. The following weight-based standard is based on formula (5.1a) discussed in Section 5. This "simple" weight-based standard requires that each manufacturer $(\mathrm{m})$ achieve less than a specified gallons-per-100-miles $\left(\mathrm{G}_{\mathrm{m}}\right)$ number that depends on the average weight of the manufacturer's vehicle fleet. Specifically, for a $k \times 100 \%$ improvement in fuel economy, the equation is:

$$
G_{m}=\frac{\left(0.0012 \times \sum_{v o c} W_{m v o c}\left(1+w_{m v o}\right) s_{m v o c}+0.0013\right)}{1.112 \times(1+k)}
$$

The average weight of a manufacturer's products in 2015 is calculated from the base-year weights $(W)$ and an endogenously calculated fractional change in weight $(w)$, taking into account the sales share for the relevant vehicle type $(v)$, origin $(o)$, and country $(c)$. Interesting features of this equation are that it (1) applies to all of the manufacturer's vehicles and does not distinguish between cars and trucks and (2) sets a manufacturer-specific target reflecting the mix of vehicles the manufacturer sells as represented by their weight. Because the gallons-per-mile requirement increases as weight increases, this standard may create an incentive for manufacturers to add weight to vehicles. Whether it does or does not will depend on (1) how changing weight changes the price of a vehicle, (2) the value of fuel savings foregone by increasing weight, and (3) the value to the manufacturer of a less-stringent requirement. Because this standard is a function of weight, there is no need to adjust for the assumed 5\% percent increase in weight due to safety and emissions regulations.

\subsubsection{Modifications for the Weight-Based Analysis}

The weight-based standard adds a second set of decision variables to the analysis. Instead of determining only how far to move up the fuel economy cost curve, manufacturers must also decide what the weights of their vehicles should be. Adding weight hurts fuel economy but effectively lowers the standard that must be met. This dual effect changes the analysis in two important ways. First, the impact on retail price of adding or subtracting weight from a vehicle must be described. Second, technologies that reduce weight (e.g., materials substitution) must be removed from the fuel economy technology cost curve.

Estimates of the cost of decreasing weight have been presented in Section 4. Weight reductions of up to $5 \%$ are estimated to be achievable at a retail price equivalent of $\$ 0.50 / \mathrm{lb}$, $5-10 \%$ at $\$ 1.00 / \mathrm{lb}, 10-15 \%$ at $\$ 1.60 / \mathrm{lb}$, and greater than $15 \%$ at $\$ 2.40 / \mathrm{lb}$. Estimates of the cost of increasing weight, however, are not available. In addition, the design changes that manufacturers would likely make to increase weight have not been studied. Would manufacturers reverse materials substitutions and revert to cast-iron engine blocks, steel for bumpers, or glass for headlamp facia, for example, or would they use thicker steel sheet or make cars of the same 
materials, only larger? How would consumers react to such changes? Until a careful analysis can be done, we make the following simple assumptions. For weight increases up to $5 \%$, we assume a savings (price reduction) of $\$ 0.50 / \mathrm{lb}$. Beyond that point, we assume that weight can be added at the average retail price equivalent of steel in automotive applications, which is about $\$ 0.30 / \mathrm{lb}$.

The above data can be well approximated by a cubic polynomial. The cubic is fitted to total price change as a function of fractional changes in weight. (Note that the dollars per pound estimates given above are slopes of the total cost curve.) The cubic function below, illustrated in Figure 6-5, fits the data with an adjusted R-squared of 0.999.

$$
C_{w}=-0.00317+-0.41551 \mathrm{w}+4.055477 \mathrm{w}^{2}+-7.02296 \mathrm{w}^{3}
$$

Use of the cubic cost function must be limited to the range +0.19 to -0.20 because of requirements that the slope be uniformly increasing. This range limits weight changes to a maximum of $+19 \%$ and a minimum of $-20 \%$.

Because weight changes are determined separately from other fuel economy improvements, it is necessary to have a fuel economy price curve that does not include weight reduction as an option. "Weightless" curves were fitted to 2015 industry-wide fuel economy price data. After

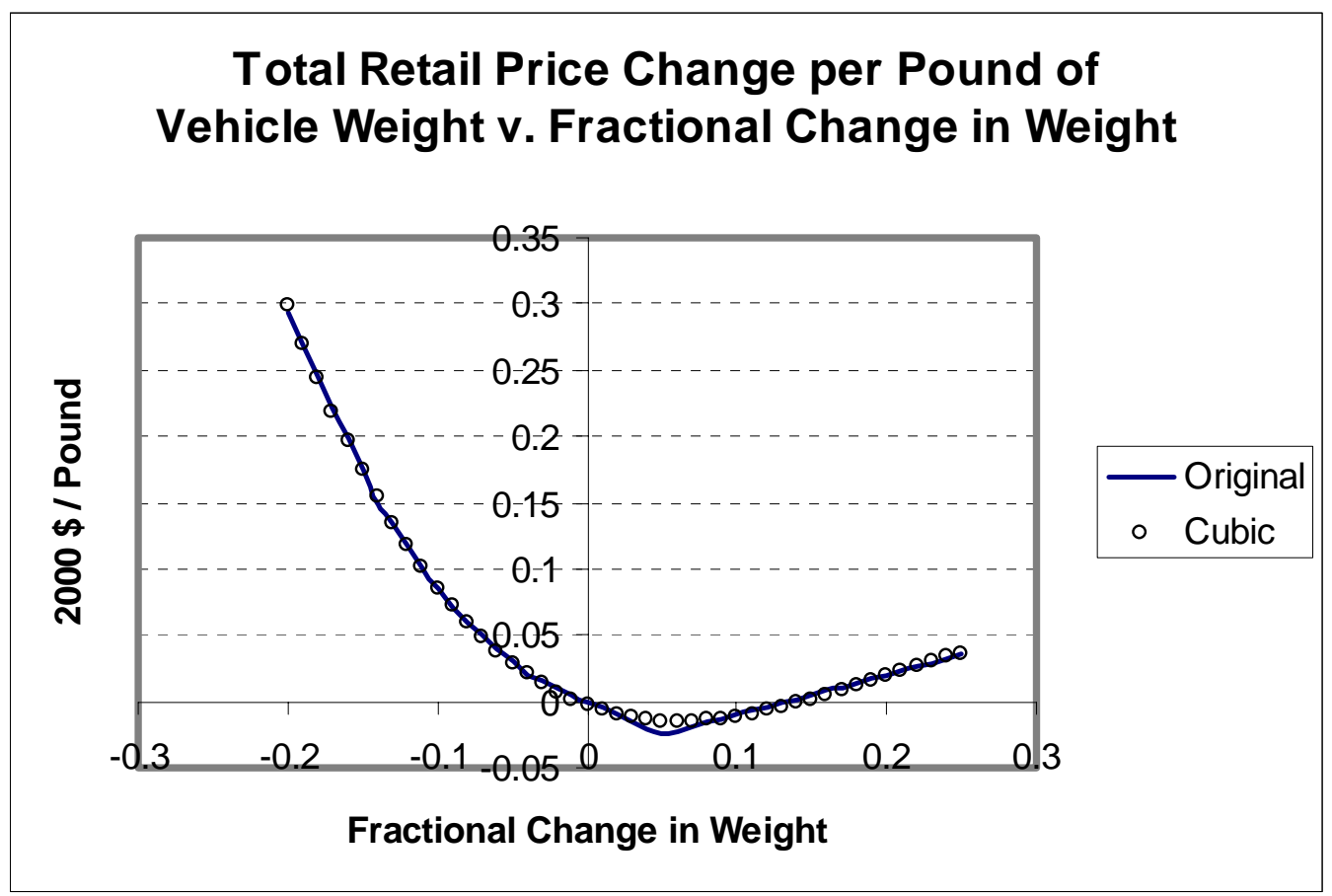

Figure 6-5. Cubic Fit to Retail Price of Light-Duty Vehicle Weight Changes 
removing the weight reduction technologies, the remaining technologies were sorted by the costeffectiveness index and the quadratic curves fitted in the usual way. ${ }^{76}$ "Weightless" curves for passenger cars and light trucks are shown in Figures 6-6 and 6-7.

Increasing vehicle weight will reduce fuel economy, thereby reducing the fuel savings to the consumer. It is assumed that for every $1 \%$ increase in weight, fuel economy will decrease by $0.54 \%$. This relationship, in effect, assumes that horsepower is not increased to maintain constant performance. In reality, any substantial increase in weight (more than a few percent) would require an increase in horsepower to avoid customer dissatisfaction. Increasing horsepower would add to the price of increasing weight. That additional cost is neglected here. In determining weight changes, the model will trade-off three elements: (1) the increase or decrease in vehicle price resulting from changes in weight, (2) the reduced fuel savings due to increasing weight, and (3) the relaxation of the fuel economy level that must be achieved as weight is increased.

\subsubsection{Sensitivity Analyses}

Three critical assumptions are tested by means of sensitivity analysis: (1) how consumers value fuel savings, (2) how much fuel economy technology costs, and (3) the price of fuel. An

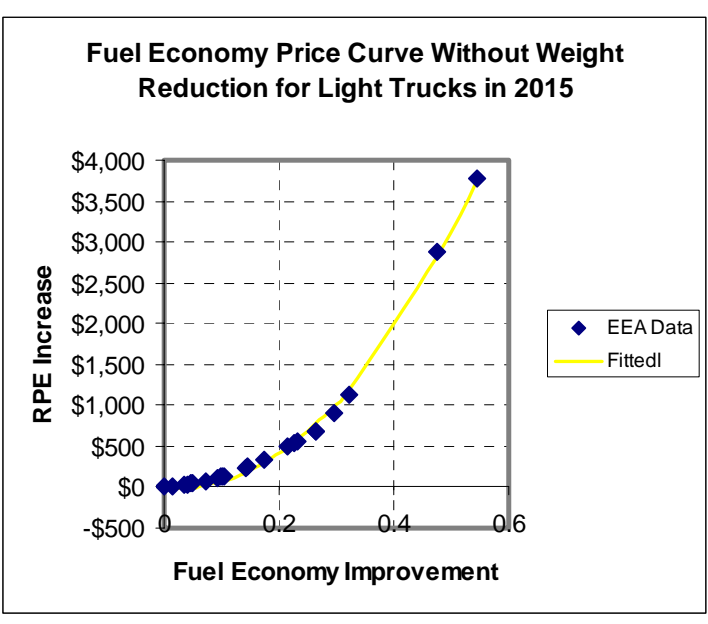

Figure 6-6. Industry Average Passenger Car Fuel Economy Price Curve without Weight Reduction

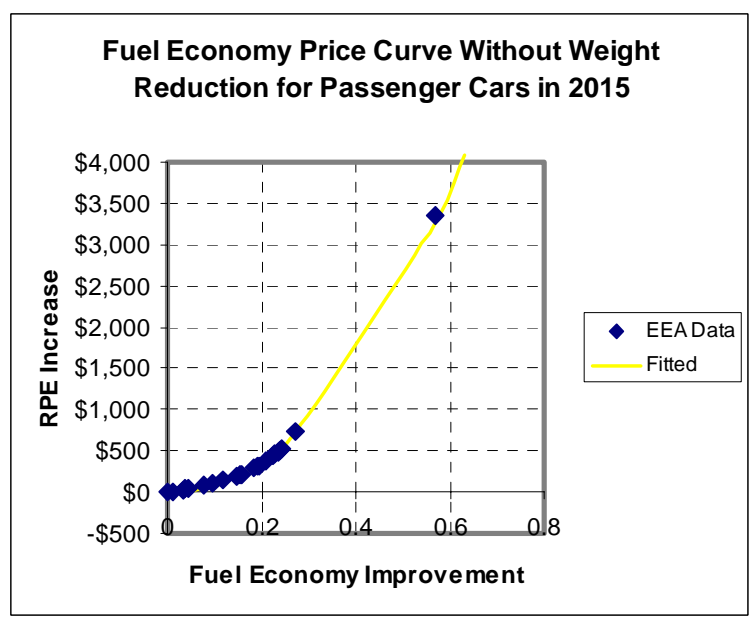

\section{Figure 6-7. Industry Average Light Truck Fuel Economy Price Curve without Weight Reduction}

76 Fitted curves based on all data points include a small negative price region close to zero. The existence of this region is caused by difficulty in fitting the two or three highest mpg data points. If the final two data points are removed, a better fit to the region (up to a $30 \% \mathrm{mpg}$ improvement) can be achieved. However, prices for improvements between $30 \%$ and $55 \%$ are significantly underestimated. For this reason, the curves fitted to all data points were used in the analysis, despite the small regions of negative price. 
alternative assumption - that consumers estimate the value of fuel saved as the simple sum of the first three years of fuel savings - is tested. This assumption was used in the recent NRC (2002) study on the CAFE standards to reflect the view that consumers do not fully account for lifetime fuel savings in their purchase decisions. Alternative fuel economy technology costs are tested by substituting cost curves derived from studies by Sierra Research (Austin et al. 1999 and the NRC (2002) and (2) two curves derived from studies with different assumptions about the potential for fuel economy technology that are quite different from those adopted in this analysis: ACEEE's advanced technology case (DeCicco et al. 2001) and the MIT 2020 study (Weiss et al. 2000). Finally, the impact of a higher fuel price, $\$ 1.75$ instead of $\$ 1.35$ per gallon, is tested.

The purpose of these analyses is to illustrate the range of uncertainty on these key issues and how different assumptions would change the results of the analysis. Although other assumptions of this analysis are also subject to uncertainty (e.g., the annual usage of vehicles), these three factors are believed to be the most important.

\subsection{Results}

A voluntary requirement of between a $20 \%$ and a $33 \%$ increase in fuel economy appears to be achievable by most manufacturers while increasing the net value of the vehicles they produce. ${ }^{77}$ A $20 \%$ requirement turns out to be below the level that provides the greatest net value for consumers, conditional on all the assumptions of this analysis. In mathematical programming jargon, it is a nonbinding constraint.

A nonbinding fuel economy target is illustrated in Figure 6-8. The figure is derived from data used in the NRC (2002) analysis of the CAFE standards but is presented here for illustrative purposes only. As passenger car fuel economy is increased beyond the base level of $28 \mathrm{mpg}$, the retail price of an average new car increases along the curve labeled "Price Increase." The discounted present value of fuel savings to the customer increases along the curve labeled "Fuel Savings." The net value to the customer of increasing fuel economy is the difference between the two curves (Net Value = Fuel Savings - Price Increase). The "Net Value" curve, which is exactly equal to the vertical distance between the Savings and Price curves, rises to a maximum value at about $33 \mathrm{mpg}$. This is the point at which the marginal price increase equals the marginal present value of fuel savings. The "Net Value" curve equals zero (crosses the x-axis) where the Price and Savings curves cross. This is the point at which the total price increase equals the total value of fuel savings. Suppose that a voluntary fuel economy target is set at $31 \mathrm{mpg}$. Under the assumptions of this analysis, manufacturers will still go beyond $31 \mathrm{mpg}$ to $33 \mathrm{mpg}$, because $33 \mathrm{mpg}$ gives the greatest net value to their customers and the greatest profits to them. Once again, these results are strictly dependent on the assumptions of this analysis (particularly our technology/price curves) - for example, that vehicle performance and weight remain constant over the next $10-15$ years.

77 Recall that, as explained in Section 6.2.1.3, the assumption of a 5\% weight increase by 2010 makes the $20 \%$ requirement into a $23.6 \%$ requirement $(1.2 \times 1.03-1=0.236)$ and the $33 \%$ requirement into a $37.0 \%$ requirement. In the tables in this section, we report the lower mpg levels (i.e., adjusted downward) to account for a 5\% weight increase. However, the higher levels were used to calculate the price increases, fuel savings, and marginal costs shown in the subsequent tables. 


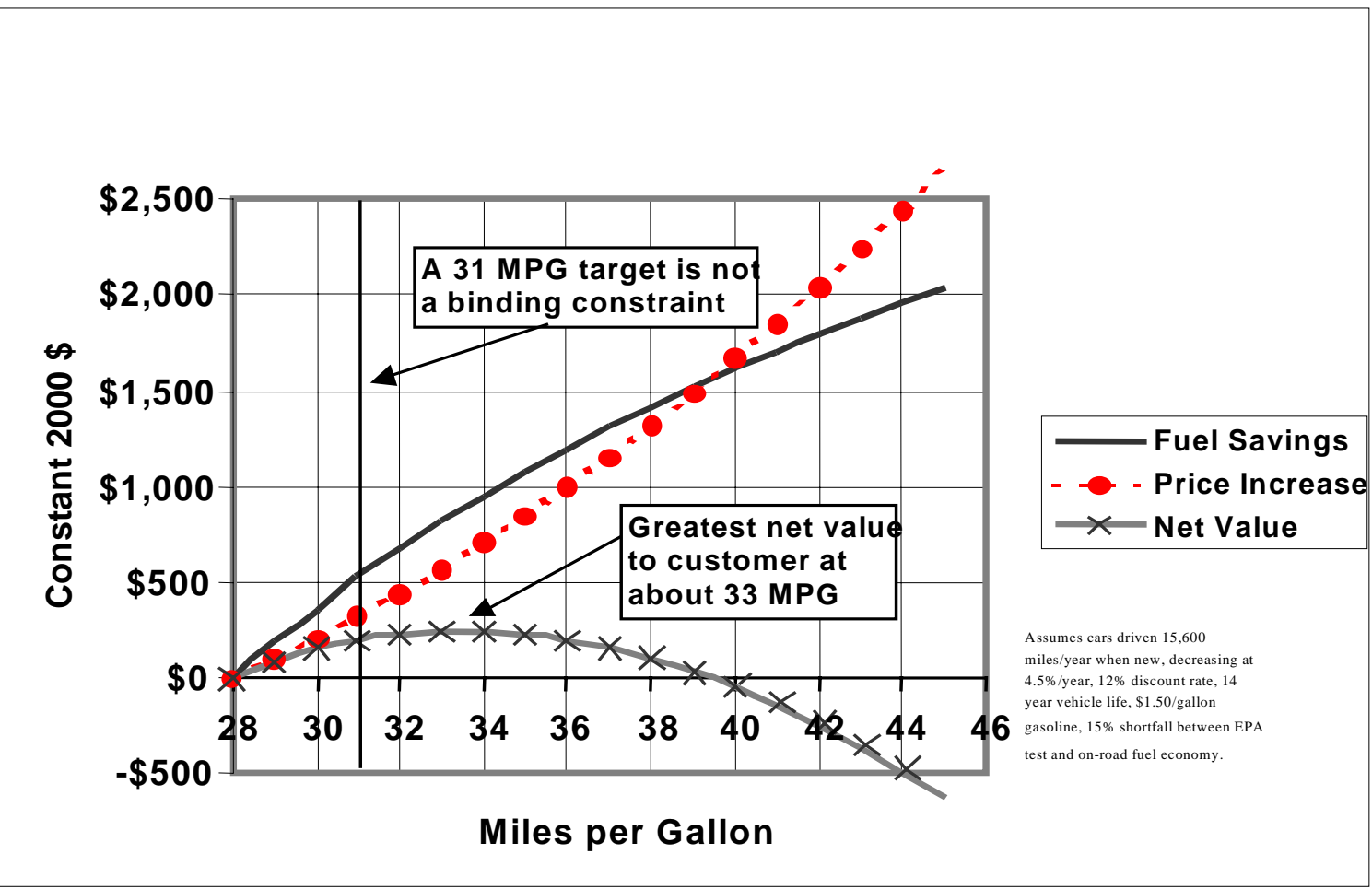

Figure 6-8. Price and Value of Increased Fuel Economy to Passenger Car Buyer, Using NRC Average Price Curves

The fact that the $20 \%$ requirement is nonbinding does not imply that in the real world, manufacturers would actually produce vehicles with that higher level of fuel economy in the absence of a voluntary agreement to do so. Manufacturers might choose to trade-off increases in weight and performance for fuel economy if they believed their customers would prefer that. Manufacturers might also have a different view of how consumers value fuel economy than the full-lifetime assumptions used here. The conclusion that maximizing net value to consumers would result in fuel economy increases greater than $20 \%$ is directly dependent on assumptions made for analytical purposes and not a prediction of what real markets will do in 2015.

The $33 \%^{78}$ requirement appears to be above the point at which the marginal cost of saving a gallon of fuel exceeds its value to the customer. In this sense, it is a binding constraint on manufacturers, in that it forces them to increase fuel economy beyond the point that provides the greatest net value to their customers. These results are strictly dependent on the reference assumptions about vehicle usage, fuel price, and consumer discounting of future fuel savings, as well as on the technology cost relationships utilized. While the statements are accurate for the reference assumptions for valuing fuel savings, use of a simple three-year payback rule generally indicates that fuel economy improvements on the order of $33 \%$ would reduce the net value of

78 Again, note that the $33 \%$ increase includes an assumed weight increase of $5 \%$. Without the weight increase, the fuel economy increase would be $37 \%$. 
vehicles to customers, and that even the $20 \%$ requirement would be a binding constraint for manufacturers.

Forms of voluntary agreements that permit greater flexibility for manufacturers to make use of fuel economy technologies according to the mix of product lines they produce are generally less costly and more equitable than those that impose either the same mpg or UPI requirement on each manufacturer. The most equitable forms also appear to be the most economically efficient (and vice versa). The single industry-wide mpg requirement that permits each manufacturer to achieve the same marginal cost per gallon of fuel saved is the most equitable and provides the greatest net benefits. Again, we have not addressed here how such a standard might be implemented or enforced.

Alternative technology cost curves produce quite different results. Curves based on more optimistic assessments or more aggressive use of existing technology (DeCicco et al. 2001), or curves that reflect more advanced technologies (Weiss et al. 2000), generally indicate that even a $33 \%$ requirement would not be binding on manufacturers. Curves based on analyses with a shorter time horizon or less-optimistic assumptions about technology cost and performance (Austin 1999; NRC 2002, high-cost/low-mpg) indicate that even a $20 \%$ requirement would be a challenge.

The discussions of overall net benefits and comparisons of impacts on manufacturers are organized as follows:

1. $20 \%$ and $33 \%$ standards, for the mpg metric, by five forms of constraints;

2. $20 \%$ and $33 \%$ standards, for the UPI metric, by five forms of constraints;

3. $20 \%$ and $33 \%$ standards, for a weight-based formula;

4. $20 \%$ and $33 \%$ standards, for the mpg metric, industry-wide constraint, but assuming a three-year simple payback method for valuing fuel savings;

5. $33 \%$ standards for seven technology cost curves, mpg metric, industry-wide constraint; and

6. $33 \%$ standards, mpg metric and weight-based metric, $\$ 1.75 /$ gallon and higher fuel prices.

\subsubsection{The mpg Metric}

The two alternative levels of voluntary fuel economy standards evaluated (20\% and 33\%) imply targets of $33.8 \mathrm{mpg}$ and $37.5 \mathrm{mpg}$, respectively, for passenger cars. The corresponding targets for light trucks are 25.4 and $28.2 \mathrm{mpg}$, and the combined light-duty fleet numbers are 29.5 and $32.7 \mathrm{mpg}$. The base year $2000 \mathrm{mpg}$ numbers are 28.2 for passenger cars, 21.2 for light trucks, and 24.6 overall for light-duty vehicles. 
The industry-wide constraint requires only that the industry as a whole meet the $20 \%$ and $33 \%$ targets. No individual manufacturer must necessarily meet the targets; some may exceed, others may fall below. Under the industry-wide standard, the marginal change in net value will be equated across all manufacturers, vehicle types, and origins. ${ }^{79}$ This approach will always give the most economically efficient result and therefore will always produce the greatest net value of all the constraint sets. For this reason, the costs and benefits of other constraint forms are compared with the industry-wide constraint.

However, it is not clear how an industry-wide voluntary agreement might be carried out. In particular, how would each manufacturer know how much fuel economy improvement to make to ensure that the industry-wide target was met? Interestingly, the European Union voluntary agreement described in Section 2 also specifies no targets for individual manufacturers. This analysis assumes that each agreement, including the industry-wide agreement, will be implemented as efficiently as possible. However, the mechanisms for monitoring or enforcing voluntary agreements are not addressed here.

In theory, the industry-wide constraint case produces the same fuel economy and price levels as would be obtained in a competitive market if each manufacturer faced the same mandatory standard but manufacturers were allowed to buy or sell fuel economy credits (for a discussion of this issue, see NRC 2002, ch. 5). Of course, credits would not be bought and sold under a voluntary agreement. Again, without the economic signals and incentives that a credit trading system would create, it is not clear how each manufacturer would determine what fuel economy level to achieve. Nonetheless, if manufacturers could find a cooperative solution to this problem, they could achieve the efficiency of a tradable credit system without the wealth transfers among manufacturers.

\subsubsection{Vehicle Price Increases and Fuel Savings}

A key result is that the $20 \%$ standard is just below the level that provides the greatest net value to customers, given the reference assumptions of this analysis. When the $20 \%$ requirement is imposed in the form of an industry-wide constraint, combined passenger car and light truck mpg increases from $24.6 \mathrm{mpg}$ to 30.3 , which is a $23 \%$ increase. Manufacturers choose to exceed the $20 \%$ standard because by doing so, they deliver more value to their customers. Note that market forces will not necessarily produce an mpg of 30.3 in 2015. As has been previously noted, market forces may lead to increases in vehicle performance and weight, rather than fuel economy, and consumers may value fuel economy less than the full-lifetime assumptions imply.

Under the industry-wide $33 \%$ constraint, light-duty vehicle fuel economy increases from $24.6 \mathrm{mpg}$ to $32.7 \mathrm{mpg}$ and vehicle retail prices increase by a total of $\$ 16.2$ billion per year (Table 6-6), which is roughly $\$ 1,000$ per vehicle. Motorists realize $\$ 24.6$ billion per year in present value fuel savings, however, so that the net value of the fuel economy increase is $\$ 8.5$ billion per year. For the $20 \%$ standard, vehicle prices rise by only $\$ 9.5$ billion per year, but

79 A proof can be found in Greene and Hopson (2002). 
Table 6-6. Summary of Vehicle Price Increases and Fuel Savings for mpg Metric ${ }^{a}$

\begin{tabular}{|c|c|c|c|c|c|c|}
\hline & & Industry & $\begin{array}{l}\text { Separate } \\
\text { Car-Truck }\end{array}$ & $\begin{array}{c}\text { Manufacturer } \\
\text { Combined } \\
\text { Car/Truck }\end{array}$ & $\begin{array}{c}\text { Manufacturer- } \\
\text { Specific } \\
\text { Separate Car- } \\
\text { Truck }\end{array}$ & CAFE \\
\hline \multicolumn{7}{|c|}{ 33\% Fuel Economy Standard } \\
\hline \multicolumn{2}{|c|}{ VEHICLE PRICE INCREASES (\$) } & 16,169 & 16,184 & 17,869 & 16,733 & 17,014 \\
\hline \multicolumn{2}{|c|}{ Increase v. Industry (\$) } & 0 & 15 & 1,700 & 564 & 845 \\
\hline \multirow{2}{*}{\multicolumn{2}{|c|}{$\begin{array}{l}\% \\
\text { Per Vehicle }(\$)\end{array}$}} & 0.0 & 0.1 & 9.5 & 3.4 & 5.0 \\
\hline & & & & & & \\
\hline \multicolumn{2}{|c|}{ Passenger Cars } & 877 & 930 & 904 & 954 & 984 \\
\hline \multicolumn{2}{|c|}{ Light Trucks } & 1,148 & 1,083 & 1,349 & 1,130 & 1,131 \\
\hline \multicolumn{2}{|c|}{ FUEL SAVINGS (\$) } & 24,631 & 24,626 & 25,363 & 24,734 & 24,907 \\
\hline \multicolumn{2}{|c|}{ Increase v. Industry (\$) } & 0 & -5 & 731 & 103 & 276 \\
\hline \multicolumn{2}{|l|}{$\%$} & 0.0 & -0.0 & 2.9 & 0.4 & 1.1 \\
\hline \multicolumn{7}{|l|}{ Per Vehicle(\$) } \\
\hline \multicolumn{2}{|c|}{ Passenger Cars } & 1,288 & 1,323 & 1,282 & 1,324 & 1,343 \\
\hline \multicolumn{2}{|c|}{ Light Trucks } & 1,807 & 1,763 & 1,916 & 1,777 & 1,778 \\
\hline \multicolumn{2}{|l|}{ NET VALUE (\$) } & 8,462 & 8,442 & 7,494 & 8,001 & 7,893 \\
\hline \multicolumn{2}{|c|}{ Decrease v. Industry } & 0 & -20 & -969 & -461 & -569 \\
\hline \multicolumn{2}{|c|}{$\%$} & 0.0 & -0.2 & -12.9 & -5.8 & -7.2 \\
\hline \multicolumn{7}{|l|}{ Per Vehicle (\$) } \\
\hline \multicolumn{2}{|c|}{ Passenger Cars } & 412 & 393 & 379 & 370 & 359 \\
\hline \multirow[t]{2}{*}{ Light Trucks } & & 659 & 680 & 566 & 647 & 646 \\
\hline & Base mpg & & & & & \\
\hline New Vehicle mpg & 24.6 & 32.7 & 32.7 & 33.1 & 32.7 & 32.8 \\
\hline New Car mpg & 28.2 & 37.2 & 37.6 & 37.1 & 37.6 & 37.8 \\
\hline New Light Truck m & 21.2 & 28.4 & 28.2 & 29.1 & 28.3 & 28.3 \\
\hline \multicolumn{7}{|c|}{ 20\% Fuel Economy Standard } \\
\hline \multicolumn{2}{|c|}{ VEHICLE PRICE INCREASES (\$) } & 9,543 & 9,543 & 10,304 & 10,010 & 10,038 \\
\hline \multicolumn{2}{|c|}{ Increase v. Industry (\$) } & 0 & 0 & 761 & 467 & 495 \\
\hline \multicolumn{2}{|c|}{$\%$} & 0.0 & 0.0 & 7.4 & 4.7 & 4.9 \\
\hline Per Vehicle $(\$)$ & & & & & & \\
\hline Passenger $\mathrm{C}$ & & 514 & 514 & 544 & 552 & 555 \\
\hline Light Trucks & & 681 & 681 & 749 & 699 & 699 \\
\hline FUEL SAVINGS & & 19,260 & 19,260 & 19,961 & 19,695 & 19,695 \\
\hline Increase v. Indus & & 0 & 0 & 701 & 435 & 435 \\
\hline$\%$ & & 0.0 & 0.0 & 3.5 & 2.2 & 2.2 \\
\hline Per Vehicle (\$) & & & & & & \\
\hline Passenger $\mathrm{C}$ & & 994 & 994 & 1,023 & 1,031 & 1,031 \\
\hline Light Trucks & & 1,429 & 1,429 & 1,491 & 1,444 & 1,444 \\
\hline NET VALUE (\$) & & 9,717 & 9,717 & 9,657 & 9,685 & 9,657 \\
\hline Decrease v. Indu & $(\$)$ & 0 & 0 & -60 & -32 & -60 \\
\hline$\%$ & & 0.0 & 0.0 & -0.6 & -0.3 & -0.6 \\
\hline Per Vehicle (\$) & & & & & & \\
\hline Passenger $\mathrm{C}$ & & 480 & 480 & 479 & 478 & 475 \\
\hline Light Trucks & & 748 & 748 & 741 & 745 & 745 \\
\hline & Base mpg & & & & & \\
\hline New Vehicle mpg & 24.6 & 30.3 & 30.3 & 30.6 & 30.5 & 30.5 \\
\hline New Car mpg & 28.2 & 34.4 & 34.4 & 34.7 & 34.8 & 34.8 \\
\hline New Truck mpg & 21.2 & 26.3 & 26.3 & 26.7 & 26.4 & 26.4 \\
\hline
\end{tabular}

a All but the base mpg numbers in this table have been divided by 1.03 to account for the effect of an assumed $5 \%$ increase in vehicle weight. 
fuel savings are also lower - $\$ 19.3$ billion in present value. The net value of the $20 \%$ standard, $\$ 9.7$ billion per year, is slightly larger than that of the 33\% standard, but the difference is small.

The manufacturer-specific combined car and truck mpg constraint is the most costly, given the $33 \%$ requirement, because it requires every manufacturer to attain the same fuel economy level, regardless of the mix of cars and light trucks each produces. The increase in total vehicle prices due to the manufacturer-specific standard is $\$ 17.9$ billion per year, which is a half billion more per year than either the CAFE or the Manufacturer Car-Truck standards. Ignoring the mix of car versus light trucks and holding each manufacturer to the same standard forces those producing large numbers of light trucks to use more expensive technology than the others to improve fuel economy. As a result, the net value of the manufacturer-specific standard is $13 \%$ lower than the most efficient, industry-wide standard.

The manufacturer-specific, separate car and truck, separate import and domestic (CAFE) constraints produce only $7 \%$ less net value than the industry-wide standard because they set separate standards for manufacturers' passenger car and light truck fleets. Taking account of the car-truck mix significantly reduces the cost of the manufacturer-car-truck and CAFE standards relative to the manufacturer standard. The $20 \% \mathrm{MPG}$ requirement does not show the same pattern of results because it continues to be nonbinding for all forms of constraints.

Another key finding is that differences in costs and benefits among the forms of regulatory constraints are relatively small. The more complex forms of standards tend to produce slightly higher fuel savings because they produce slightly higher fleet-average fuel economy (Figure 6-9). Under the less complex industry or car-truck standards, a manufacturer with mpg levels exceeding the requirement could offset the lower mpg of another manufacturer. Such flexibility

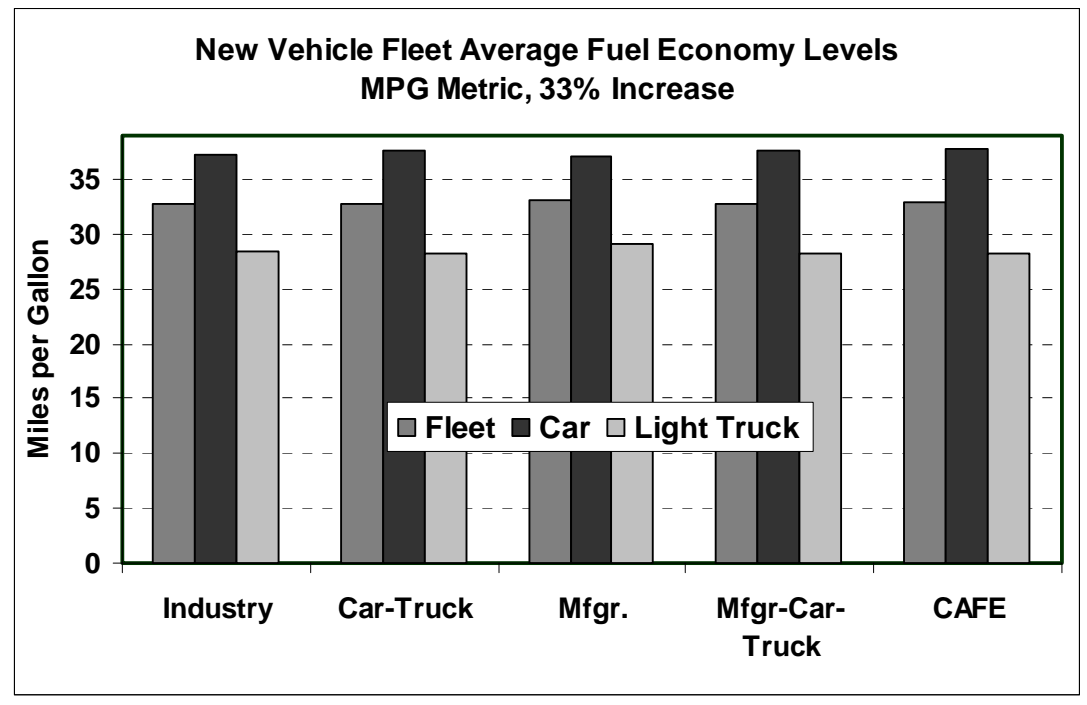

Figure 6-9. New Light-Duty Vehicle Fuel Economy for Five Forms of Voluntary Standards by Using the mpg Metric 
reduces the costs of the industry-wide and car-truck standards but reduces their fuel savings somewhat as well. Again, it is not clear how such sharing of responsibility would be carried out under a voluntary agreement, although the potential to do so exists.

\subsubsection{Impacts on Manufacturers}

The effects of different standards on manufacturers are measured here in two ways: (1) by the changes in the net value of their product lines and (2) by the marginal price increase per marginal gallon of fuel saved (Table 6-7). Changes in the net values of a manufacturer's vehicles measure the average change in value per vehicle, as perceived by the customer (again, assuming customers value fuel savings, as done here). The marginal cost of saving a gallon of fuel is a measure of the effort a manufacturer had to expend to meet the standard (i.e., how far up the technology cost curve a manufacturer had to go). Together, the two measures are still an incomplete description of the equity, or fairness, of a standard because they do not account for dynamic effects. For example, as pointed out in Section 5, a small-car manufacturer with a high base-year mpg would find it more difficult to expand into larger-car market segments under a UPI metric but would find it very easy under an mpg metric. These metrics also are based on the assumption that all customers value fuel economy in the same way. More likely, there are some differences in the market segments served by different manufacturers. Thus, the results presented here must be interpreted with caution.

Even the 33\% requirement increases the net value of passenger cars for all manufacturers (Figure 6-10). In interpreting this result, bear in mind that the value of future fuel economy improvements (in the 2012-2015 period) is being estimated relative to model year 2000 vehicles and that all other vehicle attributes are held constant. It might be possible, for example, to achieve a greater increase in value in the eyes of customers by trading some of the fuel economy improvement for more horsepower. Nevertheless, under the reference assumptions, the results indicate that all manufacturers' products increase in value by roughly $\$ 300-700$ per vehicle as a result of the 33\% requirement. Once again, these results are dependent on the key assumptions of this analysis, especially that vehicle size and performance are not increased.

There is a small decrease in both the average change in net value and its variance for the more complex forms of standards. BMW and Volkswagen of America appear to be special cases, significantly increasing the range of outcomes. Some manufacturers show a reduction in net value under the more complex forms (e.g., GM, Daimler-Chrysler), while others show a small gain (e.g., Toyota, Honda). Again, these results should not be interpreted as predictions for particular manufacturers, but rather as generally representing the kinds of outcomes that might be experienced by manufacturers with different product lines.

A similar result is obtained for light trucks under the 33\% requirement (Figure 6-11). With the exception of Volkswagen and BMW, which had very limited and specialized truck product lines in 2000 , the change in net values of light trucks ranges from $\$ 400$ to $\$ 800$, regardless of the form of the constraints. In general, the same manufacturers experience reductions in net value as the constraints become more specific. 
Table 6-7. Marginal Cost per Gallon of Fuel Saved, 33\% Requirement (Year 2000 \$/gallon)

\begin{tabular}{|c|c|c|c|c|c|c|c|c|c|c|c|}
\hline \multicolumn{12}{|l|}{ MPG Metric } \\
\hline \multirow[t]{2}{*}{ Industry } & \multicolumn{11}{|c|}{ All Manufacturers, All Vehicles } \\
\hline & \multicolumn{11}{|c|}{$\$ 2.02$} \\
\hline \multirow{3}{*}{ Car - Truck } & \multicolumn{11}{|c|}{ All Manufacturers } \\
\hline & & & & & Car & & \multicolumn{2}{|c|}{ Light Truck } & & & \\
\hline & & & & & $\$ 2.12$ & & \multicolumn{2}{|c|}{$\$ 1.93$} & & & \\
\hline \multirow[t]{3}{*}{ Manufacturer } & \multicolumn{11}{|c|}{$\underline{\text { All Vehicle Types }}$} \\
\hline & BMW & $\underline{D C C}$ & $\underline{\mathrm{FMC}}$ & $\underline{\mathrm{GMC}}$ & $\underline{\mathrm{HON}}$ & $\underline{\mathrm{HYU}}$ & $\underline{\mathrm{KIA}}$ & MIT & $\underline{N I S}$ & TOY & VWA \\
\hline & $\overline{\$ 2.08}$ & $\overline{\$ 2.56}$ & $\$ 2.20$ & $\overline{\$ 2.53}$ & $\$ 1.35$ & $\overline{\$ 1.35}$ & $\$ 1.46$ & $\$ 1.35$ & $\$ 2.10$ & $\overline{\$ 1.42}$ & $\overline{\$ 1.35}$ \\
\hline \multicolumn{12}{|c|}{ Manufacturer Car/Truck } \\
\hline & BMW & $\underline{\mathrm{DCC}}$ & $\underline{\text { FMC }}$ & $\underline{\mathrm{GMC}}$ & $\underline{\mathrm{HON}}$ & $\underline{\mathrm{HYU}}$ & $\underline{\mathrm{KIA}}$ & $\underline{\mathrm{MIT}}$ & $\underline{\mathrm{NIS}}$ & TOY & VWA \\
\hline Car & $\$ 2.67$ & $\$ 2.48$ & $\$ 2.42$ & $\$ 2.42$ & $\overline{\$ 1.46}$ & $\$ 1.74$ & $\$ 1.80$ & $\$ 1.77$ & $\$ 2.04$ & $\$ 1.59$ & \\
\hline Light Truck & $\$ 4.23$ & $\$ 1.79$ & $\$ 1.81$ & $\$ 2.56$ & $\$ 1.35$ & - & $\$ 1.35$ & $\$ 1.65$ & $\$ 1.79$ & $\$ 1.60$ & $\$ 2.89$ \\
\hline \multicolumn{12}{|l|}{ UPI Metric } \\
\hline \multirow{3}{*}{ Industry } & \multicolumn{11}{|c|}{ All Manufacturers, All Vehicles } \\
\hline & \multicolumn{11}{|c|}{$\$ 2.02$} \\
\hline & \multicolumn{11}{|c|}{ All Manufacturers } \\
\hline \multirow[t]{2}{*}{ Car - Truck } & & & & & Car & & \multicolumn{2}{|c|}{ Light Truck } & & & \\
\hline & & & & & $\$ 2.12$ & & \multicolumn{2}{|c|}{$\$ 1.93$} & & & \\
\hline \multirow[t]{3}{*}{ Manufacturer } & \multicolumn{11}{|c|}{$\underline{\text { All Vehicle Types }}$} \\
\hline & BMW & $\underline{\mathrm{DCC}}$ & $\underline{\mathrm{FMC}}$ & $\underline{\mathrm{GMC}}$ & $\underline{\mathrm{HON}}$ & $\underline{\mathrm{HYU}}$ & $\underline{\mathrm{KIA}}$ & $\underline{\mathrm{MIT}}$ & $\underline{\mathrm{NIS}}$ & TOY & VWA \\
\hline & $\$ 1.49$ & $\$ 1.88$ & $\$ 1.91$ & $\$ 2.24$ & $\$ 2.40$ & $\$ 2.39$ & $\$ 2.36$ & $\$ 1.99$ & $\$ 1.85$ & $\$ 2.01$ & $\$ 1.68$ \\
\hline \multicolumn{12}{|c|}{ Manufacturer Car/Truck } \\
\hline & BMW & $\underline{\mathrm{DCC}}$ & $\underline{\mathrm{FMC}}$ & $\underline{\mathrm{GMC}}$ & $\underline{\mathrm{HON}}$ & $\underline{\mathrm{HYU}}$ & $\underline{\mathrm{KIA}}$ & $\underline{\mathrm{MIT}}$ & $\underline{\mathrm{NIS}}$ & $\underline{\text { TOY }}$ & VWA \\
\hline Car & $\$ 1.45$ & $\$ 1.99$ & $\$ 2.21$ & $\$ 2.12$ & $\$ 2.57$ & $\$ 2.39$ & $\$ 2.37$ & $\$ 2.07$ & $\$ 1.49$ & $\$ 2.13$ & $\$ 1.68$ \\
\hline Light Truck & $\$ 1.62$ & $\$ 1.83$ & $\$ 1.72$ & $\$ 2.38$ & $\$ 1.82$ & - & $\$ 2.34$ & $\$ 1.78$ & $\$ 1.74$ & $\$ 1.85$ & $\$ 1.82$ \\
\hline
\end{tabular}

Results for the $20 \%$ requirement are not shown here because the standard is generally not binding and there are no differences in impacts for the different forms of the standard.

\subsubsection{UPI Metric}

For the industry-wide and industry-wide/car-truck standards, the mpg and UPI metrics impose identical constraints. In both cases, industry-average mpg increases of $20 \%$ or $33 \%$ are required..$^{80}$ The UPI metric differs from the MPG metric only when it is applied to individual manufacturers.

80 Just as for the mpg metric, fuel economy numbers reported here have been adjusted downward by dividing 1.03 to account for an assumed 5\% increase in average vehicle weight. 


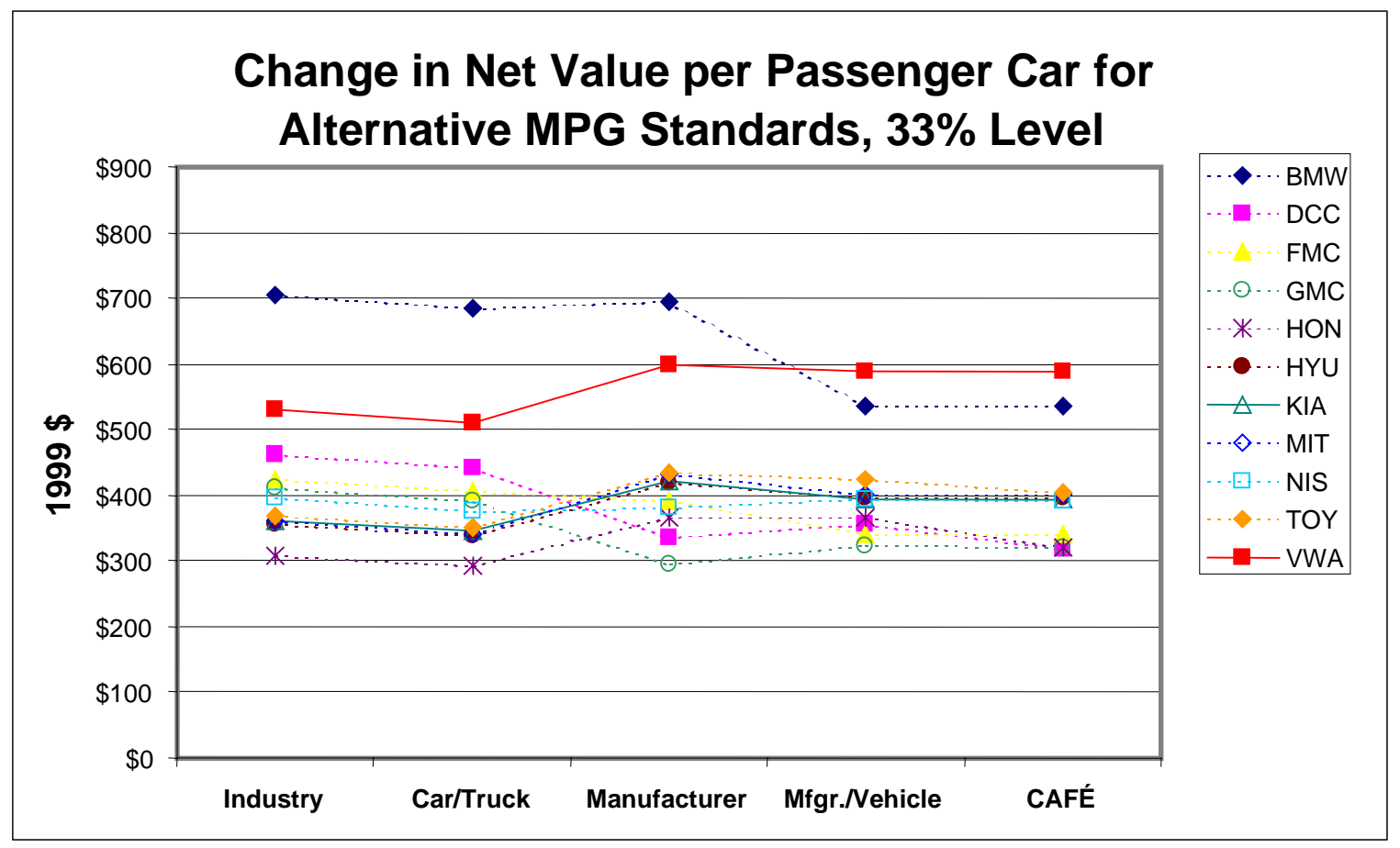

Figure 6-10. Change in Net Value of a Passenger Car by Manufacturer for Five Forms of mpg Standards

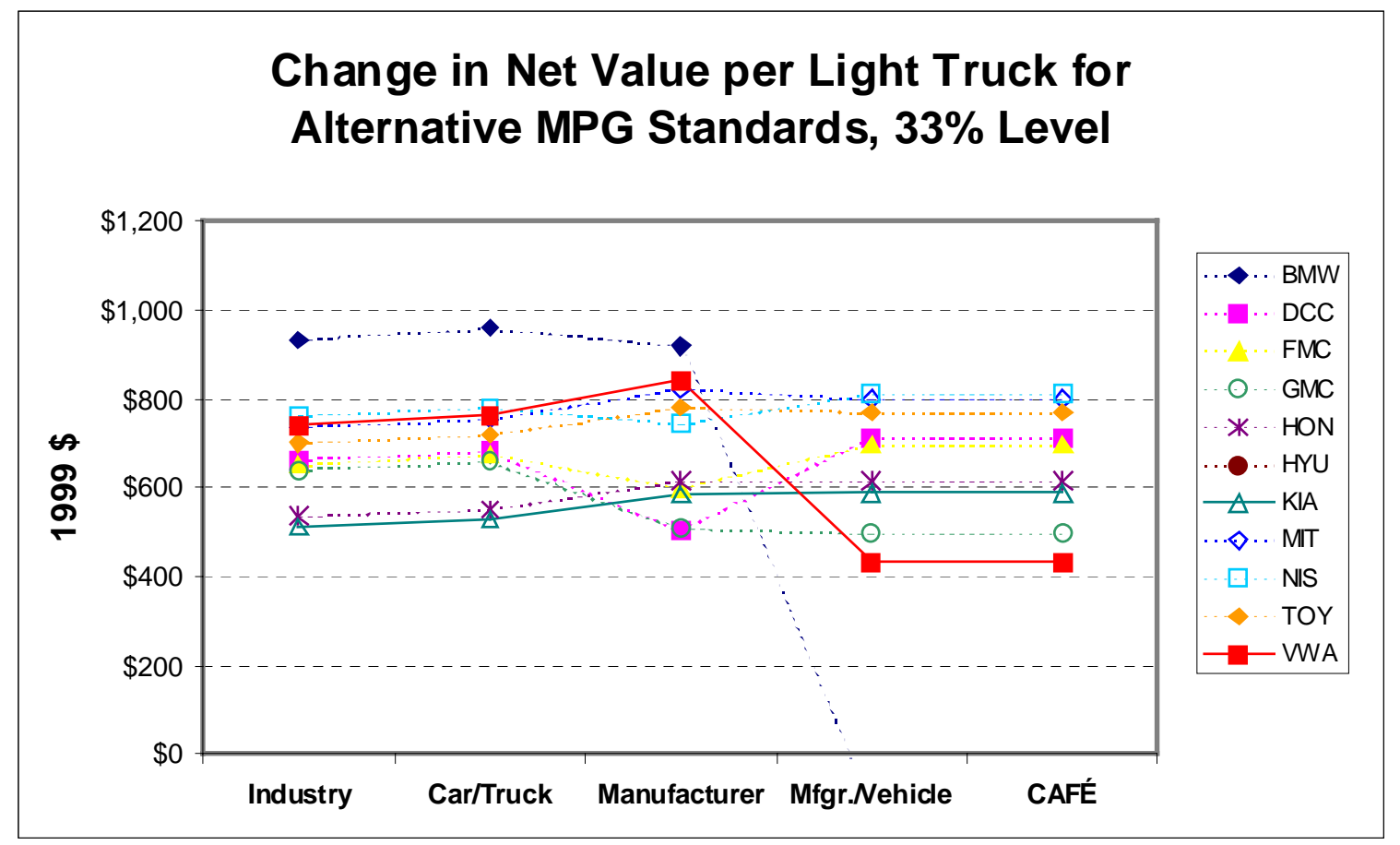

Figure 6-11. Change in Net Value of a Light Truck by Manufacturer for Five Forms of mpg Standards 
When constraints are brought down to the manufacturer level, the UPI requires a different mpg level for each manufacturer, depending on the manufacturer's base-year (2000) mpg values. Those with the highest base-year mpg levels must increase mpg by the same percent as those with the lowest base-year mpgs. For the 33\% requirement, the manufacturer-specific UPI results in a lower total price increase than the mpg metric, by about $\$ 1.6$ billion per year (Table 6-8). The net value is about $\$ 0.9$ billion higher. Similarly, the costs of the UPI metric are slightly lower and the net benefits slightly greater for the Manufacturer/Car-Truck and CAFE constraints, relative to the mpg metric.

Whereas moving to more complex forms of mpg-based standards has little effect on the impacts on manufacturers, increasing the complexity of the UPI by making it manufacturerspecific amplifies the range of impacts of UPI-based standards. As Figures 6-12 and 6-13 show, the range of changes in net values increases from approximately $\$ 300-\$ 700$ to $\$ 200-\$ 800$ for passenger cars, with a similar result for light trucks. Interestingly, the ranking of manufacturers

Table 6-8. Summary of Costs and Fuel Savings for UPI Metric

\begin{tabular}{|c|c|c|c|c|c|}
\hline & $\begin{array}{l}\text { Industry- } \\
\text { Wide }\end{array}$ & Car-Truck & Manufacturer & $\begin{array}{c}\text { Manufacturer/ } \\
\text { Car-Truck }\end{array}$ & CAFE \\
\hline \multicolumn{6}{|l|}{ 33\% Fuel Economy Standard } \\
\hline VEHICLE COSTS $(\$)$ & 16,169 & 16,184 & 16,262 & 16,333 & 16,348 \\
\hline Increase v. Industry (\$) & 0 & 15 & 93 & 164 & 179 \\
\hline$\%$ & 0.0 & 0.1 & 0.6 & 1.0 & 1.1 \\
\hline FUEL SAVINGS (\$) & 24,631 & 24,626 & 24,627 & 24,627 & 24,627 \\
\hline Increase v. Industry (\$) & 0 & -5 & -4 & -4 & -4 \\
\hline$\%$ & 0.0 & 0.0 & 0.0 & 0.0 & 0.0 \\
\hline NET VALUE (\$) & 8,462 & 8,442 & 8,365 & 8,294 & 8,278 \\
\hline Decrease v. Industry & 0 & -20 & -97 & -168 & -184 \\
\hline$\%$ & 0.0 & -0.2 & -1.2 & -2.0 & -2.2 \\
\hline \multicolumn{6}{|c|}{ Base Year mpg } \\
\hline New Vehicle $\mathrm{mpg}^{\mathrm{a}} \quad 24.6$ & 32.7 & 32.7 & 32.7 & 32.7 & 32.7 \\
\hline \multicolumn{6}{|l|}{ 20\% Fuel Economy Standard } \\
\hline VEHICLE COSTS (\$) & 9,543 & 9,543 & 9,567 & 9,606 & 9,621 \\
\hline Increase v. Industry (\$) & 0 & 0 & 24 & 63 & 78 \\
\hline$\%$ & 0.0 & 0.0 & 0.2 & 0.7 & 0.8 \\
\hline FUEL SAVINGS (\$) & 19,260 & 19,260 & 19,283 & 19,320 & 19,332 \\
\hline Increase v. Industry (\$) & 0 & 0 & 23 & 60 & 72 \\
\hline$\%$ & 0.0 & 0.0 & 0.1 & 0.3 & 0.4 \\
\hline NET VALUE (\$) & 9,717 & 9,717 & 9,717 & 9,714 & 9,711 \\
\hline Decrease v. Industry & 0 & 0 & 0 & -3 & -6 \\
\hline$\%$ & 0.0 & 0.0 & 0.0 & 0.0 & -0.1 \\
\hline \multicolumn{6}{|c|}{ Base Year mpg } \\
\hline New Vehicle $\mathrm{mpg}^{\mathrm{a}} \quad 24.6$ & 30.3 & 30.3 & 30.3 & 30.3 & 30.3 \\
\hline
\end{tabular}

Results for the UPI metric for the $20 \%$ improvement requirement are the same as those for the mpg metric because the constraints are once again not binding.

a All but base year mpg fuel economy numbers have been divided by 1.03 to account for an assumed $5 \%$ increase in average weight. 


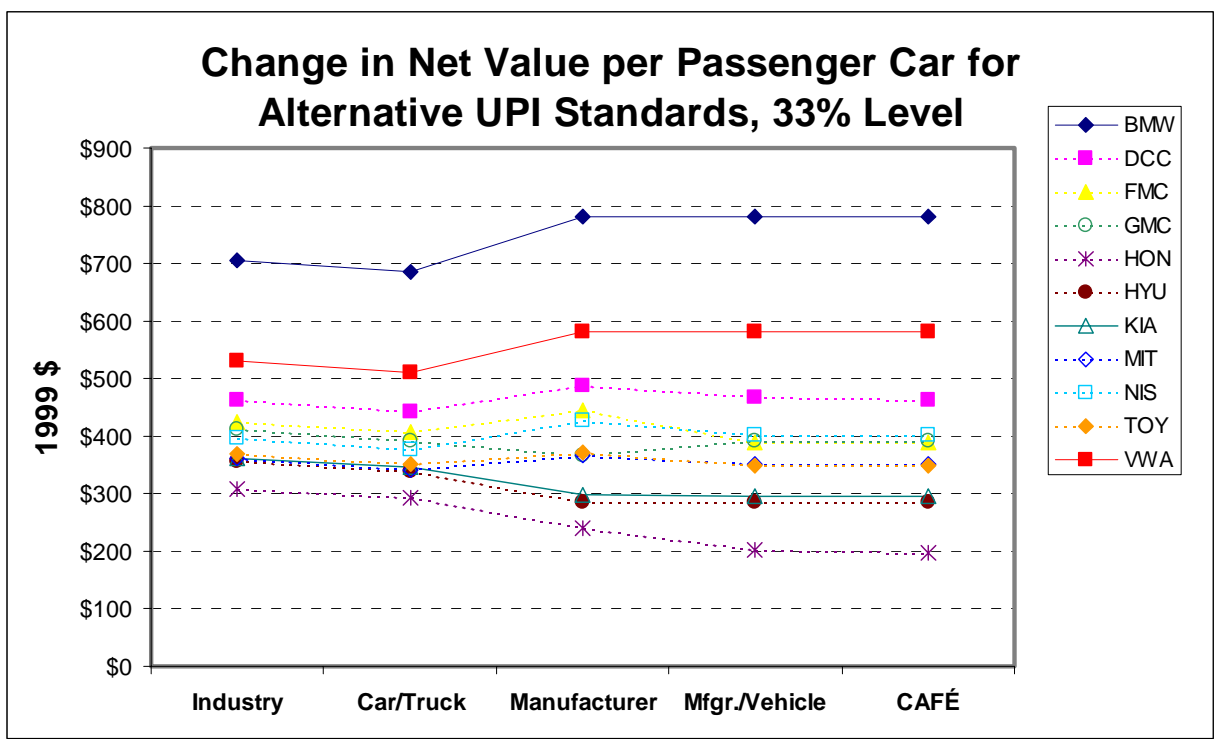

Figure 6-12. Change in Net Value of a Passenger Car for UPI Standards

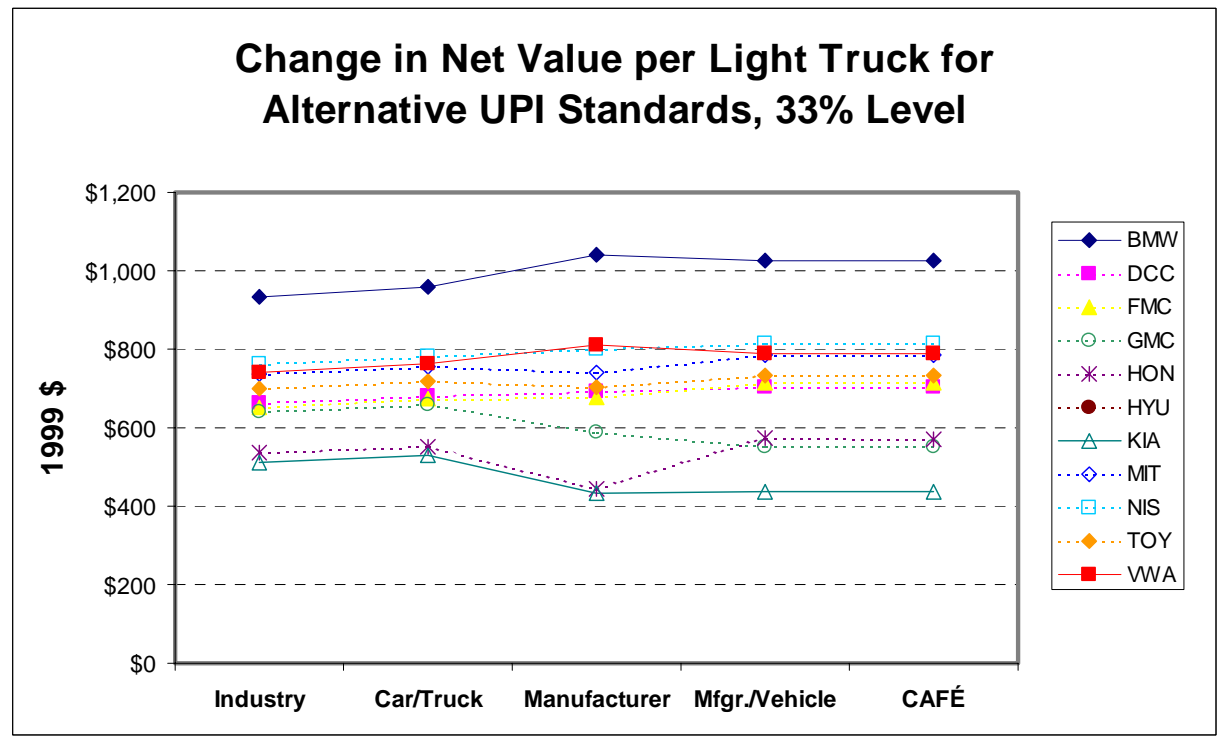

Figure 6-13. Change in Net Value of a Light Truck for UPI Standards 
by degree of impact is virtually unchanged. This outcome contrasts strongly with the mpg metric, in which relative positions change considerably.

It is important to recall that these results assume that manufacturers do not change their product offerings. A potentially important aspect of the UPI metric not addressed here is its potential to restrict the opportunity for manufacturers that produce smaller vehicles in 2000 to expand their product lines into larger vehicle segments in the future. On the other hand, the mpg metric places a heavier burden on manufacturers of large vehicles. This issue is potentially of great importance to manufacturers of smaller vehicles, but it has not been addressed in this analysis.

\subsubsection{Weight-Based Metric}

The weight-based metric uses equation 6.7 to define an individual gallons-per-mile target for each manufacturer. Although it is possible to define separate weight-based metrics for different vehicle types, only the manufacturer-specific form of the standard was tested. Thus, each manufacturer voluntarily ensures that its fleet complies with equation 6.7. Many other weight-based standards with different properties can be formulated. While this study breaks new ground in quantitatively evaluating a single weight-based metric, as an assessment of the topic of weight-based standards, it is very limited.

By making a manufacturer's fuel economy target a function of the weight of the vehicles it produces, the weight-based metric introduces the possibility that manufacturers might increase vehicle weight as part of a strategy for meeting the standards. Increasing weight would have two opposing effects: (1) lowering the mpg level a manufacturer's fleet must meet and (2) reducing the fuel savings provided to consumers. From equation 6.7, it follows that a $1 \%$ increase in vehicle weight would relax (increase) the gallons-per-mile required by $1 \%$. On the other hand, increasing weight by $1 \%$ will cause about an $0.6 \%$ loss in fuel economy. Thus, adding weight alone would bring a manufacturer closer to meeting the standard, but at the cost of lost fuel savings. According to the cost function shown in Figure 6-5, adding up to 5\% more weight would also reduce vehicle price by a small amount, but beyond $5 \%$ additional weight would increase price. Other types of weight-based standards could be formulated to remove this incentive, but they have not been analyzed here.

The assumptions about the costs and benefits of weight reduction are critical to the results. To the best of our knowledge, this study is the first to quantitatively assess the effects of a weight-based standard. Our results should therefore be interpreted with caution, and considerable further analysis should be done before decisions are taken to implement weight-based standards.

The assumed 5\% increase in weight due to safety and emission standards is incorporated into the weight-based analysis in the same way it is included in the mpg and UPI metric analyses: by multiplying the required mpg gain by 1.03 . Thus, the $\mathrm{k}$ factor in equation 6.7 becomes 0.236 for the $20 \%$ requirement and 0.37 for the $33 \%$ requirement. This variable factor is used to ensure consistency among the three metrics. The $5 \%$ weight increase produces no cost increase or cost savings in this analysis because it is assumed to have been done for reasons having nothing to do 
with fuel economy. Just as for the other metrics, the fuel economy numbers reported in Table 6-9 have been divided by 1.03 to account for the assumed weight increase.

The weight-based standard leads to very minor changes in vehicle weights while it produces almost the same increase in fuel economy as the mpg metric. Under the $20 \%$ requirement, the average weight of a light-duty vehicle decreases by $1.5 \%$ (Table 6-9). This decrease reflects the trade-off between fuel economy, price, and the relaxation of the mpg requirement, subject to the assumptions made. The light-duty vehicle fleet fuel economy achieved is $30.1 \mathrm{mpg}$, compared with 30.3 for the mpg metric. In comparison to the mpg metric, industry-wide constraint, retail prices increase $\$ 0.4$ billion less under the weight-based standard. The value of fuel savings is also about $\$ 0.4$ billion per year lower, with the net result that value to consumers is only $\$ 0.1$ billion per year lower under the weight-based formula, for the $20 \%$ requirement.

Differences this small could easily be an artifact of differences between the fuel economy cost functions used in the two analyses. The industry-wide mpg metric case uses estimated manufacturer-specific curves that include weight-reduction technologies. The weight-based analysis uses industry-wide, vehicle-type cost curves that exclude weight-reduction technologies. The cost and fuel economy impacts of weight changes are modeled separately, as described above. A difference in net value as small as the result obtained $(0.7 \%)$ could easily be due to changes in the method of calculation.

When the fuel economy improvement requirement is raised to $33 \%$, the fuel economy level achieved increases to $32.5 \mathrm{mpg}$, but average vehicle weight increases by $1.0 \%$. For the particular weight-based formula tested, increasing the stringency of the fuel economy requirement shifts the trade-off in favor of increasing weight to obtain a slightly less-demanding mpg requirement.

Table 6-9. Comparison of Costs and Savings of Weight-Based and mpg Standards

\begin{tabular}{|c|c|c|c|c|}
\hline & \multicolumn{2}{|c|}{$20 \%$ Increase } & \multicolumn{2}{|c|}{$33 \%$ Increase } \\
\hline & mpg/lndustry & Weight-Based & mpg/Industry & Weight-Based \\
\hline $\mathrm{mpg}$ & 31.18 & 30.99 & 33.69 & 33.49 \\
\hline Vehicle Costs $(\$)$ & 9,543 & 9,185 & 16,169 & 20,303 \\
\hline Increase v. mpg Metric (\$) & & -358 & & 4,134 \\
\hline$\%$ & & -3.8 & & 25.6 \\
\hline Fuel Savings (\$) & 19,260 & 18,830 & 24,631 & 24,223 \\
\hline Increase v. mpg Metric (\$) & & -430 & & -408 \\
\hline$\%$ & & -2.2 & & -1.7 \\
\hline Net Value $(\$)$ & 9,717 & 9,645 & 8,462 & 3,920 \\
\hline Increase v. mpg Metric (\$) & & -72 & & $-4,542$ \\
\hline$\%$ & & -0.7 & & -53.7 \\
\hline $\begin{array}{l}\text { Average change in vehicle } \\
\text { weight }(\%)\end{array}$ & & -1.5 & & 1.0 \\
\hline
\end{tabular}


However, the effect is rather small. These weight changes do not include the assumed 5\% increase in weight due to safety and emissions regulations. Taking the 5\% increase into account, under the $20 \%$ requirement, average weight increases by $3.5 \%$, while under the $33 \%$ standard, it increases by $6.0 \%$.

The more stringent 33\% requirement also increases vehicle prices by $\$ 4.1$ billion per year relative to the industry-wide mpg metric. This increased cost is probably a result of the higher cost of achieving fuel economy increases without using weight-reduction technologies. Fuel savings are also slightly less, with the result that net value is reduced by about $\$ 4.5$ billion per year (54\%) in comparison with the industry-wide mpg metric (Table 6-9).

A weight-based standard may also tend to reduce the variance of the distribution of weights. Under the $20 \%$ requirement, the standard deviation of vehicle weight across manufacturer, vehicle type, and origin categories decreased by $1.5 \%$. Under the $33 \%$ requirement, the decrease was $3.5 \%$. These are small changes and may be artifacts of the particular assumptions made in this analysis, but reducing the variability of the distribution of vehicle weight could have beneficial effects for highway safety, and so this result merits further investigation. Furthermore, as the NRC CAFE Committee pointed out, it should be possible to design weight-based standards to deliberately encourage a less-variable distribution of vehicle weights.

The weight-based standard does not, however, appear to reduce the measures of inequity in the impacts across manufacturers. The weight-based standard at $20 \%$ and $33 \%$ improvement requirements is compared with the industry-wide mpg metric in Figures 6-14 and 6-15. The dispersion of changes in net value increases for the weight-based standard. However, the

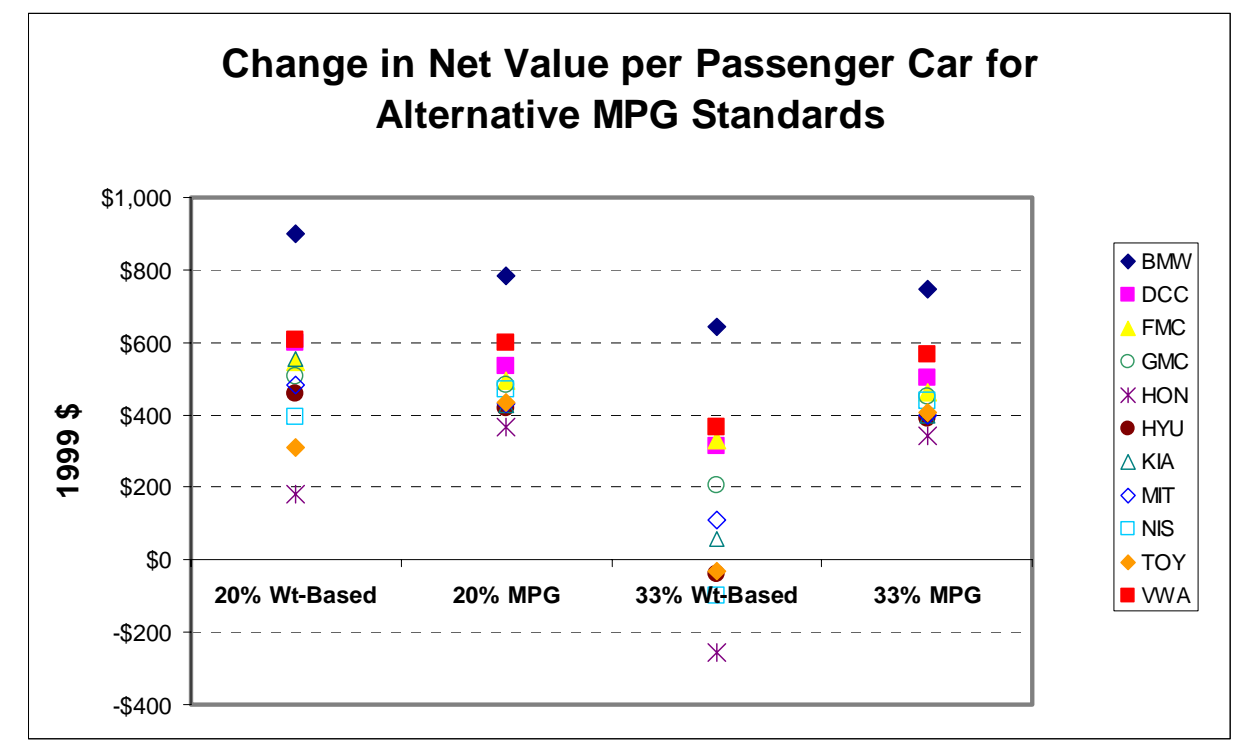

Figure 6-14. Comparison of Changes in Net Value per Passenger Car between Weight-Based and mpg Metric Standards 


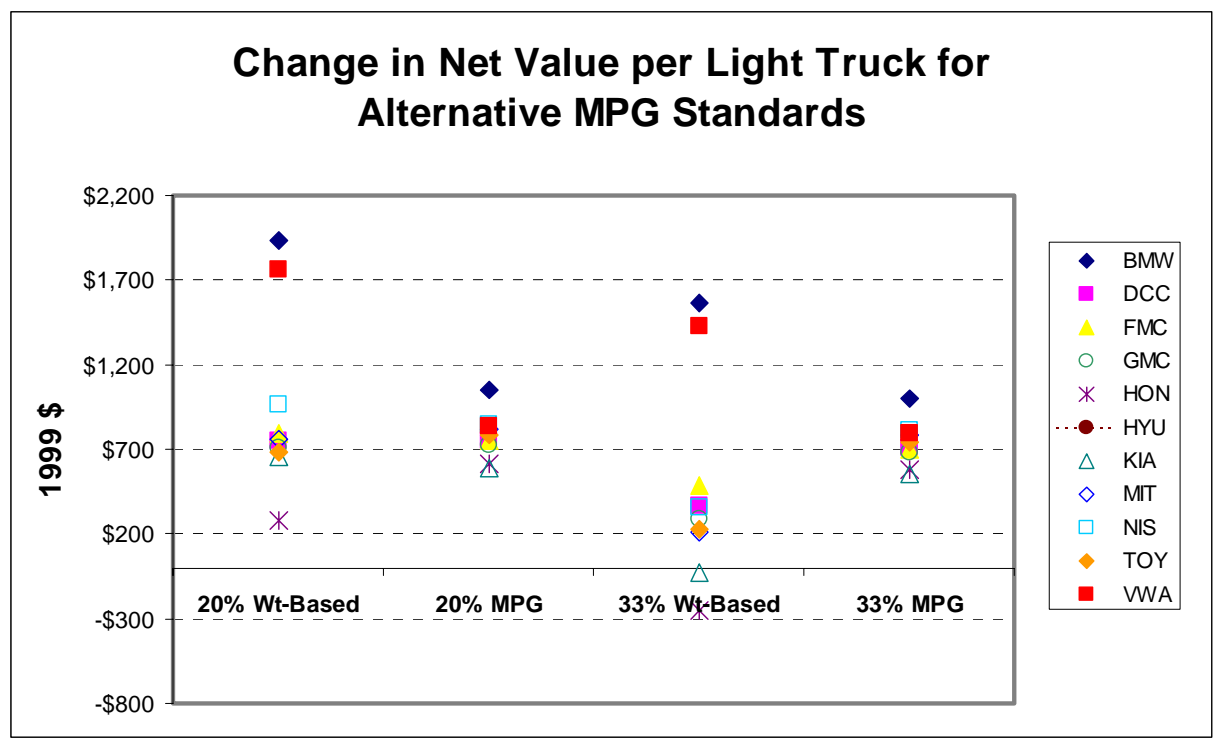

Figure 6-15. Comparison of Changes in Net Value per Light Truck between Weight-Based and mpg Metric Standards

comparison may be reflecting differences in methodology, as noted above, as well as in the impacts of the weight-based standard. Furthermore, the weight-based standard should not have a significant impact on the decisions of manufacturers to enter or leave market segments, as the UPI or mpg metrics would.

\subsubsection{Sensitivity Analyses}

The results presented above are strongly dependent on several critical assumptions. In this section, the sensitivity of results to three types of assumptions are tested: (1) consumer behavior, (2) the cost of improving fuel economy, and (3) the price of fuel.

\subsubsection{Three-Year Simple Payback}

Rather than assuming that consumers value the fuel savings that would accrue over the full (14-year) lifetime of a vehicle, we test an assumption that consumers, for whatever reason, consider only the first three-year's worth of fuel saved. Possible reasons include the failure of used car markets to fully value fuel economy, consumer uncertainty about the performance of new technologies and future gasoline prices, and incomplete information. As noted above, this amounts to a market failure. Nonetheless, if consumers do assess the benefit of fuel economy in this way, then there will be a perceived reduction in value for higher-fuel-economy vehicles, and manufacturers will be unlikely to agree to voluntary standards that significantly reduce the value of their products in the eyes of their customers. The three-year simple payback assumption is tested using the mpg metric in all cases.

If consumers value only the first three years of fuel savings, even the $20 \%$ fuel economy requirement becomes a binding constraint. This result implies that the fuel economy increase that would maximize consumer value is less than $20 \%$. Nonetheless, a $20 \%$ standard still increases 
the net value of vehicles versus no increase, but by only $\$ 1$ billion per year (Table 6-10). In sharp contrast with the $\$ 19$ billion present value of fuel savings shown in Table 6-6 for the full lifetime assumption, three-year payback consumers perceive only $\$ 9$ billion in value. Also, the mpg levels achieved are lower —about 29.5 mpg compared with 30.3.

For the $33 \%$ requirement, the net values of the fuel economy increases are negative. The same pattern of costs across the forms of standards is evident. The manufacturer-specific standard is the most costly and delivers the least net benefits. The industry-wide and car-truck standards are virtually identical, and the CAFE-like standards are intermediate in cost.

Table 6-10. Summary of Costs and Fuel Savings for mpg Metric, Three-Year Simple Payback

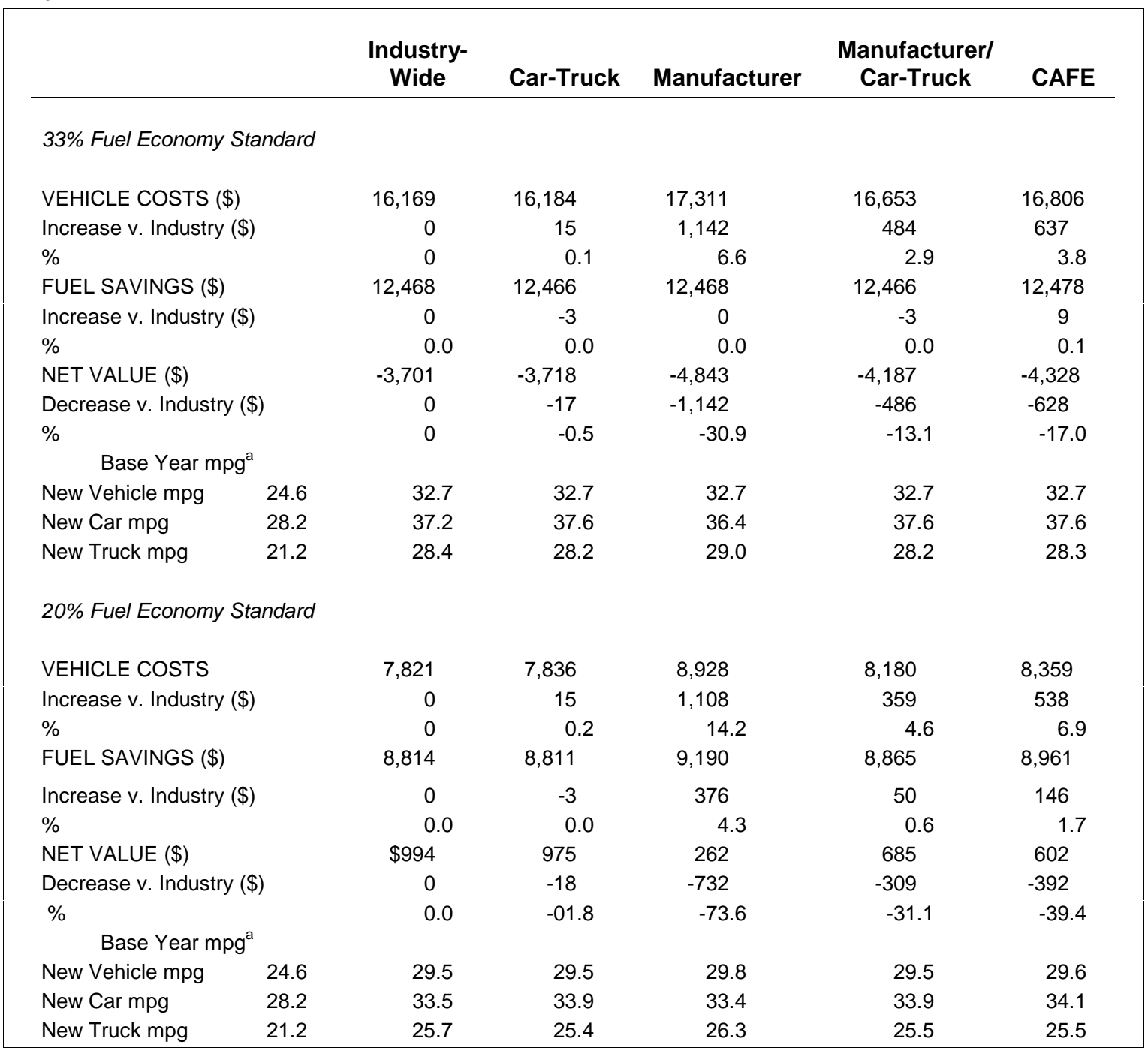

a All but the base year mpg numbers have been adjusted downward by dividing by 1.03 to account for an assumed $5 \%$ increase in weight. 
The three-year simple payback rule shows the greatest disparities in impacts under the manufacturer-specific fuel economy standards (Figures 6-16 and 6-17). On the other hand, the industry-wide forms more successfully minimize disparities. Under the three-year payback assumption, manufacturer-specific standards divide passenger car manufacturers into two distinct groups: those for which net values are in the range of $-\$ 50$ to $+\$ 150$ per vehicle and those that see a $\$ 200-\$ 500$ loss of value. Notable in the latter group are the "domestic" manufacturers: Daimler-Chrysler, General Motors, and Ford, accompanied by Nissan and BMW.

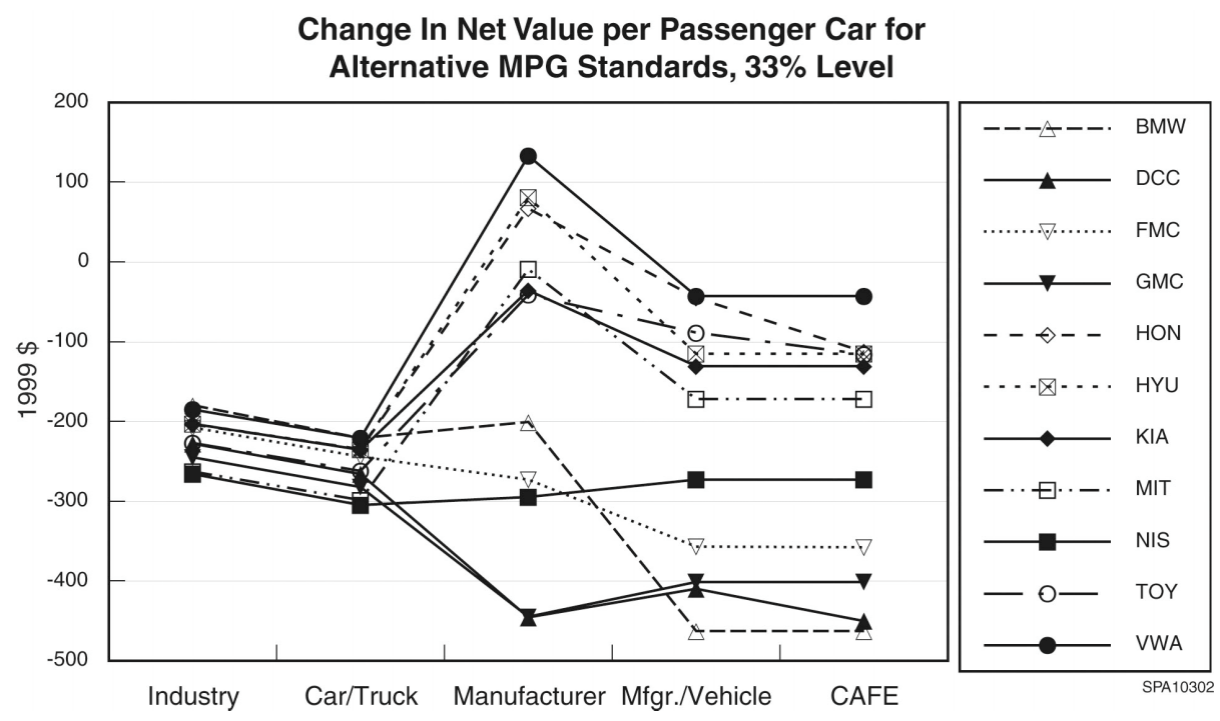

Figure 6-16. Effect of Form of Standard on Equity, Passenger Cars, Three-Year Simple Payback for Fuel Savings, 33\% Requirement

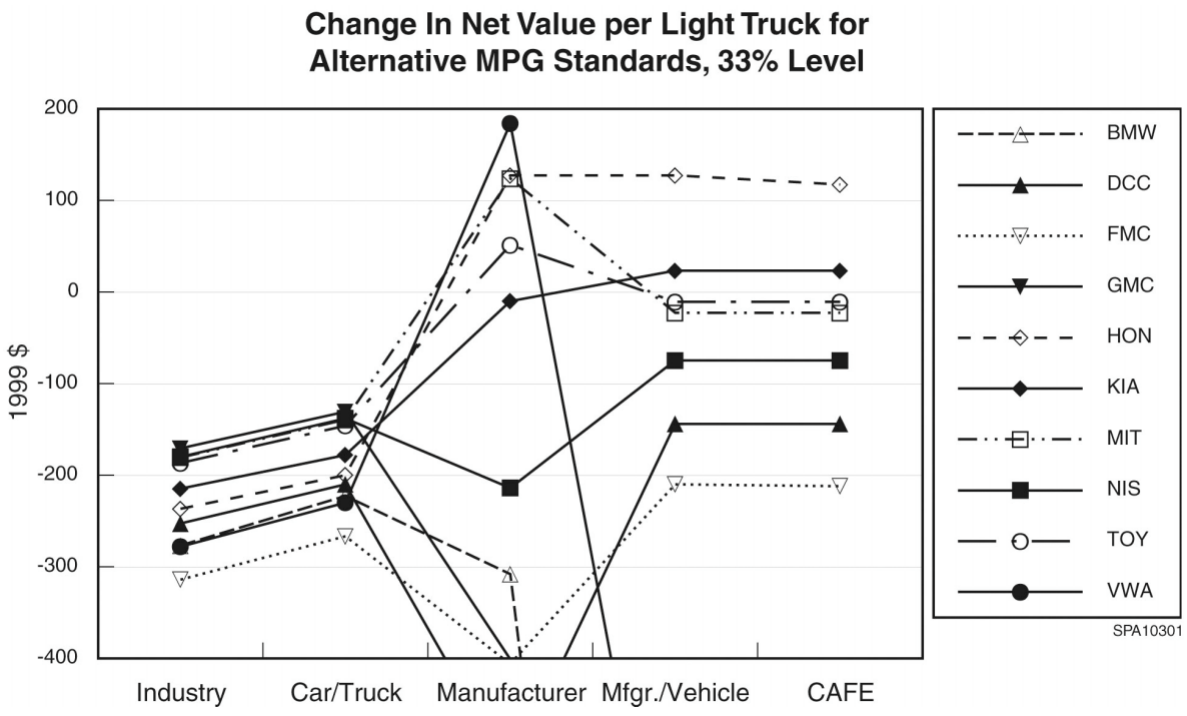

Figure 6-17. Effect of Form of Standard on Equity, Light Trucks, ThreeYear Simple Payback for Fuel Savings, 33\% Requirement 
Light truck manufacturers are similarly divided into those experiencing a gain in net value and those experiencing a loss of value. Again, General Motors, Ford, and Chrysler are in the latter group.

The inequities in net value changes are much smaller for the 20\% requirement (Figures 6-18 and 6-19). Only about $\$ 150$ separates the highest and lowest manufacturers, regardless of which standard is being evaluated. Similar results are seen for passenger cars and light trucks, except that the results for BMW and Volkswagen are far more extreme.

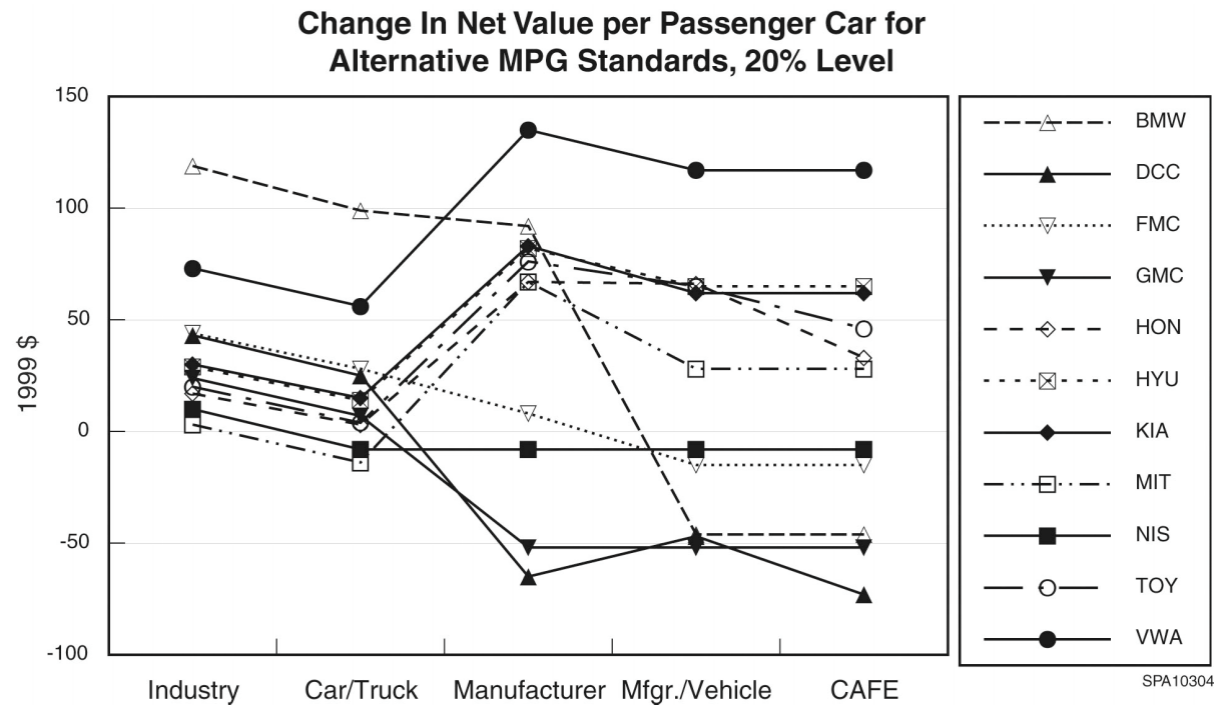

Figure 6-18. Effect of Form of Standard on Equity, Passenger Cars, Three-Year Simple Payback, 20\% Requirement

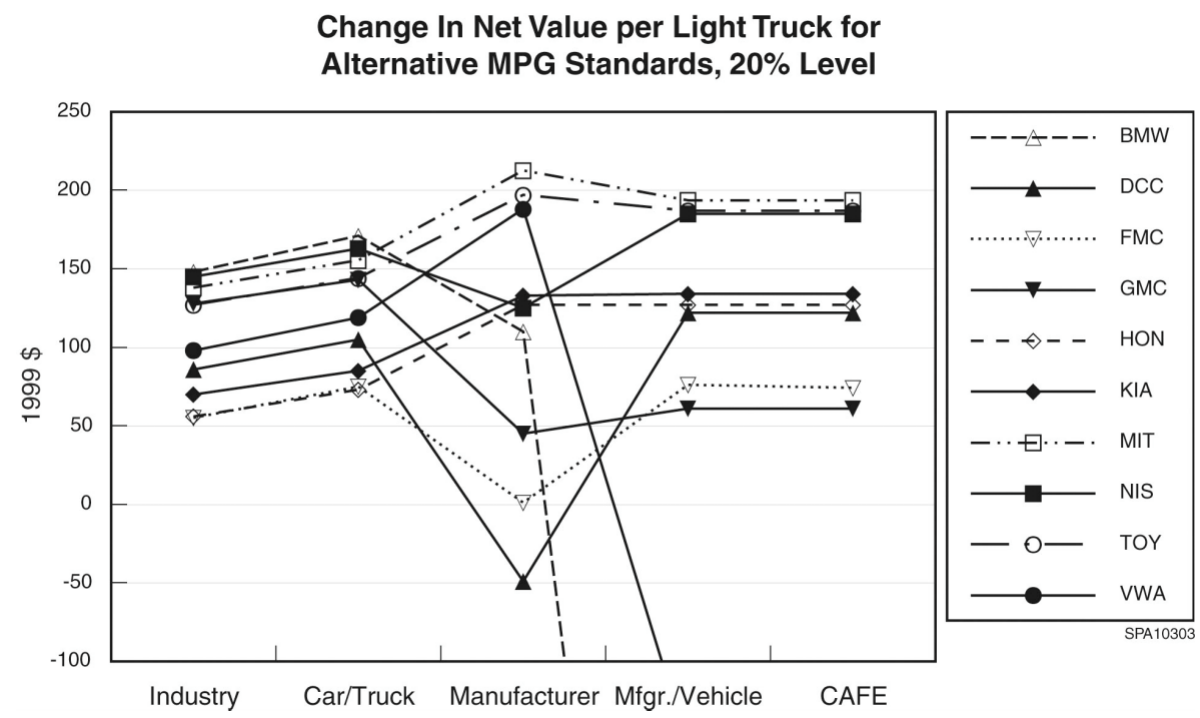

Figure 6-19. Effect of Form of Standard on Equity, Light Trucks, ThreeYear Simple Payback, 20\% Requirement 
These results suggest that to the extent manufacturers believe that consumers do not value full lifetime fuel savings, it will likely be more difficult to achieve consensus on standards, unless they are very close to the level that maximizes perceived net consumer value.

\subsubsection{Comparison of Seven Cost Curves}

The second critical assumption of this analysis is the cost of increasing fuel economy. There are significant differences of opinion on this subject, although there has also been some convergence of views in published studies over the past 10 years (e.g., see Greene and DeCicco 2000; NRC 2002). The sensitivity of results to assumptions about the cost of improving fuel economy is tested by rerunning the industry-wide mpg metric analysis, with lifetime fuel accounting, by using the seven alternative cost curves, the parameters of which are shown in Table 6-5:

1. Section 4 , without weight-reduction technologies.

2. Sierra Research (Austin et al. 1999).

3. NRC (2002), Low-mpg/High-Cost.

4. NRC (2002), Average.

5. NRC (2002), High-mpg/Low-Cost.

6. ACEEE (DeCicco et al. 2001).

7. MIT 2020 (Weiss et al. 2000).

The seven curves produce quite different results (Table 6-11). Three indicate that neither the $20 \%$ nor the $33 \%$ fuel economy targets would be a binding constraint on manufacturers. The MIT 2020, ACEEE Advanced, and NRC High-mpg/Low-Cost curves all arrive at net valuemaximizing mpg numbers above the required standards. The ACEEE Advanced curves produce the highest mpg level, indicating that a combined light-duty vehicle mpg of almost 40 would produce $\$ 36$ billion in present value fuel savings in return for a total retail price increase of $\$ 11$ billion, resulting in a net savings of \$25 billion per year. The MIT-derived advanced 2020 technology curve results in an optimal light-duty fleet average mpg of 37 . While the NRC Highmpg curve portrays mpg gains as considerably more costly, it still arrives at $33 \mathrm{mpg}$ as the valuemaximizing result in both cases.

For the 20\% requirement, the NRC Average cost curves result in an mpg level just at the requirement of $29.5 \mathrm{mpg}$. The Section 4 without weight reduction, Sierra Research, and NRC Low-mpg curves find a $20 \%$ improvement to be a binding constraint on manufacturers. Both, however, show a positive net value, with the Sierra curve indicating $\$ 5.5$ billion in gains and the NRC Low-mpg curve most pessimistic at $\$ 1.2$ billion in gains. 
Table 6-11. Comparison of Seven Alternative Fuel Economy Cost Functions

\begin{tabular}{|c|c|c|c|c|c|c|c|}
\hline & $\begin{array}{c}\text { Section } 4 \\
\text { without } \\
\text { Weight } \\
\text { Reduction }\end{array}$ & Sierra & NRC Low & $\begin{array}{c}\text { NRC } \\
\text { Average }\end{array}$ & NRC High & $\begin{array}{c}\text { ACEEE } \\
\text { Advanced }\end{array}$ & MIT 2020 \\
\hline \multicolumn{8}{|c|}{ 33\% Requirement, MPG Metric, Industry-Wide Standard } \\
\hline VEHICLE COSTS(\$) & 20,058 & 24,194 & 26,311 & 18,802 & 13,454 & 10,911 & 14,688 \\
\hline Change v. S4 w/o W (\$) & & 4,136 & 6,253 & $-1,256$ & $-6,604$ & $-9,147$ & $-5,370$ \\
\hline$\%$ & & 21 & 31 & -6 & -33 & -46 & -27 \\
\hline FUEL SAVINGS (\$) & 24,631 & 24,631 & 24,631 & 24,631 & 25,216 & 36,287 & 32,209 \\
\hline Change v. S4 w/o W (\$) & & 0 & 0 & 0 & 585 & 11,656 & 7,578 \\
\hline$\%$ & & 0 & 0 & 0 & 2 & 47 & 31 \\
\hline NET VALUE (\$) & 4,573 & 437 & $-1,680$ & 5,829 & 11,762 & 25,377 & 17,521 \\
\hline Change v. S4 w/o W (\$) & & $-4,136$ & $-6,253$ & 1,256 & 7,189 & 20,804 & 12,948 \\
\hline$\%$ & & -90 & -137 & 27 & 157 & 455 & 283 \\
\hline $\mathrm{MPG}^{\mathrm{a}}$ & 32.7 & 32.7 & 32.7 & 32.7 & 33.0 & 39.6 & 36.9 \\
\hline \multicolumn{8}{|c|}{ 20\% Requirement, MPG Metric, Industry-Wide Standard } \\
\hline VEHICLE COSTS (\$) & 8,239 & 11,952 & 15,992 & 12,836 & 13,454 & 10,911 & 14,688 \\
\hline Change v. S4 w/o W (\$) & & 3,713 & 7,753 & 4,597 & 5,215 & 2,672 & 6,449 \\
\hline$\%$ & & 45 & 94 & 56 & 63 & 32 & 78 \\
\hline FUEL SAVINGS (\$) & 17,412 & 17,412 & 17,412 & 19,391 & 25,216 & 36,287 & 32,209 \\
\hline Change v. S4 w/o W (\$) & & 0 & 0 & 1,979 & 7,804 & 18,875 & 14,797 \\
\hline$\%$ & & 0 & 0 & 11 & 45 & 108 & 85 \\
\hline NET VALUE (\$) & 9,173 & 5,460 & 1,420 & 5,829 & 11,762 & 25,377 & 17,521 \\
\hline Change v. S4 w/o W (\$) & & $-3,713$ & $-7,753$ & $-3,344$ & 2,589 & 16,203 & 8,348 \\
\hline$\%$ & & -40 & -85 & -36 & 28 & 177 & 91 \\
\hline $\mathrm{MPG}^{\mathrm{a}}$ & 29.5 & 29.5 & 29.5 & 30.3 & 33.0 & 39.6 & 36.9 \\
\hline
\end{tabular}

a All mpg numbers have been adjusted downward by dividing by 1.03 to account for an assumed $5 \%$ increase in average vehicle weight.

At the 33\% level, manufacturers are constrained under the Section 4 without weight reduction, Sierra, NRC Low-mpg, and NRC Average curves, as evidenced by the fact that the same mpg level, 32.7, is achieved in each case. Only the NRC Low curve indicates a loss of net value: $-\$ 1.7$ billion per year. The Sierra cost curve produces the smallest increase in value $\$ 0.4$ billion per year. The Section 4 without weight reduction and NRC Average curves produce results similar to each other's.

The three NRC curves were derived from vehicle size class-specific curves used in Chapter 4 of the NRC CAFE report (NRC 2002) by taking a size-class sales weighted average of the quadratic curves in fractional improvement form. The sales shares are as follows: cars subcompact; 17.7\%; compact, 26.8\%; midsize, 39.8\%; large, 24.8\%; light trucks — SUV (small), 5.1\%; SUV (midsize), $29.0 \%$; SUV (large) 15.5\%; minivan, 22.6\%; pick-up (small), 3.9\%; and pickup (large), $23.9 \%$.

\subsubsection{Higher Fuel Prices}

Two alternative fuel prices were compared by using the manufacturer-specific cost curves for the mpg metric and the industry average "weightless" curves for the weight-based metric. Assuming full lifetime accounting for fuel savings, raising the price of fuel from $\$ 1.35$ per gallon to $\$ 1.75$ has no effect on the levels of fuel economy achieved in the $33 \%$ mpg increase, industrywide standard case. Not until the price of gasoline gets above $\$ 2.00$ per gallon is there any 
impact on fuel economy (Figure 6-20). This is because the 33\% improvement constraint is still binding, even with fuel at $\$ 2.00$ per gallon. At $\$ 2.25$ per gallon, however, manufacturers spend more to increase mpg, but the cost is more than offset by the increased value of fuel savings, so that net value is $\$ 16.5$ billion higher than in the $\$ 1.35$ per gallon case (Table 6-12). Nearly all of the difference is due, however, to the higher price of fuel since mpg increases from 32.7 to only 33.4.

Increasing the price of gasoline all the way to $\$ 4.00$ per gallon, which is similar to European fuel prices, raises the net-value-maximizing mpg level to 37.9, a bit below the European $2008 \mathrm{mpg}$ target level. The implied price elasticity of mpg (using the midpoint formula) is 0.2 , a value generally consistent with estimates derived by Greene and DeCicco (2000).

There is some impact of the $\$ 1.75$ price for the weight-based standard:. mpg increases by 0.6 to 33.1 from 32.5. Increasing the price of fuel alters the trade-off between fuel savings and weight in favor of fuel savings, so vehicles are made somewhat lighter to provide better fuel economy to customers. The explicit trade-off under the weight-based standard leads to a slightly higher level of fuel economy than the implicit trade-off incorporated in the cost curves used in the mpg metric analysis.

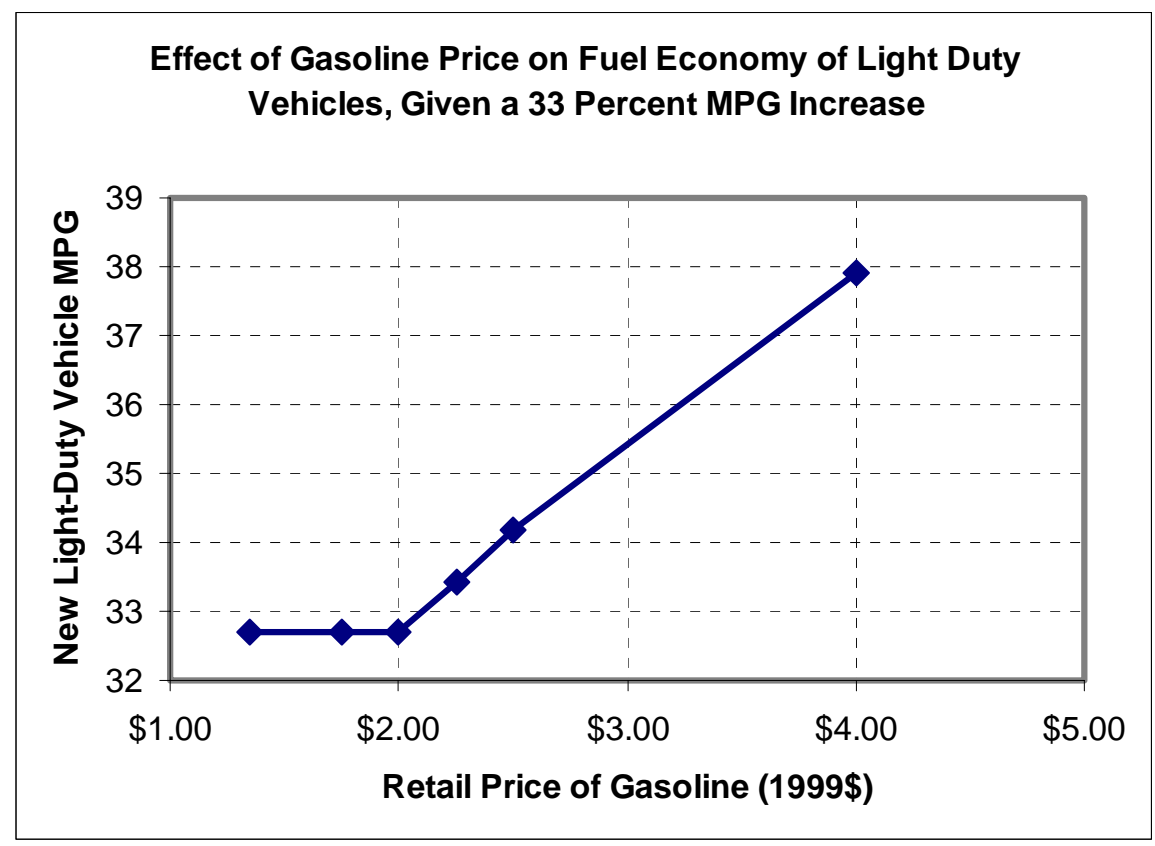

Figure 6-20. Effect of Gasoline Price on the Net Value Maximizing Level of Light-Duty Vehicle Fuel Economy 
Table 6-12. Comparison of Weight-Based and mpg Metrics at \$1.35 and \$1.75 per Gallon, 33\% Increase Requirement

\begin{tabular}{|c|c|c|c|c|c|}
\hline & \multicolumn{3}{|c|}{$\begin{array}{l}33 \% \text { mpg Metric Industry-Wide } \\
\text { Standard }\end{array}$} & \multicolumn{2}{|c|}{$\begin{array}{l}\text { Weight-Based } \\
\text { Metric }\end{array}$} \\
\hline & $\$ 2.25$ & $\$ 1.75$ & $\$ 1.35$ & $\$ 1.75$ & $\$ 1.35$ \\
\hline VEHICLE COSTS (\$) & 18,430 & 16,169 & 16,169 & 21,205 & 20,303 \\
\hline Change v. $\$ 1.35 /$ gallon $(\$)$ & 2,261 & 0 & & 902 & \\
\hline$\%$ & 14.0 & 0.0 & & 4.4 & \\
\hline FUEL SAVINGS (\$) & 43,435 & 31,929 & 24,631 & 32,914 & 24,223 \\
\hline Change v. $\$ 1.35 /$ gallon $(\$)$ & 18,804 & 7,298 & & 8,691 & \\
\hline$\%$ & 76.3 & 29.6 & & 35.9 & \\
\hline NET VALUE (\$) & 25,005 & 15,760 & 8,462 & 11,708 & 3,920 \\
\hline Change v. $\$ 1.35 /$ gallon $(\$)$ & 16,543 & 7,298 & & 7,789 & \\
\hline$\%$ & 195.5 & 86.2 & & 198.7 & \\
\hline $\mathrm{mpg}^{\mathrm{a}}$ & 33.4 & 32.7 & 32.7 & 33.1 & 32.5 \\
\hline
\end{tabular}

a The mpg numbers have been adjusted downward by dividing by 1.03 to account for an assumed $5 \%$ increase in average vehicle weight.

\subsection{Conclusions}

A method has been created and implemented for (1) evaluating the costs and benefits to consumers and (2) measuring the impacts on individual manufacturers of alternative levels, metrics, and forms of voluntary fuel economy standards. The method combines representations of the abilities of manufacturers' to supply fuel economy with a representation of the value of fuel economy to consumers, within a mathematical programming model. Beginning with data on model-year 2000 product offerings, the impacts of alternative formulations of voluntary standards are evaluated for the 2012-15 period.

By using base-case assumptions about technology costs and consumer behavior, it appears that about a $25 \%$ improvement in fuel economy would maximize the net value of fuel economy changes to consumers. This result depends on fuel economy cost curves that are similar to the "Average" cost curves calculated from data made available in a recent National Research Council study, but it is somewhat more optimistic than conclusions from a recent study for Natural Resources Canada by Sierra Research and is substantially less optimistic than results of recent assessments by ACEEE and MIT for the year 2020.

Standards that permit all manufacturers to achieve the same marginal net benefits (of fuel economy improvements) both across the industry and, for each manufacturer, across all its product lines are not only the most cost-effective but produce the smallest range of differential impacts on manufacturers as well. In particular, a single industry-wide voluntary standard — like the one now in effect in Europe - uniformly provides the greatest net value and the least variance in the change in net value across manufacturers. However, while the methodology of this analysis ensures that the industry-wide standard is achieved in the most efficient way possible, it is not clear how this level of efficiency would be achieved under a voluntary agreement in the real world. Perhaps a more accurate statement is that the industry-wide standard has the potential to be the most efficient and most equitable. 
A uniform mpg target applied to all manufacturers, regardless of the mix of vehicles (e.g., passenger cars versus light trucks) they produce, is least efficient and appears to be no more equitable than other forms. Manufacturer-specific standards with separate car and truck targets are intermediate in cost and are similar in differential impacts on manufacturers to the industrywide standard. Yet, relative differences in net value among the standards are not large, other assumptions equal.

UPI standards do not appear to be less economically efficient than standards based on an mpg metric. In some instances, they are less costly than standards based on the mpg metric and provide similar benefits. In general, those manufacturers that are disadvantaged by the UPI metric are given a relative advantage by the mpg metric and vice versa. The potential for the UPI metric to restrict the options of manufacturers of smaller vehicles to move into larger- vehicle market segments has not been assessed here, and the appropriateness of requiring a higher level of fuel economy for those that already achieve higher fuel economy levels has not been considered.

A weight-based standard was somewhat more costly and did not equalize impacts on manufacturers. Under this type of standard, the relative increase in cost and reduction of net value were \$1-\$4 billion per year. The average weight of a light-duty vehicle decreases by only $1.5 \%$ for the $20 \%$ requirement and by only $1 \%$ for the $33 \%$ requirement. Although explicit weight reductions were not calculated for the mpg and UPI metrics, weight reductions of 5-10\% are implicit in the technology price curves. Only one of many possible forms of weight-based standard has been analyzed here. Other formulations might be designed to reduce the variance in vehicle weights or to affect heavier vehicles differently from lighter vehicles. Clearly, a good deal more analysis is needed to understand the pros and cons of weight-based standards.

Additional analyses tested the sensitivity of results to key assumptions. The base case assumes that consumers account for fuel savings over the entire 14-year expected life of a vehicle. If it is assumed that consumers count only the first three-years of fuel savings, then even a $20 \%$ increase would be too much. The $33 \%$ requirement would produce negative net value, however, regardless of the form of the standard. The three-year view also magnifies the variation in impacts across manufacturers. To the extent that this is a more correct description of consumer behavior or that manufacturers believe that it is, they will be more reluctant to agree to a higher fuel economy requirement.

Tests of seven alternative technology cost curves showed rather wide differences in costs and benefits associated with improvements in fuel economy. Curves based on more optimistic assumptions or technological advances that may be achieved by 2020 indicate that even the $33 \%$ requirement is well below the optimal fuel economy level, given the assumptions of the base case. A cost curve derived from ACEEE's advanced technology analysis indicates an optimal light-duty vehicle mpg of about 40, while one derived from MIT's 2020 study suggests $37 \mathrm{mpg}$. Only the curve derived from the NRC study's lower-bound technology costs indicates negative net value for a $33 \%$ improvement in fuel economy, under reference assumptions.

Given a $33 \%$ requirement, fuel prices above $\$ 2.00$ per gallon ( $\$ 0.65 /$ gallon more than the reference price) would be necessary to encourage greater use of fuel economy technology than 
required by the standard. Given a weight-based standard, increasing the price of fuel would shift the weight-fuel economy trade-off in favor of fuel economy, with the result that vehicle weight would decrease somewhat. Higher fuel prices would undoubtedly prompt consumers to prefer products with higher fuel economy, and the change in sales mix would produce some increase in fuel economy. Sales-mix changes, however, have not been considered in this analysis.

Finally, more methodological research should be directed toward defining and measuring the fairness or equity of fuel economy standards. The measures used here, though relevant, may be overlooking important factors, such as differences in consumer preferences in the market segments served by different manufacturers. This study has made an initial effort to quantify the impacts of alternative standards on different manufacturers. Clearly, this area deserves more attention.

\subsection{References}

Austin, T.C., R.G. Dulla, and T.R. Carlson, 1999, Alternative and Future Technologies for Reducing Greenhouse Gas Emissions From Road Vehicles, Sierra Research, Inc., Sacramento, Calif., for Natural Resources Canada.

Brooke, A., D. Kendrick, A. Meerhause, and R. Raman, 1998, GAMS: A User's Guide, GAMS Development Corp., Washington, D.C.

Davis, S.C., 2001, Transportation Energy Data Book: Edition 21, ORNL-6966, Oak Ridge National Laboratory, Oak Ridge, Tenn., Sept.

Davis, S.C., 2000, Transportation Energy Data Book: Edition 20, ORNL-6959, Oak Ridge National Laboratory, Oak Ridge, Tenn., Sept.

DeCicco, J.M, F. An, and M. Ross, 2001, "Technical Options for Improving the Fuel Economy of U.S. Cars and Light Trucks by 2012-2015," forthcoming American Council for an Energy Efficient Economy (ACEEE), Washington, D.C.

Greene, D.L., 1991, "Short-Run Pricing Strategies to Increase Corporate Average Fuel Economy," Economic Inquiry 29(1):101-114.

Greene, D.L., and J.L. Hopson, 2002, "Voluntary Fuel Economy Standards Policy Model and Analysis of Alternative Standards," to be published, Oak Ridge National Laboratory, Oak Ridge, Tenn.

Greene, D.L., and J.M. DeCicco, 2000, "Engineering-Economic Analyses of Automotive Fuel Economy Potential in the United States, Annual Review of Energy and the Environment, 25:477-536.

Harrison, I.M., 1996, “RTECS Research Fuel Purchase Log Study,” Office of Energy Markets and End Use, Energy Information Administration, U.S. Department of Energy, Washington, D.C., May 2. 
Hellman, K.H., and J.D. Murrell, 1984, "Development of Adjustment Factors for the EPA City and Highway MPG Values," SAE Technical Paper Series \#840496, Society of Automotive Engineers, Warrendale, Penn.

Mintz, M., A.D. Vyas, and L.A. Conley, 1993, "Differences between EPA-Test and In-Use Fuel Economy: Are the Correction Factors Correct?," Transportation Research Record 1416, pp. 124-130, Transportation Research Board, National Research Council, National Academy Press, Washington, D.C.

NRC: National Research Council.

NRC., 2002, Effectiveness and Impact of Corporate Average Fuel Economy (CAFE) Standards, National Academy Press, Washington, D.C., July.

Weiss, M.A., et al., 2000, On the Road in 2020, Energy Laboratory Report MIT EL 00-003, Massachusetts Institute of Technology, Cambridge, Mass., Oct. 
$\Delta$ 


\section{Appendix A \\ Technology Baselines of Automobile and Light-Truck Manufacturers}


군

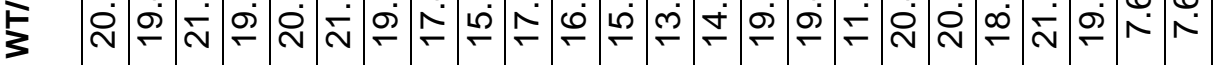

ব

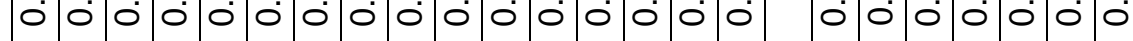

J

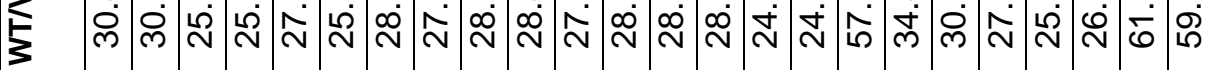

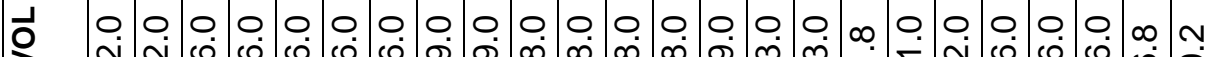

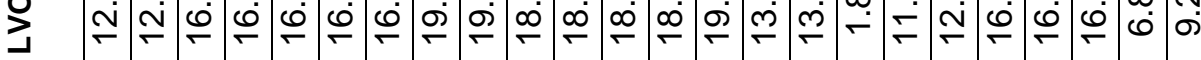

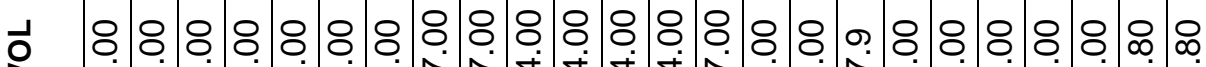
a

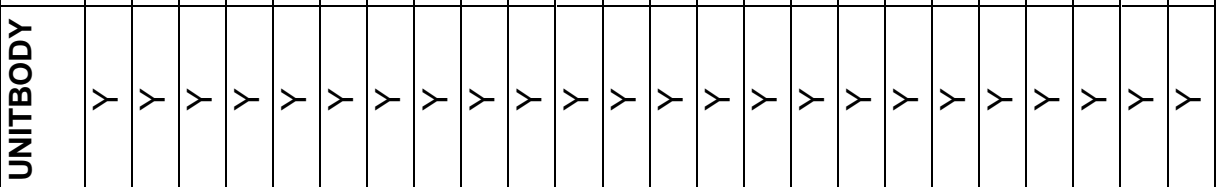

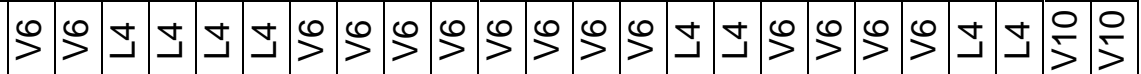

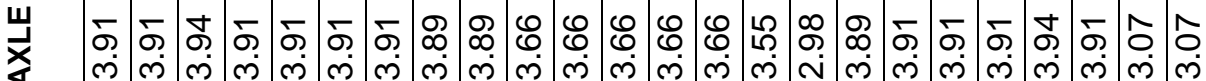

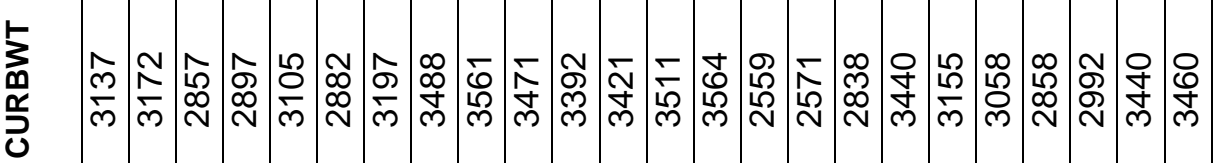

உ

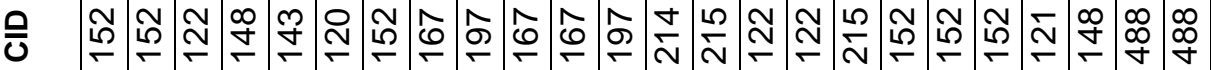

乩

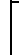

齐至

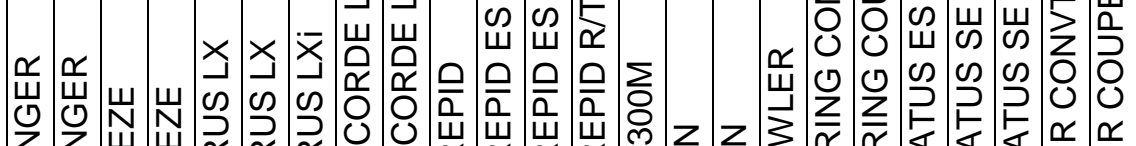

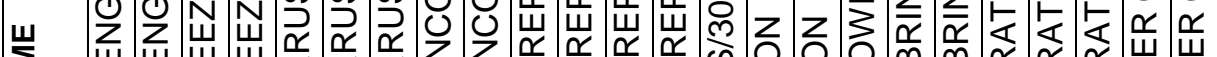

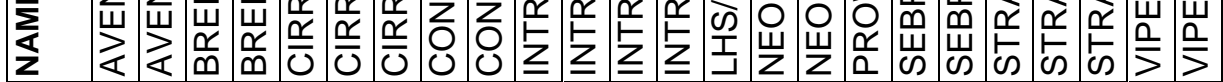

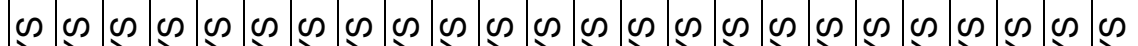

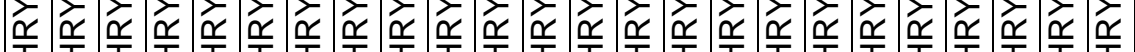

Z

产 


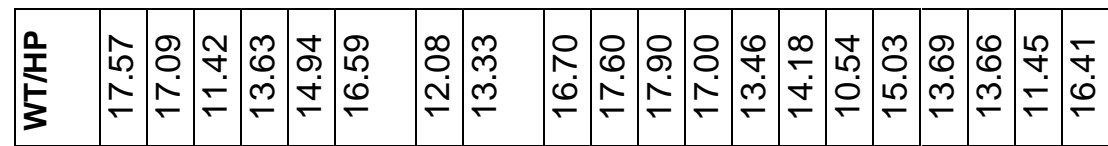

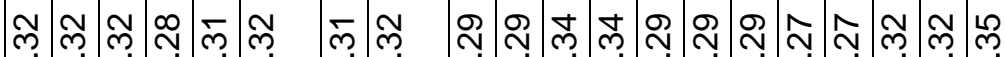

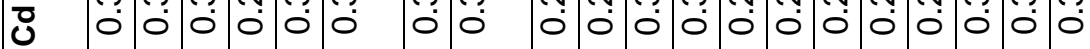

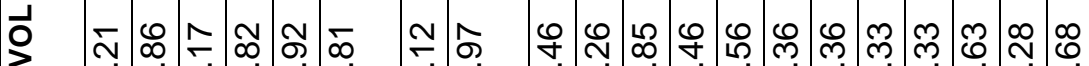

క

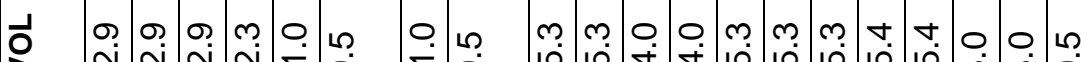

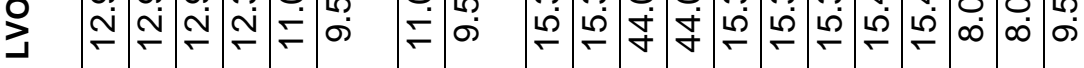

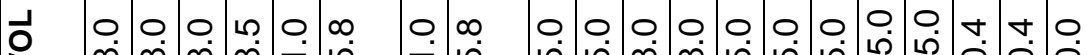

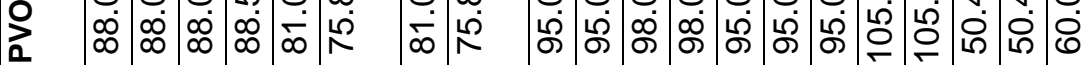

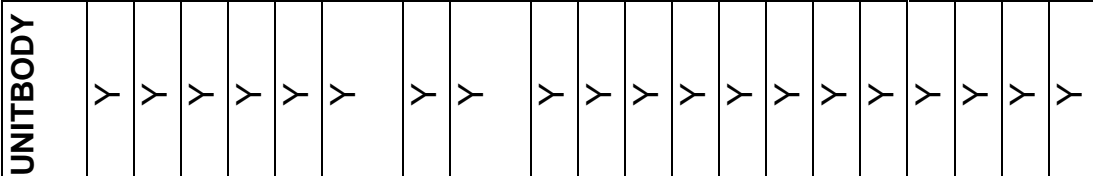

U.

山 స̂े

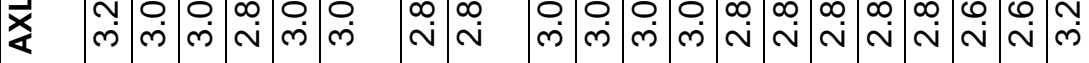

క

ن

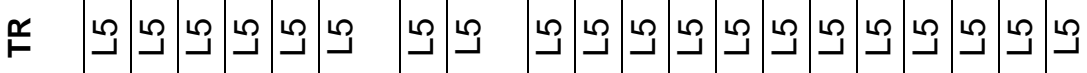

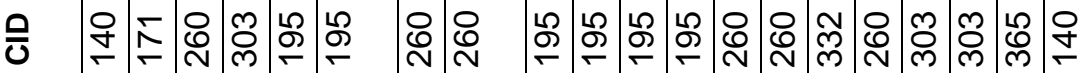

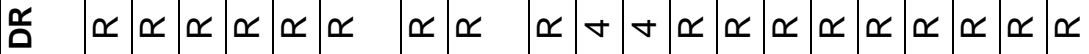

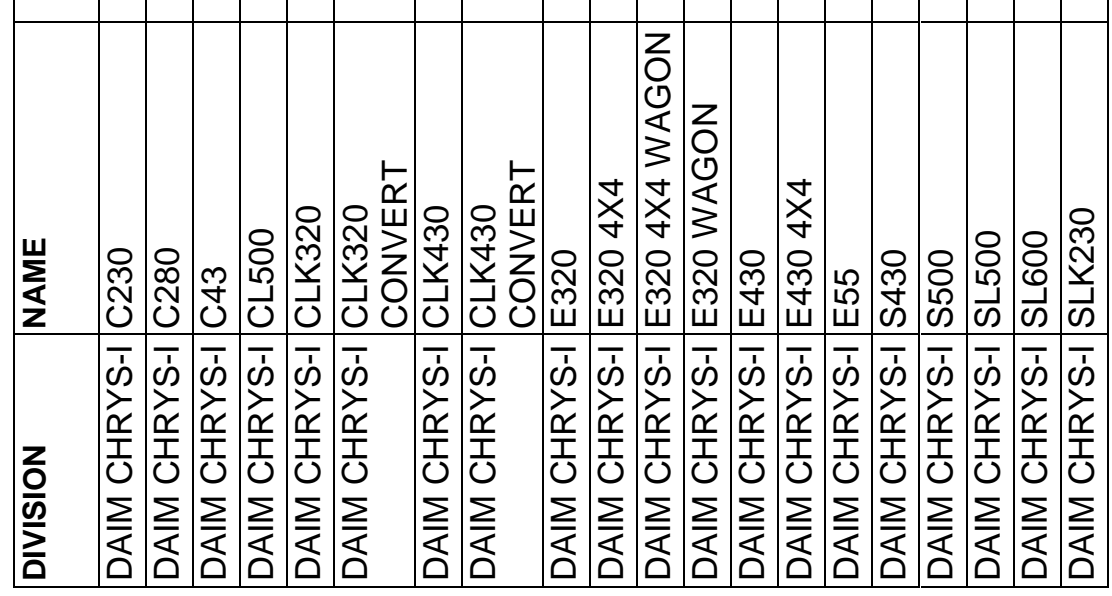




\begin{tabular}{|c|c|c|c|c|c|c|c|c|c|c|c|c|c|c|c|c|}
\hline 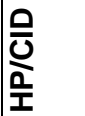 & $\mid$\begin{tabular}{l}
$\infty$ \\
\hdashline \\
-
\end{tabular} & $\underset{-}{\sigma}$ & 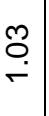 & $\check{F}$ & $\underset{ָ}{\bar{N}}$ & & & $\begin{array}{l}\tilde{N} \\
\widetilde{O} \\
\tilde{O}\end{array}$ & $\stackrel{\widetilde{N}}{-}$ & $\underset{\square}{\check{r}}$ & & \begin{tabular}{l}
$m$ \\
\hdashline \\
\end{tabular} & & & & ó. \\
\hline$\stackrel{5}{3}$ & $z$ & $z$ & $z$ & $z$ & $z$ & $z$ & $z$ & $z$ & $\vdash$ & $z$ & $z$ & $z$ & $z$ & $z$ & $z$ & $\vdash$ \\
\hline 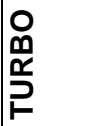 & $z$ & $z$ & $z$ & $z$ & $z$ & $z$ & z & $z$ & $\bar{\omega}$ & $z$ & $z$ & $z$ & $z$ & $z$ & $z$ & $z$ \\
\hline 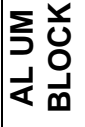 & $z$ & $z$ & $z$ & $z$ & $>$ & $>$ & $>$ & $>$ & $>$ & $>$ & $>$ & $>$ & $>$ & $>$ & $>$ & $>$ \\
\hline 递虽 & $>$ & $>$ & $>$ & $>$ & $>$ & $>$ & $>$ & $>$ & $>$ & $>$ & $>$ & $>$ & $>$ & $>$ & $>$ & $>$ \\
\hline ঢ্ & $\simeq$ & $\simeq$ & $\simeq$ & $\simeq$ & $\simeq$ & $\simeq$ & $\simeq$ & $\infty$ & D & $\simeq$ & $\simeq$ & $\simeq$ & $\simeq$ & $\simeq$ & $\simeq$ & ه \\
\hline$\frac{1}{\leqslant}$ & $\nabla$ & $\nabla$ & $\nabla$ & $\nabla$ & $\nabla$ & $\nabla$ & $\nabla$ & $\sim$ & 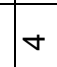 & m & $m$ & $m$ & $m$ & $m$ & m & $\nabla$ \\
\hline$\sum_{0}$ & 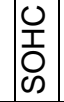 & $\left|\begin{array}{l}0 \\
0 \\
\text { 임 } \\
0\end{array}\right|$ & $\begin{array}{l}0 \\
\text { I } \\
0 \\
\text { S }\end{array}$ & $\begin{array}{l}0 \\
\text { OT } \\
\text { O } \\
\infty\end{array}$ & $\begin{array}{l}0 \\
0 \\
0 \\
\square\end{array}$ & & $\begin{array}{l}0 \\
\text { Oบ } \\
\text { @ }\end{array}$ & $\begin{array}{l}\geq \\
0 \\
\end{array}$ & $\begin{array}{l}0 \\
\text { O } \\
\text { O }\end{array}$ & \begin{tabular}{|l} 
\\
\\
\\
$\infty$ \\
$\mathcal{\infty}$
\end{tabular} & $\begin{array}{l}\text { OU } \\
\text { O }\end{array}$ & $\begin{array}{l}0 \\
\\
\text { O } \\
\text { @ }\end{array}$ & \begin{tabular}{l|l} 
\\
\\
0 \\
$\infty$
\end{tabular} & & & 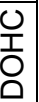 \\
\hline$\sum_{\frac{N}{n}}^{N}$ & 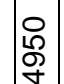 & \begin{tabular}{|l|} 
\\
\\
\end{tabular} & $\begin{array}{l}8 \\
\text { ¿ }\end{array}$ & 号 & 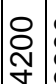 & 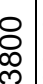 & 足 & 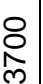 & $\begin{array}{l}\text { ৪ } \\
\infty \\
\$ \\
+\end{array}$ & $\begin{array}{l}8 \\
0 \\
\end{array}$ & $\begin{array}{l}8 \\
\text { O } \\
\end{array}$ & \begin{tabular}{l}
8 \\
\hdashline \\
\end{tabular} & $\begin{array}{l}\text { ৪ } \\
\text { ৪্ল }\end{array}$ & & & 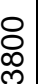 \\
\hline 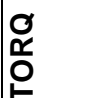 & $\begin{array}{l}0 \\
\underset{+}{ \pm} \\
\end{array}$ & $\begin{array}{l}- \\
\hat{N} \\
\text { N. }\end{array}$ & $\begin{array}{l}0 \\
\dot{\tilde{D}} \\
\tilde{N}\end{array}$ & $\begin{array}{l}0 \\
\text { O্ं } \\
\text { }\end{array}$ & 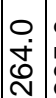 & o & 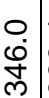 & $\begin{array}{l}\dot{0} \\
\dot{0} \\
0 \\
0\end{array}$ & $\begin{array}{l}0 \\
\stackrel{N}{N} \\
\text { N }\end{array}$ & 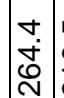 & $\begin{array}{l}\frac{n}{0} \\
\frac{0}{m}\end{array}$ & $\begin{array}{l}\infty \\
\dot{\forall} \\
m\end{array}$ & $\begin{array}{l}0 \\
\dot{8} \\
\dot{y}\end{array}$ & & - & $\begin{array}{l}0 \\
0 \\
0 \\
0 \\
1\end{array}$ \\
\hline$\sum_{\substack{\alpha \\
\boldsymbol{\alpha}}}$ & ৪ & \begin{tabular}{|l} 
\\
న్ \\
م
\end{tabular} & $\begin{array}{l}8 \\
\\
\\
\end{array}$ & $\begin{array}{l}8 \\
8 \\
\infty \\
1\end{array}$ & \begin{tabular}{l}
8 \\
\hdashline \\
$\infty$ \\
1 \\
10
\end{tabular} & $\begin{array}{l}\text { ৪ } \\
\bar{c} \\
0\end{array}$ & $\begin{array}{l}8 \\
8 \\
0 \\
0\end{array}$ & 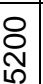 & ৪ & $\begin{array}{l}8 \\
\varnothing \\
0 \\
1\end{array}$ & & $\begin{array}{l} \\
8 \\
\circ \\
1\end{array}$ & 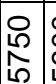 & & $\begin{array}{l}8 \\
\circ \\
\circ\end{array}$ & ¿্. \\
\hline$\frac{\text { 足 }}{\frac{\mathbf{m}}{\mathbf{n}}}$ & $\underset{\widetilde{m}}{\sim}$ & 点 & $\begin{array}{l}\mathscr{L} \\
\stackrel{2}{2}\end{array}$ & $\begin{array}{l}\infty \\
\wp \\
ٍ\end{array}$ & $\stackrel{\sim}{\sim}$ & $\stackrel{\mathrm{N}}{\mathrm{N}}$ & న్న & 号 & $\stackrel{\infty}{\infty}$ & क্ & $\frac{\infty}{N}$ & $\overline{\mathbb{N}}$ & 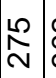 & స్లి & gे & 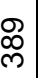 \\
\hline 孚 & $\begin{array}{l}\infty \\
0 \\
0\end{array}$ & $\begin{array}{l}\forall \\
\dot{0}\end{array}$ & $\begin{array}{l}0 \\
\dot{\sigma}\end{array}$ & $\dot{\sigma}$ & $\hat{\sigma}$ & م. & g. & $\begin{array}{l}0 \\
\dot{\sigma}\end{array}$ & $\begin{array}{l}\infty \\
\infty \\
\infty\end{array}$ & $\begin{array}{l}0 \\
0\end{array}$ & $\begin{array}{l}\circ \\
\dot{0}\end{array}$ & $\begin{array}{l} \\
0 \\
\dot{0}\end{array}$ & \begin{tabular}{|l|} 
\\
0 \\
0
\end{tabular} & 웅 & 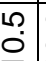 & $\begin{array}{l}0 \\
0 \\
0\end{array}$ \\
\hline 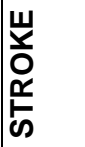 & $\begin{array}{l}0 \\
\infty \\
\infty\end{array}$ & 움 & $\begin{array}{l}\circ \\
\dot{e}\end{array}$ & $\begin{array}{l}0 \\
0 \\
0\end{array}$ & \begin{tabular}{|l}
$\infty$ \\
$\infty$ \\
$\infty$ \\
1
\end{tabular} & $\frac{0}{\infty}$ & $\begin{array}{l}0 \\
\dot{\infty}\end{array}$ & $\begin{array}{l}n \\
\infty \\
\infty \\
\infty\end{array}$ & $\mid \begin{array}{l}+ \\
\infty \\
\infty\end{array}$ & $\begin{array}{l}0 \\
\\
\end{array}$ & $\begin{array}{l}0 \\
\dot{0}\end{array}$ & $\begin{array}{l}0 \\
\dot{+} \\
\infty\end{array}$ & $\begin{array}{l}0 \\
\dot{\infty} \\
\infty\end{array}$ & & 옹 & \begin{tabular}{l}
\multirow{\infty}{*}{} \\
$\stackrel{\infty}{\infty}$
\end{tabular} \\
\hline 峁 & $\begin{array}{l}0 \\
\infty \\
\infty \\
\infty\end{array}$ & $\mid$ & $\begin{array}{l}\infty \\
\infty \\
\infty\end{array}$ & 卢 & $\begin{array}{l}0 \\
\dot{0} \\
\infty\end{array}$ & 어 & $\begin{array}{l}\circ \\
\dot{g}\end{array}$ & $\begin{array}{l}0 \\
\dot{\sigma} \\
0\end{array}$ & ஓ̊. & $\begin{array}{l}\infty \\
\ddot{\infty} \\
\infty\end{array}$ & $\begin{array}{l}\dot{\infty} \\
\stackrel{\infty}{\infty}\end{array}$ & $\begin{array}{l}\text { ه } \\
\varnothing \\
\infty\end{array}$ & $\begin{array}{ll}\mathscr{\infty} \\
\dot{\infty} \\
\infty\end{array}$ & & \begin{tabular}{l}
0 \\
\multirow{2}{a}{} \\
\end{tabular} & $\begin{array}{l}\circ \\
\stackrel{\infty}{\infty}\end{array}$ \\
\hline ठ্ত & \pm & $\Xi$ & $\stackrel{9}{>}$ & 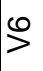 & $\stackrel{9}{>}$ & 9 & $\stackrel{\varphi}{>}$ & $\stackrel{0}{5}$ & $\Xi$ & ט & 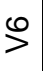 & 9 & $\stackrel{\infty}{>}$ & $\infty$ & $\stackrel{\infty}{>}$ & $\stackrel{N}{\lessgtr}$ \\
\hline$\frac{0}{\frac{0}{2}}$ & $\stackrel{O}{\mathrm{~N}}$ & $\mid \begin{array}{l}\vec{N} \\
\stackrel{N}{ }\end{array}$ & 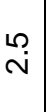 & 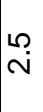 & $\hat{N}$ & & ְִ & 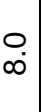 & $\stackrel{\text { N }}{\text { N }}$ & $\begin{array}{l}\infty \\
\stackrel{N}{N}\end{array}$ & 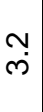 & 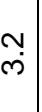 & $\stackrel{m}{\sim} \underset{\sim}{\sim}$ & & $\dot{\Delta}$ & $\begin{array}{l}0 \\
0 \\
0\end{array}$ \\
\hline 응 & $\underset{\mathbb{N}}{\mathbb{N}}$ & $\underset{\sim}{\infty}$ & 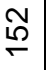 & ָָ & $\hat{0}$ & $\begin{array}{c}\hat{\sigma} \\
-2 \\
\end{array}$ & $\stackrel{10}{\sim}$ & $\begin{array}{c}\infty \\
\infty \\
\stackrel{+}{+}\end{array}$ & 守 & $\Sigma$ & 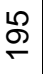 & 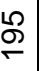 & $\underset{N}{\stackrel{Q}{2}}$ & ల్m & స్ల్లి & 迎 \\
\hline$\frac{z}{\text { Oे }}$ & 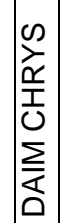 & 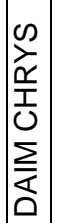 & 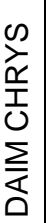 & 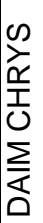 & 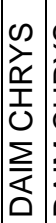 & 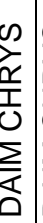 & 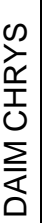 & 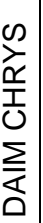 & 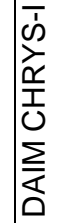 & 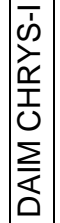 & 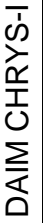 & 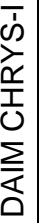 & 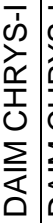 & 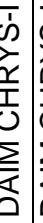 & 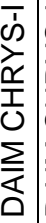 & 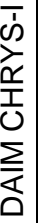 \\
\hline
\end{tabular}




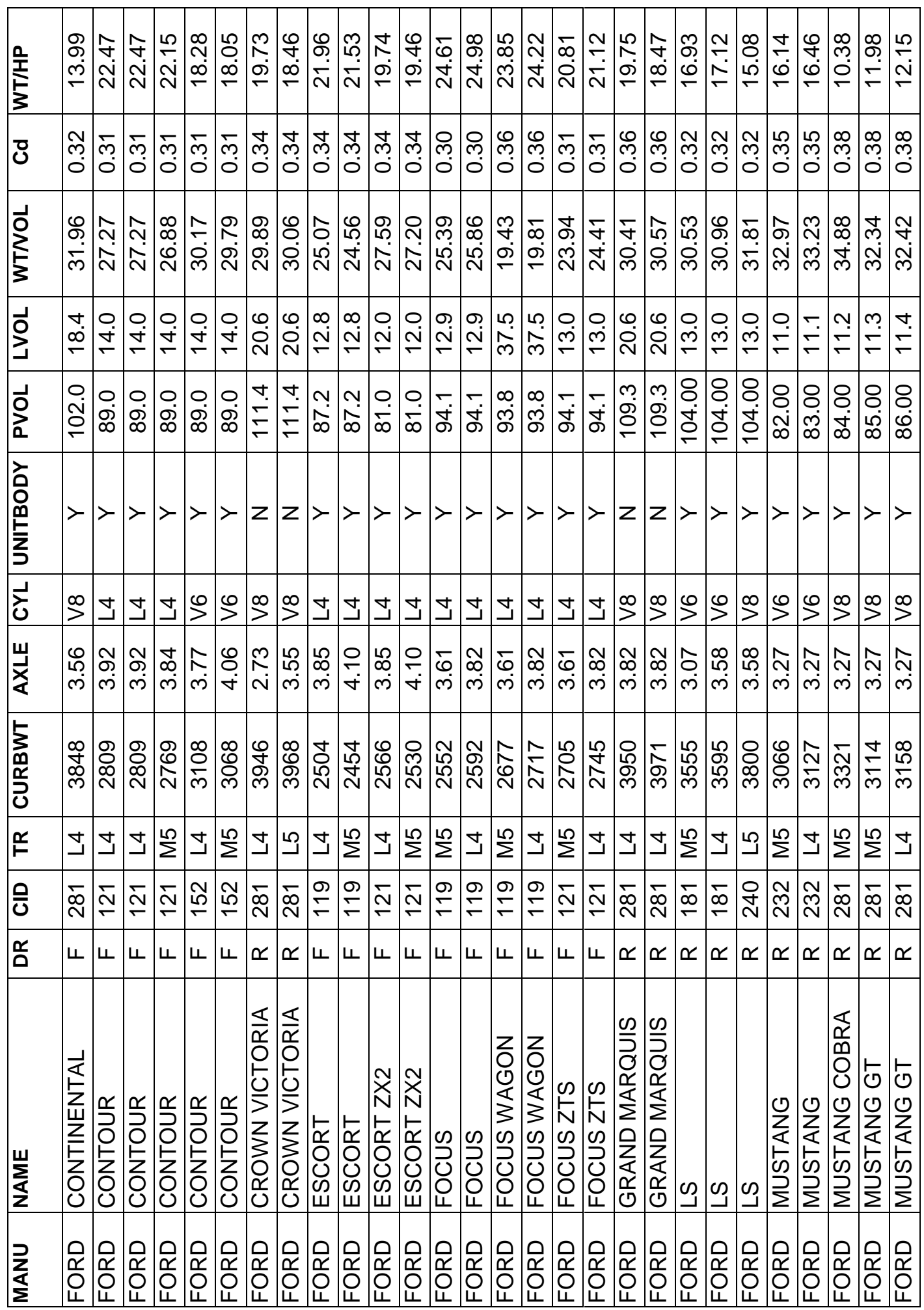




\begin{tabular}{|c|c|c|c|c|c|c|c|c|c|c|c|c|c|c|c|c|c|c|c|c|c|c|c|c|c|c|c|}
\hline & $\begin{array}{l}\widetilde{N} \\
\infty \\
\bar{N}\end{array}$ & लִ & $\begin{array}{l}\stackrel{0}{0} \\
0 \\
0\end{array}$ & 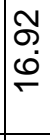 & $\frac{N}{N}$ & $\begin{array}{l}\circ \\
0 \\
0 \\
-\end{array}$ & $\begin{array}{l}\infty \\
\stackrel{\infty}{N} \\
\text { N }\end{array}$ & $\begin{array}{l}\infty \\
\infty \\
\\
\end{array}$ & 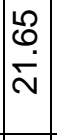 & 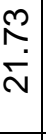 & 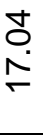 & $\begin{array}{l}\Omega \\
\stackrel{2}{a} \\
\text { Na }\end{array}$ & $\begin{array}{l}\text { হ } \\
\text { Ṅ }\end{array}$ & 足 & & $\begin{array}{l}20 \\
\mathscr{\infty} \\
\infty \\
-\end{array}$ & $\begin{array}{l}\tilde{N} \\
\tilde{m} \\
\tilde{\sigma}\end{array}$ & $\begin{array}{l}\mathbf{1} \\
\infty \\
\sigma \\
\sigma\end{array}$ & $\begin{array}{l}\text { ठे. } \\
\sigma\end{array}$ & & $\begin{array}{l}\hat{\infty} \\
\underline{c} \\
\bar{T}\end{array}$ & & & & 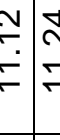 & & 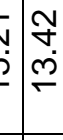 \\
\hline كُ & $\bar{m}$ & ma. & ח̋ & ๓n & లె & ले & $\begin{array}{l}\tilde{m} \\
\text { m. } \\
0\end{array}$ & $\begin{array}{l}\stackrel{N}{m} \\
\stackrel{0}{0}\end{array}$ & $\begin{array}{l}0 \\
m \\
0\end{array}$ & $\begin{array}{l}0 \\
\text { m. } \\
0 \\
0\end{array}$ & 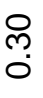 & $\begin{array}{l}\vec{m} \\
\dot{m} \\
\dot{0}\end{array}$ & $\begin{array}{l}\text { ले } \\
0 \\
0\end{array}$ & $\begin{array}{l}\text { ले } \\
\dot{0}\end{array}$ & $\begin{array}{c}\hat{m} \\
\dot{0}\end{array}$ & $\begin{array}{l}\hat{n} \\
\hat{o} \\
0\end{array}$ & & & & & & & & & & & 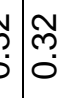 \\
\hline & $\begin{array}{l}\infty \\
\stackrel{\infty}{+} \\
\stackrel{N}{0}\end{array}$ & & $\begin{array}{l}\mathcal{N} \\
\infty \\
\mathscr{N} \\
\stackrel{N}{*}\end{array}$ & & 实 & $\begin{array}{l}\overline{1} \\
\infty \\
\infty \\
\sim\end{array}$ & $\begin{array}{l}\widetilde{N} \\
\stackrel{\sim}{\sim} \\
\stackrel{2}{*}\end{array}$ & $\begin{array}{l}\text { ठ } \\
\text { مُ } \\
\text { N }\end{array}$ & $\begin{array}{l}\text { 오 } \\
\text { Na } \\
\text { N }\end{array}$ & & & $\begin{array}{l}\stackrel{N}{N} \\
\stackrel{d}{\sim}\end{array}$ & $\begin{array}{l}\dot{U} \\
\dot{\sim} \\
\dot{\sim}\end{array}$ & $\begin{array}{c}\mathfrak{N} \\
\dot{\sim} \\
\stackrel{\sim}{N}\end{array}$ & & $\begin{array}{l}\mathscr{0} \\
छ \\
\dot{p}\end{array}$ & $\begin{array}{l} \pm \\
\check{0} \\
\infty\end{array}$ & $\mid$ & 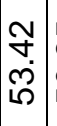 & & $\begin{array}{l}\hat{\infty} \\
\dot{\infty} \\
\dot{0} \\
\text { L }\end{array}$ & & & & 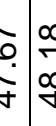 & & $\begin{array}{l}\hat{j} \\
\text { j. }\end{array}$ \\
\hline $\overrightarrow{0}$ & $\underset{+}{\stackrel{0}{+}}$ & 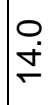 & 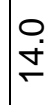 & $\begin{array}{l}0 \\
\dot{J}\end{array}$ & $\begin{array}{l}0 \\
\dot{0}\end{array}$ & $\stackrel{0}{\oplus}$ & $\begin{array}{l}\infty \\
\infty \\
\infty \\
\infty\end{array}$ & $\begin{array}{l}\infty \\
\infty \\
\infty \\
\infty\end{array}$ & \begin{tabular}{l}
0 \\
0 \\
\hdashline
\end{tabular} & $\begin{array}{l}\circ \\
\dot{\theta} \\
\end{array}$ & $\begin{array}{l}\circ \\
\underline{0}\end{array}$ & $\mid \begin{array}{l}\infty \\
\infty \\
\infty \\
\infty\end{array}$ & $\begin{array}{l}\infty \\
\infty \\
\infty \\
m\end{array}$ & \begin{tabular}{l|}
$\infty$ \\
$\infty$ \\
$\infty$ \\
$m$
\end{tabular} & $\begin{array}{l}0 \\
\dot{N} \\
\stackrel{N}{*}\end{array}$ & $\begin{array}{l}0 \\
\grave{N}\end{array}$ & $\overline{0}$ & $\overline{\dot{0}}$ & $\overline{0}$ & $\bar{c}$ & б. & $\dot{\sigma}$ & $\dot{c}$ & & $\bar{c}$ & & $\dot{\vec{p}} \overline{\frac{m}{m}}$ \\
\hline$\vec{~}$ & $\begin{array}{l}0 \\
\infty \\
\infty\end{array}$ & ○ & ○ & ○ & 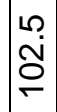 & $\begin{array}{l}0 \\
\stackrel{0}{0} \\
\text { Oे }\end{array}$ & 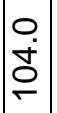 & $\begin{array}{l}0 \\
\dot{J} \\
\stackrel{0}{-}\end{array}$ & 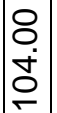 & $\begin{array}{l}\text { ㅇ } \\
\dot{0} \\
\text { 이 }\end{array}$ & $\begin{array}{l}8 \\
\dot{+} \\
\dot{0} \\
\end{array}$ & $\begin{array}{l}0 \\
\\
\\
\end{array}$ & $\begin{array}{l}0 \\
\dot{0} \\
\stackrel{0}{-}\end{array}$ & $\begin{array}{l}0 \\
\dot{J} \\
\\
\end{array}$ & $\begin{array}{l}\stackrel{m}{\underline{N}} \\
\stackrel{T}{\sigma}\end{array}$ & $\begin{array}{l}m \\
\stackrel{m}{N} \\
\underline{T}\end{array}$ & 옹 & $\begin{array}{l}0 \\
\stackrel{N}{N} \\
N\end{array}$ & 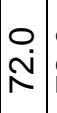 & \begin{tabular}{l|l}
$\circ$ & \\
& $\mathfrak{r}$
\end{tabular} & \begin{tabular}{l|l}
0 \\
$\stackrel{N}{N}$
\end{tabular} & $\begin{array}{l}0 \\
\stackrel{N}{N}\end{array}$ & \begin{tabular}{l|l}
0 & \\
& \\
\end{tabular} & & 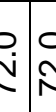 & & 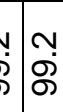 \\
\hline & $>$ & $>$ & $>$ & $>$ & $>$ & $>$ & $>$ & $>$ & $>$ & $>$ & $>$ & $>$ & $>$ & $>$ & $\mathbf{z}$ & $z$ & $>$ & $>$ & $>$ & $>>$ & $>$ & $>$ & $>$ & $>>$ & $>>$ & $->$ & $-1>$ \\
\hline & 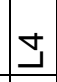 & $\Xi$ & $\stackrel{0}{>}$ & $\stackrel{0}{>}$ & $\stackrel{\varphi}{>}$ & $\stackrel{\infty}{>}$ & $\stackrel{\oplus}{>}$ & $\stackrel{\oplus}{>}$ & 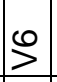 & $\stackrel{\oplus}{>}$ & $\stackrel{\leftrightarrow}{>}$ & $\stackrel{\bullet}{>}$ & $\stackrel{9}{>}$ & $\stackrel{9}{>}$ & $\stackrel{\infty}{>}$ & $\stackrel{\infty}{>}$ & $\stackrel{N}{\lessgtr}$ & $\stackrel{N}{\mp}$ & $\frac{N}{\lessgtr}$ & $\$$ & 9 & $\stackrel{N}{\mathcal{N}}$ & $\coprod_{\searrow}$ & $\stackrel{N}{\lessgtr}$ & $\stackrel{s}{>}$ & $\$$ & $>$ \\
\hline$\overleftrightarrow{\vec{x}}$ & ᄋ & 웅 & 웅 & 웅 & $\begin{array}{l}\hat{N} \\
\dot{m}\end{array}$ & $\begin{array}{l}\infty \\
\infty \\
\text { ले }\end{array}$ & $\begin{array}{c}\hat{N} \\
\dot{m}\end{array}$ & $\begin{array}{l}\infty \\
\sigma \\
\text { ల் }\end{array}$ & $\begin{array}{c}\hat{N} \\
\dot{m}\end{array}$ & $\begin{array}{c}\hat{N} \\
\dot{m}\end{array}$ & $\begin{array}{l}\infty \\
\infty \\
\infty \\
\end{array}$ & $\begin{array}{l}\hat{N} \\
\dot{m}\end{array}$ & $\begin{array}{l}\stackrel{⿰}{\circ} \\
\text { ले }\end{array}$ & $\hat{N}$ & $\begin{array}{l}\infty \\
0 \\
\dot{m}\end{array}$ & $\begin{array}{l}\infty \\
0 \\
\dot{\infty} \\
\text { ஸे }\end{array}$ & $\hat{N}$ & $\begin{array}{l}\hat{N} \\
m\end{array}$ & $\begin{array}{l}0 \\
0 \\
\dot{m}\end{array}$ & $\begin{array}{c}\hat{N} \\
\dot{m}\end{array}$ & $\begin{array}{l}9 \\
\dot{0}\end{array}$ & $\begin{array}{l}0 \\
\dot{0} \\
\dot{m}\end{array}$ & $\begin{array}{l}\hat{N} \\
\dot{m}\end{array}$ & 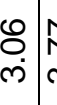 & $\begin{array}{l}\bar{c} \\
\dot{n} \\
\bar{c}\end{array}$ & & $\begin{array}{c}\bar{j} \\
\bar{\rho} \\
\bar{m}\end{array}$ \\
\hline$\frac{\mathscr{m}}{\tilde{N}}$ & N & 胥 & ָָ & $\begin{array}{l}0 \\
\stackrel{0}{\infty} \\
\stackrel{N}{N}\end{array}$ & $\begin{array}{l}0 \\
\mathbb{E} \\
\mathbb{ల}\end{array}$ & $\begin{array}{l}\stackrel{9}{\hat{N}} \\
\stackrel{m}{\infty}\end{array}$ & 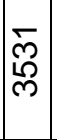 & 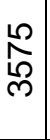 & 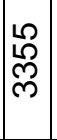 & 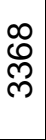 & $\begin{array}{l}\infty \\
0 \\
0 \\
\text { ले }\end{array}$ & 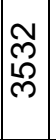 & $\frac{\Omega}{\stackrel{\Omega}{L}}$ & $\begin{array}{l}\widetilde{N} \\
\text { ద్ల }\end{array}$ & $\begin{array}{l}\text { 守 } \\
\text { f }\end{array}$ & 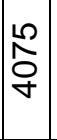 & $\frac{\omega}{\delta}$ & $\frac{m}{\frac{m}{q}}$ & $\frac{d}{\frac{d}{2}}$ & ల్ & 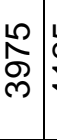 & & & 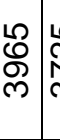 & 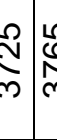 & & b \\
\hline$\stackrel{\mathbb{q}}{\mathfrak{r}}$ & $\exists$ & $\sum^{10}$ & $\sum^{10}$ & 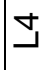 & $\exists$ & 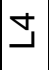 & $\Xi$ & 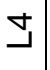 & $\Xi$ & $\Xi$ & $\Delta$ & \pm & $\Xi$ & $\Xi$ & $\Xi$ & $\Xi$ & $\stackrel{10}{\Sigma}$ & $\stackrel{\varrho}{\Sigma}$ & 10 & $\sum^{\infty}$ & 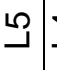 & $\checkmark$ & $\stackrel{0}{\Sigma}$ & 1 & $\stackrel{10}{\Sigma}$ & S & صـ נ] \\
\hline 음 & $\bar{\sim}$ & $\stackrel{\bar{N}}{\sim}$ & $\underset{N}{N}$ & ָิ & $\underset{\infty}{\infty}$ & $\infty$ & $\underset{\infty}{\infty}$ & $\underset{\infty}{-\infty}$ & $\underset{\infty}{\infty}$ & $\begin{array}{l}\infty \\
\infty \\
\end{array}$ & $\infty$ & $\underset{\infty}{\infty}$ & $\underset{\infty}{-}$ & 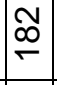 & $\stackrel{\infty}{N}$ & i & 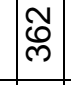 & \begin{tabular}{|c}
$\tilde{ల}$ \\
ల
\end{tabular} & $\begin{array}{l}\widetilde{W} \\
\tilde{ల} \\
\tilde{\omega}\end{array}$ & ब & बे & $\begin{array}{l}\widetilde{W} \\
\text { ల్ }\end{array}$ & 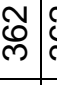 & 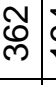 & '大 & $\stackrel{\infty}{\infty}$ & $\begin{array}{l}5 \\
\end{array}$ \\
\hline & ш & L & ш & 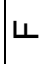 & ४ & 山 & ४ & 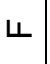 & 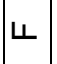 & レ & | & ४ & $\sqcup$ & 山 & $\simeq$ & $\simeq$ & $\simeq$ & $\simeq$ & $\simeq$ & $\simeq$ & $\simeq$ & $\simeq$ & $\simeq$ & $\propto$ & $\Upsilon$ 工 & $\Omega$ & $\varepsilon \simeq$ \\
\hline
\end{tabular}

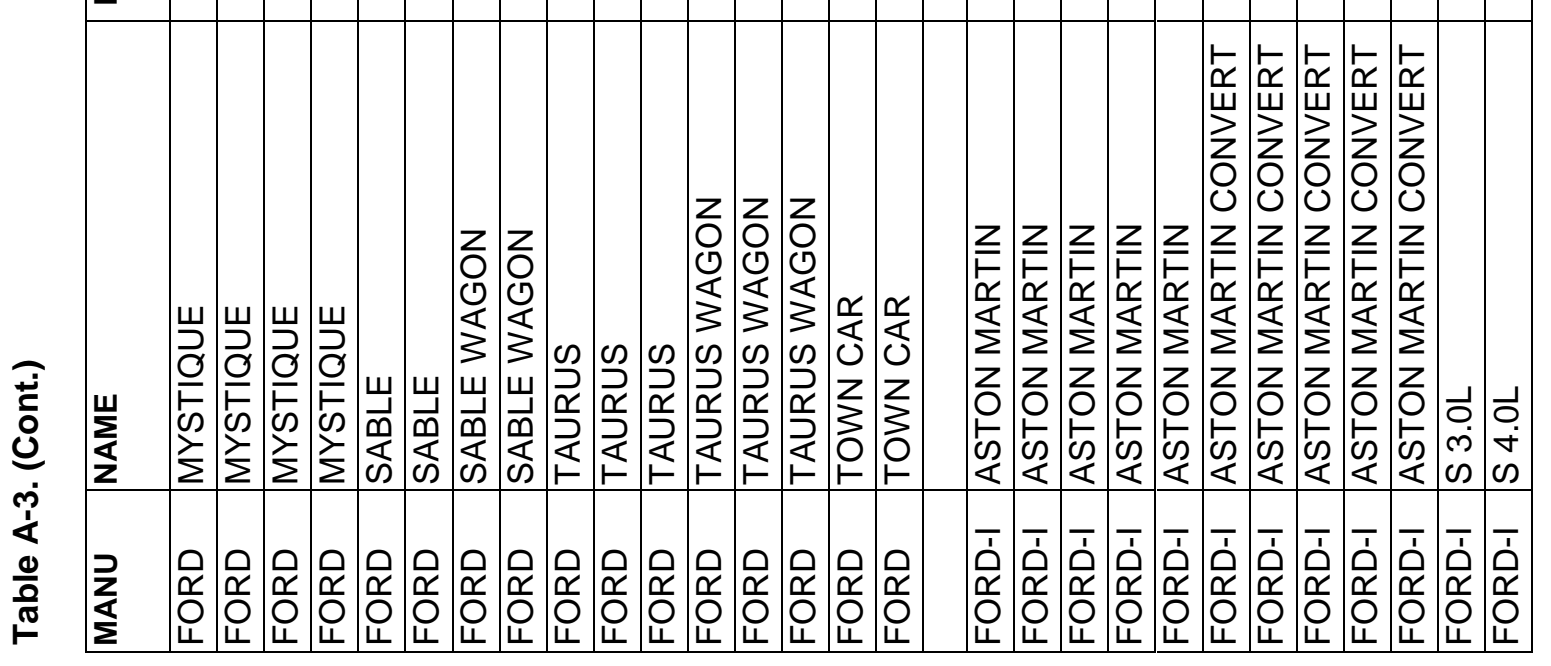




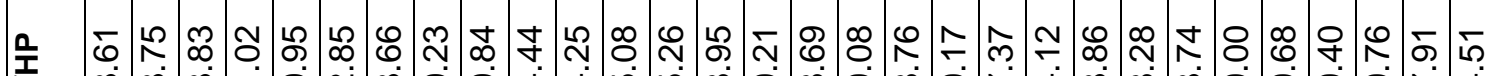

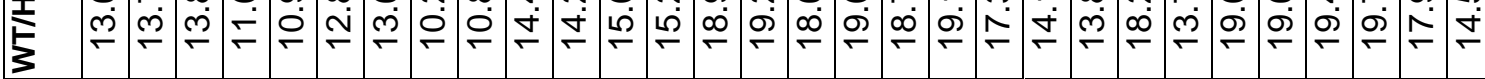

ర

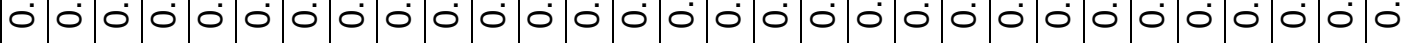

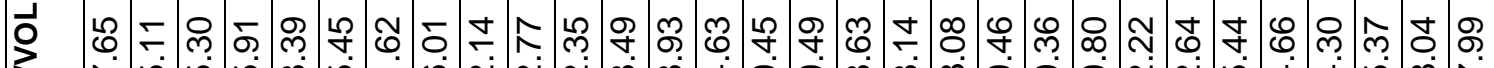

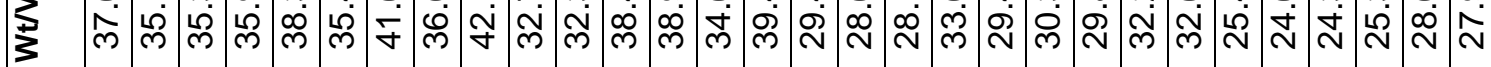

D

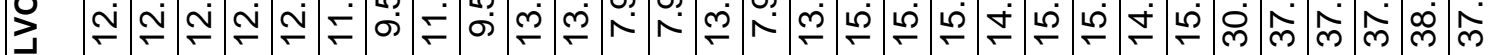

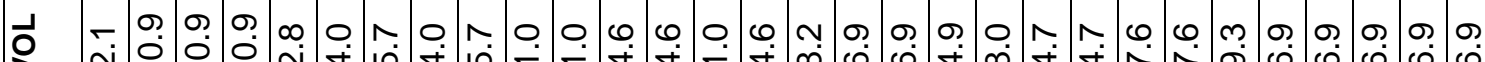
ฉ Л่

穴

$>>>>>>>>>>>>>>>>>>>>>>>>>>>$

خ

щ

《

焦

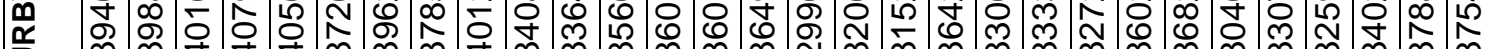
Ј

䍃

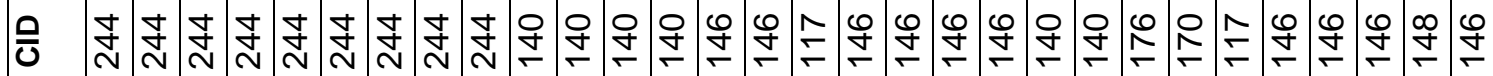

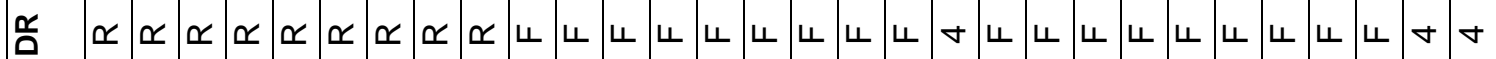

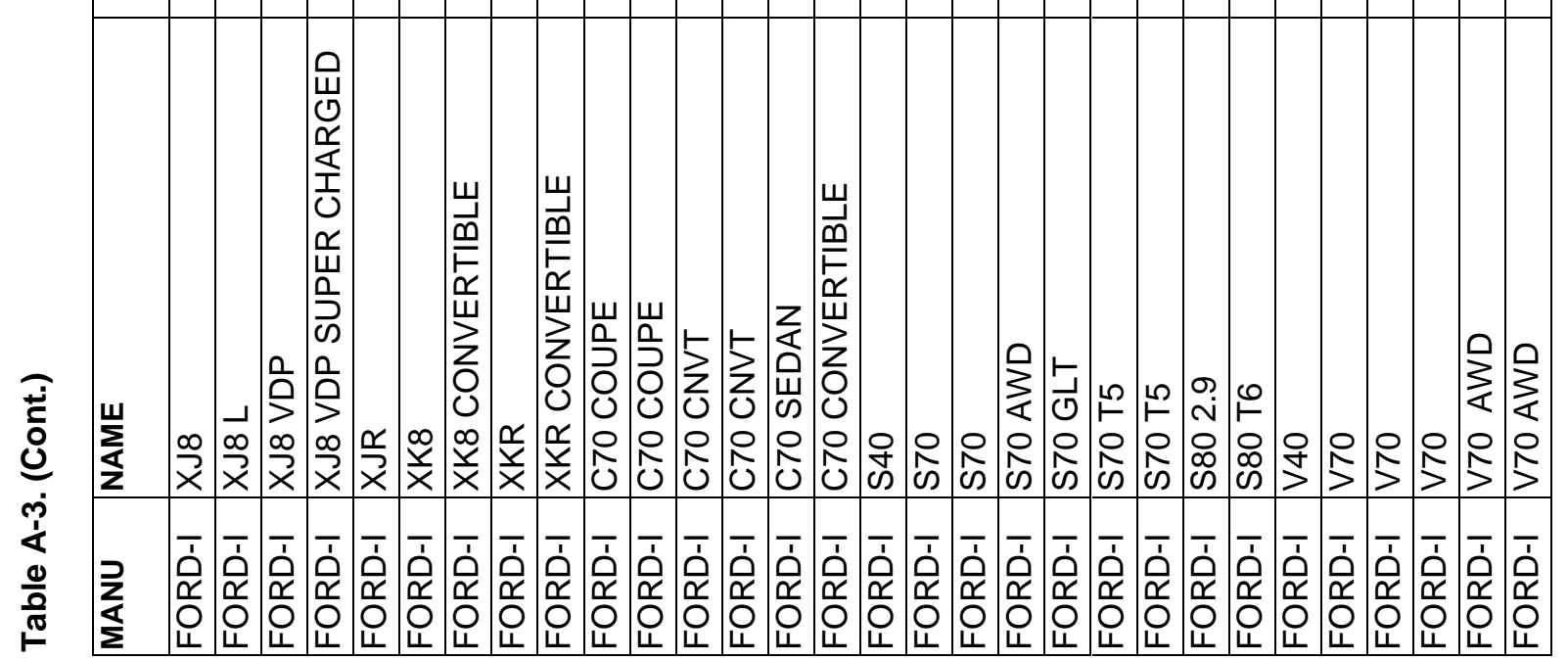




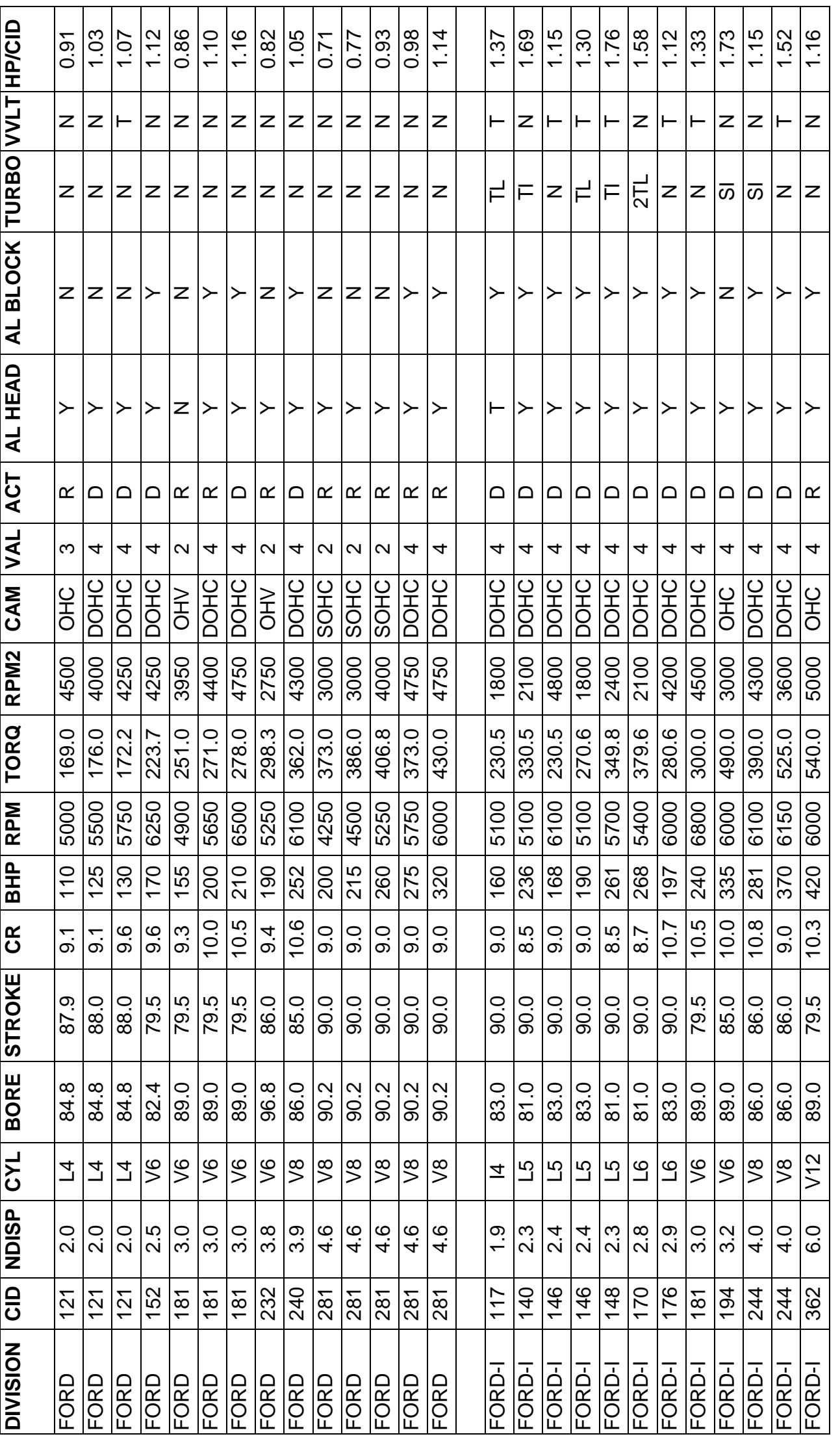




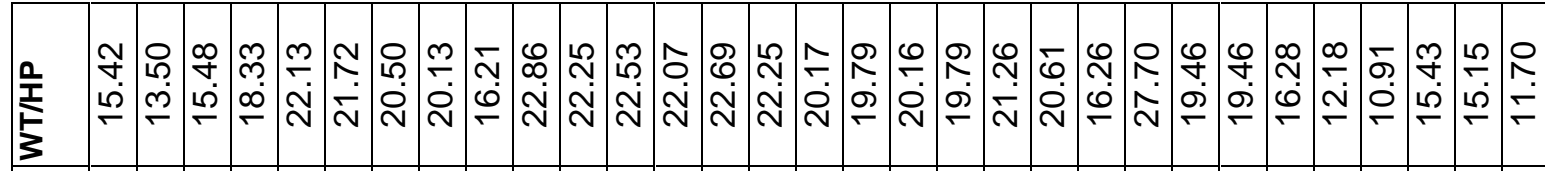

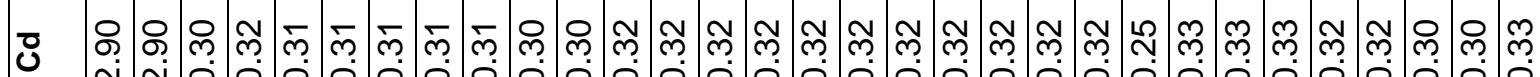

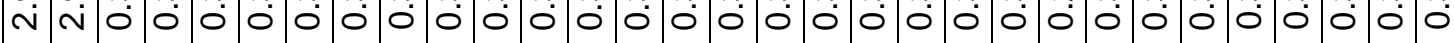

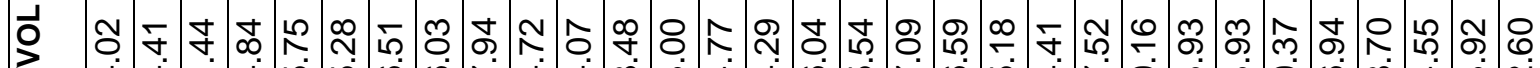

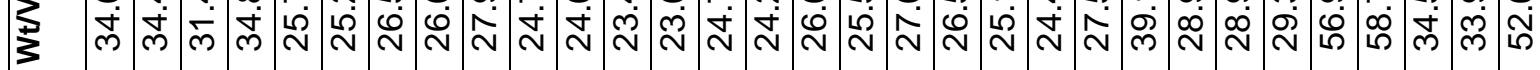

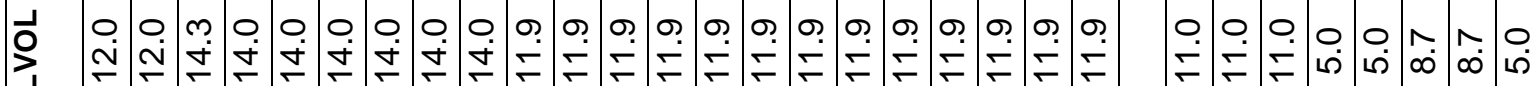

(1)

○ $\quad 0$. ฉ

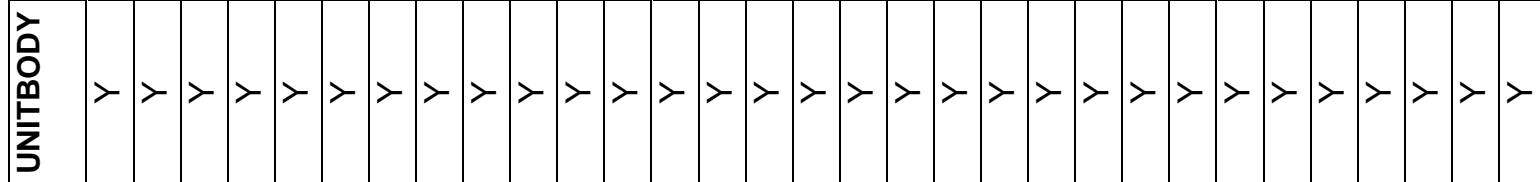

ப

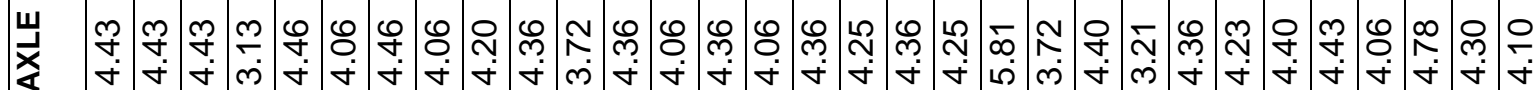

㟀

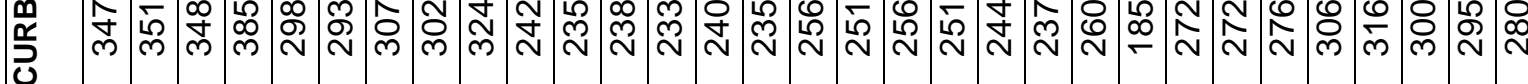

뜬

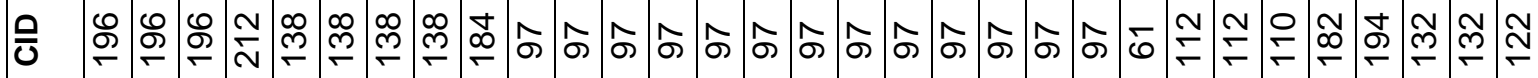

吕

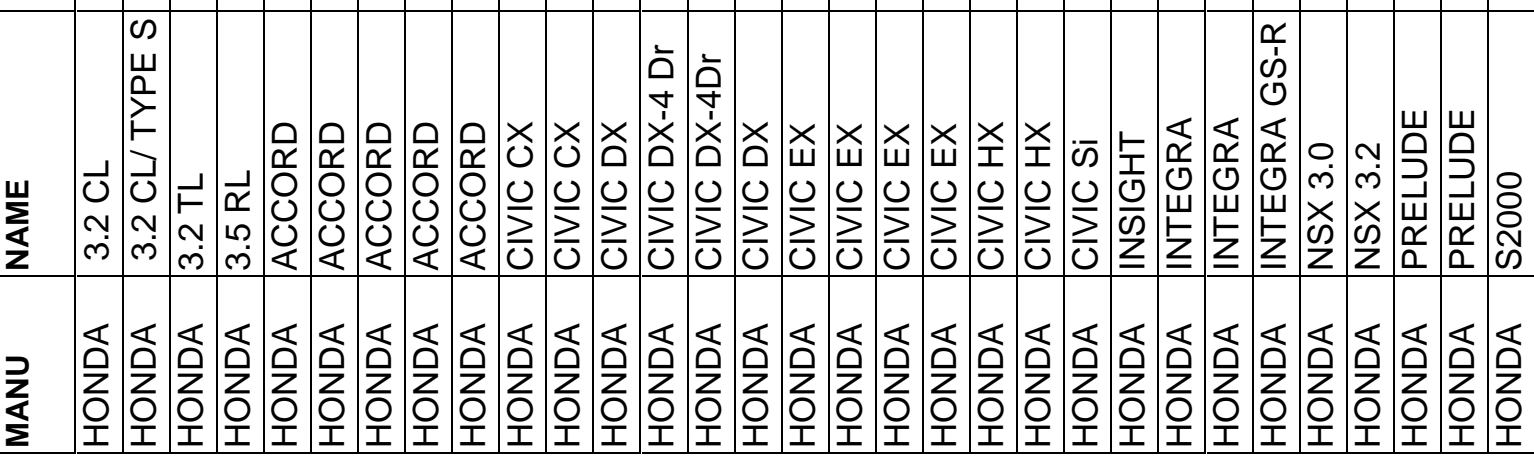




\begin{tabular}{|c|c|c|c|c|c|c|c|c|c|c|c|c|c|c|c|c|}
\hline $\begin{array}{l}\frac{0}{0} \\
\frac{0}{1}\end{array}$ & $\stackrel{0}{ }$ & $\begin{array}{l}8 \\
\stackrel{2}{2} \\
\\
\end{array}$ & $\stackrel{\sigma}{\square}$ & 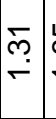 & & & & S. & 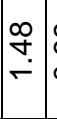 & & & ?ִ & 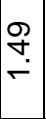 & 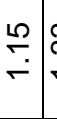 & & $\begin{array}{l}9 \\
\mathscr{0} \\
0 \\
\end{array}$ \\
\hline 3 & $\sim$ & $z$ & $\sim$ & $\sim$ & N & N & z & $\sim$ & $\sim$ & z & $\sim \curvearrowright$ & $\sim \sim$ & $\sim$ & $\sim$ & $N$ & $z$ \\
\hline$\stackrel{u}{\stackrel{u}{\mathfrak{r}}}$ & $z$ & $z$ & $z$ & $z$ & $z$ & $z$ & $z$ & $z$ & $z$ & $z$ & $z z$ & $z$ & $z$ & $z$ & $z$ & $z$ \\
\hline هُ & & $>$ & $>$ & $>$ & $>$ & $>$ & $>$ & $>$ & $>$ & $>$ & $>>$ & $->$ & $>$ & $>>$ & $>$ & $\succ$ \\
\hline$\frac{Q}{\varangle}$ & & $>$ & $>$ & $>$ & $>$ & $>$ & $>$ & $>$ & $>$ & $>$ & $>>$ & $->$ & $>$ & $>>$ & $\succ$ & $>$ \\
\hline ঢ্য & $\simeq$ & $\infty$ & $\omega$ & $\infty$ & $\omega$ & . & 口 & $\simeq$ & $\omega$ & $\omega$ & $\infty$ & D & o & $\omega c$ & is & c) \\
\hline 4 & $\theta$ & $\nabla$ & $\nabla$ & $\nabla$ & 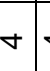 & $\nabla$ & $\nabla$ & $\nabla$ & $\nabla$ & $\nabla$ & $\nabla \nabla$ & t & $\nabla$ & $\nabla$ & + & $\nabla$ \\
\hline ¿ & $\begin{array}{l}\mathcal{U} \\
\text { Oे } \\
\mathcal{O}\end{array}$ & \begin{tabular}{l}
0 \\
0 \\
0 \\
0 \\
\hdashline
\end{tabular} & $\mid \begin{array}{l}0 \\
\\
\\
\mathcal{O}\end{array}$ & $\begin{array}{l}0 \\
0 \\
0 \\
\omega\end{array}$ & 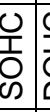 & 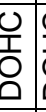 & $\begin{array}{l}0 \\
\mathbf{1} \\
0 \\
\end{array}$ & 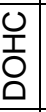 & \begin{tabular}{|l} 
\\
\\
\\
$\square$
\end{tabular} & $\begin{array}{l}\mathbf{U} \\
\mathbf{1} \\
0 \\
0\end{array}$ & 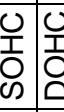 & 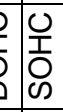 & \begin{tabular}{|l|} 
\\
\\
\\
\\
\end{tabular} & & & $\begin{array}{l}0 \\
\text { O⿱ } \\
0 \\
\Theta\end{array}$ \\
\hline$\sum_{\frac{\alpha}{\alpha}}^{\infty}$ & 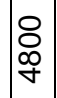 & 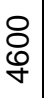 & $\begin{array}{l}8 \\
0 \\
0 \\
10\end{array}$ & 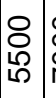 & ঃ & С్ & : & $\begin{array}{l}\text { 足 } \\
\text { م }\end{array}$ & 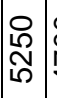 & $\begin{array}{l}8 \\
\stackrel{8}{*} \\
\forall\end{array}$ & 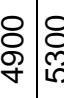 & ? & 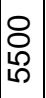 & & & 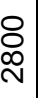 \\
\hline 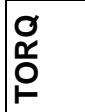 & $\begin{array}{l}\infty \\
\infty \\
\infty \\
\infty\end{array}$ & 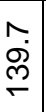 & 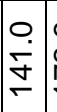 & 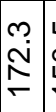 & 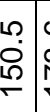 & 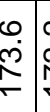 & $\begin{array}{c}\underset{N}{N} \\
\stackrel{N}{ } \\
\end{array}$ & $\begin{array}{l}\stackrel{+}{*} \\
\stackrel{N}{N}\end{array}$ & $\begin{array}{l}N \\
\stackrel{N}{N} \\
\\
\end{array}$ & 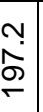 & 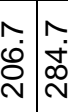 & 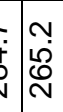 & $\begin{array}{l}\hat{m} \\
\ddot{\rho}\end{array}$ & & 'ִ & $\begin{array}{l}\hat{y} \\
\tilde{e} \\
\bar{\rho}\end{array}$ \\
\hline$\sum_{0}$ & $\begin{array}{l}8 \\
i\end{array}$ & 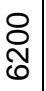 & \begin{tabular}{|l} 
\\
\\
\hdashline
\end{tabular} & 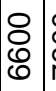 & \begin{tabular}{l}
8 \\
0 \\
\hdashline
\end{tabular} & 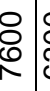 & 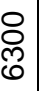 & 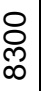 & $\begin{array}{l}8 \\
0 \\
0 \\
\mathbb{0}\end{array}$ & $\begin{array}{l}8 \\
\text { Q } \\
\text { L }\end{array}$ & & 5 & $\frac{8}{1}$ & & & 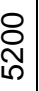 \\
\hline 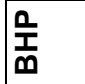 & $\widehat{\hat{\theta}}$ & 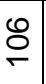 & $\stackrel{20}{=}$ & $\stackrel{\mathbb{N}}{\mathbb{N}}$ & 8 & 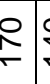 & 암 & 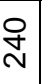 & 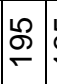 & 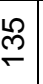 & 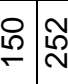 & ড্ & న্ণ & 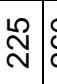 & : & $\frac{0}{N}$ \\
\hline 뭉 & & $\stackrel{\dot{\sigma}}{\dot{\sigma}}$ & $\ddot{\sigma}$ & $\ddot{0}$ & 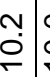 & $\begin{array}{l}0 \\
0 \\
0\end{array}$ & ִָ & $\begin{array}{l}0 \\
\mp \\
\mp\end{array}$ & $\begin{array}{l}0 \\
0 \\
0\end{array}$ & $\stackrel{m}{\sigma}$ & 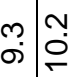 & $\dot{\sigma}$ & \begin{tabular}{l}
\multirow{2}{*}{} \\
$\stackrel{0}{0}$
\end{tabular} & $\begin{array}{lll}\infty & \\
\infty & \\
\sigma & \end{array}$ & ?ִ & $\begin{array}{l}0 \\
\\
0\end{array}$ \\
\hline 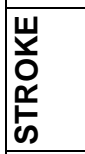 & & $\begin{array}{l}\circ \\
\dot{8} \\
\dot{8}\end{array}$ & ○् & : & $\begin{array}{l}0 \\
\dot{8}\end{array}$ & 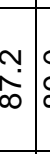 & $\begin{array}{l}\circ \\
\infty \\
\infty\end{array}$ & $\begin{array}{l}0 \\
\dot{0} \\
\infty\end{array}$ & o: & 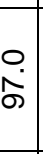 & 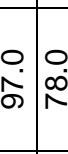 & $\begin{array}{l}\stackrel{0}{0} \\
\dot{0} \\
\dot{\infty}\end{array}$ & 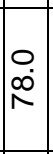 & $\begin{array}{l}0 \\
\dot{0} \\
\infty \\
\infty\end{array}$ & & o. \\
\hline 峁 & & $\begin{array}{l}0 \\
\stackrel{2}{R}\end{array}$ & \begin{tabular}{|l|}
0 \\
$p^{\circ}$ \\
\end{tabular} & 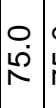 & $\begin{array}{l}\circ \\
\stackrel{0}{R}\end{array}$ & $\frac{0}{\infty}$ & $\frac{0}{\infty}$ & $\begin{array}{c}0 \\
\stackrel{1}{\infty} \\
\infty\end{array}$ & \begin{tabular}{|c}
0 \\
$\dot{x}$ \\
$\infty$ \\
$\infty$
\end{tabular} & $\begin{array}{l}0 \\
\dot{0} \\
\infty\end{array}$ & \begin{tabular}{l|l}
0 & 0 \\
$\dot{\infty}$ & $\infty$ \\
\end{tabular} & 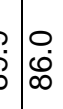 & ô & $\begin{array}{ll}\circ \\
\stackrel{8}{\infty} \\
\infty\end{array}$ & : & $\begin{array}{l}0 \\
\dot{8}\end{array}$ \\
\hline ¿ & a & 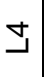 & \pm & 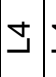 & 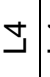 & 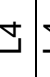 & 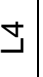 & \pm & $\Xi$ & $\Xi$ & $\Delta \gg$ & 9 & 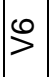 & $\rho$ & $\rho$ & 9 \\
\hline$\frac{10}{0}$ & $\stackrel{0}{-}$ & $\stackrel{\varphi}{-}$ & $\stackrel{0}{-}$ & $\stackrel{0}{0}$ & $\stackrel{6}{-}$ & $\stackrel{\infty}{\infty}$ & $\stackrel{\infty}{\stackrel{\infty}{-}}$ & $\stackrel{\circ}{\stackrel{O}{i}}$ & $\stackrel{N}{N}$ & $\stackrel{m}{\stackrel{m}{N}}$ & $\begin{array}{lll}m & 0 \\
& \text { m. }\end{array}$ & j) & $\begin{array}{l}\sim \\
\oplus \\
\end{array}$ & & & $\begin{array}{l}n \\
\tilde{n} \\
\tilde{n}\end{array}$ \\
\hline 응 & $\overline{0}$ & ब̀ & ò & ब̀ & ă & 음 & $\stackrel{N}{\mp}$ & 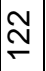 & $\underset{m}{\tilde{m}}$ & $\widehat{\underline{m}}$ & $\begin{array}{ll}\hat{m} \\
\stackrel{\infty}{\infty}\end{array}$ & $\stackrel{\infty}{\infty} \underset{-}{\infty}$ & $\stackrel{\text { g }}{\sigma}$ & 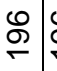 & '0) & $\frac{N}{N}$ \\
\hline$\stackrel{\circ}{\underline{O}}$ & 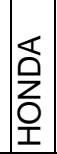 & & 号 & 号 & 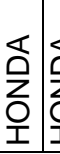 & & & & 造 & & & 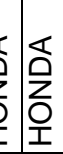 & & 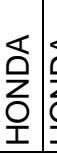 & $\frac{1}{2}$ & 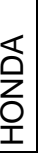 \\
\hline
\end{tabular}




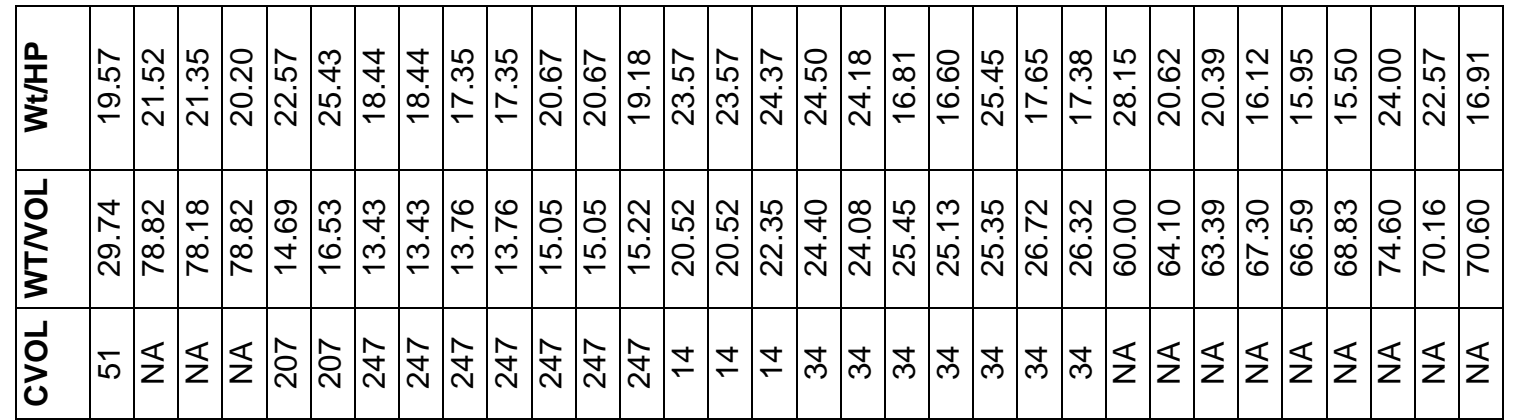

ว்ุ

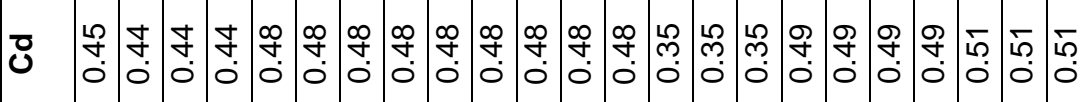

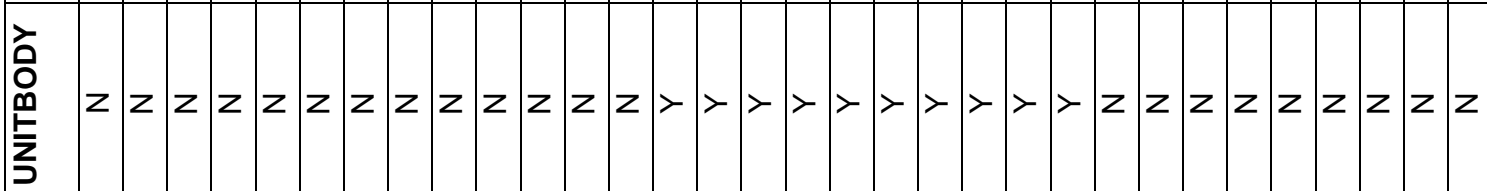

隹

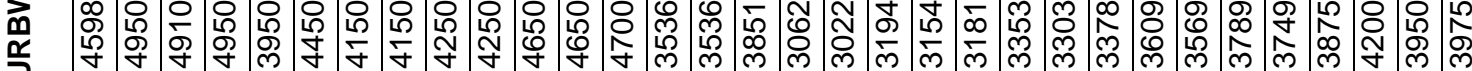
U f F f f

ณ

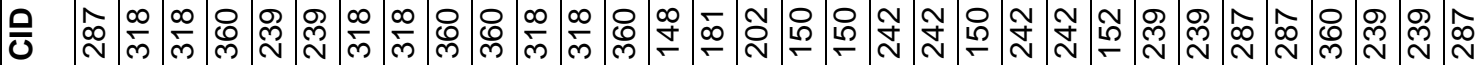

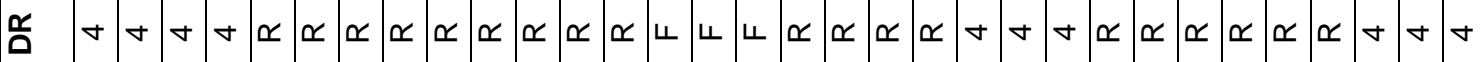

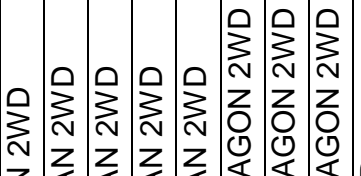

茥 0

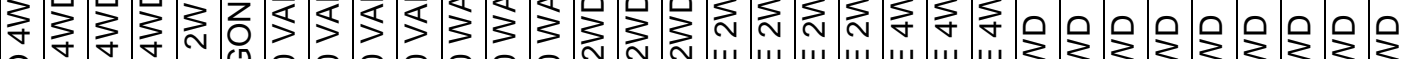

잉ㅇㅇㄹㄹ

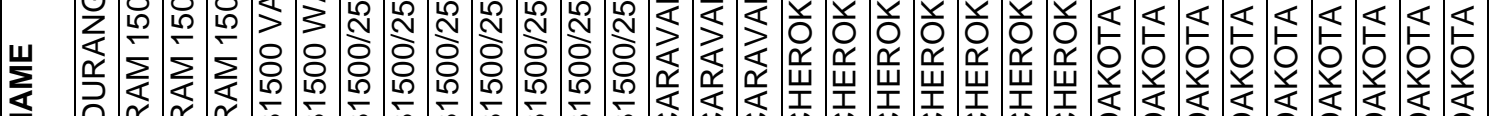

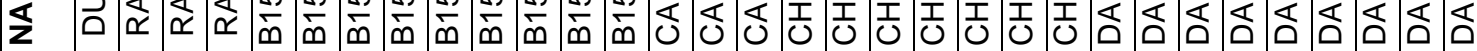

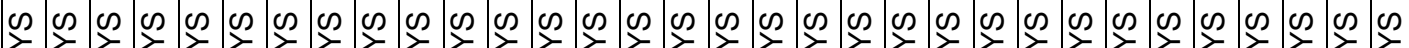

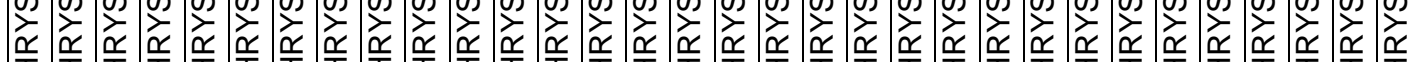

z

商 


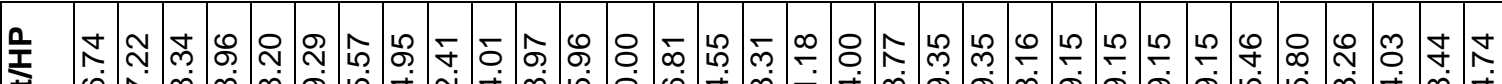

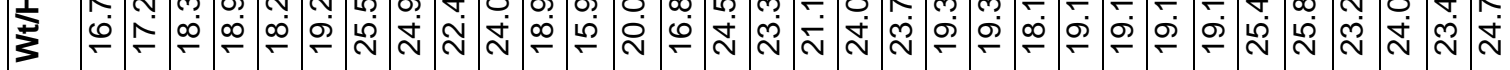

○ \&

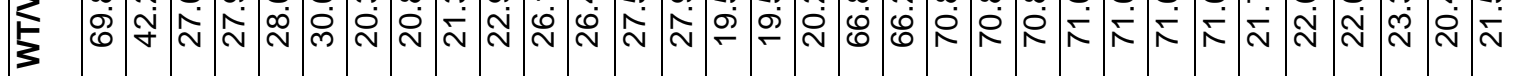

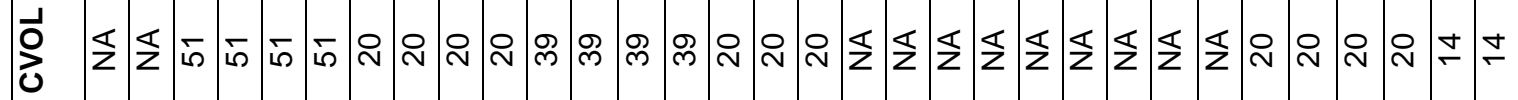

ౌ

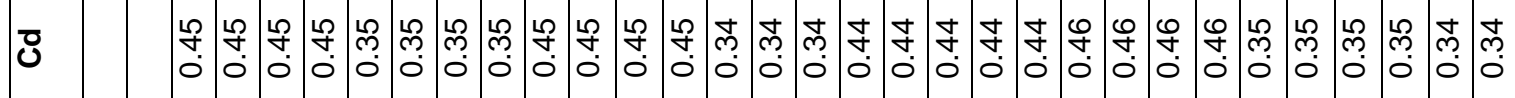

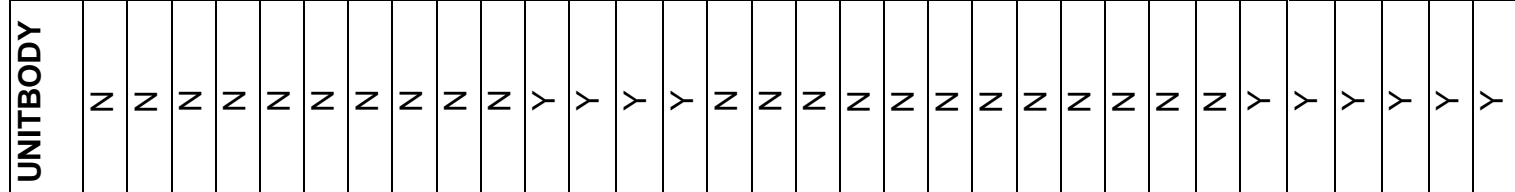

隹 寽

乩

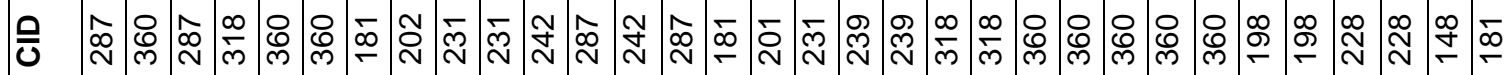

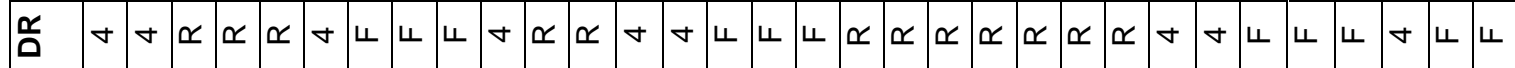

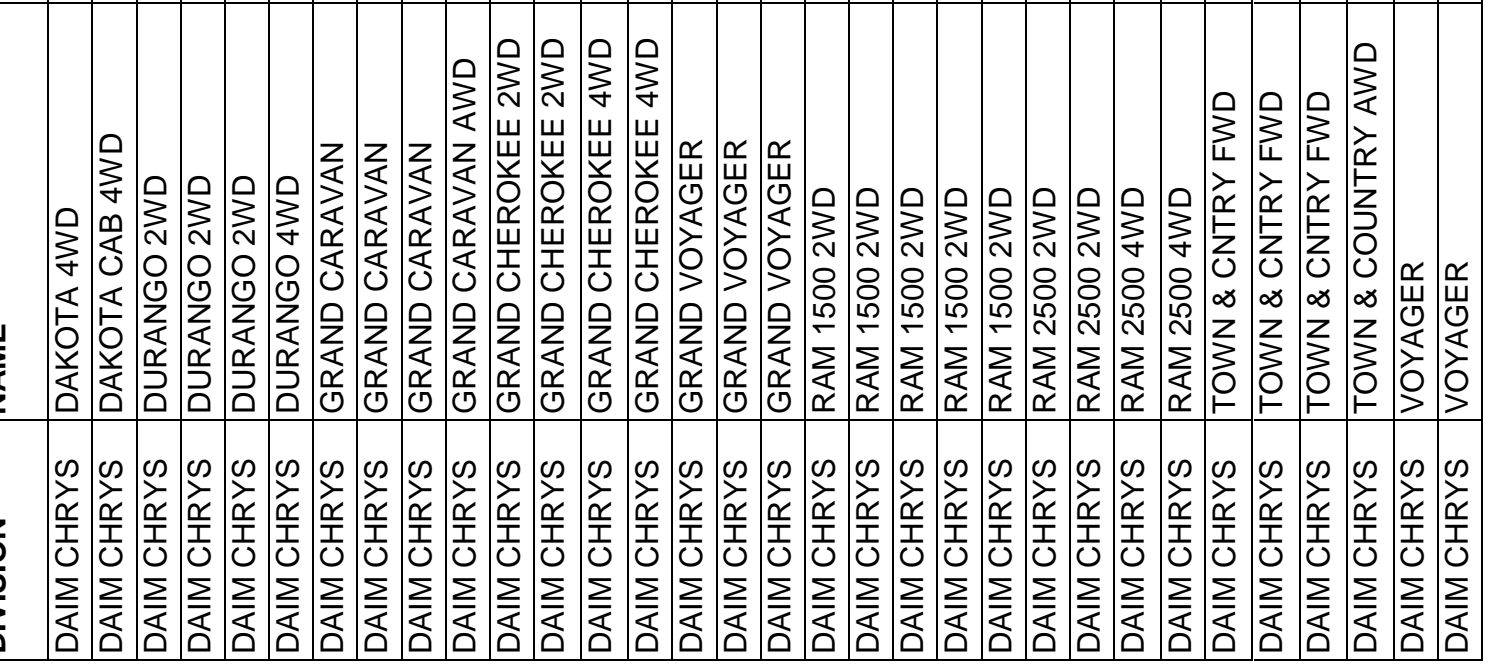




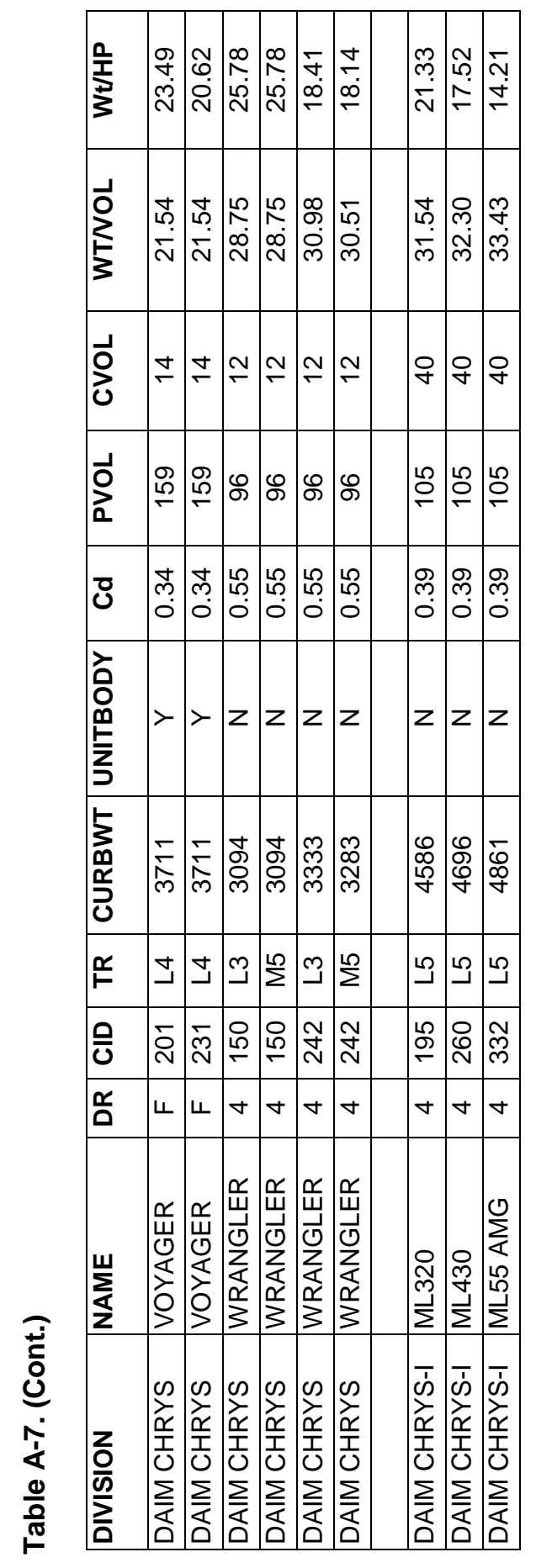




\begin{tabular}{|c|c|c|c|c|c|c|c|c|c|c|c|c|c|c|c|c|c|c|c|c|}
\hline 只 & 둗 & 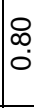 & $\begin{array}{l}M \\
\infty \\
0 \\
0\end{array}$ & 番 & 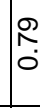 & $\stackrel{2}{2}$ & & $\begin{array}{l}\infty \\
\stackrel{1}{0} \\
0\end{array}$ & $\stackrel{m}{n}$ & $\begin{array}{l}\frac{0}{2} \\
0 \\
0\end{array}$ & o. & - & œ & N & $\stackrel{N}{N}$ & $\mid \begin{array}{l}\infty \\
0 \\
0 \\
0\end{array}$ & @ְ & $\stackrel{0}{\frac{0}{r}}$ & ఝִ & $\stackrel{m}{\circ}$ \\
\hline ভِ & $z$ & $z$ & $z$ & z & $z$ & $z$ & & $z$ & z & $z$ & $z$ & $z$ & $z$ & $z$ & $z$ & $z$ & $z$ & $>$ & $>$ & $>$ \\
\hline 足 & $>$ & $z$ & $z$ & $>$ & $>$ & $>$ & & $>$ & z & $z$ & $z$ & $z$ & $>$ & $z$ & $z$ & $z$ & $\mathbf{z}$ & $>$ & $>$ & $>$ \\
\hline ن & $\simeq$ & $\simeq$ & $\simeq$ & $\simeq$ & $\simeq$ & $\propto$ & & $\simeq$ & $\simeq$ & $\simeq$ & $\simeq$ & $\simeq$ & $\simeq$ & $\simeq$ & $\simeq$ & $\simeq$ & $\simeq$ & $\simeq$ & $\simeq$ & $\simeq$ \\
\hline क्ज & 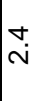 & in & $\stackrel{\sim}{\sim}$ & ले. & $\stackrel{m}{m}$ & $\begin{array}{l}\infty \\
m \\
m\end{array}$ & & $\begin{array}{l}\infty \\
\dot{m}\end{array}$ & क् & $\underset{\forall}{\stackrel{\leftrightarrow}{*}}$ & $\stackrel{\circ}{+}$ & $\stackrel{\circ}{\circ}$ & $\stackrel{\gamma}{\circ}$ & 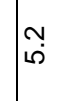 & ஸָ & ه & $\begin{array}{l}0 \\
1 \\
10\end{array}$ & Nָ & $\stackrel{m}{\dot{q}}$ & $\mid \begin{array}{l}\nabla \\
\leftarrow\end{array}$ \\
\hline$\$$ & $\forall$ & $\sim$ & $\sim$ & $\sim$ & $N$ & $\curvearrowright$ & & $N$ & $\sim$ & $\sim$ & $\sim$ & $N$ & $N$ & $N$ & $\sim$ & m & $\sim$ & $m$ & m & ल \\
\hline$\frac{3}{4}$ & 옴 & \} $&{\text { \) }} &{\begin{array}{l}\text { O } \\
\text { O }\end{array}} &{\text { 꽁 }} &{\text { خ }} &{5} &{\text { \\
} } &{\gtrless} &{\text { \} } &{\text { \} } &{\text { \} } &{\begin{array}{l}\text { 옴 } \\
\text { Oे }\end{array}} &{\text { \} } &{\text { \\
} } &{\text { \} } &{\text { \丶 }} &{\text { 옹 }} &{\text { 옹 }} &{\text { 옴 }} \\
\hline\end{array}$
\end{tabular}

\begin{tabular}{|c|c|c|c|c|c|c|c|c|c|c|c|c|c|c|c|c|c|c|c|}
\hline$\sum_{\substack{\mathbf{\alpha} \\
\mathbf{\alpha}}}^{\mathbf{N}}$ & ঠ্ণি & ৪ & 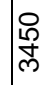 & ৪্ণ & 芯 & 㣽 & ్ㅠ & 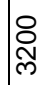 & 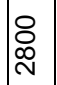 & ৪্ঠি & ষ্ঠি & 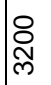 & 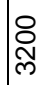 & 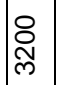 & 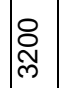 & 尺ి & ৪্ণ & 응 & ৪্টি \\
\hline 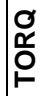 & $\begin{array}{l}0 \\
\dot{\mathfrak{N}} \\
\text { N }\end{array}$ & $\begin{array}{l}0 \\
\dot{\infty} \\
\stackrel{0}{-}\end{array}$ & $\begin{array}{l}0 \\
\infty \\
\stackrel{\infty}{T} \\
\stackrel{0}{0}\end{array}$ & $\begin{array}{l}0 \\
\stackrel{\dot{N}}{N} \\
\text { Non }\end{array}$ & $\begin{array}{l}0 \\
\text { in } \\
\text { N }\end{array}$ & ○ & o. & $\frac{O}{\stackrel{O}{N}}$ & O্ণ & ọ & $\begin{array}{l}\stackrel{o}{\mathrm{~N}} \\
\frac{\mathrm{m}}{\mathrm{m}}\end{array}$ & $\begin{array}{l}0 \\
\dot{8} \\
\dot{+}\end{array}$ & ஜ் & $\begin{array}{l}\text { o } \\
\text { ió } \\
\text { \& }\end{array}$ & $\begin{array}{l}0 \\
\dot{\dot{d}} \\
\dot{q}\end{array}$ & $\begin{array}{l}0 \\
\infty \\
o \\
o \\
g\end{array}$ & $\frac{\sigma}{\infty}$ & مُ & 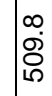 \\
\hline
\end{tabular}

\begin{tabular}{|c|c|c|c|c|c|c|c|c|c|c|c|c|c|c|c|c|c|c|}
\hline$\frac{\sum}{\alpha}$ & 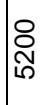 & 呑 & 豆 & 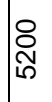 & $\begin{array}{l}0 \\
\stackrel{\infty}{\infty} \\
\dot{\infty}\end{array}$ & ஓ & 导 & 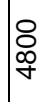 & ठ্টি & ষ্ণ & 엉 & $\begin{array}{l}\stackrel{8}{\infty} \\
\& \\
\stackrel{\infty}{+}\end{array}$ & ষ্ণে প্ণ & $\begin{array}{l}\text { lo } \\
+ \\
f\end{array}$ & ஓ & $\begin{array}{l}\text { 응 } \\
\text { 슈 } \\
10\end{array}$ & 员 & 응 \\
\hline 诖 & 임 & $\stackrel{N}{N}$ & $\stackrel{\sim}{N}$ & 10 & $\stackrel{\infty}{\infty}$ & $\stackrel{\infty}{\infty}$ & 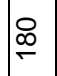 & $\stackrel{2}{\stackrel{2}{=}}$ & $\infty$ & প & $\stackrel{\text { ڤ }}{\longrightarrow}$ & 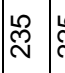 & $\stackrel{\text { N }}{\text { N }}$ & 守 & 유 & $\frac{n}{N}$ & 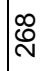 & ঙे \\
\hline 엉 & $\dot{\sigma}$ & $\begin{array}{l}N \\
\sigma\end{array}$ & Na & $\begin{array}{l}\sigma \\
\infty\end{array}$ & $\begin{array}{l}\infty \\
\infty\end{array}$ & Oे & $\begin{array}{l}0 \\
0 \\
\end{array}$ & $\bar{\sigma}$ & \begin{tabular}{|l|}
$\infty$ \\
$\infty$
\end{tabular} & $\begin{array}{l}\infty \\
\infty \\
\infty\end{array}$ & $\begin{array}{ll}\infty & 0 \\
\infty & 0\end{array}$ & $\begin{array}{ll}m & \\
\sigma & 0 \\
\end{array}$ & 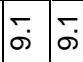 & $\Rightarrow \quad \begin{array}{l}\sigma \\
\infty\end{array}$ & $\begin{array}{l}\infty \\
\infty\end{array}$ & \# & \# & \# \\
\hline 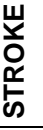 & 움 & $\frac{0}{\infty}$ & $\frac{0}{\infty}$ & $\begin{array}{l}0 \\
0 \\
0\end{array}$ & $\frac{0}{\infty}$ & $\begin{array}{l}0 \\
\infty \\
\infty\end{array}$ & $\begin{array}{l}0 \\
\infty \\
\infty\end{array}$ & 崩 & $\begin{array}{l}1 \\
\infty \\
\infty\end{array}$ & $\begin{array}{l}\hat{D} \\
\infty \\
\infty\end{array}$ & $\begin{array}{l}\hat{0} \\
\infty \\
\infty\end{array}$ & \begin{tabular}{|l|l}
$\infty$ \\
\hdashline \\
$\infty$ \\
$\infty$
\end{tabular} & \begin{tabular}{|l|l}
$\dot{\Phi}$ & $\bar{\infty}$ \\
$\dot{\infty}$
\end{tabular} & $\begin{array}{l}\dot{f} \\
0\end{array}$ & வ & $\begin{array}{l}0 \\
\dot{\infty} \\
\infty\end{array}$ & $\begin{array}{l}\bigcirc \\
\dot{\infty}\end{array}$ & ๙̊․ \\
\hline 峁 & $\begin{array}{l}n \\
\infty \\
\infty \\
\infty\end{array}$ & $\stackrel{+}{\infty}$ & $\begin{array}{l}+ \\
\infty \\
\infty\end{array}$ & $\frac{5}{\sigma}$ & 임 & $\begin{array}{l}0 \\
\dot{\varphi} \\
\mathscr{\theta}\end{array}$ & $\mid \begin{array}{l}0 \\
\dot{\phi} \\
\mathscr{8}\end{array}$ & $\begin{array}{l}m \\
\dot{g}\end{array}$ & \begin{tabular}{l|}
$\Delta$ \\
$\infty$ \\
$\sigma$
\end{tabular} & $\begin{array}{l}+ \\
\infty \\
\infty\end{array}$ & $\begin{array}{l}+ \\
\infty \\
\infty\end{array}$ & $\begin{array}{ll}\text { ஜு } \\
\text { ळ̆ }\end{array}$ & \begin{tabular}{l|c}
$m$ & $m$ \\
$\ddot{g}$ & $\ddot{\sigma}$
\end{tabular} & \begin{tabular}{l|l}
$\stackrel{\varphi}{p}$ \\
$\dot{p}$
\end{tabular} & ọ & $\begin{array}{l}\infty \\
\varnothing \\
\infty \\
\infty\end{array}$ & ळ. & $\begin{array}{l}0 \\
\text { ஸे }\end{array}$ \\
\hline خ & 寸 & J & $\unlhd$ & $>$ & 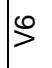 & $\stackrel{\infty}{>}$ & 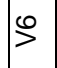 & $\stackrel{\varphi}{>}$ & (6) & & $\stackrel{\varphi}{=}$ & $\stackrel{\infty}{>} \stackrel{\rho}{=}$ & $>^{\infty}>^{\infty}$ & $p$ & $\stackrel{\infty}{>}$ & 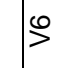 & $\infty$ & $\infty$ \\
\hline$\stackrel{\mathbb{F}}{F}$ & 3 & 3 & 3 & $\Xi$ & $\Xi$ & $\Xi$ & 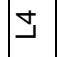 & 10 & 10 & $\stackrel{10}{\Sigma}$ & $\Xi$ & $\Xi$ & 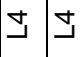 & † & $\Xi$ & ص & 10 & 19 \\
\hline 은 & $\stackrel{\infty}{+}$ & 10 & 10 & $\bar{\infty}$ & ळે & 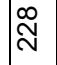 & $\overline{\mathfrak{N}}$ & న్ల & $\stackrel{\mathfrak{N}}{\stackrel{\sim}{\sim}}$ & $\stackrel{\mathfrak{Y}}{\stackrel{\sim}{\sim}}$ & 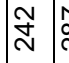 & \begin{tabular}{|l|l}
$\hat{\infty}$ & $\frac{\alpha}{d}$ \\
$\stackrel{N}{c}$
\end{tabular} & $\frac{\infty}{m} \frac{\infty}{m}$ & $\frac{0}{5}$ & ஜ্ర & $\stackrel{\varrho}{\wp}$ & ¿્ల & స్ల్ల \\
\hline$\sum_{\Sigma}^{2}$ & 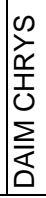 & 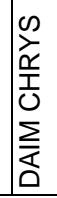 & 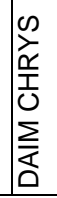 & 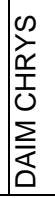 & 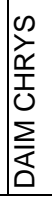 & 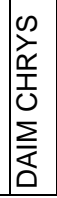 & 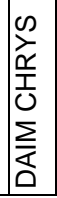 & 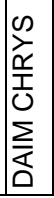 & 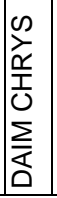 & 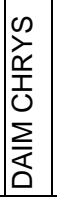 & 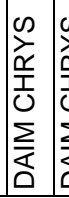 & 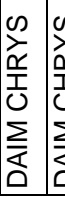 & 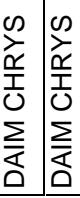 & 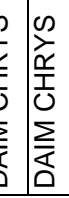 & 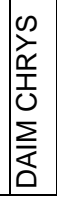 & 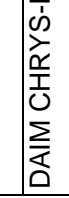 & 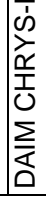 & 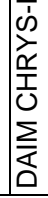 \\
\hline
\end{tabular}




\begin{tabular}{|c|c|c|c|c|c|c|c|c|c|c|c|c|c|c|c|c|c|c|c|c|c|c|c|c|c|c|c|c|c|c|c|}
\hline$\frac{\text { 足 }}{\sum_{3}^{3}}$ & $\begin{array}{l}0 \\
10 \\
\infty \\
\infty \\
\text { N }\end{array}$ & $\begin{array}{l}\overline{1} \\
\stackrel{\omega}{0} \\
\stackrel{0}{0}\end{array}$ & $\frac{m}{\stackrel{M}{N}}$ & $\begin{array}{l}\infty \\
0 \\
\stackrel{0}{\infty} \\
\end{array}$ & & $\underset{c}{c}$ & 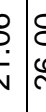 & & $\begin{array}{l}\text { હे } \\
\stackrel{\mathrm{N}}{\mathrm{N}}\end{array}$ & 今. & $\begin{array}{l}\stackrel{\infty}{\infty} \\
\stackrel{\infty}{N}\end{array}$ & 策 & $\begin{array}{l}\frac{\sigma}{\sim} \\
\stackrel{\sim}{\sim}\end{array}$ & $\begin{array}{l}\overline{0} \\
\mathbb{N}\end{array}$ & $\begin{array}{l}\stackrel{N}{N} \\
\stackrel{N}{N}\end{array}$ & $\begin{array}{l}\text { శ్ } \\
\text { N }\end{array}$ & 㲾 & $\begin{array}{l}\hat{N} \\
\sigma \\
\sigma\end{array}$ & 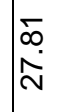 & $\begin{array}{l}\infty \\
\stackrel{\infty}{0} \\
\end{array}$ & $\begin{array}{l}\bar{T} \\
\bar{N}\end{array}$ & $\begin{array}{l}\mathscr{D} \\
\stackrel{N}{\infty} \\
\stackrel{N}{2}\end{array}$ & $\mid$ & $\begin{array}{l}\bar{\infty} \\
\dot{\sigma} \\
\overline{-}\end{array}$ & 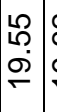 & 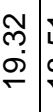 & & 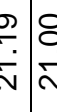 & & & $\begin{array}{l}\infty \\
\infty \\
\infty \\
\infty \\
\infty\end{array}$ \\
\hline$\stackrel{3}{\lessgtr}$ & $\mid \begin{array}{l}\infty \\
\stackrel{\infty}{\sim} \\
\stackrel{n}{-}\end{array}$ & 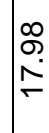 & 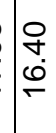 & $\begin{array}{l}\mathscr{N} \\
\stackrel{N}{0} \\
\underline{n}\end{array}$ & 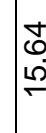 & {$\left[\begin{array}{l}8 \\
6 \\
15\end{array}\right.$} & 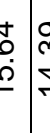 & 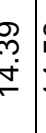 & 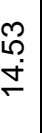 & 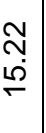 & 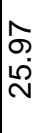 & 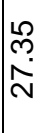 & $\begin{array}{l}\mathcal{N} \\
\infty \\
\sim \\
\sim\end{array}$ & $\begin{array}{l}\mathcal{M} \\
\stackrel{\mathcal{D}}{N}\end{array}$ & $\begin{array}{l}\hat{\omega} \\
\infty \\
\sim \\
\sim\end{array}$ & $\begin{array}{l}\hat{\infty} \\
\hat{\omega} \\
\stackrel{N}{0}\end{array}$ & $\begin{array}{l}\hat{n} \\
\infty \\
\stackrel{\infty}{N}\end{array}$ & $\begin{array}{l}\bar{\delta} \\
\infty \\
\stackrel{\infty}{\infty}\end{array}$ & $\begin{array}{l}\hat{N} \\
\bar{\infty} \\
\dot{m}\end{array}$ & $\begin{array}{l}8 \\
\dot{p} \\
\dot{p}\end{array}$ & $\begin{array}{l}\hat{N} \\
\tilde{e} \\
\dot{m}\end{array}$ & $\begin{array}{l}\overline{6} \\
\dot{m}\end{array}$ & $\mid \begin{array}{l}N \\
\hat{N} \\
0\end{array}$ & $\begin{array}{l}0 \\
\stackrel{1}{\hat{\theta}}\end{array}$ & $\begin{array}{l}n \\
\dddot{m} \\
\dot{\theta}\end{array}$ & 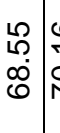 & $\stackrel{\substack{0 \\
i}}{i}$ & & & $=\frac{m}{\frac{m}{\pi}}$ & $\frac{d}{\frac{\sigma}{T}}$ \\
\hline गे & م & م & $\stackrel{\text { L }}{\mathrm{N}}$ & $\stackrel{L}{\stackrel{2}{N}}$ & $\stackrel{10}{2}$ & & 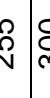 & & ৪্লি & ৪্ল & ஜூర & ల్ర & $\widetilde{0}$ & ర్ర & $\mathscr{\wp}$ & 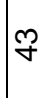 & $\mathscr{m}$ & $\mathscr{P}$ & \& & $\mathscr{P}$ & $\stackrel{\mathscr{P}}{\&}$ & $\mathscr{q}$ & $\S$ & $\S$ & & $\Sigma$ & $\Sigma \leq$ & 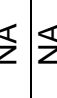 & & & $\frac{\nwarrow}{Z}$ \\
\hline $\bar{\partial}$ & $\widetilde{\widetilde{\sigma}}$ & $\mid \widetilde{\mho}$ & $\tilde{\widetilde{U}}$ & $\widetilde{\widetilde{E}}$ & $\tilde{\widetilde{E}}$ & $\tilde{\varepsilon}$ & & & $\widetilde{\widetilde{\sigma}}$ & & $\stackrel{\infty}{\mp}$ & $\stackrel{\infty}{\mp}$ & $\stackrel{\infty}{\mp}$ & $\stackrel{\infty}{\mp}$ & \& & $\underset{+}{\stackrel{+}{0}}$ & $\underset{ }{\mathbb{O}}$ & ¿্ & $\underset{+}{\stackrel{0}{0}}$ & $\underset{0}{0}$ & 믐 & 吉 & $\widetilde{\sigma}$ & $\widetilde{\mho}$ & & $\mathfrak{\widetilde { E }}$ & $\tilde{c}$ & $\tilde{0})$ & $\begin{array}{l}0 \\
0\end{array}$ & & $\tilde{E}$ \\
\hline O & & & & & & & & & & & & & & & & & & & & & & & $\mid$ & 占 & \begin{tabular}{l}
10 \\
\multirow{0}{0}{} \\
0
\end{tabular} & $\begin{array}{l}n \\
0 \\
0\end{array}$ & & & & & 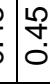 \\
\hline 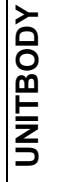 & $z$ & z & & $z$ & $z$ & $z$ & $z 2$ & & $z$ & & $z$ & $z$ & $z$ & $z$ & $z$ & $z$ & $z$ & $z$ & $z$ & $z$ & $z$ & $z$ & $z$ & $z$ & & $z$ & $z z$ & $z \mid z$ & $z 2$ & & $z$ \\
\hline 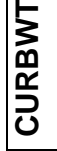 & $\begin{array}{l}8 \\
0 \\
10\end{array}$ & $\mid \begin{array}{l}8 \\
0 \\
10\end{array}$ & 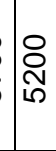 & $\frac{0}{\frac{m}{5}}$ & & & 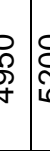 & స్. & & 足 & $\underset{\stackrel{8}{8}}{\stackrel{8}{f}}$ & 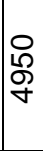 & 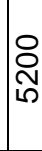 & 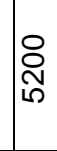 & ণ্ণ & 足 & 衣 & & $\stackrel{\circ}{\stackrel{0}{8}}$ & $\frac{0}{\dot{y}}$ & 号 & $\begin{array}{l}8 \\
\dot{b} \\
\forall\end{array}$ & \begin{tabular}{l}
$\stackrel{D}{0}$ \\
\multirow{T}{*}{}
\end{tabular} & $\frac{8}{\frac{8}{8}}$ & & 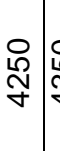 & & & & & 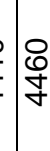 \\
\hline 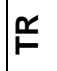 & $\nabla$ & $\Delta$ & $\Delta$ & 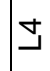 & \pm & 5 & 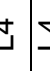 & $\exists$ & 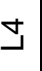 & \pm & $\exists$ & 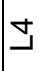 & 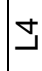 & $\exists$ & صـ & $\sum^{10}$ & صـا & 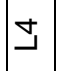 & صـ & $L^{\infty}$ & صـ & $\Delta$ & $\Xi$ & $\stackrel{\llcorner}{\Sigma}$ & 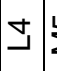 & $\sum^{\infty}$ & $\nabla$ & \pm & & $\sum^{L}$ & 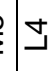 \\
\hline 은 & $\stackrel{\mathscr{N}}{\stackrel{N}{2}}$ & \& & 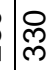 & $\stackrel{\mathscr{N}}{\mathfrak{N}}$ & $\stackrel{\infty}{\stackrel{\infty}{\sim}}$ & હ્ર & 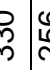 & مْ & প্ল & প্লি & $\stackrel{\infty}{\infty}$ & প্ল্ল & 这 & প্লি & $\underset{N}{\stackrel{d}{~}}$ & $\underset{N}{\stackrel{d}{~}}$ & 苾 & ণ্ & $\underset{\sim}{\text { d }}$ & $\underset{N}{\stackrel{J}{*}}$ & $\underset{N}{\stackrel{J}{*}}$ & స్ల & 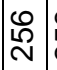 & $\begin{array}{l}\text { : } \\
\stackrel{N}{N}\end{array}$ & 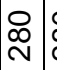 & 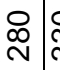 & 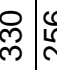 & 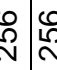 & 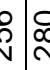 & 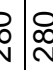 & 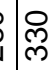 \\
\hline 茴 & $\llbracket$ & $\simeq$ & $\simeq$ & 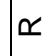 & $\propto$ & $\alpha$ & $r$ & $\Upsilon$ & $\simeq$ & $\simeq$ & $\simeq$ & $\simeq$ & $\nabla$ & $\nabla$ & $\simeq$ & $\simeq$ & $\simeq$ & $\simeq$ & $\nabla$ & $\nabla$ & $\nabla$ & $\nabla$ & $\simeq$ & $\simeq$ & & $\simeq 0$ & $\simeq>$ & $\nabla \nabla$ & $+\nabla$ & J & $\nabla$ \\
\hline$\sum_{\mathbf{k}}$ & 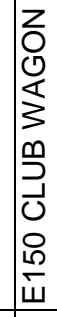 & 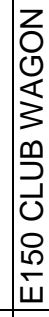 & $\begin{array}{l}z \\
0 \\
0 \\
\frac{1}{z} \\
3 \\
9 \\
د \\
0 \\
0 \\
0 \\
\frac{10}{w} \\
\end{array}$ & $\begin{array}{l}z \\
z \\
\\
0 \\
1 \\
\\
w\end{array}$ & 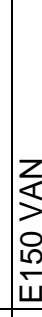 & $\frac{4}{4}$ & 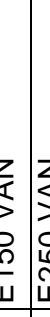 & 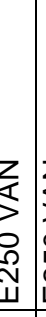 & 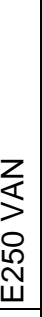 & 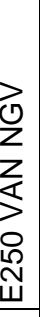 & 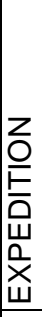 & 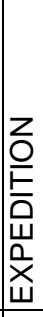 & 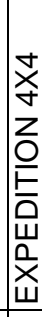 & 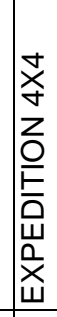 & 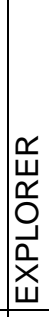 & 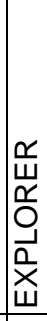 & 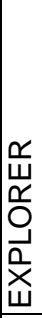 & 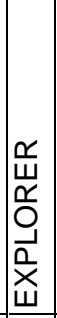 & 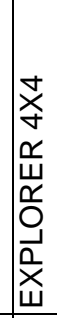 & 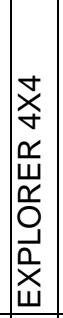 & 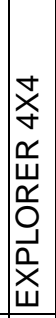 & 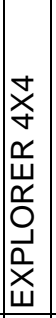 & 通 & $\frac{8}{\square}$ & $\frac{0}{\square}$ & & 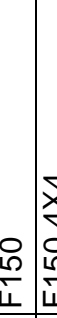 & 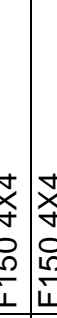 & 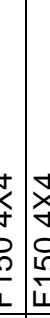 & 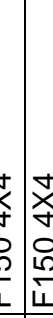 & 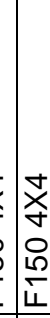 \\
\hline$\frac{0}{D}$ & 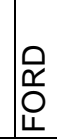 & | & 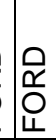 & & & ? & & $\begin{array}{r}\frac{\gamma}{2} \\
1 \\
\end{array}$ & U. & & 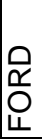 & 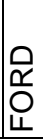 & & 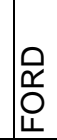 & & 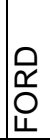 & 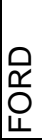 & 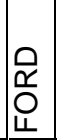 & 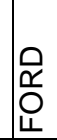 & 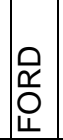 & 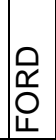 & 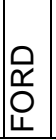 & 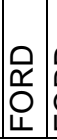 & 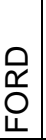 & 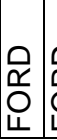 & 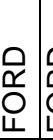 & 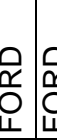 & 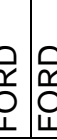 & 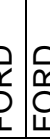 & 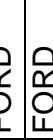 & 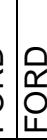 \\
\hline
\end{tabular}




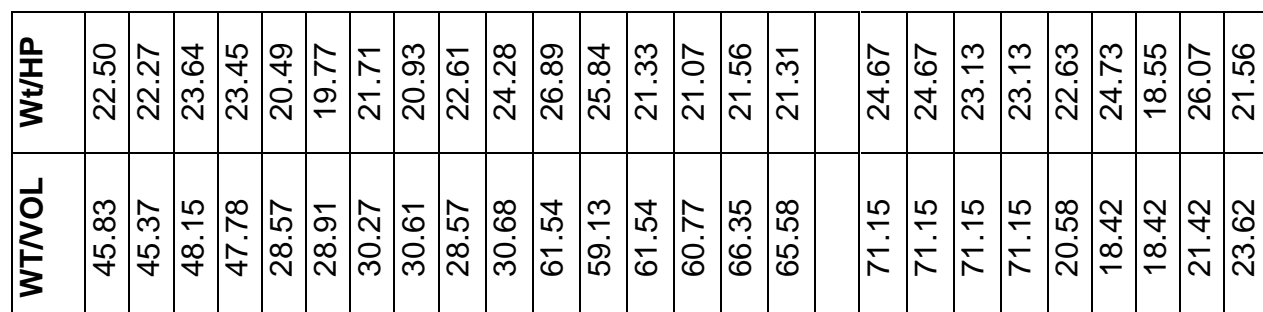

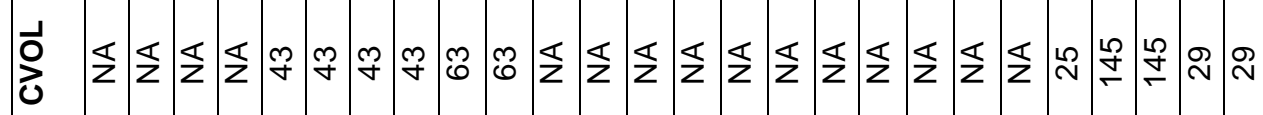

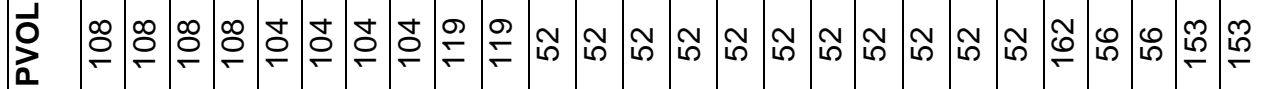

¿

学
旁

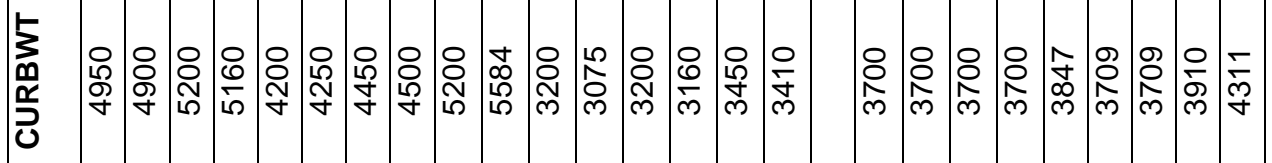

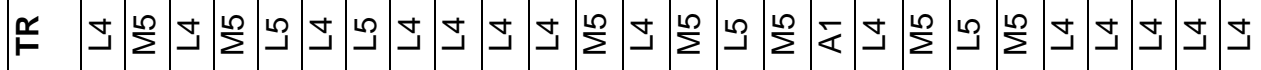

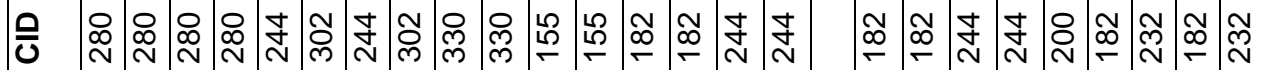

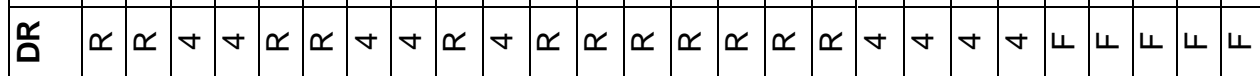
文齐齐齐妾

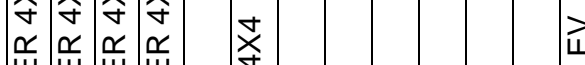

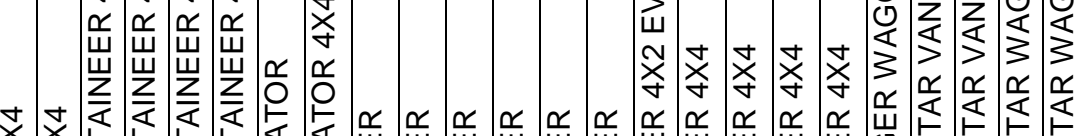

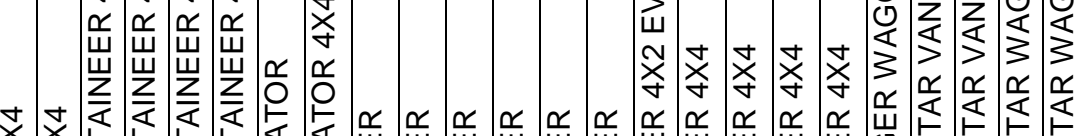

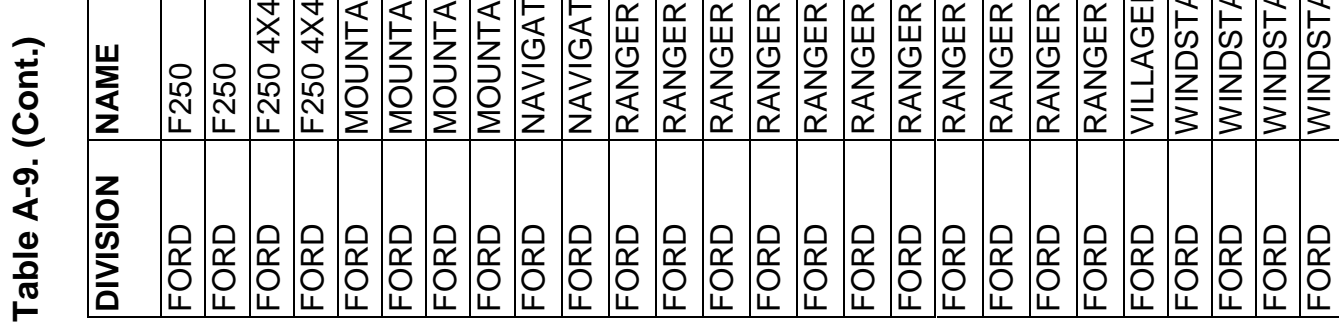




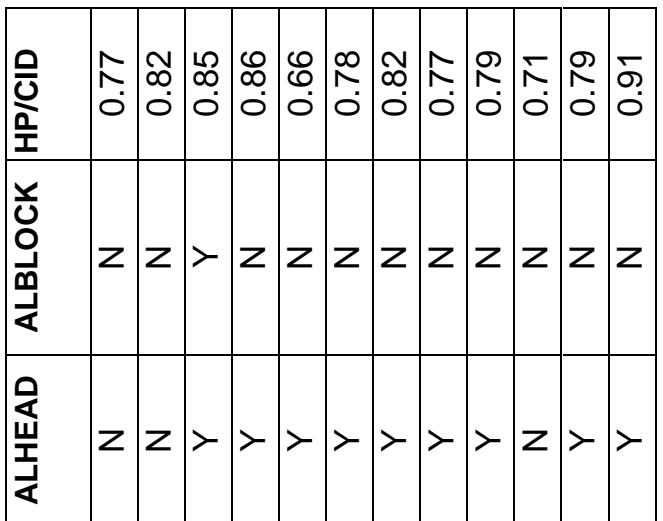

ঢ

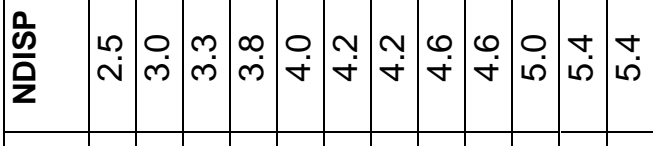

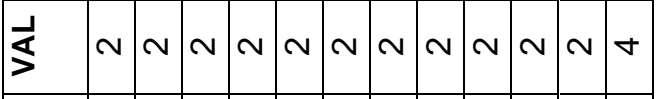

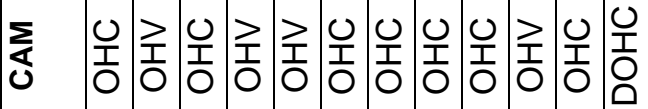

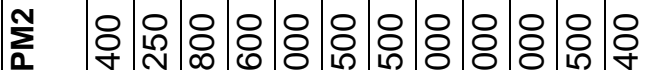

๙ N N

o $\quad 0$.

ơ

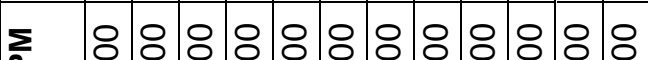

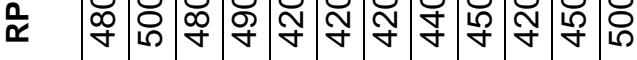

\begin{tabular}{|c|c|c|c|c|c|c|c|c|c|c|c|}
\hline 呈 & $\frac{\Omega}{\square}$ & ?ִ & $\stackrel{2}{2}$ & & 0 & & & & & & $\begin{array}{l}\text { D } \\
\text { D }\end{array}$ \\
\hline$\frac{\pi}{0}$ & $\stackrel{\nabla}{\circ}$ & $\begin{array}{l}n \\
\dot{\sigma}\end{array}$ & $\begin{array}{l}\infty \\
\infty \\
\infty\end{array}$ & $\dot{\sigma}$ & $\begin{array}{l}0 \\
\text { के }\end{array}$ & $\begin{array}{lll}\infty & \\
\infty & & \end{array}$ & m) & c & & & ") \\
\hline 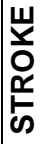 & $\begin{array}{l}+ \\
\dot{0} \\
\infty\end{array}$ & $\begin{array}{l}\infty \\
\dot{p}\end{array}$ & $\begin{array}{l}0 \\
\dot{\mathscr{D}} \\
\infty\end{array}$ & $\begin{array}{l}0 \\
0 \\
\infty\end{array}$ & $\begin{array}{l}\infty \\
\dot{0} \\
\infty\end{array}$ & 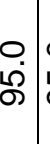 & & s. & & & 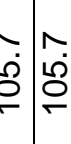 \\
\hline 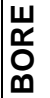 & $\begin{array}{l}0 \\
\dot{\theta}\end{array}$ & $\begin{array}{c}\tau_{\infty} \\
\stackrel{\infty}{\infty}\end{array}$ & مَ & $\begin{array}{l}\infty \\
\dot{g} \\
\varnothing\end{array}$ & $\begin{array}{l}m \\
\dot{0} \\
\dot{0}\end{array}$ & $\begin{array}{l}\infty \\
\dot{8} \\
\mathscr{8}\end{array}$ & $\begin{array}{l}\infty \\
\dot{g} \\
\dot{s}\end{array}$ & $\begin{array}{l}y \\
\dot{s} \\
\dot{s}\end{array}$ & & & \begin{tabular}{ll}
\multirow{2}{*}{} \\
$\dot{s}$
\end{tabular} \\
\hline 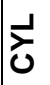 & 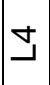 & ( & 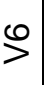 & 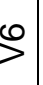 & $\stackrel{9}{>}$ & 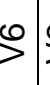 & & & & & $\stackrel{\infty}{>} \stackrel{\infty}{>}$ \\
\hline$\stackrel{\mathscr{R}}{\mathrm{f}}$ & $\sum^{10}$ & 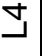 & \pm & $\Xi$ & $\sum^{10}$ & 寸 & \pm & 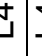 & & 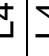 & $\Delta$ \\
\hline$\frac{9}{0}$ & L & $\underset{\infty}{\infty}$ & ટ્ণ & స్ స్ & 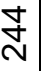 & $\stackrel{0}{\mathfrak{N}}$ & 怘 & $\stackrel{f}{0}$ & & & 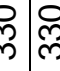 \\
\hline z & 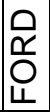 & 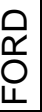 & 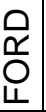 & 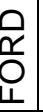 & 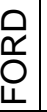 & حُ & 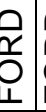 & 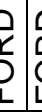 & & 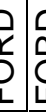 & 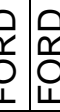 \\
\hline
\end{tabular}




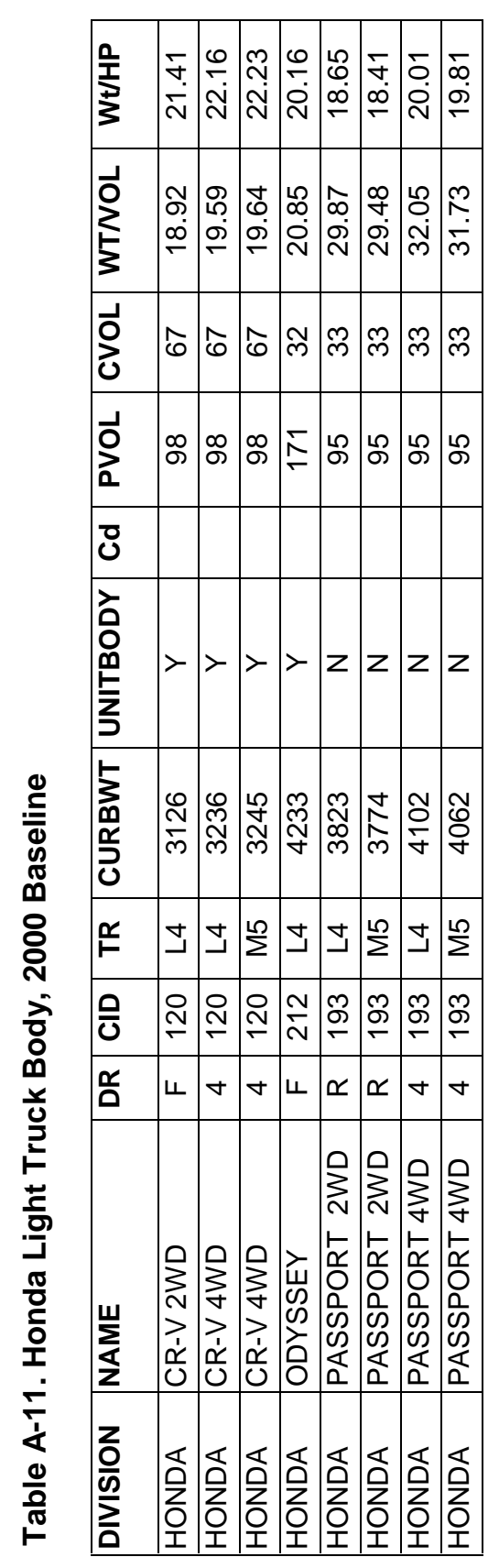




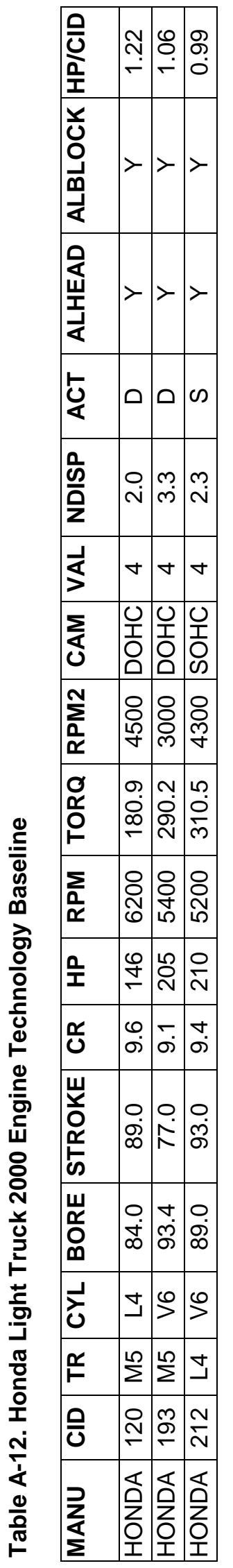


$\Delta$ 


\section{Appendix B Methodology}

\section{B.1 Overview}

The consideration of future technology potential requires the assessment of each technology's "cost" and its benefits to the customer, as well as to GHG emissions. The term cost is one that can have many different meanings and needs to be carefully considered in the context of technology analysis. Benefits to the consumer can be measured in several dimensions that can range from fuel savings, to improved vehicle driveability, to better utilization of space.

\section{B.2 Technology Price Estimates}

The term "technology cost" has created a considerable degree of confusion, as some observers have linked it to manufacturing costs, others to the retail price of the technology. In this analysis, the term "price" has a very specific meaning, and it relates to the incremental change in retail price due to technology adoption on a new car. This change is measured as an average across new cars and is called the "retail price equivalent," or RPE. The price effect on an individual car or light truck model may be higher or lower than the estimated RPE, but these price variations represent cross subsidies between consumers. For example, marketing strategies may require certain models to be priced lower than other technologically similar models to efficiently compete in the marketplace, but average price increment is the focus of this analysis.

The underlying concept behind the use of RPE is that in a highly competitive industry, economic theory states that manufacturers can earn only a "normal" return on capital unless they possess proprietary technology or production methods. Most of the technologies considered in this report, except for battery and fuel cell technology, cannot be considered as proprietary. This also holds for production methods, although different companies can be more or less efficient in production. In a competitive marketplace, all manufacturers must price their product so that the average producer earns a normal rate of return on capital; more efficient producers can gain market share by pricing lower than average at the expense of less-efficient producers. In reality, the auto manufacturers are not correctly modeled as a competitive industry but as an oligopoly, in that seven manufacturers control over $70 \%$ of the worldwide market, and barriers to market entry are high. The picture is even more complex since the car market can be segmented, and some market segments are highly competitive while others, such as large car segments, are less competitive. In order to predict how much the price of cars will actually increase, on average, we have used a methodology that is based on a manufacturer's "expected" rate of return on capital, which may be higher than the "normal" rate of return (if sales volume goals are attained) because the market is not perfectly competitive. The calculated price impact using this method may overstate the actual price impact in very competitive segments, but may understate the impact in less-competitive segments. It is also not applicable to luxury car manufacturers, where fixed costs are amortized over much smaller sales volumes.

It is important to note that the entire cost of a technology need not be allocated to fuel economy if the technology affects other vehicle attributes. For example, fuel injection is used to 
provide emission reductions, with improved driveability and improved fuel economy. In earlier modeling, before fuel injection captured $100 \%$ of the market, its RPE assigned to fuel economy was (arbitrarily) allocated half its total RPE impact, with the other half assigned to emissions control. For technologies that affect horsepower and performance, the RPE is adjusted by the market value of any performance gain or the cost savings of foregoing a performance increase. For example, the RPE of a 4-valve engine is determined as the price increment from a 2-valve engine of equal performance, which would be a larger displacement engine.

\section{B.2.1 Methodology to Derive RPE from Costs}

We have established a defined methodology to track the development of RPEs from supplier costs to RPEs both to overcome confusion among analysts and policymakers about what the terms "cost" and "price" actually refer to and to allow us to use cost and price data from various parts of the supply chain to produce RPEs in an analytically consistent manner. Our methodology depends on the assumption that, in a competitive market, the average retail price of a technology bears a relationship to the cost of manufacturing. The methodology uses an approach followed by industry that includes the variable cost per unit of the component or technology and the allocation to each unit of a portion of the fixed costs associated with facilities, tooling, engineering, and launch expenses (EEA 1994). The methodology has also been widely used by U.S. regulatory agencies.

Since automotive technologies require significant investment in $\mathrm{R} \& \mathrm{D}$, engineering, tooling, production, and launch, the amortized investment costs are very large, of the same order in "per unit" terms as the variable costs associated with labor, material costs, and plant operating costs. In the short run, the marginal technology cost to the manufacturer may be the variable cost only, but the long run marginal costs must include a return on investment. Because we are examining investment decisions for vehicles in the 2012-2015 time frame, our calculations are for long-run marginal costs and their impact on RPE (that is, they include investment costs). Further, in calculating the incremental price effects of substituting a new technology for an existing one, the calculation includes investment costs for both. In this context, the manufacturer's choice is not between continuing to produce an existing technology whose investment costs may have been fully amortized versus producing a new technology for which investment costs must be accounted for. Instead, the decision is between producing a new model with baseline technology versus producing a new model with new technology, with both the baseline and new technologies having investment costs that must be accounted for. This is a crucial assumption that potentially accounts for the large differences between some public estimates of technology RPE and estimates presented here. The fact remains that no engine model or vehicle model can be continued indefinitely and must eventually be redesigned or at least retooled as the tooling wears out. The amortization periods we have used are based on typical industry benchmarks for retooling and redesign, but it is common to see a distribution of amortization periods in reality. It may be possible to continue producing an old-design vehicle or engine for a few more years above the standard amortization period, and this extended life usually occurs if the manufacturer is having cash flow problems. However, this also translates to a market perception of outdated products, and discounts must often be used to keep sales from declining, so that cost savings are often offset by revenue declines. Hence, the use of normal amortization periods for comparing costs is reasonable. 
It is in this calculation that the oligopoly "rent" on capital is included, in that we use the "expected" rate of return rather than the normal rate, based on expected sales; this is similar to the accounting concept of "normal" costs. In accounting terms, fixed costs are amortized over a "normal" sales volume; if actual sales volume exceeds normal volumes, the manufacturer records a higher profit margin, but a lower volume can result in a loss. These excess profits and losses are balanced over a range of models that exceed, or are below, sales targets for a given manufacturer. The expected rate of return is set at $15 \%$ (real), which is higher than the normal rate of about $10 \%$, and represents a risk adjusted oligopoly rate of return.

The methodology uses a three-tier structure to the allocation of costs. A specific component, such as an electric motor or a turbocharger, is first manufactured by a supplier company, or by a division of the manufacturer that is an in-house supplier (e.g., Delphi supplies GM/Opel/Saab with electrical components). The supplier part "cost" to the manufacturer has both variable and fixed components; the variable cost is associated with materials, direct labor and, manufacturing overhead. The supplier or divisional overhead is associated with corporate and administration costs, and the pre-tax profit is calculated as a percent of variable costs. Tooling Expense and Facilities Expense are based on amortization of investments undertaken prior to production, including a return on capital. Since in-house and external suppliers are treated identically, RPEs are not affected by the sourcing decision, which is consistent with the idea of a competitive marketplace for subassemblies. Where the cost to the auto-manufacturer can be obtained, this cost is the starting point for our analysis.

The second cost tier is associated with vehicle assembly, where all of the "components" are brought together. (For example, the stamping plant producing body sheet metal parts can be treated as a "supplier" for costing.) Again, manufacturer overhead and manufacturer pre-tax profit are applied to components supplied to an assembly plant, plus assembly labor and manufacturing overhead. Fixed costs include the amortization of Tooling, Facilities, and Engineering and include return on capital. Note that the profit margins used refer to gross margins and are not the net profit margins.

The final tier leads to the retail price equivalent and involves the markups associated with transportation, dealer inventory and marketing costs, and dealer profits. Sales taxes are not included, but dealer and manufacturer margins are based on pre-tax profits.

The cost methodology is summarized in Table B-1, and all of the overheads and profits are specified as standard percentage rates applied to variable costs. These percentages are documented in a report to the U.S. Department of Energy (EEA 1994), as well as in industry submissions to U.S. Department of Transportation. Dealer margin was obtained from industry submissions. 
Table B-1. Costing Methodology

\begin{tabular}{|c|c|c|c|}
\hline \multicolumn{4}{|l|}{ Tier I } \\
\hline \multicolumn{3}{|l|}{ Supplier/Division Cost } & $\begin{array}{l}\text { [Materials + Direct Labor + Manufacturing Overhead }] \text { x } \\
{[1+\text { Supplier Overhead }+ \text { Supplier Profit }]+\text { Tooling }} \\
\text { Expense + Facilities Expense + Engineering Expense }\end{array}$ \\
\hline \multicolumn{4}{|l|}{ Tier II } \\
\hline \multicolumn{2}{|l|}{ Auto-manufacturer Cost } & $=$ & $\begin{array}{l}\text { [Supplier Cost + Assembly Labor + Assembly Overhead }] \\
x \text { [1 + Manufacturing Overhead + Manufacturing Profit }] \\
+ \text { Engineering Expense + Tooling Expense + Facilities } \\
\text { Expense }\end{array}$ \\
\hline \multicolumn{4}{|l|}{ Tier III } \\
\hline \multicolumn{2}{|l|}{ Retail Price Equivalent } & $=$ & Manufacturer Cost x Dealer Margin \\
\hline \multicolumn{4}{|l|}{ Notes } \\
\hline \multicolumn{2}{|l|}{ Supplier Overhead } & $=$ & 0.20 \\
\hline \multicolumn{2}{|l|}{ Supplier Profit } & $=$ & 0.08 \\
\hline \multicolumn{2}{|c|}{ Manufacturer Overhead } & $=$ & 0.25 \\
\hline \multirow[t]{2}{*}{ Manufacturer Profit } & Dealer Margin & $=$ & 0.08 \\
\hline & & $=$ & 0.17 \\
\hline
\end{tabular}

Fixed cost amortization involves converting total program costs to unit costs, which requires estimates of:

- Fixed cost spending distribution over time,

- Return on capital,

- Annual production capacity, and

- Amortization period.

The rate of return on capital has been set to $15 \%$ real (inflation adjusted) and is consistent with "normal" rate for projects used by the automotive industry. Using this rate, every dollar of total investment in a project has a net present value of $\$ 1.358$ at launch. For minor changes, the net present value is $\$ 1.330$.

Based on analysis of plant capacity by model, we have selected a plant capacity of 200,000 units per year as a "representative average" for automotive body-related technologies. A typical model lifecycle is eight years, but there is a "facelift" at the midpoint in a model's product cycle so that the appropriate period for amortization of engineering expenses related to the exterior design is four years. Engine and drivetrain components usually have a longer lifecycle than vehicle platforms, ranging from eight to ten years. In general, there are no major changes over this period, so cost recovery over an eight-year period is appropriate. Typical production capacity is 500,000 units per year for engines and transmission plants/designs. Calculations to derive unit costs assume operation at $85 \%$ capacity. (Increasing the price of vehicle by one dollar provides a return of four dollars over the four-year period for body related 
parts, and eight dollars for engine related parts, but these returns must be discounted for the time value of money. The net present value of $\$ 1$ in added price to a vehicle results in a return of $\$ 2.855$ for body parts, and this increases to $\$ 4.487$ for an engine or drivetrain [calculated at a $15 \%$ rate of return] over the amortization period back to launch date. These figures can be used to translate the effects of fixed costs on retail price.)

Some observers have commented on the possibility that this RPE calculation approach may overstate the costs, since most overhead costs can be insensitive to the variable cost. Such arguments are fundamentally incorrect as they ignore demand-side effects. It is well known that the demand elasticity of vehicle sales to price is close to -1, implying that a one percent increase in price results in a one percent decrease in sales. Since overhead costs are spread over annual sales, a fixed overhead cost spread over a smaller sales volume implies increased overhead costs per vehicle. When demand elasticity is close to -1 , using a multiplicative overhead rate is similar to using a fixed absolute overhead while accounting for sales decreases.

\section{B.3 Estimating the Fuel Economy Impact of New Technologies}

\section{B.3.1 Overview}

This section discusses our methodology for estimating the effect on a vehicle's fuel economy of adding a single or multiple technologies. The focus here is on trying to isolate the effects of the added technologies from other changes that may occur in vehicles. Consequently, in comparing a "before" (with base technology) and "after" (with new technology) vehicle, we keep both interior room and acceleration performance constant. When forecasting the impact of technologies in future years, we maintain constant interior room and acceleration performance over time, even though manufacturers have tended to increase these over the past decade; however, we do allow for continuing increases in body rigidity and other safety-related features by adding a weight correction to the future vehicles. The use of a constant interior room and constant acceleration performance scenario is identical to the procedure used by Sierra, so that our estimates of technology benefits are comparable with theirs.

One exception to the constant acceleration performance assumption is for gasoline-electric hybrid vehicles, which do not have the same performance characteristics as conventional vehicles (EEA 1995). For hybrids, we have set performance requirements as follows: Continuous power demand (i.e., power output that must be sustained indefinitely) is set to a level that allows vehicle to climb a six percent grade at $60 \mathrm{mph}$ with a modest payload, which equates to $30 \mathrm{kw}$ per ton. Of course, it is recognized that such a long grade is encountered rarely, but this requirement is to cover a number of other situations where the vehicle is fully loaded with five passengers and luggage, such as $80 \mathrm{~km} / \mathrm{h}$ climb up a three or four percent grade. Peak power demand is based on a zero to $100-\mathrm{km} / \mathrm{h}$ acceleration time under $12 \mathrm{~s}$, with a nominal load; this requires about $50 \mathrm{~kW} /$ ton, or $20 \mathrm{~kW} /$ ton in addition to the $30 \mathrm{~kW} /$ ton needed for the continuous power requirement. We have required that peak power be sustained for over a minute, to cover situations where two highway "merge" cycles are required back-to-back or the need to climb a steep highway entrance ramp (for an elevated highway) and then have enough power to merge into $70 \mathrm{mph}$ traffic. Hence, the $50 \mathrm{~kW} /$ ton and $30 \mathrm{~kW} /$ ton power requirements are to cover a wide variety of traffic conditions under full load, not just the example cases cited above, and most internal-combustion-engine-powered vehicles meet or easily exceed these performance levels. 


\section{B.3.2 Engineering Model}

It is relatively easy to derive a simple model of energy consumption in conventional automobiles that provides insight into the sources and nature of energy losses. In brief, the engine converts fuel energy to shaft work. This shaft work provides the tractive energy required by the vehicle to move forward (taking into account driveline losses) and the energy needed to run the accessories. The tractive energy can be separated into the energy required to overcome aerodynamic drag force, rolling resistance, and inertia force. It is useful to consider energy consumption on the USA Federal Test Procedure (FTP) and Highway (HWY) test cycles, which are the official driving cycles used in the United States for measuring fuel economy for regulatory compliance.

The engineering model follows the work by GM Research Laboratory scientists Sovran and Bohn (1981). Defining the average engine brake specific fuel consumption over the test cycle as bsfc, we have fuel consumption, FC, given by

$$
F C=\frac{b s f c}{\eta_{d}}\left[E_{R}+E_{A}+E_{K}\right]+b s f c E_{A C}+G_{i}\left(t_{i}+t_{b}\right)
$$

where:

$\begin{array}{ll}\eta_{\mathrm{d}} & \text { is the drive train efficiency } \\ \mathrm{E}_{\mathrm{R}} & \text { is the energy to overcome rolling resistance } \\ \mathrm{E}_{\mathrm{A}} & \text { is the energy to overcome aerodynamic drag } \\ \mathrm{E}_{\mathrm{K}} & \text { is the energy to overcome inertia force } \\ \mathrm{E}_{\mathrm{AC}} & \text { is the accessory energy consumption } \\ \mathrm{G}_{\mathrm{i}} & \text { is idle fuel consumption per unit time } \\ \mathrm{t}_{\mathrm{i}}, \mathrm{t}_{\mathrm{b}} & \text { are the time spent at idle and braking }\end{array}$

The first term in the above equation represents the fuel consumed to overcome tractive forces. $\mathrm{E}_{\mathrm{R}}, \mathrm{E}_{\mathrm{A}}$, and $\mathrm{E}_{\mathrm{k}}$ can be readily calculated as functions of the vehicle weight, the rolling resistance, body drag coefficient, and frontal area. Table B-2(a) shows the energy distribution in percent for a medium size car, between the tractive forces for the city and highway cycles as well as the EPA 55/45 composite cycle.

Note that weight reduction reduces both inertia force and rolling resistance. It should also be noted that not all of the inertia force is lost to the brakes, since aerodynamic drag and rolling resistance also help slow the vehicle. Braking energy loss is approximately $35 \%$ of all losses on the city cycle and seven percent of all losses on the highway cycle. The fuel energy is used not only to supply energy requirements at the engine shaft but also to overcome transmission losses, accounting for the transmission efficiency that is in the first term. 
Table B-2(a). Energy Consumption as a Percent of Total Energy Requirements for a Midsize Car

\begin{tabular}{|c|c|c|c|}
\hline & City & Highway & Composite ${ }^{a}$ \\
\hline \multicolumn{4}{|l|}{ Percent of Total Tractive Energy } \\
\hline Rolling Resistance & 27.7 & 35.2 & 30.5 \\
\hline Aerodynamic Drag & 18.0 & 50.4 & 29.9 \\
\hline Inertia (Weight) Force & 54.3 & 14.4 & 39.6 \\
\hline Total & $\underline{100}$ & $\underline{100}$ & $\underline{100}$ \\
\hline \multicolumn{4}{|l|}{ Percent of Total Fuel Consumed } \\
\hline Tractive Energy & 58.5 & 81.5 & 66.6 \\
\hline Accessory Energy & 11.0 & 7.0 & 9.6 \\
\hline Idle + Braking Consumption & 16.0 & 2.0 & 10.7 \\
\hline Transmission + Driveline Loss & 14.5 & 9.5 & 12.9 \\
\hline \multicolumn{4}{|c|}{$\begin{array}{l}\text { Assumes that highway fuel economy }=1.5 \times \text { City } F / E \\
\text { Midsize car of inertia weight }=1,588 \mathrm{~kg}, \mathrm{C}_{\mathrm{D}}=0.33, \mathrm{~A}=2.1 \mathrm{~m}^{2}, \mathrm{C}_{\mathrm{R}}=0.011,3 \mathrm{~L} \\
\mathrm{HV} \text { V-6, Power Steering, 4-speed automatic transmission with lock-up, air } \\
\text { onditioning.) }\end{array}$} \\
\hline
\end{tabular}

The second term in the equation is for the fuel consumed to run the accessories. Power is required to run the radiator cooling fan, alternator, water pump, oil pump, and power steering pump (but the water pump and oil pump are sometimes excluded from the accessory drive loads). Air conditioners do not enter the picture since they are not turned on during the test cycles. Idle and braking fuel consumption are largely a function of engine size and idle rpm, while transmission losses are function of transmission type (manual or automatic) and design. The engine produces no shaft power during idle and braking but consumes fuel, so that factor is accounted for by the third term. Table 2-B(a) shows the energy consumed in percent by all of these factors in a typical midsize car with a 3-L OHV engine, 4-speed automatic transmission with lock-up power steering, and typical alternator size. Table B-2(b) shows the absolute energy consumption for a midsize car and estimates its engine efficiency.

The values in Table B-2(a) can be easily used to derive sensitivity coefficients for the reduction of various loads. For example, reducing the weight by $10 \%$ will reduce both rolling resistance and inertia weight forces, so that tractive energy is reduced by $(30.5+39.6) \times 0.1$ or $7.01 \%$ on the composite cycle. Fuel consumption will be reduced by $7.01 \% \times 0.708$, which is the fraction of fuel used by tractive energy, or $4.96 \%$. This matches the common wisdom that reducing weight by $10 \%$ reduces fuel consumption by $5 \%$. However, if the engine is also downsized by $10 \%$ to account for the weight loss, fuel consumption will be reduced by $6.02 \%$ since idle and braking fuel consumption will be reduced in proportion to engine size. Tables B-2(a) and (b) provide a framework by which total fuel consumption for any automobile can be analyzed for the fuel economy test cycle. 


\section{Table B-2(b). Energy Consumption for a Midsize Car (consumption in $\mathrm{kW}-\mathrm{h} / \mathrm{mi})^{\mathrm{a}}$}

\begin{tabular}{|lccc|}
\hline & City & Highway & Composite \\
\cline { 2 - 4 } & & & \\
Tractive Energy & 0.2064 & 0.1974 & 0.2024 \\
$\quad$ Requirement & & & \\
Transmission Loss & 0.0336 & 0.0160 & 0.0257 \\
Accessory Energy & 0.0314 & 0.0164 & 0.0247 \\
Total Energy & 0.2714 & 0.2298 & 0.2528 \\
$\quad$ Required & & & \\
Total Fuel & 1.2146 & 0.8469 & 1.0490 \\
$\quad$ Energy Used & & & \\
Idle and Braking Loss & 0.2314 & 0.0173 & 0.1348 \\
Total Fuel Used & 1.4460 & 0.8642 & 1.1838 \\
(In L/100 km) & $(10.60)$ & $(6.45)$ & $(8.72)$ \\
& & & \\
Engine Efficiency (\%) & 22.34 & 27.13 & 24.10 \\
(w/idle) (\%) & 18.77 & 26.59 & 21.35 \\
\hline
\end{tabular}

a Fuel lower heating value of $32.8 \mathrm{~kW}-\mathrm{h} / \mathrm{gallon}$. Base car has automatic transmission.

The analysis of conventional vehicles in this report is based on the formulae and sensitivity indices computed by using a methodology similar to the one described for weight. The weighting factors for $\mathrm{E}_{\mathrm{K}}, \mathrm{E}_{\mathrm{A}}$, and $\mathrm{E}_{\mathrm{R}}$ use the relationships developed by Sovran and Bohn (1981). All of the other coefficients are computed as ratios so that the actual equation used is in the form of $\mathrm{FC}_{\text {new }} / \mathrm{FC}_{\text {old }}$. This is particularly convenient since most of the variables (such as bsfc) have been analyzed in terms of potential changes from current values (e.g., engine average bsfc over the composite cycle was forecast to be reduced by $18 \%$ from current values). All of the analysis is in fuel consumption space. The same tractive energy equations also hold for electric and hybrid vehicles, although the bsfc and weight calculations for hybrid vehicles are more complex.

\section{B.4 References}

EEA: Energy and Environmental Analysis, Inc.

EEA, 1994, Documentation of Fuel Economy, Performance and Price Impact of Automotive Technology, prepared for Martin Marietta Energy Systems, July.

EEA, 1995, Automotive Technologies to Improve Fuel Economy to 2015, prepared for the U.S. Congress Office of Technology Assessment, June. 